Florida International University FIU Digital Commons

\title{
From Passive to Active Community Conservation:
} A Study of Forest Governance in a Region of the Sierra Norte of Oaxaca, Mexico

Eric Van Vleet

Florida International University, evanv001@fiu.edu

DOI: $10.25148 /$ etd.FI13042201

Follow this and additional works at: https://digitalcommons.fiu.edu/etd

\section{Recommended Citation}

Van Vleet, Eric, "From Passive to Active Community Conservation: A Study of Forest Governance in a Region of the Sierra Norte of Oaxaca, Mexico" (2013). FIU Electronic Theses and Dissertations. 823.

https://digitalcommons.fiu.edu/etd/823 
FLORIDA INTERNATIONAL UNIVERSITY

Miami, Florida

\section{FROM PASSIVE TO ACTIVE COMMUNITY CONSERVATION: A STUDY OF FOREST GOVERNANCE IN A REGION OFTHE SIERRA NORTE OF OAXACA, MEXICO}

A thesis submitted in partial fulfillment of the requirements for the degree of MASTER OF SCIENCE

in

Environmental Studies

by

Eric Van Vleet

2013 
To: Dean Kenneth Furton

College of Arts and Science

This thesis written by Eric Van Vleet, and entitled From Passive to Active Community Conservation: A Study of Forest Governance in a Region of the Sierra Norte of Oaxaca, Mexico, having been approved in respect to style and intellectual content, is referred to you for judgment.

We have recommended that this thesis be approved.

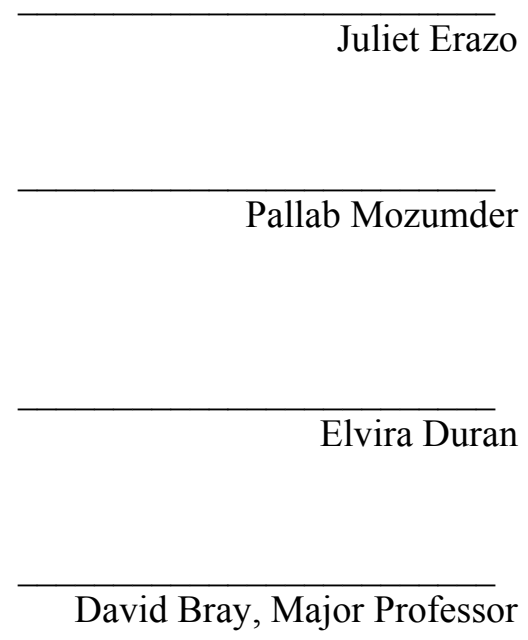

Date of Defense: March, 25, 2013

The thesis of Eric Van Vleet is approved

Dean Kenneth Furton College of Arts and Sciences

Dean Lakshmi N. Reddi University Graduate School

Florida International University, 2013 


\title{
ABSTRACT OF THESIS \\ FROM PASSIVE TO ACTIVE COMMUNITY CONSERVATION: A STUDY OF FOREST \\ GOVERNANCE IN A REGION OFTHE SIERRA NORTE OF OAXACA, MEXICO
}

\author{
by \\ Eric Van Vleet \\ Florida International University, 2013 \\ Miami, Florida \\ Professor David Bray, Major Professor
}

This thesis investigates how seven communities in a subregion of the Sierra Norte of Oaxaca are conserving high forest cover in the absence of national protected areas. To conduct this study I relied on archival research and the review of community documents, focus group interviews and land use transects to explore historical and current land use. I found that communities have conserved $88.34 \%$ of the subregion as forest cover, or 58,596 hectares out of a total territory of 66,264 hectares. Analysis suggests that the communities have undergone a historical transition from more passive conservation to more active, conscious conservation particularly in the last decade. This thesis further contends that communities deserve additional financial compensation for this active conservation of globally important forests for biodiversity conservation and that exercises in systematic conservation planning ignore the reality that existing biodiversity conservation in the subregion is associated with community ownership. 


\section{TABLE OF CONTENTS}

CHAPTER

PAGE

Chapter 1- Literature Review

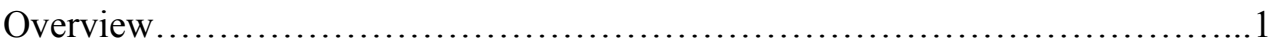

Deforestation - Globally and in Mexico..................................... 5

Global Protected Areas..................................................... 7

Protected Areas in the Mexican Context.................................... 11

Systematic Conservation Planning in Mexico.................................. 15

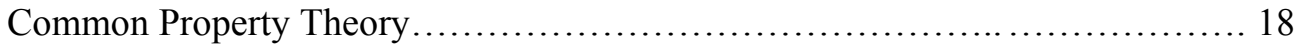

Common Property in the Mexican Context................................... 24

Community Conservation................................................... 29

Voluntary Conserved Areas................................................ 31

Payments for Environmental Service in Mexico................................ 37

Chapter 2 - Research Methods and Biodiversity in Oaxaca

Research Methods.....................................................43

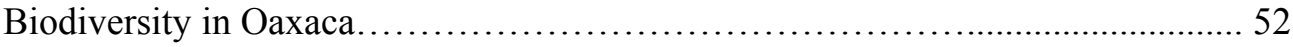

Chapter 3 - Results

General Community Descriptions....................................... 63

Factors Leading to Passive Conservation.................................. 71

Regional Land Uses.................................................... 76

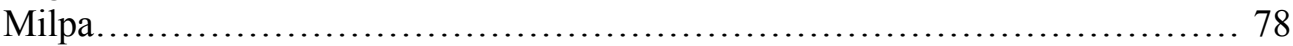

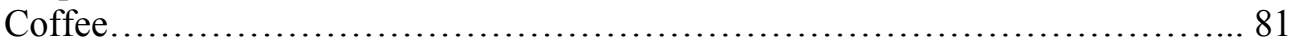

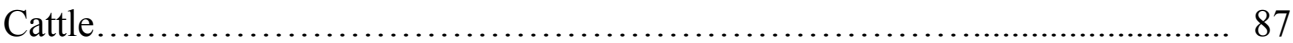

Community Rules Regarding Cattle ........................................ 89

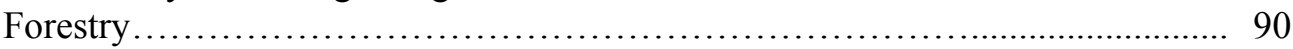

Migration.............................................................. 96

Active Conservation..................................................... 98

Forest Types and Conservation............................................ 97

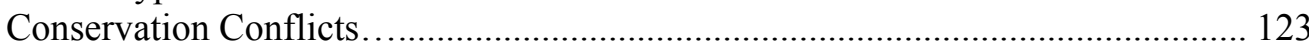

Chapter 4 - Discussion-A Critical Analysis of the Implications of Passive and Active

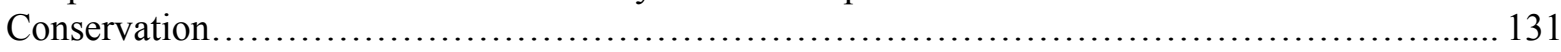

Underlying Factors Leading to Passive Conservation...................................... 136

Increased Compensation for Active Conservation......................................... 145

VCAs and the Seal of Sustainability for Coffee......................................... 168

Flaws of Systematic Conservation Planning in the Sierra Norte............................ 172

Chapter 5 - Conclusion ........................................................ 179

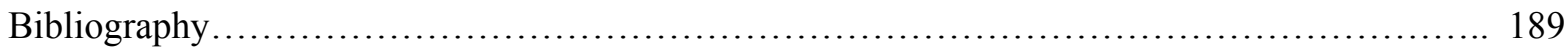




\section{LIST OF FIGURES}

FIGURE

PAGE

1.1. Mexico's Protected Area Network...............................................13

1.2. Proposed Protected Area Network by CONABIO ................................ 17

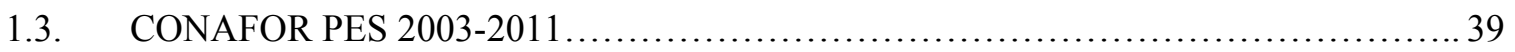

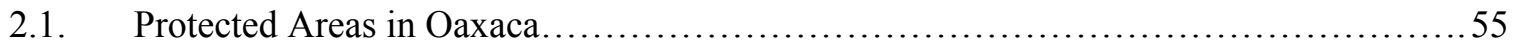

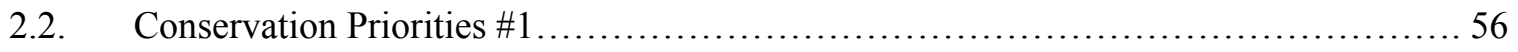

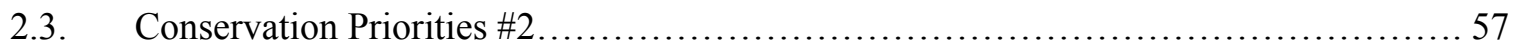

2.4. Forest Cover in Velasco-Murguia (2011) and this Study .......................... 61

3.1. Locations in Mexico, Oaxaca and the Subregion................................. 65

3.2. The state of Oaxaca with Major Roads, Cities and Elevation......................... 66

3.3. Villages and Communities of the Subregion.................................. 67

3.4. Subregional Population by Community.......................................... 68

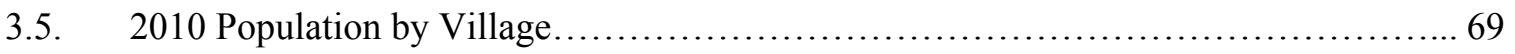

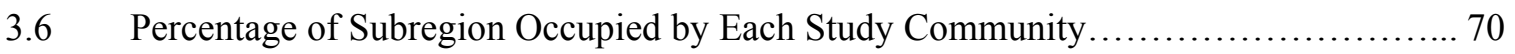

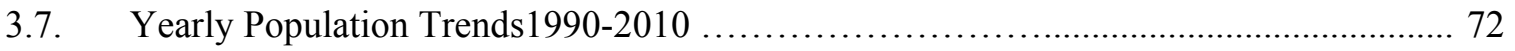

3.8 Hectares per Rightsholder and Population Densities............................ 73

3.9. Slope, Roads and Marginalization in the Subregion.............................. 74

3.10. Non-Forested and Forested Areas with Roads and Village Populations................ 75

3.11. Area of Annual Agriculture/Milpa in the Subregion.............................. 78

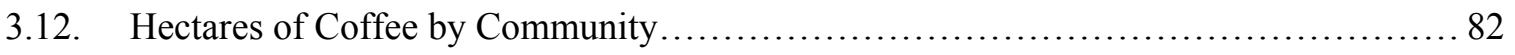

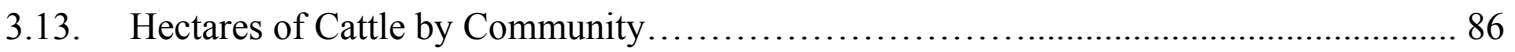

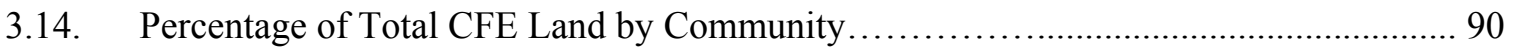

3.15. Percentage of Total Subregional Forest Cover................................ 107

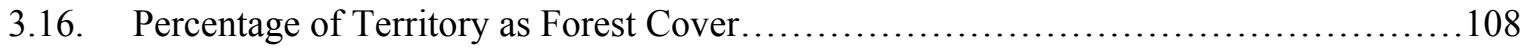


3.17. Type of Forest Cover by Community .......................................... 109

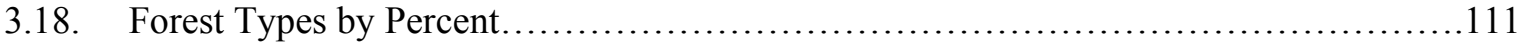

3.19. Conserved Forests by Management Type.......................................................112

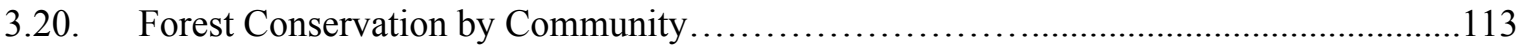

3.21. Conservation in Comaltepec................................................... 115

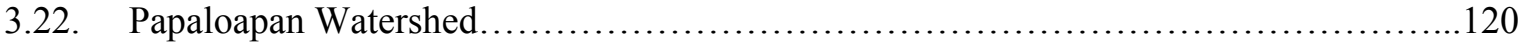

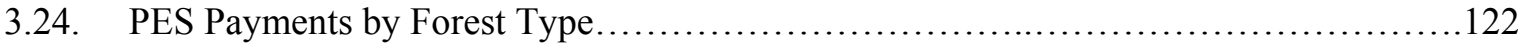

4.1. Land Use Changes from 1979-2008 in Nuevo Rosario

Temextitlán with Soils and PES............................................... 136 


\section{CHAPTER 1}

\section{Literature Review}

\section{Overview}

Many argue that we are living through a planetary biodiversity crisis, whereby rates of threatened and endangered species are rapidly accelerating (Vitousek et al., 1997; Pimm et al., 2001; Brandon et al., 2005; Gordon, 2006). Extinction rates of species are now 100 to 1000 times above background extinction rates. Invasive species introduced intentionally or unintentionally by humans have created major disruptions for native flora and fauna. Humans have dominated much of the planet and altered species distribution as well as biogeochemical cycles to the extent of changing the very climate that we depend on for survival (Vitousek et al., 1997).

Land use and cover change is a force that leads to the human domination of ecosystems. For this reason many of the conservation interventions I will discuss in this literature review are focused on conserving forests and limiting potentially harmful impacts on biodiversity for land use and cover changes such as deforestation (Bruner et al., 2001; DeFries et al., 2005; Ellis et al., 2008; Porter-Bolland et al., 2012). Scholars believe that massive investments and often top-down policies are needed to stave off these ecological collapses (Terborgh, 1999; Brooks et al., 2004; Balmford et al., 2004).

Yet, all is not uniformly dire. Deforestation and degradation is by far not the only process facing forests globally. In this thesis, I will explore a subregion of the Sierra Norte of Oaxaca, Mexico composed of the territories of seven communities that are engaging in conservation at the community level for a variety of reasons. This subregion is part of a larger region has received recognition from the Mexican government as an important area for biodiversity and bird conservation (Arriaga, 2000), as well as from the World Wildlife Fund (WWF) and Conservation International (CI) for the globally-important forests present in the communal lands of the Sierra Norte (Gordon; 2006; Robson, 2011). Despite the subregion's high conservation value, 
communities on two separate occasions in the Sierra Norte have democratically voted against the creation of Biosphere Reserves that would have included their community lands (Bray, 1991; Bray et al., 2012).

Instead of supporting Biosphere Reserves being created on their lands, communities, from a historical base of large areas of forests not needed or not suitable for subsistence purposes, have in more recent periods worked with the government by applying for and receiving payments for environmental services (PES) from CONAFOR (National Forest Commission) as well as certified community lands as Voluntary Conserved Areas (VCAs) with CONANP (National Commission on Natural Protected Areas). Since VCAs count as federal protected areas by CONANP (LGEEPA, 2008), the only federal protected areas recognized by CONANP in the Sierra Norte are VCAs, though communities themselves manage these areas. In addition three of the communities have, since the early 1980s, managed their forests for the commercial production of timber, retaining extensive forest cover through well-managed silvicultural practices.

Prior to forest management both during the period of parastatal concessions and late under community forestry enterprises (CFE), conservation occurred largely through passive processes and community governance did not prioritize forest conservation. Having successfully navigated what was often a time-consuming tangled bureaucracy to gain legal land tenure (Bartra, 1985), these communities focused on agricultural production generally located near roads and settlements, leaving vast territories with little direct anthropogenic impacts. In the 1980s, some of the study communities won the right to manage their own forests for timber, and in the $2000 \mathrm{~s}$ forest policy focused more heavily on conservation in the form of PES. CFEs early and PES later have been important in helping to provide incentives for communities to more actively and consciously conserve their forests. Beyond conservation linked to these environmental and management initiatives, in the last two decades communities have completed land use zoning plans (ordanamiento territoriales comunitarios) (OTCs) and specifically set aside areas for 
conservation at the community level, or at the least created rules against agricultural expansion into primary forests. Most of these community conserved areas are considered "informal" in this thesis since they are rules established only at the level of the community, and not recognized by a higher government authority. Therefore, while protected areas continue to play an important role in global conservation initiatives as well within Mexico, the seven communities that make up this subregion have decided through democratic decisions at their community assembly against protected areas decrees and instead have chosen to continue to maintain control at the community level for decision-making related to conservation.

However, they seek financial support for less-binding and potentially restrictive agreements than a protected area created by a presidential decree that would last for perpetuity and my reduce community management sovereignty of their forests. Conversely, VCAs are certified with CONANP, and as their name suggests, are voluntary and communities can choose whether or not to maintain their certification without fear of sanctioning from CONANP for noncompliance to their VCA management plan. In this thesis I have chosen to classify VCAs and PES areas as formal conservation since they are recognized by the government as conserved areas.

Therefore, a central theme of this thesis is that conservation in practice does not need to occur in formal public protected areas. In fact, since communities own $82.3 \%$ of forested lands in Oaxaca (Madrid et al., 2009), it is likely that protected area proposals will either specifically have to seek innovative ways to engage with communities from incipient stages of exploring the idea of a park through its creation and ongoing management or look elsewhere to create protected areas. In other cases, such as communities in this subregion, they may choose to maintain forest governance primarily at the community level. Nonetheless, public policy can then play an important role with financial and technical support provided to these communities for their past and increasingly conscious ongoing conservation. While such community conservation is no 
panacea for global environmental change, this thesis will argue that conservationists have more pressing concerns than to advocate for protected area creation in areas where robust institutions exist around forest governance as well as important variables which lead to de facto conservation such as: large territories with well-delimited boundaries, low population densities, lack of mechanized farming, decreasing agricultural subsidies and support, a history of limited cattle ownership, steep slopes and poor soils. Therefore, while this long list of factors may in itself lead to de facto conservation, communities have increasingly engaged in a more de jure form of conservation at the community level as well as in concert with Mexican environment policy such as payments for environmental services and voluntary conserved areas.

Yet, despite the fact that communities have increased forest governance and enacted collective action for conservation through informal conservation at the community level as well as conservation in concert with government policies like VCAs and PES, earnings from conservation are modest for PES and a vocal minority throughout the subregion have begun to question if conservation is truly the most beneficial land use in communities that both work and manage their territories in a multiple use system (Toledo et al., 2003) of market agriculture, subsistence agriculture as well as forest conservation.

While he communities of Ixtlan de Juarez (Ixtlan), Santiago Comaltepec (Comaltepec), San Pedro Yolox (Yolox), Nuevo Rosario Temextitlan (Nuevo Rosario), Santiago Cuasimulco (Cuasimulco), San Mateo Yetla (Yetla) and San Felipe de Leon (San Felipe) have vastly different histories and land uses, they all have maintain high forest cover ranging from $78 \%$ in Yetla to $94 \%$ in Ixtlan. In the communities with community forestry enterprise (CFE) active and formal conservation recognized by the government began in the late $1980 \mathrm{~s}$, while active and formal conservation began in the non-CFE communities largely began with the arrival of PES in the mid-2000s. While CFEs, especially in the case of Ixtlan, have spurred considerable community development, thus far PES have not had the same results in diversifying local economies. 
This thesis also explores the disconnect between communities who are conserving forest which conservation scholars, NGOs and governments say are important for global conservation policy and the modest payments communities receive for these activities. This thesis will argue that if such conservation provides valuable environmental services (ES), then communities should be compensated at corresponding levels.

\section{Deforestation - Globally and in Mexico}

The hypothesis of the destruction of rainforests by swidden agriculturists living in poverty has been shown to be, in varying degrees and places, not true, exaggerated, or confined to a particular historical period, though forest colonization that granted land tenure did drive deforestation in some cases (Gomez-Pompa et al., 1972; Angelsen and Kaimowitz, 1999; Lambin et al., 2001; Rudel et al., 2005).

Causes of deforestation commonly found in the literature are: 1) Rising agricultural prices 2) Lack of off-farm employment 3) Greater access to roads and markets 4) Land tenure gained through the clearance of forests for agriculture or pasture (Angelsen and Kaimowitz, 1999). Population density is not necessarily explanatory as in some regions deforestation continues largely because of highly-capitalized and mechanized agricultural ventures and not wholly explanatory by mere population. Prior deforestation did in fact occur largely because of colonization programs by governments which granted land tenure to small holders who cleared forests. Governments advocated this policy because it was often more politically expedient than regulated agrarian reform and planned land redistribution (Rudel, et al., 2009).

Studies in Mexico have examined many similar variables, though not always with similar findings. Deininger and Minten (2002) found the following variables explanatory for deforestation in Oaxaca and Chiapas: 1) Increased agricultural infrastructure 2) Proximity to roads 3) lower altitudes 4) Decreased slopes 5) Increased rainfall 6) Poverty with a lack of off- 
farm employment 7) government agricultural subsidies. Other factors like land tenure, either communal, state or private had no explanatory power.

Barbier and Burgess (1996) has taken a more directly institutional approach in his study, which found no statistical significance between common property regimes and deforestation. Therefore, common property neither increased the rate nor decreased the rate of deforestation compared to private and public land in Mexico. Instead, important explanatory variables for increased deforestation included: 1) high corn prices compared to lower prices for fertilizers 2) Increased population growth in areas of predominantly smallholder agriculturalists 3 ) lower wages for agricultural day laborers.

Finally Bonilla-Moheno et al. (2013) have found that ejidos have higher rates of deforestation than both private property and common property granted to comunidades. In part the higher deforestation in ejidos comes from 1992 reforms to Article 27 of the 1917 Mexican Constitution which has allowed for the creation of private property from what was previously common property, which has in some cases spurred investments that have led to increased agricultural production and agricultural expansion.

The subregion under study demonstrates few of the deforestation drivers identified in the literature. The main ones include a lack of off-farm employment (Angelsen and Kaimawitiz, 1999) as well as lower altitudes and increased rainfall (Deininger and Minten, 2002), while access to road is variable. As I will discuss, the government in the late 1980 s greatly reduced support for corn and especially for coffee (Jaffee, 2007), the two main agricultural crops in the region. Save for the village of Ixtlán, human populations as a whole declined, likely reducing drivers of deforestation from agriculture. As a consequence of this immigration, wages for agricultural day laborers have tripled in the region since the late 1980s. Finally, though the study area does contain two ejidos), both have maintained their entire territory as communal lands and so lack the 
deforestation drivers through the creation of individual parcels as described by Bonilla-Moheno et al. (2012).

\section{Global Protected Areas}

The primary response to combat the complex sets of factors that drive deforestation has been to create protected areas. Governments and more recently non-governmental organizations and communities have begun explicitly to set aside areas as protected areas for the conservation of biodiversity conservation, ecosystems services, native landraces of crops, scenic beauty and sacred spaces (Brandon et al., 1998; Borrini-Feyerbrand et al., 2002; Naughton-Treves et al., 2005; Kothari, 2006; Brockington et al., 2008). Often generically referred to as parks, these interventions to curb environmental degradation encompass a wide array of categories and regulations.

In fact, there is little debate among prominent conservationists that protected areas are a fundamental strategy to conserve global biodiversity from endangerment and extinction (Brandon and Wells, 1992; Terborgh, 1999; Bruner, 2001; Brooks et al., 2004; Rodrigues et al., 2004;

Deardon and Bennnet, 2005; Defries et al., 2005; Nagendra, 2008; Caro et al., 2009; Ponce-Reyes et al., 2012).

The agreed upon definition from the IUCN (International Union for the Conservation of Nature) for protected areas is : "an area of land and/or sea especially dedicated to the protection and maintenance of biological diversity, and of natural and associated cultural resources, and managed through legal or other effective means". The CBD (Conventions on Biodiversity) defines it as "a geographically defined area which is designated or regulated and managed to achieve specific conservation objectives," (Borrini-Feyerbrand et al., 2002). These definitions do not necessitate state management nor favor any single property regime, although in practice most protected areas are under public management. 
Recently, the CBD has further increased this goal to $17 \%$ of all terrestrial areas (Duran et al., 2012). Globally there are 161,226 protected areas (PAs), $95 \%$ of which are terrestrial. Within the Americas there are 34,060 protected areas with 21,914 in the United States, Brazil with 1,697 and Mexico with 972 (Protected Planet.net, 2012). Since 1990, protected areas globally have increased in sheer number by $58 \%$ and in spatial extent by $48 \%$. Currently, they cover $12.7 \%$ global terrestrial surface (Butchart et al., 2012). While these goals of a certain percent conserved abstractions of complex ecological systems in that some areas not of equal conservation value as other areas, they have proven powerful a policy instrument for protected area expansion (Svancara et al., 2005).

Protected areas generally fall within six categories as created by the IUCN from category I, which has the strictest protection and greatest limit on productive uses, to category VI, which prescribes core zones of protection with other areas designated for sustainable use (BorriniFeyerbrand et al., 2002; Butchart et al., 2012). Though there are debates as to the effectiveness of various designations (Leroux et al., 2010), in many countries in the global south less restrictive areas dominate compared to areas of strictly protected, people-free areas. In developing nations, as in the case of Mexico, the vast majority of parks are inhabited (Naughton-Treves et al., 2005; Gomez-Pompa and Kaus, 1999).

Though $12.7 \%$ of land globally is conserved in some form, conservation is not equally distributed in all ecosystems (Cantu et al., 2004; Brandon et al., 2005), nor do current protected areas afford sufficient coverage to a variety of species (Rodrigues et al., 2004; Brookes et al., 2004). Certain ecosystems such as tropical montane forests have recently received greater attention for their species richness, while other critical areas for biodiversity like tropical montane cloud forests(TMCF) have not received the same conservation interest in protected areas gazetting (Aldrich et al., 1997;). As I will discuss, these are two of the most important forest types in my study region. Such inequalities in the conservation of global biomes have led to the 
argument for a marked expansion of the global protected area network (Brooks et al., 2004; Rodrigeus et al., 2004).

Gap analysis studies have demonstrated that $12 \%$ of all species analyzed did not have coverage in a single protected area. Furthermore, $20 \%$ of all endangered species lacked coverage and so were also gap species. In other cases, species had partial coverage, but not likely for their full range (Rodrigues et al., 2004). In other cases, protected areas increasing are becoming isolated by surrounding land use and cover changes (Defries et al., 2005).

Bruner et al., (2001) conducted a mailed survey with park managers that found that $43 \%$ of all parks have avoided vegetation clearance since their gazetting and only $17 \%$ of parks faced more clearing than vegetation regrowth. The parks in Bruner et al. (2001) also fared better than surrounding areas, while $97 \%$ had faced less clearing than surrounding areas. Effectiveness depended on the population density of guards in the park as well as their ability to punish rule violators. Despite the study's strong endorsement for protected areas, some have criticized its methodology of judging park effectiveness by those whose reputation and paycheck depends on their park success (Naughton-Treves et al., 2005; Joppa et al., 2008; Nagendra, 2008).

An alternative method to study protected area effectiveness is the examination of institutions which lead to the success or failure in the conservation of nature (Hayes, 2006). While this thesis will include a far more expanded examination of common property theory, Hayes (2006) specifically proposes novel ideas for gauging protected area effectiveness. For one, public protected areas are not inevitably the superior management strategy for a certain landscape.

Hayes (2006) argues that Bruner et al., (2001) actually lists important institutional components such as boundary delimitation, monitoring and enforcement for rule-breakers which could exist in many contexts and not solely in protected areas. Studies of vegetation density in worked forests versus protected areas shows that local users in the worked forests have more 
flexibility and in the end create more rules than the protected areas included in this study and vegetation densities between the two showed no significant differences (Hayes, 2006). In Mexico, studies have arrived at similar findings in community forests managed for timber (Duran et al., 2005; Ellis et al., 2008). Therefore, it is not exactly necessary that an area become a public protected area, but rather that it has robust institutions governing it. This thesis will show that institutions exist that help drive conservation even in the absence of public protected areas my study region.

Another important variable recognized in protected area effectiveness is remoteness (Nepstad et al., 2006; Joppa et al., 2008). In some cases the most remote protected areas receive more of a de jure protection and that they are nominally classified as reserves may be of little consequences given their remoteness. Protected areas that still maintain forest cover near agricultural frontiers or areas of high deforestation are de facto protected areas, in that the rules, monitoring and sanctions provided by park managers effectively maintain forest cover (Joppa et al., 2008). Nonetheless, in some areas the expanding deforestation zone is reaching parks that were once far more remote (Defries et al., 2005). By the same token, community lands may also be protected by remoteness, as discussed a factor in the study area.

While these studies largely focus on the success of protected areas in conserving biodiversity, political ecology has studied protected areas and their impacts on people living in and around these conservation areas. Protected areas have in some cases caused massive human displacements (Dowie, 2009), have led to active resistance against the aims of the protected area since it impinged on local food sovereignty and other cultural practices (Neumann, 1998), have privileged urban, middle-class, white concerns above those of rural, working class, non-white concerns (Kosek, 2007) and created protected areas without the knowledge of local people (Haenn, 2005). While many of the conservations cited above call for a massive expansion of public protected areas globally in order to conserve biodiversity (Brooks et al., 2004; Rodrigues 
et al., 2004), political ecology has shown how when done against the wishes of local people or oblivious to them, public protected areas can breed resentment and in some cases resistance to conservation (Neumann, 1998; Chapin, 2004; Dowie, 2009).

I will show that while resistance does exist to conservation practices in the subregion, the programs in existence at least do not threatened land tenure as has been the case for conservation policies in other parts of the world (Dowie, 2009).

\section{Protected Areas in the Mexican Context}

During the 1930s Mexico was the world leader in its sheer number of protected areas (Wakild, 2011). While these were small areas designated as National Parks and located near urban areas (Simonian, 1995), the Cardenas administration attempted to balance ongoing land redistribution through agrarian with reform with a conservation agenda largely based upon these public protected areas (Wakild, 2011). While more recently, communities have created lands that officially count as public protected areas (LGEEPA, 2008; Bray et al., 2012; Duran et al., 2012), administrators of these parks from the 1930s attempted to balance human uses and forest conservation before such concepts become more mainstream thinking in conservation (Wakild, 2011). Yet, as the nation shifted attention away from agricultural production and especially away from smallholder agriculture (Simonian, 1995), public protected area policy focused more on large Biosphere Reserves distant from urban areas largely conserved based on the rational of conservation biology (Wakild, 2011). Conflicts have continued, though in some cases administrators have been less willing to modify management for expanded human uses (Haenn, 2005; Garcia-Frapolli et al., 2009). Also, in some cases public protected areas in Mexico have been underfunded and are essentially paper parks, in that they exist only on paper and have no real impact on the ground (Brandon et al., 1998), yet others have argued that Biosphere Reserves have been a successful largely because communities retained significant autonomy (GomezPompa and Kaus, 1999). 
Scholars have focused attention on public protected areas in Mexico because it is considered a megadiverse nation, which contains roughly $10 \%$ of global species within its national territory and globally important mammal endemism (Ceballos et al., 1998; Ceballos, 2007). One reason that has driven the Mexican government to seek to create more protected areas is that lands both within and outside of protected areas have faced high rates of deforestation since the 1970s (Gomez-Pompa et al., 1972; Simonian, 1995; Gomez-Pompa and Kaus, 1999; Deininger and Minten, 2002; Barbier, 2002, Velazquez et al., 2003; Sanchez-Cordero et al., 2005; Gomez-Mendoza et al., 2006). In the twentieth century alone, Mexico lost half of its forest cover (Velazquez et al., 2003). Humid tropical forests have lost $90-95 \%$ of their initial spatial extent (Durand and Lazos, 2004; Sanchez Cordero et al., 2005). Mexico faced deforestation rates of 500,000 hectares a year in the 1990s (Velazquez et al., 2003).Overall, deforestation has decreased in the most recent period, with all forest types losing 354,035 hectares annually from 1993-2002 and dropping to 115,152 hectares annually from 2002-2007 (CONAFOR, 2010).

Studies have attempted to gauge the effectiveness of Mexico's protected areas in preventing land use and cover changes and in the prevention of fires. Flamenco-Sandoval et al. (2007) found that the rates of land use changes outside the were six times as high as those inside the park, though the park still did face land use changes at 2.5\% annual. Flamenco-Sandoval et al. (2007) also cites Mendoza and Dirzo (1999), which found far great land use changes outside the Montes Azules Biosphere Reserve than with its boundaries. Mas (2005) found that greater land use changes outside of the Calakmul Biosphere Reserve boundaries, but this study places large caveats in the need for accurate boundary comparison with protected areas.

Figure 1.1 shows Mexico's current public protected area network. The blue arrow demonstrates that the subregion lacks any public protected areas, which means that the common property forest governance is providing conservation in the Sierra Norte. 
Figure 1.1. Mexico's Protected Area Network

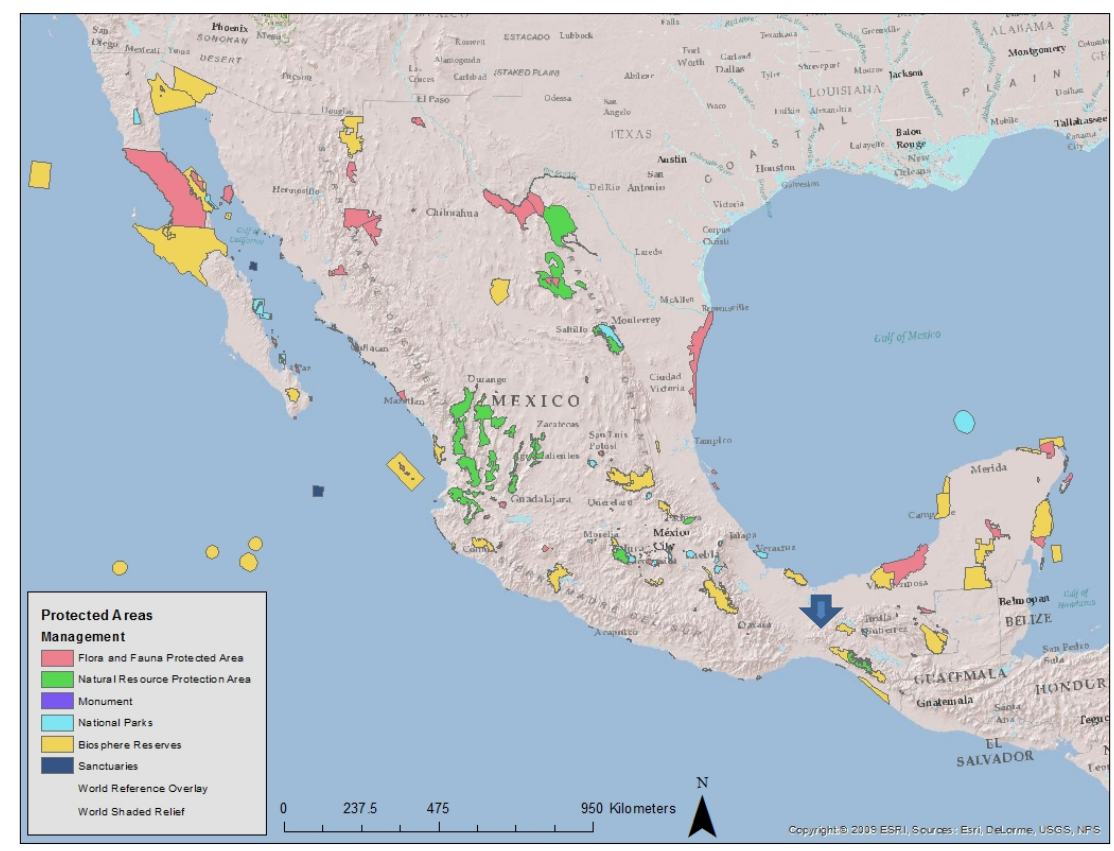

Source: $\underline{\text { http://www.conabio.gob.mx/informacion/gis/ }}$

Conversely, Roman-Cuesta and Martinez-Vilata (2006) found that protected areas in Chiapas were less ineffective in limiting fires compared to their surrounding areas. Surrounding areas did benefit from increase roads which often aid in firefighting.

Figueroa and Sanchez-Cordero (2008) found that 54\% of all protected areas in Mexico were effective at limiting land use changes compared to their boundaries as well as state rates. Of the different categories as far as their effectiveness: $65 \%$ of Biosphere Reserves, $53 \%$ of Flora and Fauna Protected Areas and 45\% of national parks were effective. Furthermore, $23 \%$ of protected areas were weakly effective and $23 \%$ were not effective.

Figueroa et al. (2009) is a novel study in that it attempts to draw correlations between socio-economic variables and land use changes in protected areas. Echoing the previously reviewed deforestation studies, this study found that in 17 Biosphere Reserves in Mexico faced 
increased conversion with explanatory variables that include: increased populations, greater road density, high numbers of cattle and low percentages of indigenous peoples.

In contrast to government-managed protected areas, many scholars have examined how communities can managed their forests for timber, which can provide by economic and environmental benefits in some cases (Bray, 1991; Klooster, 2000; Bray et al., 2005; Antinori and Rausser, 2007; Barismantov, 2009; Mathews, 2011). Studies have also attempted to test deforestation in protected areas versus community forests managed for timber (Duran-Medina et al., 2005; Bray et al., 2008; Ellis et al., 2008; Porter-Bolland et al., 2011).

Ellis et al., (2008) found that forests managed for timber maintained their spatial extent while areas of a nearby Biosphere Reserve faced land clearing in part because of policies that subsidized pasture subsidization as well as Mennonite inholdings devoted to agriculture. Furthermore, those managing their forests for timber additionally had additional potential drivers of deforestation such as higher population densities, greater infrastructure like roads and more human settlements. Still community forests maintained forest cover more effectively than the adjacent protected area.

Another study across tropical regions of the global found community forestry to be as effective as protected areas at reducing land use and cover changes (Porter-Bolland et al., 2011). Bray et al. (2008), in a Mexico-Guatemala cross-national comparison, found both longestablished and recently established community forests managed for timber to be more effective than protected areas at preventing land use and cover changes, though the difference was not statistically significant.

Lastly, a study by Duran-Medina et al., (2005) compared a variety of community forests managed for timber in the Mexican states of Guerrero and Quintana Roo against 67 Mexican protected areas established before 1993. Forests in Guerrero maintained 92\% of their forest cover between 1979-2000. Those forests in Quintana Roo faced net forest gains. Protected areas 
maintained $98 \%$ of original land cover from $1980-2000$. There was no statistically significant difference shown in this study between protected areas and community forests managed for timber. To better examine this important activity, I will return to community in forestry in chapter 2 of this thesis, as three of the seven communities manage their forests for timber.

These studies show that it is not necessary that public protected areas will better conserve forests than those forests managed by communities. I will analyze systematic conservation plans (SCP) in Chapter 4 which assume protected areas are the only means of conserving forests against communities which likely will fell forests (Ponce-Reyes et al., 2012). The findings of this thesis will show that the rational that forests can only be conserved in protected areas is fallacious given a complex host of factors in the subregion. Ostrom et al. (2007) argued that common property regimes are no "panaceas" for sustainable resource management, while the same can easily be said of protected areas.

The government has also faced increasing difficulties in creating protected areas (Anta, 2007) in part because under a 1988 environmental law, communities need to agree to the gazetting of lands for a protected area (Bray, 1991; Bray et al. 2012). In a response to high forest cover and endogenous conservation initiatives by communities (Duran et al., 2012), the government has formed their Voluntary Conserved Areas (VCA) policy (LGEEPA, 2008), which allows communities to manage lands that count equally as protected areas to the designations I have reviewed above. Therefore, communities can not only participate in protected areas, but they can actually be the drivers of protected area creation, as I will discuss later. Each community plans their VCA independently. Therefore, VCA may not be contiguous or distant from each other as communities have the total prerogative to certify these areas.

\section{Systematic Conservation Planning in Mexico}

Systematic conservation planning (SCP) attempts bring the design that is lacking in the certification of VCAs in order to provide coverage for the most species in as little areas as 
possible while using existing protected areas as a basis for selecting future protected areas. While SCP looks at ecological criteria, only in one case have plans factored on land tenure in Mexico (Brandon et al., 2005). As communities own $60 \%$ of forest nationwide and $82.3 \%$ in Oaxaca such (Madrid et al., 2009), such factors would be important, especially since communities can reject reserves designed by SCP exercises (LGEEPA, 1988; Anta, 2007).

Land tenure is not the only factor which had made SCP difficult in Mexico and Oaxaca. High rates of deforestation in Mexico since the 1970s, reduced beginning in 1990s, have increased the costs in expanding the country's protected area network costs as areas of once high conservation value have faced degradation and deforestation (Fuller, Sanchez-Cordero et al., 2006). Others have countered that despite the ad hoc nature of the protected area network in Mexico it has still done a fair job of habitat provision (Ceballos et al., 1998).

In 2000, in order to increase its coverage of protected areas, the Mexican governmental agency CONABIO (The National Commission for Biodiversity) proposed 151 new protected areas for a total of $51,429,500$. At the time the country had 144 protected areas for a total of $17,904,000$ hectares. Such a massive addition to its protected area network would have protected $12 \%$ of land at all elevation ranges save for 0-200 m (Arriaga, 2000). Nonetheless, even with these additions, gaps would still exist in biodiversity conservation (Cantu et al., 2004; Fuller, Sanchez-Cordero et al., 2006). Thus far, this expansion in protected area covered has not yet occurred despite these ambitions plans (CONANP, 2012). Figure 1.2 below is a map of the areas proposed by CONABIO as well as existing protected areas.

Also, I will now review a series of studies which have engaged in SCP exercises for the Sierra Norte based on its high existing biodiversity. Figure 1.2 below demonstrates that the subregion is of particular conservation interest for terrestrial conservation. In fact, the map shows that the entire Sierra Norte of Oaxaca would be designated as a protected area under this SCP. I will show in the Biodiversity in Oaxaca section in Chapter 2 how the region has gained interest 
by large conservation NGOs as well as the Mexican agency CONABIO (National Commission on the Use and Knowledge of Biodiversity).

\section{Figure 1.2. Proposed Protected Areas by CONABIO}

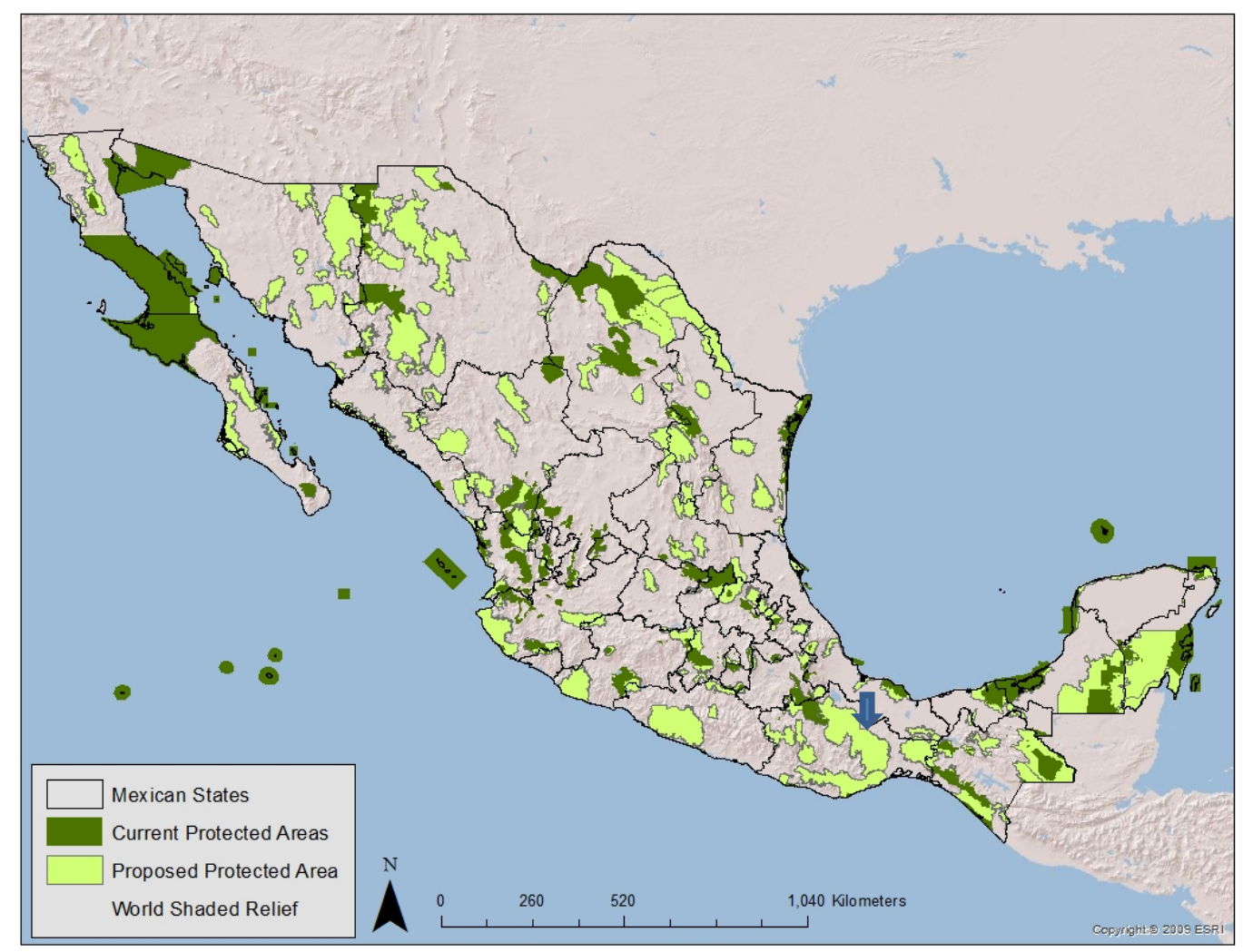

Source: http://www.conabio.gob.mx/informacion/gis/

In proposing 94 gap cells nationwide that would cover important deficiencies in the currently protected area network in Mexico, Brandon et al., (2005) have attempted to focus on areas of poor or limited agricultural suitability for potential protected areas. Areas from unsuitable to moderate suitability for agriculture make up $92 \%$ of the proposed area. The authors have used such criteria because they argue that there are few areas in Mexico where the government could place reserves where no one lives. The study also demonstrates areas where significant biodiversity conservation potential exists near large urban settlements. Importantly, 
the protected area network proposed by this study covers important gap species in only $7.1 \%$ of the massive increase CONABIO considered.

Lastly, these authors admit that subsistence agriculturalists do not always make decisions solely based on agricultural suitability as they do not have access to whatever land they wish (Brandon et al., 2005). Of further interest to this article is that the largest section of gap cells selected by the authors is in the Sierra Norte of Oaxaca and would hypothetically cover the seven communities included in this subregional study.

Illoldi-Rangel et al. (2008) have chosen the Sierra Norte as a priority for mammalian conservation. This study specifically addresses that limited funding for the creation of public protected areas, though even at the lowest budget, they selected the subregion and much of the Sierra Norte as well. Yet, Figel et al. (2011) demonstrated that community-managed territories in the Sierra Norte were suitable for jaguar conservation.

There are other systematic conservation plans relating to the cloud forests of the Sierra Norte that I will discuss in Chapter 2 in the Biodiversity in Oaxaca section. Suffice it to say these systematic conservation plans see protected areas as the only effective means of conserving cloud forests which will face large reductions in size as a result of anthropogenic climate change (Ponce-Reyes et al., 2012; Rojas-Soto et al., 2012).

\section{Common Property Theory}

The region of study is entirely composed of a common property tenure regime, and thus it is important to review some aspects of common property theory. It will be my contention that common property theory can in many cases provide important insights to explain forest cover. The term 'common-pool resource' includes resources managed in common that are 1) large enough that exclusion of outsiders is costly but not impossible and that are 2) subtractable, which means that the use from one user limits the quantity available for other users. These "resource systems" can include pastures, irrigation systems, fisheries, groundwater (Ostrom, 1990), forests 
(Agrawal et al., 2007) with expanding scales to the point that the atmosphere could be considered a global commons (Dietz et al., 2003).

Through collective action users govern these resources through a variety of complex means that attempt to limit benefits to those who do not contribute to the resource's maintenance and to also encourage sustainable use to maintain benefits for all who do contribute. It is largely economic benefits which will drive users to create the collective action necessary to manage these lands (Ostrom, 1990).

Common pool resource management exists at different levels. First there is "constitutional choice" which helps to determine "rules and eligibility" for governing the resource. "Operational choice" includes the rules that affect the day to day management of the resource made through "collective choice" (Ostrom, 1990), which I will analyze later.

Next, much focus in the study of common property resources focuses on institutions. Institutions can be defined as "the sets of working rules that are used to determine who is eligible to make decisions in some arena, what actions are to be allowed or constrained, what aggregation rules will be used, what procedures must be followed, what information must or must not be provided, and what payoffs will be assigned to individuals dependent on their actions. All rules contain prescriptions that forbid, permit, or require some action or outcome. Working rules are those actually used, monitored or enforced when individuals make choices about the actions they will take," (Ostrom, 1990).

In this theory, institutions create the mechanisms to allow for the "provision" and "appropriation" of resources with effective "exclusions" of outsiders and responsive governance to problems of "subtractibility" for sustainable outcomes. Continued provision is often crucial because "the appropriators in these cases are heavily dependent on a flow of scare resource units for economic returns," (Ostrom, 1990). 
At times, groups face great challenges for collective action. They govern often amid social-ecological variability. While there are many clear examples of success stories of robust institutions governing common property, as Ostrom notes, some groups are successful and others are not at collective action around resource "provision" and "appropriation" (Ostrom, 1990).

While acknowledging the complexity of common property resource management, Ostrom famously proposed certain "design principals" that the diversity of case studies analyzed due lead to correlative success in the management of common pool resources.

Common pool resource design principles include (Ostrom, 1990): 1) Clearly Defined Boundaries 2) Congruence between appropriation and provision based on local conditions 3) Collective Choice Arrangements 4) Monitoring 5) Graduated Sanctions 6) Conflict Resolution Mechanisms 7) Minimal recognition of rights to organize 8) Nested Enterprises.

Others have made important additions from continued commons research (Agrawal, 2001), only some of which I will enumerate here: 1) Group size of users is small 2) they have shared past interactions 3) they have "appropriate leadership" 4) they live in close proximity to the resource 5) rules governing the resources are "easy to understand" 6) limiting access to outside users is relatively inexpensive 7) "external institutions" will support any sanctions leveled 8) that users are adequately compensated for conservation activities.

Hardin's "Tragedy of the Commons" (1968) assumed that users would not create rules, have had no had past interactions upon which to base future trust levels upon, be able to level sanctions or monitor the resource. Instead as rational actors they would continue to place more cattle on the common pasture until it was overgrazed. Ostrom (1990) agrees in the self-interested rational actor as the decision makers in common pool resources, but contrarily she argues that collective action is possible under the above conditions of her design principles as such selfinterest will maximize individual and group benefits. 
First, clear boundaries lower discount rates and make longer term invest in resource management as users can worry less about appropriation by those who do not help in resource provision. Such boundaries help eliminate the problem of freeriders "appropriating" with limited to no assistance in the "provision" of the resource. The opposite problem exists also that of the "sucker" whose "provision" is not commensurable to their "appropriation," (Ostrom, 1998).

Also, the strictness of boundary delimitations depends on the resource in question and its mobility, while studies have generally favored smaller spatial sizes for successive management (Agrawal, 2001). While communities can vary boundary fixedness, lack of set physical boundaries can be incredibly detrimental to private, public and common property resource management (Gibson et al., 2005).

The next design principle is the congruence between appropriation and provision based on local conditions (Ostrom, 1990). These conditions can include ecological, local customs and beliefs as well as reliance on the resource by local users (Ostrom, 1998). Another way to look at congruence is through sustainable use of a resource. For forests this would include maintaining the ecological function of both "biotic and abiotic components." Institutions charged with managing a forest for timber production may attempt to retain the qualities of human dominated landscape as well as limiting "degradation" undertaking "restoration" and negotiation management taking into account local factors (Tucker, 2010).

Third "collective choice arrangements" allows users to govern the resource and importantly to change rules pertaining to common pool resources (Ostrom, 1990). Collective choice can also work at the community level to international treaties for international treaties. These "collective choice arrangements" can come from top down or bottom up arrangements. Groups could grant decision making to a single user to necessitating a unanimous decision (Ostrom, 1998). Furthermore, users can devise rules in collective choice arrangements about technology used for harvest as in the case of a fishery (Paavola, 2007). 
Frequent opportunities for users to discuss and debate collective choice arrangements can be crucial for resource management. As these principles interact with each other, users with increased access to the resource and more secure tenure will base collective choice arrangements on perceived lower discount rates, while those with limited access and unsecure tenure my favor rules based on higher discount rates (Ostrom, 1990).

The fourth principle, monitoring will examine whether or not users are successfully implementing the first three principles. Rules pertaining to monitoring will determine who does the monitoring, the resource being monitored and whom they will monitor (Paavola, 2007). Monitoring as an activity can widely vary in costs to users especially as users change rules. Furthermore, the nature of the resource affects costs as varying technology and nature of use will also help to set costs. Continued interaction may decrease monitoring costs as well as if users share norms. Clearer rules can also decrease monitoring costs, especially rules that users support and find legitimate. Instead of a complete reliance on authorities or external monitoring, mutual monitoring between users can also lower costs (Ostrom, 1990). One advantage of relatively small groups is the amount of knowledge they have about other users and that this knowledge can lower information costs that could be too high for successful management either through government ownership or private property (Bowles and Gintis, 2000).

Following monitoring, in some cases graduated sanctions are necessary. Much of the idealization of government and private management of resources assumes that both monitoring and sanctions will enact low transaction costs. In each case, it would be a top down approach that external monitoring officials would enact sanctions. Questions arise as motives of this external authority and in the cases of common property, there may not be written codified laws that enable external officials sanctioning capacity (Ostrom, 1990). Yet government acknowledgment of common property and some degree of support will add extra backing to sanctions at the community level and potentially increase legitimacy (Bowles et al., 2000). 
What is important to note about the case studies Ostrom (1990) chose was that often the graduated sanctions began as a trifling fine to rule breakers. In the Japanese example, a monitor from the village could sanction rule breakers at first in sake. If rule-breaking continued, sanctions could progress to "ostracism" and even "banishment". The basis for collective action and the enforcement of small almost insignificant fines leads users to believe that such graduate sanctions produce "collective" benefits and that as fair and continued sanctioning continues more users will continue to "comply". Also as a consequence of the fact that in the case studies the a "monitorappropriator" handles sanctioning duties that it is possible that they understand the personal circumstances which may have led to the rule breaking and are able to adapt punishment for these circumstances (Ostrom, 1990). Such graduated sanction by legitimate can breed cooperation before sanction amounts need to escalate (Dietz et al., 2003). Also these small sanctions can provide valuable information to other users about the trustworthiness of those who being sanctioned. The obtained information would then be used in future interactions and show that a certain level of justice exists in intra-group dealings (Ostrom, 2008).

The sixth design principal is that groups have "confliction resolution mechanism". Having such mechanisms means that "appropriators" have "low cost" means of resolving conflicts between "appropriators" and officials (Ostrom, 1990). Opportunities conflict solutions include both "distributive" and "procedural" justice (Paavola, 2007). Most importantly such "mechanisms" need to be cost-efficient, timely and within the context of local circumstances. Rules must be understandable and clear help aid this process (Ostrom, 1998). Such mechanisms are vital to the long standing legitimacy of rules (Ostrom, 1990).

The seventh design principal is "minimal rights to organize" (Ostrom, 1990). Such rights will often need recognition from local or national governments. If governments do not recognize these rights than it would be possible that disgruntled users could go to governments and jeopardize common property management for the user group (Ostrom, 2008). 
Finally, the final design principle is "nested enterprises" (Ostrom, 1990). The idea here is that interactions at different scales of "systems" that creates the opportunities for "cross-scale physical relationships". Any shocks to the system at one level may be absorbed at the other level to help create more robust institutions (Ostrom, 2008).

The additional rules listed above largely provide further nuisance to these design principles (Agrawal, 2001; Ostrom 1990). Therefore, I will refer to them in the analysis of my case study, but will not further elaborate on them now.

\section{Common Property in the Mexican Context}

In light of the previous literature review, now I will explore common property in the Mexican context. Such an exploration is necessary for analyzing community conservation both in conservation covered by community institutions and those lands which remain largely outside of community institutions. Also, like the groundwater basins surrounding Los Angeles from Governing the Commons, scholars can trace the creation of common property in Mexico and how communities have taken the overarching framework from the government and adapted it to local conditions (Bray, 2012).

The two groups who received common property lands as a result of Article 27 of the Mexican constitution are ejidos and comunidades. Ejidos are in general non-indigenous citizens who received redistributed common property land that they had not originally inhabited. Comunidades are in general indigenous communities who received recognition and legal control of the communal land that they had traditionally inhabited and where titles given by the Spanish crown in the colonial period exist. I will use the English word "community" when discussing them together, and the Spanish ejidos and comunidades when it is important to distinguish between them.

Communities have legally gained their lands through a presidential resolution. The presidential resolution includes exact territorial size, the number rightsholders and clear 
geographical boundary measurements. The federal agency in charge of this process is the Secretario de Reforma Agraria Nacional (RAN) (National Agrarian Reform Secretariat). Rightsholders need to be Mexican citizens, and are normally born in the community to parents who are rightsholders. One can lose rights by the dictates of the community assembly, and the rightsholder themselves can renounce their rights (Ley Agraria, 1992).

What makes the comparison of these seven communities in the study cleaner is that they all have the same "constitutional choice" (Ostrom, 1990) in place as communities are required by agrarian law to have the same basic governance structure. The "supreme organ" and most important governance structure of these communities is the Asamblea General de Ejidatarios/Comuneros - General Assembly of Rightsholders (hereafter referred to as the Assembly): the collective choice arena, also largely determined by law

By law each community needs to convoke twice yearly assemblies, although one indicator of well-organized communities, such as those in the study area, is much more frequent assemblies. During assemblies communities conducted the following business: 1) Create and modify community statutes 2) Accept and excluding new rightsholders 3) Distribute information from community leaders 4) manage community finances and accounts 5) vote on contracts with third parties 6) Distribute profits to community members if applicable 7) Create parcels for human settlement and agriculture 8) Formalize the rights of posesionarios 9) Transfer common property to private parcels 10) Formalize areas as common property 11) Divide or unite ejidos 12) Complete the termination of an ejido 13) Convert an ejido to a comunidad or entirely to communal management14) Modify or cancel communal extraction of resources 15) other responsibilities according to the community's statutes (Ley Agraria, 1992).

During assemblies all rightsholders will vote on the above issues as they arise and in general the majority will rule in their decisions. Rightsholders legally range from the ages of 18 to 60 and attendance is obligatory often backed by sanctions at the community level. Therefore in 
a functioning community according to Agrarian Law, community members will make important decisions in an open and democratic fashion to provide the "collective and operational choice" for users, while exercising their rights to organize as users of common property (Ostrom, 1990).

Next in the communal governance hierarchy is the comisariado de bienes

ejidales/comunales (The Commission on Common Property), commonly referred to as the Comisariado. The Comisariado includes the 1) President 2) Treasurer and 3) Secretary. The role of the Comisariado is to: 1) Act on behalf of the assembly's decisions as well as conflict resolution and community finances 2) Foment the respect of wishes of rightsholders 3) Convoke the assembly according to the law 4) Communicate and aid management and use of lands managed as common property 5) other duties conferred by the assembly (Ley Agraria, 1992). For the individual roles, the president is the main representative of the community and will meet with government officials as well as grant permission for outside parties to work in the community. The treasurer keeps incredibly detailed record of community expenses that are presented at community assemblies. Often the communities will include this detailed accounting for everything from gasoline receipts to meals bought while traveling in documents provided to state and local governments even though it is not required. Corruption is a constant concern and so the comisariado needs to document and explain their expenses at least twice a year before the community assembly.

Finally there is the consejo de vigilancia (Oversight Council) The consejo includes a president and two secretaries 1) Provide oversight and monitoring to the activities of the comisariado according to community statutes 2) Review financial accounts of the comisariado and report their findings to the assembly, including 3) Convoke the assembly when not done by the Comisariado 4) other duties specified by the assembly (Ley Agraria, 1992). Despite the detailed accounting in the comisariado, the position of consejo acts as a check to the considerable power of the comisariado to ensure that no corruption is occurring within the comisariado. 
Requirements to act as a part of either the comisariado or consejo include: 1) having worked in the community in the last six months 2) be in full possession of their rights 3 ) and to have a clear criminal background 4) and remain in the community during these positions of authorities. Generally members of the comisariado and consejo will complete a three year term with equal downtime out of these governance structures before they may return (Lay Agraria, 1992).

Common property provides the "economic livelihood" for communities. All land that remains as common property is "unalienable, un-mortgage-able and unassailable" (inalienable, imprescriptible e inembargable) (Ley Agraria, 1992), which insures communities continued rights to their lands for comunidades and ejidos if they choose to continue communal management of their lands.

A wave of neoliberalism swept Mexico under the Salinas de Gortari administration which led to the reforms of Article 27 of the Mexican constitution (Osborne, 2011). Now privatization and the parceling of community lands was argued to be in the public's benefit, as it would be driver of economic growth (Ley Agraria,1992). Such benefits are as follows: 1) the “establishment, exploitation or conservation" of a service or public function 2) Land use zoning to increase territorial reserves and as well as areas for housing, industry and tourism 3) fomenting the conservation of agricultural/pastoral, forest or fishery resources 4) the exploitation of petroleum and other minerals 5) the strengthening of rural and urban tenure 6) the creation, support and conservation of goods and services of doubtless benefit for the community 7) the construction of basic infrastructure 8) other aspects of the Appropriation Law (Ley Agraria, 1992).

Yet, widespread privatization has not occurred. Largely when it has occurred, it is because the ejido was near a large population center or marquee tourist attraction that raises land values to the extent that ejidatarios choose to (Barismantov et al., 2009). Others have argued that 
instead of weakening the relation between the Mexican peasant and the State, the rejection of privatization from ejidos has been an attempt for communities to prolong their relationship with the state (Haenn, 2006). Furthermore, Antinori et al. (2005) argue it strengthened communities' abilities to manage their forests. Even more so, communities could not privatize and sell their forests and so they had more incentive to manage their forests (Bray et al., 2005). Importantly this changed community property rights from usufruct to more secure land tenure (Haenn, 2006).

To help register lands for either private parcels, for the dissolution of an ejido or for the reinforcement of current territorial boundaries, the Mexican government launched the PROCEDE program (Programa de Certificación de Derechos Ejidales y Titulación de Solares) or in English (Certification Program for Ejidal Rights and Private House Lots). From 1992 to 2006, 95\% of all communities in Mexico had registered with PROCEDE. If they so choose, ejidatarios could sell "membership rights", selling their lands as private property on an individual basis or selling the entire territory all together (Barismantov et al., 2009). The Mexican government also implemented the conflict resolution mechanism to help guide reform called the Procuraduria Agraria.

Furthermore, PROCEDE and the 1992 Reforms appear at this juncture to have further clarified boundaries and for those that have continued to manage forests as common property have achieved clearer land tenure (Bray et al., 2005; Antinori et al., 2006). Community members had prior to reforms and continue to hold "ownership" rights over their common lands as they have rights to use as a rightsholders, management through the community assembly, rightsholders can determine who in their family will inherit rights as well as the assembly can allow entrance of new rightsholders. Finally they had the right alienate property from one community member to another, whereas the 1992 reforms now allow complete alienation of the ejido (Barismantov et al., 2010). Throughout this thesis I will use the term rightsholder for those who have rights to use 
community lands within the terms of agrarian law and who met their obligations to the community.

While the above governance structures will be elaborated in important documents like community statutes (estatutos) which detail a wide variety of community rules, as well as communal land use zoning (ordenamiento territorial comunitario) provide the "operational choice" level that include the community rules as well as designation of land uses. Communities will to create clear and thorough rules and sanctioning mechanisms. The overarching framework of Agrarian Law then allows communities to adapt to governance for the particulars of their local social-ecological systems to attempt to balance "provision" and "appropriation".

My thesis will specifically focus on how this agrarian reform through the granting of large territories, with high conservation value and low agricultural value, relatively low population densities and considerable autonomy for diverse local strategies has led to a historical background of positive conservation outcomes with conscious decisions by the communities.

\section{Community Conservation}

Estimates state that communities globally are conserving 370 million hectares of forests compared with 470 million hectares of forests in public protected areas, including 23 million hectares in Mexico. These conserved areas will include large, contiguous forest blocks much in the vein of the typical protected area, but also in areas with a patch-matrix landscape, frontier areas as well as in systems with considerable anthropogenic imprint. These conserved areas, especially in tropical regions of the earth have crucial linguistic diversity. Not only will communities have superior management practices in some cases compared to protected areas, but the costs of community conservation can be drastically lower than a government-managed protected area (Molnar et al., 2004).

Given the changing land tenure and increasing recognition of the abilities of local communities to conserve their lands, community conservation has the opportunity to begin to 
explore important questions that often remain outside the scope of the traditional, protected area focused conservation (Escobar, 2008):

"Here lies one of the most difficult predicaments for conservation advocates and activists: pushed to rationalize ecological and environmental practices to ensure "conservation," they are aware that in doing so they are moving away from the long-standing, placebased notions and practices which ensured a reasonable level of sustainability until recent decades... Or are activists and conservationists forever doomed to bring nature into the realm of modern planning to ensure conservation? And if so, how can this be done without reinforcing coloniality (that is, the subalternization or even elimination of local grammars and knowledge of the environment) at both cultural and ecological levels?"

In effect, how can local voices and sovereignty remain in a debate of conservation that is increasingly driven by global crisis, the need for immediate action and in some cases a distrust of people working and living in the area which conservationists wish to conserve? While not nearly so theoretical, various communities are beginning across Mexico to conserve their forests, while maintaining agriculture production. As I will discuss in Chapter 3, communities are governing their entire territories and not just conserved forests, though increasing attention especially in commercial forestry communities has been directed to forest conservation

Recently international organizations such as the CBD and IUCN have recognized conservation occurring outside of protected areas as either IUCN Category 5 or Category 6 areas which combine conservation with other cultural and productive uses. A resulting classification includes indigenous and community conserved areas (ICCA) (Duran et al., 2012). ICCA's exist where communities themselves are managing their lands if not specifically for conservation but in ways that leads to the conservation biodiversity (Borrini-Feyerabend et al, 2002; Berkes, 2007). 
A matter that I examine in the thesis is how communities have increased their forest governance in the last two decades much in the mold of ICCAs. While I will thoroughly explore how transpired in Chapter 3 and examine potential implications in Chapter 4, understanding how communities begin to care about and care for their forests is important. One study that provides a useful analytic framework for the subregion is Agrawal's 2005 study on "environmentality".

Agrawal (2005) coined the term environmentality, which is based on Foucault's concept of governmentality. Agrawal defines environmentality as: "a framework of understanding in which technologies of self and power are involved in the creation of new subjects concerned about the environment. There is always a gap between efforts by subjects to fashion themselves anew and the technologies of power that institutional designs seek to consolidate..."

What Agrawal (2005) hypothesizes in community forest conservation in Kumaon, India is that "subjects" did not discuss and debate forest management prior to conservation, but rather their conservationist discourse emerged after their actual conservation in practice. What has occurred is peasants are largely sharing and repeating government discourses of conservation, as community members see such conservation to some degree is in their best interests. These villages in many cases formed forest councils to manage their forests as a result of their emphasis on conservation. With the decentralization of governance, these communities could develop forest councils to manage their forests as well as circulate a discourse favoring conservation.

There are strong parallels to communities in the subregion, with environmentality emerging from both forest management for timber and the more recent strict conservation programs.

\section{Community Conservation in Mexico and Voluntary Conserved Areas}

The creation of environmental subjects in Mexico has occurred within communities as well as through more recent governmental policies. Dalle et al., (2006) has taken and a historical and institutional outlook to the occurrence of forest conservation in the ejido X-Maben in the 
state of Quintana Roo. While practicing milpa agriculture to meet subsistence needs, the ejido has relied on harvest from the Malinkara zapota, which produces an ingredient for chewing gum. After the demand for this commodity decreased, the ejido worked with organizations to begin logging valuable tropical species in their forests. Communal rightsholders in X-Maben have placed land use restrictions on certain forest types since the mid-1950s from the conservation of stands of Malinkara zapota to in 2001 creating an ecotourism reserve. While outside organizations have played an important role in forest management, the community began to create rules around their forests prior to the arrival of these other organizations.

In other cases, communities like those in the Chimalapas region of Oaxaca have reached out to NGOs for financial support for conservation and rural development projects such interactions can reformulate and re-orient notions of participation in conservation interventions when communities begin to appropriate conservation discourse in order to appeal to international donor organizations. Previously organizations with programs had come to the Chimalapas with ideas for programs and essentially gain consent to start these projects under the guise of participation. With the knowledge gain from these presentations leaders from the Chimalapas came to the offices of the World Wildlife Fund in Oaxaca City with ideas of their own for projects, which the WWF eventually did not accept. Yet the WWF programs in the region are notably participative at least in some part because community leaders demand active local participation in any conservation project (Walker et al., 2007).

In this bottom up model, communities specifically must debate and discuss what they wish to conserve and how they can do it. Such is the case of the Otoch Ma'ax Yetel Kooh Flora and Fauna Protected area in Quintana Roo, which is a public protected area, registered among other such designated areas with CONANP, but was gazetted at the behest of the community. Yet a true partnership has encountered difficulties. A fire in the protected area caused CONANP and a partnering NGO along with community participation to craft a management plan for the area to 
more strictly delimit uses. One source of contention is that the management plan has banned the use of fire, which is a practice in swidden agricultural systems (milpa) in favor of a prospective ecotourism sector, even though the community whose lands make up the reserve is a predominantly agricultural community.

The community did create core zones as well as multiple use zones. If anything, budgetary constraints from CONANP have reduced options for promoting and launching ecotourism products, which have cause some degree of disappointment in local people who saw the reserve as a means to boost the local economy as well as access to health care, education and other local visions of development (Bonilla-Moheno and Garcia-Frapolli, 2012).

In part to organize and recognize this local biodiversity conservation, and to expand formal protection without having to declare protected areas on top of community lands, Mexico has created an innovative policy for community conservation called Voluntary Conserved Areas (áreas destinadas voluntariamente a la conservación). A seedling of the idea first appeared in the 1988 LGEEPA (Ley General de Equilibrio Ecológico y Protección Ambiental) (The General Law of Ecological Equilibrium and Evironmental Protection) (LGEEPA, 1988). With the addition of the reglamento (rules and regulations) to the LGEEPA in 1996, the policy further specified that indigenous groups, private landowners, civil organizations and local governments could set lands aside for conservation and receive certification from CONANP for doing so. Article 59 from the 1996 LGEEPA stated: - “Indigenous peoples, social organizations, public or private, and other interested persons, may promote the establishment with the Secretary on land owned or under contract to third parties, natural protected areas for the preservation, protection and restoration of biodiversity,” (LGEEPA, 1996).

By 2008, a further modification to Article 59 of the LGEEPA further specified Voluntary Conserved Areas. Certificates for Voluntary Conserved Areas would last from 15 years until perpetuity on the basis of a management plan co-crafted by the land manager and CONANP, 
though the land manager would provide regulation. Furthermore, CONANP could incorporate these areas into the national protected area system. Also, CONANP floated the idea of a seal of sustainability for products extracted from the conserved area. Unlike CONAFORs payments for environmental services program, there are no direct payments for voluntary conserved areas, though landowners can both certify territory as a voluntary conserved area and also apply for PES for the same tract of land. In practice communities often receive community infrastructure or a small community project for certifying a VCA. The policy has promised the pertaining rules and regulations to better specify and operation those precepts set out in 2008 (LGEEPA, 2008). Long overdue, now three years later, the policy has not received it rules and regulations and there is no seal of sustainability. Yet, despite these lingering uncertainties, certifications continue.

As of January, 2013 there are 324 voluntary conserved areas covering 370,805 hectares. Communities (ejidos and comunidades) have created through CONANP's certification process 237 of the 324 total certifications and $246,313.76$ hectares of the total 370,805 , which is $73 \%$ of all certifications and $66 \%$ of all land certified. Notably, for some ejidos that have created individual parcels within their ejido still certified land as a voluntary conserved area, but have done so with individual parcels, which have driven up the sheer number of certification by ejidos.

The two leading states by far in the certification of voluntary conserved areas are Oaxaca and Guerrero with 141,128 hectares or $38 \%$ of all certified lands and 67,649 hectares or $18 \%$ respectively. These two states combined then have certified $56 \%$ of all land certified as voluntary conserved areas in Mexico (http://www.conanp.gob.mx/que hacemos/listado_areas.php, 04/04/13.

Yet, Oaxaca is 4.7\% of Mexico's national territory and Guerrero 3.2\% (Mexico en Cifras, 2012), so their predominance is certification is not explained by the size of their territory alone. Again, Oaxaca has $82.3 \%$ and Guerrero $81.9 \%$ of their forests under management by communities (Madrid et al., 2009). Yet, conversely highly forested states like Quintana Roo with 
$72.9 \%$ of forests held by communities only have certified a total of 2823 hectares of voluntary conserved areas (CONANP LISTADO DE ÁREAS CERTIFICADAS, 2012) and is $2.1 \%$ of national territory (Mexico en Cifras, 2012). Therefore, there are potentially other processes occurring that lead to the certification of voluntary conserved areas other than merely having common property in forested areas. Furthermore, though the trend of Voluntary Conserved Areas is promising, it is worth noting that eight different Biosphere Reserves each conserve more land than all the land conserved in VCAs. Despite the small area occupied by Voluntary Conserved Areas, studies have shown their potential role in helping to improve connectivity along the Mesoamerican Biological Corridor (Elizondo et al., 2009).

The communities in CORENCHI are neighboring communities to the north of the subregion I have chosen to study and will provide fruitful comparisons and contrasts in examining the large extensions of their communal lands that they have designated as VCAs.

While much land use planning occurs at the level of a single community, the Natural Resource Committee of the Upper Chinantla (CORENCHI) consists of six communities in the Sierra Norte of Oaxaca who conserved $77 \%$ percent of their 34,908 ha of their territory as Voluntary Conserved Areas with the Mexican federal agency CONANP (National Commission of Natural Protected Areas). The CORENCHI communities have largely certified montane tropical forest and montane tropical cloud forests in the program (Bray, 2012) even though the VCA program provides no direct cash payments (LGEEPA, 2008). The communities of CORENCHI do receive payments for sizable tracts of land from the Mexican federal agency CONAFOR—Comisión Nacional Forestal (National Forest Commission) for PSA. Unlike other communities in the Papaloapan watershed such as the community San Mateo Yelta included in my study area, CORENCHI distributes $70 \%$ or more to community members as the both the VCAs and PES conservation occurs on communal land. Therefore, while the VCA nets the 
community no profits, the PES money has helped alleviate poverty at the community level (Nieratka, 2011).

The PES funds have become more important as a consequence of the declining importance of coffee in some communities in CORENCHI. Coffee was once the major source for income in the CORENCHI communities. Coffee abandonment in these communities came in the wake of Mexico's dissolution of its state-sponsored coffee support program the Mexican Institute of Coffee (INMECAFE) as a result of the failure to broker the International Coffee Agreement (ICA) in 1989. Because of low prices, farmers chose various pathways from full conversion of coffee plots to corn fields are less intensive farm techniques that will generally rely less on paid labor. Yet another response to the fall of coffee prices was outmigration to the United States, though community estimates downplay this movement compared to official estimates (Hite, 2011). An attempt at community forestry in one community failed due to corruption of a community authority and to ecological concerns (Bray et al., 2012)

While cattle are a source of income for some in CORENCHI, topography keeps the CORENCHI communities from large scale cattle raising (Figel et al., 2011). These cattle ranchers have in general been the vocal minority in the opposition to conservation projects (Bray et al., 2012), though 93\% of CORENCHI members support current conservation programs (Figel et al., 2011), even if there is still some lingering misunderstanding over the regulations and extent of the VCA area (Berget, 2012).

Despite this vocal minority opposition largely made up of cattle owners to conservation, CORENCHI community members have shown interest in expanding their conservation activities. In a choice game, there was interest in entering carbon capture programs in various settings in CORENCHI (Nieratka, 2011), showing continued support and a democratic desire for the expansion of conservation activities. They have also received support from the brewery Grupo Modelo's philanthropic wing for an ecotourism project in CORENCHI. While conservation is 
now occurring at the community level with linkages to the federal government and business, plans previously existed for a Biosphere Reserve that would have included the CORENCHI territories (Bray et al., 2012).

The CORENCHI communities initially communicated their interest in the reserve to CONANP in 2005. Eventually fears of loss of control of their land and dominance of Biosphere authorities caused suspicion. CORENCHI hired lawyers to further investigation the reserve's implications and members visited other Biosphere Reserves in neighboring states to judge on the ground practices. By 2009, CORENCHI had decided against the reserve and CONANP leaders who were once supportive apologized in the inter-community assembly for backing the idea (Bray et al., 2012).

Despite the rejection of the Biosphere Reserve, CORENCHI has continued its conservation activities and the largest blocks of land under VCA in Mexico (Duran et al., 2012). Such a complex landscape matrix of community conserved forests, coffee farms in various stages of production and abandonment, rotating traditional milpa agriculture and cattle pastures have been able to conserve high quality enough habitat to support jaguars, pumas and other large mammals (Figel et al., 2011).

\section{Payments for Environmental Services in Mexico}

Mexico's PES program (PSAH_-pagos de servicios hidrológicos - in Spanish) launched in 2003 with the intention to counter two simultaneous phenomenon-high deforestation rates as well as over-exploited aquifers. Tropical montane cloud forests (TMCF) had recently faced increasing conversion to cattle pastures and agricultural fields (Alix-Garcia et al., 2005). A combination of withdrawal by large cities as well as perverse incentives for large irrigation projects led to aquifers becoming exploited in north and central Mexico (Muñoz-Piña et al., 2008) as the government subsidized as much as $80 \%$ of irrigation costs, leading to aquifer overexploitation (Wilder, 2010). 
The focus of hydrological services fell in line with a prolonged campaign by the Mexican government to convince communities that forest conservation was directly related to water provision (Alix-Garcia et al., 2005), even though this hypothesis is of debatable validity in some cases (Mathews, 2011). Such is the case of the sub-region in this thesis that almost all communities will say that the conservation of forests is absolutely necessary for the provision of oxygen and water necessary for their survival.

Funds for the PES program came from a tax on water users as well as the World Bank. Program planners hoped to solve the above problems of deforestation and overexploitation of aquifers with a single program, even though large exploited aquifers remained in the northern and central Mexico, while the majority of cloud forests are located in the southern states of Oaxaca and Chiapas. Furthermore, the Mexican environmental agency SEMARNAT Secretaria del Medio Ambiente y Recursos Naturales (The Secretary of the Environmental and Natural Resources) had invested time in promoting forests and their water provision capabilities, so planners assumed people would recognize the connection of forest conservation and hydrological services. Also, given the rushed nature of implementing the program, CONAFOR has no baseline ecological measures to test for additionality and relies on the proxy of remote sensed images of forest cover and periodic visits to assume ES provision. Therefore no real measures of additionality of service provision are possible in many cases (Alix-Garcia et al., 2005). Payments for those who signed a five year contract in 2004 were $\$ 400$ pesos for cloud forests (USD\$ 33) and $\$ 300$ pesos for other forest types (USD\$ 30) (Alix-Garcia et al., 2010).

The CONAFOR PES program has varied widely in its coverage and well as payments provided for the conservation of forests (García Romero, 2012): 
Figure 1.3. CONAFOR PES 2003-2011

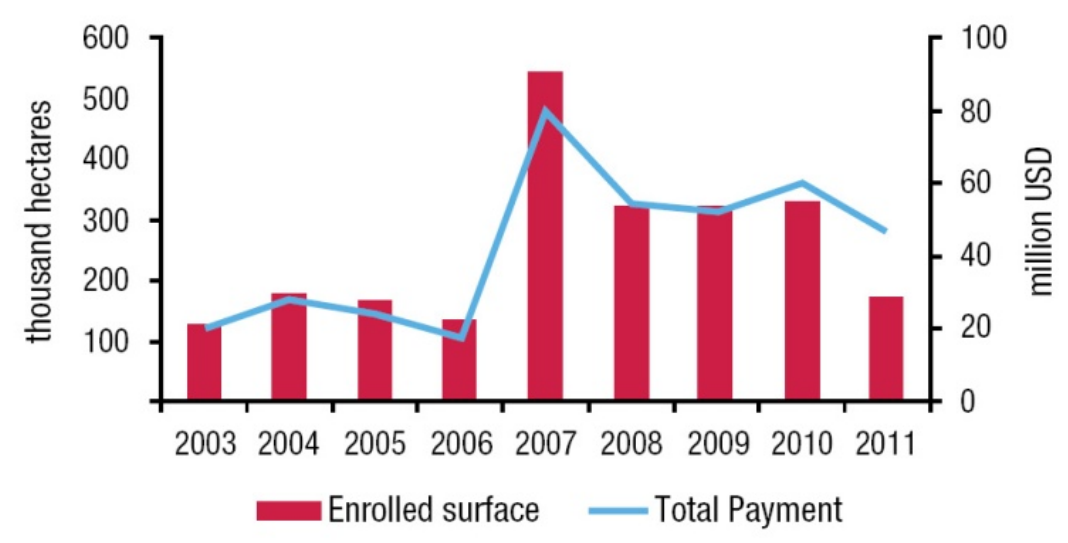

Source: García Romero (2012).

All forests eligible for payments must be native forests and forest plantations are not acceptable. Mexico's PES program has altered its manner of selecting participants as the program has evolved. While the program was beginning between 2003 and 2005, the selection was "adhoc" as CONFOR had a budget it needed to rapidly allocate in 2003. Between 2006 and 2010 the following criteria emerged: hydrology, deforestation pressure, poverty, gender and ethnicity of the applicant, as well as the land managers' participation in other programs. As it turns out the socially focused categories as well as those to whether or the applicant participated in other programs accounted for two-thirds of the point system for program eligibility. These nonexplicitly environmental criteria accounted for $56 \%$ of possible points in 2006 , while in these areas accounted for $81 \%$ of possible points by 2011 (Muñoz-Piña et al., 2011).

Conversely then, more environmentally focused variables such as hydrologic importance and deforestation pressure reduced from $44 \%$ of possible points in 2006 to $19 \%$ in 2011. Comparatively in Costa Rica the application process has no such criteria and is a first come, first serve system for funding. Through these criteria CONAFOR selected $10 \%$ of areas with high pressures for deforestation in 2003 and $18 \%$ in 2009 with a peak of those five-year contracts in 
2007 covering $33 \%$ of areas with high deforestation pressures. Areas with high and very high rankings of marginalization found their high also in 2007 with 50\% and their low in 2003 with 25\%. Annual deforestation rate for participants in Mexico's PES program was .6\% annually, while the rate for statistically similar communities was $1.56 \%$, or roughly 17,500 hectares of avoided deforestation. The vast majority of the avoided deforestation is attributable to the areas entered into the program with high rates of deforestation and actually lessened deforestation as a result of payments. In other cases the payments to communities will little deforestation pressure has created little avoided deforestation (Muñoz-Piña et al., 2011). Others also found modest decreases in deforestation as a result of the program (Alix-Garcia, 2011). Largely with the few exception of payments actually reducing deforestation, payments have largely transformed into green "subsidies" and "rewards" for past environmental conservation (Shapiro, 2010). In my study area six of the seven communities receive PES from CONAFOR on a yearly basis. In five out of six of these communities, the PES areas are distant from agricultural areas and pose negligible deforestation risks.

To conclude, in this chapter I have explored a movement which has led to the substantial increase of protected areas worldwide (Naughton-Treves et al., 2005). Nonetheless, conservationists feel that the extent of protected areas should be increased (Brooks et al., 2004). Similar trends have occurred in Mexico. The agency CONABIO has created an ambitious systematic conservation plan for an expansion of its protected area network, which would include the entire Sierra Norte (Arriaga, 2000). Beyond creating large systematically planned protected areas, the Mexican government has implemented policies relating to payments for environmental services (PES, which in the single year of 2007 enrolled over 500,000 hectares for five year conservation contracts (Garica-Romero-2012). The Voluntary Conserved (VCA) area policy has enrolled 370,805 hectares in its program (CONANP, 2012), with the CORENCHI communities have together conserved the largest block of VCAs in the country (Bray et al., 2012). As 
communities control $60 \%$ of forests in Mexico, and $82.3 \%$ of forests in Oaxaca (Madrid et al., 2009), protected areas, PES and VCA programs often occur on communal lands governed by rightsholders.

Furthermore, the subregion has few drivers of deforestation which include increased lack of off-farm employment, increased rainfall and lower elevations. As I will discuss in Chapter 3, rightsholders largely respond to the lack of off-farm labor through migration and less so by opening up additional land for agriculture. For better or worse, many see migration as a more desirable option than agriculture given the steep slopes, poor soils, lack of roads and market access for distant portions of the territory, declining subsidies and rising wages for agricultural day laborers. Also communities have secure land tenure and so they do not need to maintain tenure through continue forest clearance.

This secure land tenure granted through agrarian reform also allows communities rights over their lands and the ability to manage it based on the will of the community's assembly and unpaid non-partisan leaders elected at the community level. The broad powers of collective and institutional choice communities have has helped to create environmental subjects indicated by communities' which have produced community statutes and OTC specifically with the intent to better govern their territories and forests.

In Chapter 2 I will detail my research methods as well as justify my selection of the subregion made up by seven communities as my research site. I will also examine SCP exercises related to the Sierra Norte as well as other previous studies that have studied community conservation. Later, in Chapter 3 I will detail the results that demonstrate the high forest cover in the subregion in addition to the process that led communities to begin more comprehensive territorial governance that transformed passive conservation to active conservation. In Chapter 4, I will analyze the underlying factors which have led to passive conservation and argue that these factors, which also entrenched economic marginalization in the subregion, should lead to an 
increased in PES to better compensate these communities for the conservation. Also, I will argue that systematic conservation planning exercise should begin to incorporate land tenure and the existence of community conservation into their methodology in the Sierra Norte and elsewhere. Lastly, Chapter 5 acts as the conclusion for this thesis. 


\section{CHAPTER 2}

\section{Research Methods and Biodiversity in Oaxaca}

In this chapter I will discuss my research methods, rationale for community selection as well as review literature relating to the biodiversity of the subregion. I chose the subregion because of its increasing recognition as a globally important area for biodiversity conservation, and it was part of a larger research project proposed by my thesis advisor. The region is important enough for biodiversity conservation that CONABIO, the World Wildlife Fund, Conservation International and various systematic conservation planning articles have designated the area as important for conservation (Arriaga, 2000; Brandon et al., 2005; Gordon, 2006; Illoldi-Rangel et al., 2008; CONABIO, 2010; Ponce-Reyes et al., 2012; Rojas-Soto et al., 2012). This chapter will show that the seven study communities may be analyzed as part of conservation in an eighteen community block of 114,923 hectares, 103,080 hectares of which are forested, which is $89 \%$ of the total territory. Communities receive support for conservation from Mexican environmental agencies, as in the PSA program, in other cases conservation occurs by community decision with no external support. This large forested block has a large swath of tropical montane cloud forests (TMCF) which researchers have repeatedly singled out for their high conservation value in the region (CONABIO, 2010; Toledo-Aceves et al., 2011; Ponce-Reyes et al., 2012). Given the risks these forest face under different future scenarios of anthropogenic climate change, some scholars have advocated for the creation of protected areas on top of these community lands. These papers (Rojas-Soto et al., 2012; Ponce-Reyes et al., 2012) make little to no mention of the conservation practices community are currently carrying out in this eighteen community block, or the reasons why such large blocks are currently in existence, a subject to which I will return in my discussion and conclusions. 


\section{Research Methods}

There have been extensive studies of community forestry enterprises in the Sierra Norte of Oaxaca, Mexico (Antinori et al., 2005), carbon capture (Figueroa-Navarro et al., 2005), payments for hydrological services (Nieratka, 2011), agricultural abandonment on coffee plantations (Hite, 2011), conservation and migration (Robson et al., 2011) and the political ecology of community forest management and State forest governance (Mathews, 2011).

Given the aforementioned high forest cover and communal land ownership make this a fascinating area for community-based conservation. Community management largely avoids "The Tragedy of the Commons" (Hardin, 1968) and lends itself to applying the work of Ostrom and others in the management of common pool resources to conserve natural resources at the local level (Ostrom, 1990). My study may be considered a "disciplined configurative" case study (George, 2005), since I will use a well-studied theory (communal pool resource management) to explain high forest cover and communal land management in specific case study area. Furthermore, much of the above research has focused on the higher altitude pine and oak forests, while my research focused in mainly different communities, or less examined areas of wellstudied communities, and areas of bosque mesófilo (tropical montane cloud forests and tropical montane humid forests) as these forests have received considerably less attention.

My major research objective has been to understand why there remains a large block of tropical montane cloud forests and tropical montane humid forests on the slope leading down to the Gulf of Mexico in the state of Oaxaca, especially given that these ecosystems types have faced major transformation nationally as well as in Oaxaca. My goal was to examine land-use histories, and contemporary institutional processes in the management of common pool resources, including specific norms and informal and formal regulations that have led to such conservation, when the expected outcome of traditional thinking would indicate that individual private property 
rights or top-down government ownership would be needed to produce lasting conservation results (Hardin, 1968).

Such a study could aid other researchers in examining community-based formal and informal conservation in tropical humid rain forests and tropical montane cloud forests as well as give the involved communities data which would support their evident environmental stewardship. The region is quite extensive and includes the aforementioned CORENCHI communities, but I have focused on seven communities, including the smaller settlements known as agencies and ranches that pertain to these municipalities will well represent the region.

These seven communities include 66,254 hectares, of which 88.34 percent or 58,569 hectares are forested are forested. There are 1,995 rightsholders with access to community lands and all land outside of urban areas; including the $100 \%$ of forests that are managed as common property. The communities of Ixtlán de Juárez, Santiago Comaltepec and San Pedro Yolox all have sections of their pine-oak forests managed for timber. All communities save Ixtlán grow coffee, all communities have cattle pasture, though limited in extent, and all communities practice swidden agriculture (milpa). Also, the communities of Ixtlán, Nuevo Rosario Temextitlán, Yolox and Santiago Cuasimulco all have one permanently populated village, whereas San Felipe de Leon has two, San Mateo Yetla has three with one additional roadside settlement and Comaltepec has three villages with two additional roadside settlements. As I will explore in detail in Chapter 2 and 3 , these additional settlements affect conservation in different ways.

\section{$\underline{\text { Hypothesis }}$}

Prior to collecting data, I hypothesized that 1) low population densities, large to very large territories with secure defensible boundaries, relative remoteness, and traditional farming practices used to cultivate corn and coffee helped conserve forests into the recent period, by what could be called passive conservation, or conservation by default 2) Since the 1990s, conservation has become increasingly more conscious, active and directed, for varying reasons, and the focus 
of community land use policy in interaction with other levels and scales of governance, in the absence of systematic conservation planning. Both low opportunity costs for forest conservation and low discount rates, due to an interest in conserving forests for future generations, play a role. As well, complex and robust community institutions and governance may have made some contributions to conservation in earlier periods but are now more consciously and actively guiding the management of these forests for conservation, although there are minority dissident voices in some communities. Strong collective action and increasing knowledge of Western ecological concepts as well as traditional ecological knowledge (Berkes et al., 2000) of the benefits of conservation has propelled the community to, by strong majority democratic vote, either formally through governmental programs or informally set areas aside for conservation at the community level and managed through governance structures to reciprocate cooperation or sanction any community members or outsiders who attempt to challenge conservation restrictions.

While documenting the shift from passive to active conservation in the subregion is important, what is far more important for community livelihood is examining the benefits community may or may not deserve for conserving what would amount to a medium-sized protected area of forest, including thousands of hectares of tropical montane cloud forests (TMCF). Six of seven communities do receive PES, but it is not clear that PES have yet made the impacts for poverty alleviation observed in other communities (Nieratka, 2011).

\section{Community Selection}

I have chosen these seven communities for a variety of reasons. They were identified as a partially unstudied block of forested territories to the south of the relatively well-studied Corenchi communities. It was thought that they have conserved forest types which have faced high rates of deforestation nationally. It was found in the course of the study that these communities have not officially certified their conservation with the government save for one, San Felipe de Leon. I was 
also unaware prior to visiting these communities that all are receiving payments for environmental services; again save for San Felipe de Leon.

The studies in the CORENCHI communities just to the north of my study region have shown that they their communal lands provide habitat for large predators like the jaguar (Figel et al., 2011), successfully distribute PES payments to help alleviate poverty (Nieratka, 2011), have faced the coffee crisis in a various ways, including converting their coffee farms to other land uses, semi-abandonment and complete abandonment and outmigration (Hite, 2011) and also the management of invasive species (Berget, 2012). Furthermore, the CORENCHI communities have maintained $96 \%$ of their territory as forest (Velasco-Murguia, 2011).

It was hypothesized that the findings of these studies would present similar processes to those in the CORENCHI communities. A considerable difficulty exists in that the CORENCHI communities have exhibited inter-community collective action largely based around conservation (Velasco-Murguia, 2011; Bray et al., 2011), while the seven communities in this thesis each make entirely intra-community land use decisions without any collaboration whatsoever from the other communities.

Not all communities in the Sierra Norte have been able to limit deforestation and even fewer have decided to dedicate forests strictly to conservation. My study area includes one such area called San Martín Soyolapam, an agencia in the large and generally well-conserved community of Santiago Comaltepec, which has engaged deforestation to create cattle pastures (Robson, 2011). This is an example of a community which has a reputation for conservation, but nonetheless has not been able to control deforestation in a lowland tropical region of its territory. Including this agencia in my study will be more representative of adjacent lowland regions, as to not only investigate communities which have specifically set aside forests for conservation.

While there are other communities which include parts of the block of conserved forest that I have studied, I was for the most part a solo researcher and had 14 weeks from May-August 
2012. While I was unable to visit San Felipe de Leon during my first visit as a result of difficulties in arranging my visit as well as my own problems with amoebic dysentery, I was able to visit San Felipe de Leon to finish the study featured in this thesis during December-January

2012-2013 when I visited the community to also conduct a field experiment examining payments for multiple ecosystems services, though I have not used the field experiment data in this thesis.

I used a mixed methods approaches in this study including archival research, structured and semi-structured interviews, focus groups and land use transects. I have chosen this mixedmethods approach to attempt understand the ongoing conservation of this block of forest.

\section{Archival Research}

Archival research is notable for being one of the few research methods where research and the participants have no interaction (Ragin, 2011). Importantly, it is non-reactive research and therefore if records have been diligently and truthfully kept, subjects are not able to alter their behavior after the fact. Also, archives are a useful tool in studying material which may be too controversial or questions which may make participants uneasy or offend them. Another strength of archives is that they are an important means of studying change over time with documents that reflect the time the events occurred and not a remembrance of them (Bernard, 2011).

While not official archives, much of the quantitative data I gained throughout this study came from the review of land use zoning plans (ordanamiento territorial) OTC, which communities have created of their own volition, commonly paid for by Mexican government agencies. I also revised documents created in compliance with agrarian law including: forest management plans, reports for the payments of environmental services program with CONAFOR and other documents dealing with forest management. Communal statutes (estatutos comunales/ejidales) provided rich detail about community rules pertaining to a wide variety of topics. Much of the data provided in chapter three comes from these documents. They proved invaluable. Also, as communities closely guard this information, one must visit the communities 
and gain permission to review them. Although most were funded with public monies, and thus theoretically should be available to the public, in a nod to community sensitivities CONAFOR declines to make them available to researchers without written community permission

Above all the OTCs provided the amount of land under a variety of designations including agricultural, urban and forest. As each OTC had different classifications, I was at least able to obtain forest types and their coverage in hectares. In some cases OTC and/or forest management plans had in depth categorization of community conservation. In other cases OTC listed areas merely as conservation or as forest without creating specific classifications to indicate how communities were managing these forests or why they had decided to explicitly conserve them at the community level.

Largely because of the diversity in classification of forest management and forest conservation, throughout this thesis I will refer to informal conservation as that which occurs at the community level and in the absence of outside recognition. This would include areas zoned for conservation in OTCs and also areas more explicitly designated at the community level. It is correct to refer to conservation at the community level as informal conservation, because SCP on the Sierra Norte largely assume that local institutions do not exist in the region potentially because much of the conservation remains informal and unrecognized beyond communities who closely guard such information.

To further clarify informal conservation, there is community conservation which exists only in OTC documents as in the case of Yolox, Nuevo Rosario and Cuasimulco and informal conservation that is recognized through votes taken at the community assembly and through their community statutes as in the case of Ixtlan, Comaltepec and Yetla.

I will refer to PES areas and VCAs as formal conservation in those communities make agreements with the federal government pertaining to the conservation of these areas. While my research does not necessary indicate that formal actually provides increased protection of these 
areas, it is more a heuristic classification than one that may have vastly different impacts in their effectiveness. Formal conservation receives one-time compensation of a community project in the case of VCAs, while communities receive yearly payments in a five-year contract for PES. While communities can exist both agreements, PES incentivize that communities comply with program rules and pass yearly inspections so that they continue to receive PES.

Also, communities are responsible for conserving these areas; there is no outside governmental monitoring or sanction. In effect, they then have conservation status largely at the community level with linkages to governmental policy. That being said, communities are not necessarily more supportive of informal or formal conservation. In fact, dissent exists in the subregion to both formal and informal conservation.

\section{Focus Groups}

My archival research allowed me to triangulate the information I learn in my structured and semi-structured interviews. After gaining clear permission to conduct my study from community authorities, with a letter of introduction from the NGO Geoconservacion that works in the some of the communities, I was able to begin my research. Along with my advisors Dr. David Bray and Dr. Elvira Duran, I also met with partnering NGOs of other communities in order to gain access and also went on introductory visits to communities. I began the tasks of arranging a time to reunite these communal authorities for a focus group style interview, which lasted from one to two hours.

Communities have a governing structure called the comisariado de bienes comunales (the Committee on Common Properties) with a communal president, a treasurer and a secretary of each community. An additional governance institution, the consejo de vigilancia (Oversight Council), which consists of a president and two secretaries attend. I interviewed those who currently held these jobs because they should be knowledgeable about current land use, and I also attempted to interview those who have held these posts in the past who may be able to recall past 
uses of the land currently in conservation, or past debates about exploiting or conserving this area. After having interviewed these officials I used snowball sampling to speak to elders who may have further historical knowledge as well as others who frequently visit the area, worked previously in or near the conserved area or even anyone who has strong opinions about the management of the area.

Instead of my initial inclination to conduct one-on-one structured and semi-structured interviews, I chose focus groups largely create a discussion around conservation among community leaders. Also because this study includes seven communities, focus groups were an efficient way to gain basic information about all communities. By scheduling a time to speak together with the officials of community governance institutions, I hoped to create a focus group which would lead to voluminous data for my research (Bernard, 2011) and a potentially more comfortable environment for participants than a one on one interview. A limiting factor in participation was both the demanding work of these positions of authority as well as the simultaneous agriculture labor most authorities balance. Therefore, I had between two and six participants in focus groups conducted in all of main community villages, as well as in the agencias as much as was possible.

Unfortunately, contrary to ideal design principles for a focus group, the participants were not strangers, which could have affected honest disclosure. The small size of these focus groups might have led to the more outspoken members dominating the proceedings (Bernard, 2011), which could have limited the scope of data collected. As a consequence of personal time constraints, I conducted a single focus group in each of my nine study communities lasting $1 \frac{1 / 2}{2}$ to 2 hours depending on participant availability and their personal schedules. I first visited several of the communities with Dr. Bray and Dr. Duran and he conducted the first focus group interview in the community of San Mateo Yetla. 
The English version as well as the Spanish translation used in the field are included in the Appendix of this thesis as to demonstrate how my focus group interviews provided data not available in OTCs as well as provided data that could triangulate information in the OTCs

\section{Land Use Transects}

When conducting land use transects I hired a community guide in order to explore land uses such as milpas, coffee farms, cattle pastures and conserved forest fragments. Given that PES and the more conserved areas are all but uniformly distant from villages and difficult to access, because of time constraints I only visited the PES are in San Mateo Yetla. At various stops, I questioned the guide as to what the current land use of the land was, if it had changed and if he believed that it would change. I have extensively utilized this data in the results in Chapter 3 when discussing the various lands uses of the subregion.

\section{Biodiversity in Oaxaca}

Biodiversity as a concept emerged in the 1980s and quickly garnered academic and then popular attention (Ghilarov, 1996). Many see continued biodiversity conservation is vital to human well-being (Pimentel et al., 1997; Chapin III et al., 2000; Brandon et al., 2005). Others add caution that attempts to alleviate poverty without specifically considering biodiversity conservation will reinforce the same modernist development agenda that helped to create ecosystem degradation and species endangerment in the first place. They argue that biodiversity conservation must lead economic development and not vice versa (Sanderson and Redford, 2003).

Others argue that biodiversity is a global discourse that was initially created in a complex series of largely top-down interactions from the global north to the global south (Brown, 1998; Escobar, 1998). The CBD (Convention on Biodiversity) emerged as an international effort that would minimize the direct role of states in the conservation of biodiversity (Brown, 1998; Gordon, 2006). Through the CBD and other international meetings, indigenous and other activists 
have been able to attempt to refute ideas such as bio-prospecting, while affirming their sovereignty over their land (Escobar, 1998; Colchester, 2004). Other groups have formed their own understandings of nature far removed from discourse of global biodiversity based on a changing local knowledge (Escobar, 1998). A further project is to contest the notion that any human influence in an ecosystem automatically degrades that ecosystem (Brown, 1998). Communities may in some cases be far more interested in conserving species directly useful to their productive activities (Toledo et al., 2003) based on local knowledge systems (Gupta and Sinha, 2001). Also, in some cases certain epistemologies support the idea that humans can pass between various states of animals and at least temporarily become that animal (Figel, 2011). Therefore the idea of crucial need of top-down interventions meant to conserve all species that are intrinsically distinct from one another is far less than a universal ideal, even when much is made of global biodiversity.

Also, as I will explore in Chapter 4 notions of global biodiversity have potential implications in the amount provided by PES programs as well as potential funding sources. Again as Escobar (2008) argued, a challenge for conservations is to conserve biodiversity while also valuing local knowledge and practices in communities like those in the subregion, and so also in Chapter 4 I will examine SCP that largely ignore any community-based conservation in the subregion.

Similarly to this thesis, scholars are increasingly recognizing communities' efforts at maintaining biodiversity with patch-matrix landscapes as well as in community conserved areas (Gomez-Pompa and Kaus, 1992; Alcorn, 1993; Gomez-Pompa and Kaus, 1999; Moguel and Toledo, 1999; Bray et al., 2003; Toledo et al., 2003; Bray et al., 2005; Dalle et al., 2006; Robson, 2011; Figel et al., 2011; Bray et al., 2012; Duran et al., 2012). A strong focus on community conservation in Mexico in part stems from long historical habitation by indigenous peoples, which make the prospects of a wilderness discourse difficult to sustain (Gomez-Pompa and Kaus, 
1992; Alcorn, 1993; Gomez-Pompa and Kaus, 1999; Bonillo-Moheno et al., 2012). Furthermore, agrarian reform granted roughly $60 \%$ of Mexico's for common property regimes in the form of ejidos and comunidades (Madrid et al., 2009).

Oaxaca is in some ways a microcosm for Mexico in that the state is cultural and biologically diverse (Gordon, 2006), while $82.3 \%$ of all land in Oaxaca belongs to ejidos and comunidades (Madrid et al., 2009). In fact, Oaxaca is Mexico's most biodiverse state (GomezMendoza et al., 2006). In terms of biodiversity, Oaxaca contains at least $70 \%$ of all vegetation in just $5 \%$ of national territory (Velazquez et al., 2003). The state also contains widely ranging, climates soils and topography (Velazquez et al., 2003; Sanchez-Cordero et al., 2005), which further increases biodiversity (Sanchez-Cordero, 2001). Oaxaca also exists in a transitional zone between the Neararctic and Neotropical zones. Vegetative, topographic and climatic diversity has led to the state of Oaxaca containing $63 \%$ of bird species, $55 \%$ of the species of terrestrial mammal, $50 \%$ of vascular plant species, $35 \%$ of amphibian species and $26 \%$ of reptile species in Mexico (Illoldi-Rangel et al., 2008). There are 702 plants and 128 vertebrates endemic to the state of Oaxaca (Robson, 2011).

Despite Oaxaca's recognition as an area of global importance for biodiversity conservation, protected areas cover only $5 \%$ of its area, while areas designated as national parks with stricter protection cover only .2\% (Illoldi-Rangel et al., 2008). The combination of high biodiversity and a low percentage of protected areas have made Oaxaca especially an area of interest for increased protected areas (Bray, 1991; Brandon et al., 2005; Illoldi-Rangel et al., 2008; Ponce-Reyes et al., 2012; Rojas-Soto et al., 2012; Bray et al., 2012). Figure 2.1 shows current protected areas in Oaxaca. 
Figure 2.1. Protected Areas in Oaxaca

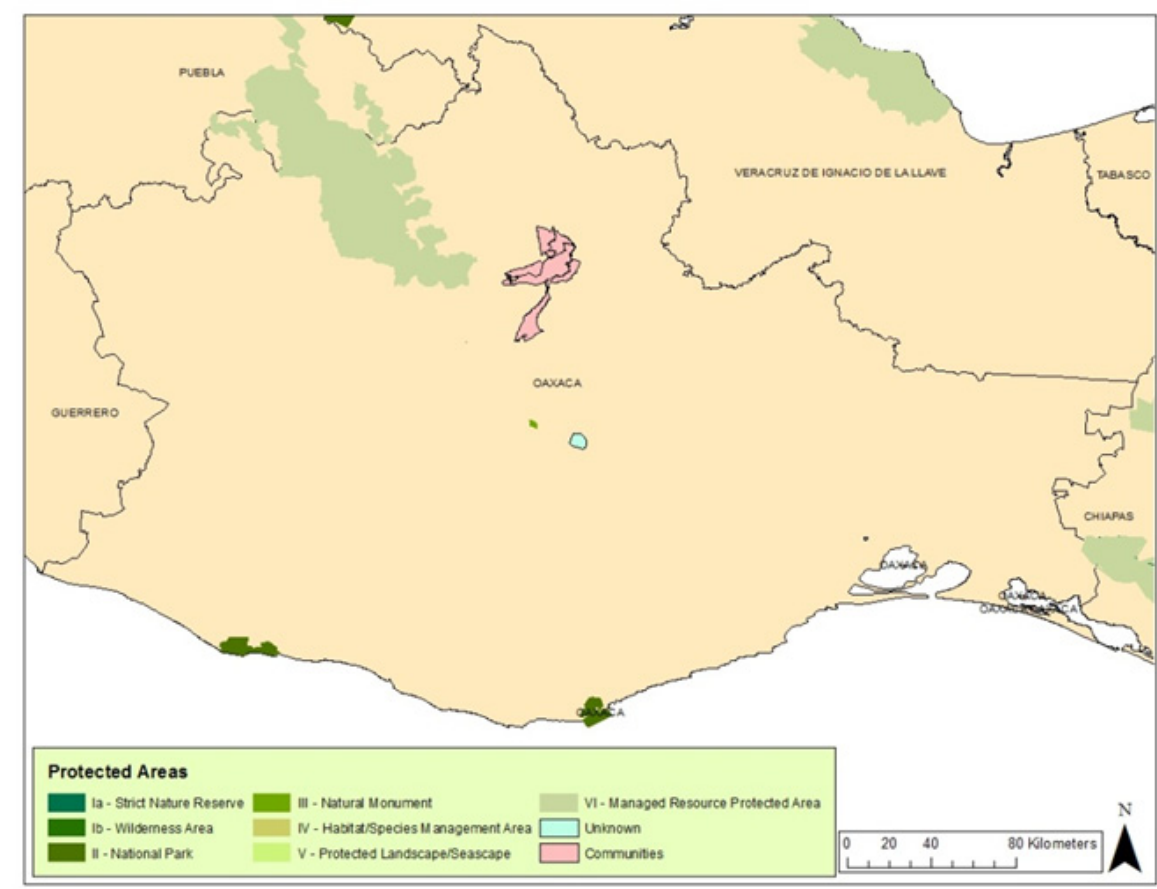

Source: http://www.conabio.gob.mx/informacion/gis/

Within the state of Oaxaca, the region of Sierra Norte, also known as the Sierra Juárez, is one of the state's most biodiverse areas as well as being of importance for national biodiversity (Peterson et al., 1993; Gomez-Mendoza et al., 2006; Martin et al., 2010; Robson, 2011).

Much like the state as a whole, the Sierra Norte has a wide diversity of climates, altitudes and vegetation types. It is a region notable for its steep and variable topography (CONABIO, 2010). Estimates for land cover in the Sierra Norte include $73 \%$ forest. Roughly $56 \%$ of this is temperate and tropical forest, while $17 \%$ is secondary forest. Agricultural, urban areas and scrublands account for the other $27 \%$ of land uses. Conservation International recognizes the region as a biodiversity hotspot for Madrean Pine-Oak Woodlands (Robson, 2011).

The next two sets of figures (Figure 2.2 and Figure 2.2) show the high conservation value given the study region by eight different conservation planning exercises. Figure 2.2 shows priority conservation areas in four different conservation planning exercise, with the location of 
the communities outlined in black within each area. The study communities are within CONABIO's Priority Areas for Terrestrial Conservation as well as its Priority Bird Areas (Figure 2.2A, B). Figure $2.2 \mathrm{C}$ shows that beyond merely being listed as CONABIO's Priority Areas for Terrestrial Conservation, certain areas of the study region have high and very high conservation value. Figure 2.2D shows that these communities are within what the World Wildlife Fund has designated the Pine-Oak forests logged in the communities of Ixtlán, Yolox and Comaltepec as Ecoregion for the conservation of Mesoamerican pine/oak species.

\section{Figure 2.2. Conservation Priorities \#1}

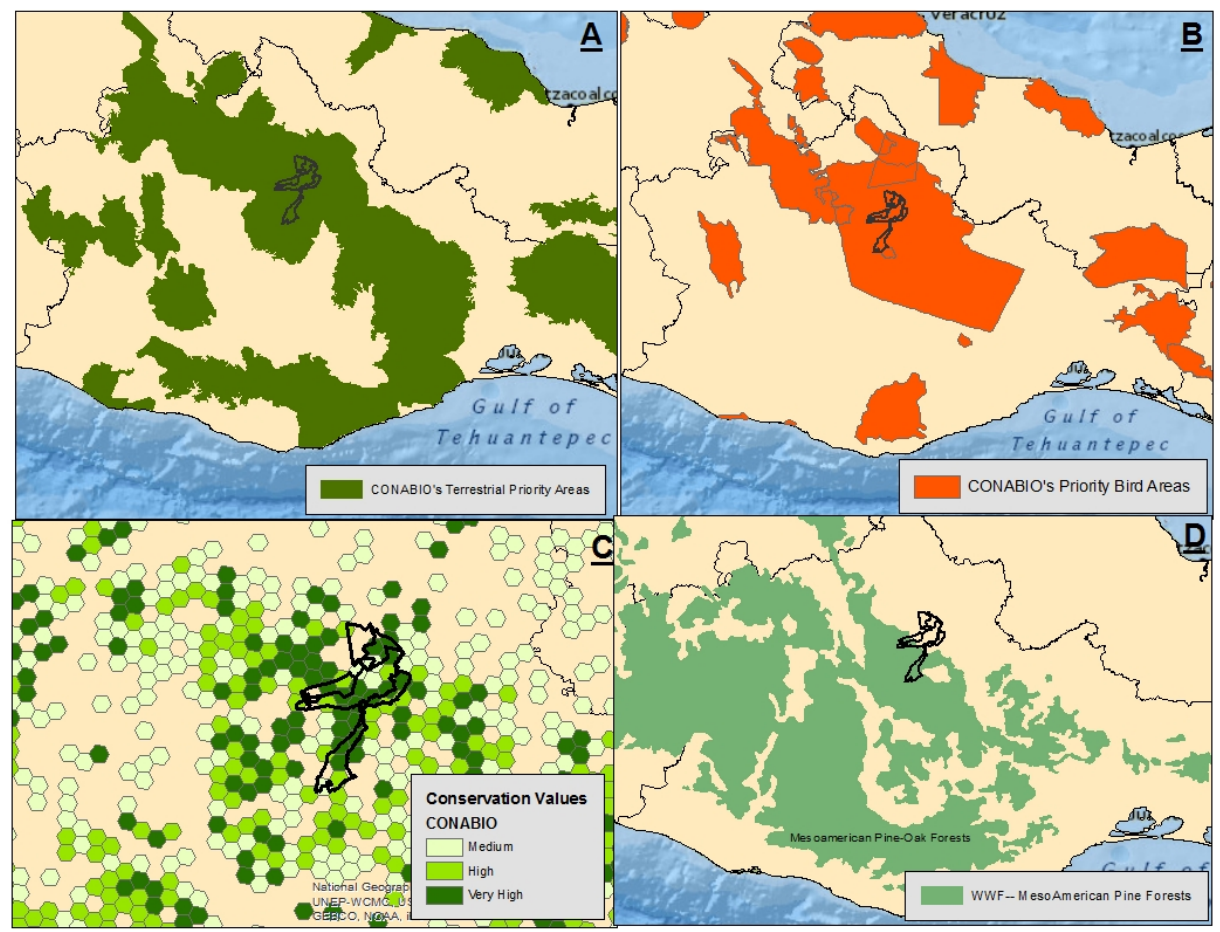

Sources: http://www.conabio.gob.mx/informacion/gis/;

http://worldwildlife.org/publications/terrestrial-ecoregions-of-the-world

Figure 2.3A shows the following designations: Conservation International Priority

Regions which include both the expansive Mesoamerican Hotspot as well as the Mexican Pine-

Oak Forests. Figure 2.3B shows that CONABIO has also placed areas within the Papaloapan

Basin as an important hydrological area as it provides water for major metropolitan areas such as 
Veracruz. Next, Figure 2.3C shows that despite high forest cover and high biodiversity, this subregion is somewhat curiously classified as comparatively less "wild" than other areas of Oaxaca. In effect, the conservation studied in this thesis occurs in places where communities live and farm and so is no "wild" place. Finally, in Figure 2.3D CONABIO has listed these forests as important points for connectivity for potential biological corridors.

\section{Figure 2.3. Conservation Priorities \#2}

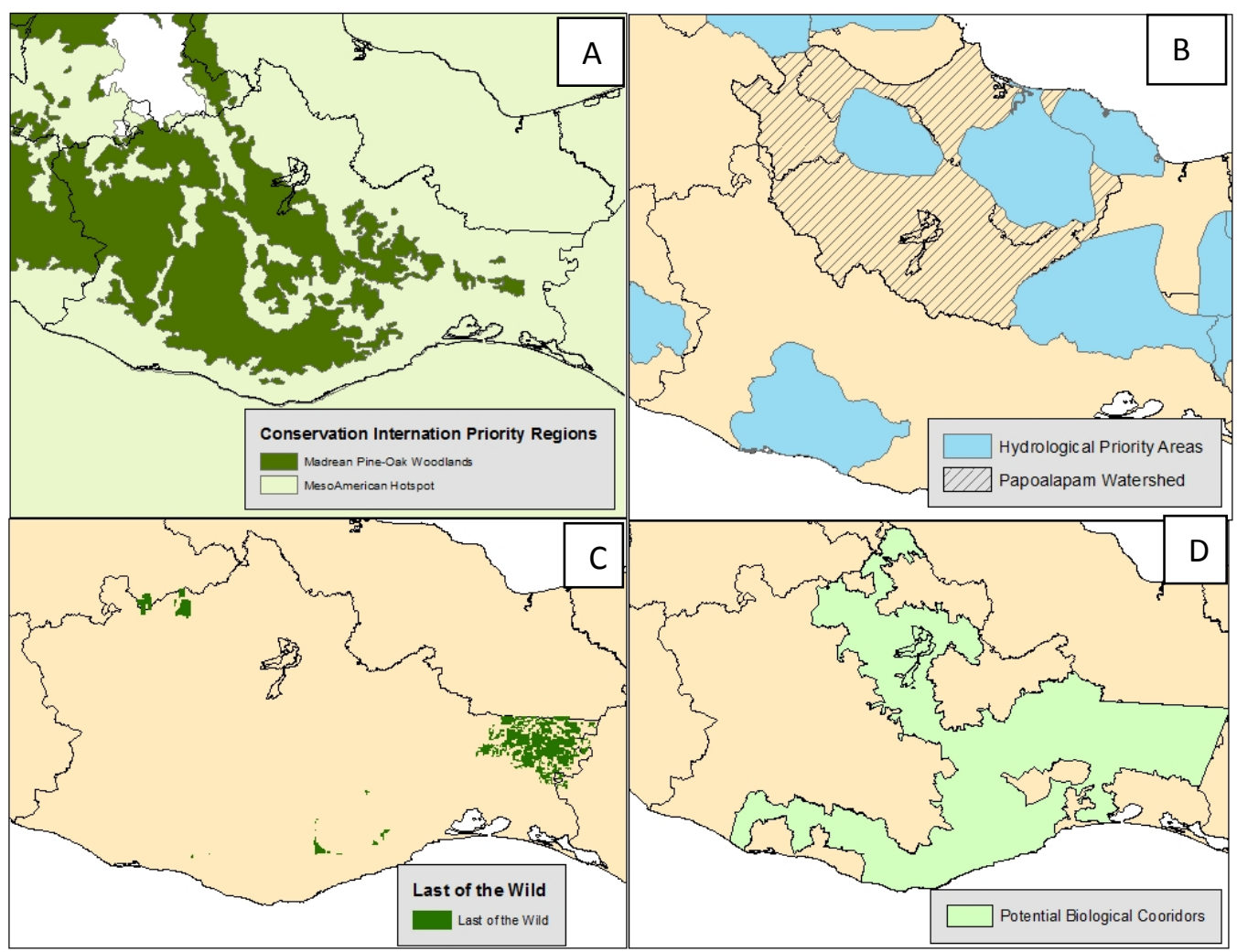

Sources: http://www.conabio.gob.mx/informacion/gis/;

http://www.conservation.org/where/priority areas/hotspots/Pages/hotspots main.aspx

http://sedac.ciesin.columbia.edu/data/collection/wildareas-v2

Many of these SCP have focused on the region's large areas of intact tropical montane cloud forests (TMCF) (Ponce-Reyes et al., 2012; Rojas-Soto et al., 2012). Notably, TMCF are known for the nearly continuous layer of clouds present in these forests (Aldrich et al., 1995), 
which provide these forests with as much as $5500-8000 \mathrm{~mm}$ of rainfall through almost constant vertical and horizontal precipitation (Martinez et al., 2009; CONABIO, 2010). Such precipitation leads to persistently moist soils (Brujinzeel et al., 1998).

The large extent of TMCF present in the Sierra Norte of Oaxaca is important given this forest type cover only $1 \%$ of Mexico's territory and has lost $50 \%$ of its original extent. Typical drivers of land use change include agriculture and pasture (CONABIO, 2010). Coffee cultivation has been the major driver of land use change in TMCF (Pineda and Halffter, 2004). In some cases, farmers will maintain part of the forest structure through the introduction of shade coffee (CONABIO, 2010), which can contain important amphibian diversity in certain contexts (Pineda and Halffter, 2004). In some cases, scenarios less amicable to biodiversity than shade tree coffee are playing out worldwide in TMCF. In fact TMCF are endangered globally due to conservation to agriculture or pasture (Aldrich et al., 1997; CONABIO, 2010). Furthermore, deforestation in lowland areas has the potential to alter cloud formation that is vital for the continuation of TMCF (Still et al., 1999; Lawton et al., 2001; Holwerda et al., 2010).

Nonetheless, if patches of TMCF remain around cleared areas, seed rain can quickly lead to early secondary succession TMCF and mature forest in 100 years. In fact swidden agriculture, if near forest fragments, does not generally greatly inhabit forest regrowth (del Castillo and Perez-Rios, 2008). The levels of fragmentation and location in the local patch-matrix landscape are important for regeneration, though in some areas in the state of Chiapas patch size of TMCF has continued to decrease (Cayuela et al., 2006). Further important to TMCF regeneration is the length and intensity of the given disturbance (Ramirez-Marcial, 2003).

In Mexico, less than $12 \%$ of all TMCF are located in protected areas (Ponce-Reyes et al., 2012). However, as this thesis will demonstrate large areas of TMCF in the study region and areas to the north are under formal and informal forms of conservation, TMCF are Mexico's most biodiverse forest type for its spatial extent and are an important forest type for endemic species 
(CONABIO, 2010; Still et al., 1999). Part of their high number of endemic species results from their isolation in specific altitudinal and precipitation bands (Stadmuller, 1987).

Tropical montane cloud forest cover only $1 \%$ of Mexican national territory but contain 2500-3000 vascular plants, which is roughly 12\% Mexico's plant species (Toledo-Aceves et al., 2010). They also have high epiphyte biomass (Holwerda et al., 2010) and are important in the conservation of endemic epiphytes and ferns (Williams-Linera et al., 2005). At least 400 of these plants have uses for humans (CONABIO, 2010). Tropical montane cloud forests likely play a vital role in the provision of hydrological services in both the provision of water and in maintaining water quality (CONABIO, 2010; Holwerda et al., 2010). One estimation of the value of TMCF found that they produce 728USD\$/ha/year in environmental services, which has made them of special interest for Mexico's PES program. Yet, the government pays a fraction of the actual worth of TMCF (Martinez et al., 2009). In Chapter 4, I will examine the divergence between the value attributed to these forests by the above studies and the actual compensation through Mexico's PES program.

Despite it being one of the more intact areas of TMCF in Mexico (CONAFOR, 2010), Gomez-Mendoza et al.(2006) found high rates of deforestation in Sierra Norte, including in TMCF with yearly losses of $1 \%$ or 1148 hectares. Despite high rates of deforestation in TMCF primary pine and oak forest increased in extent from 1980-2000 (Gomez-Mendoza et al., 2006). As well, Gomez-Mendoza et al. (2006), has argued than an expansion of secondary forests is uniformly a sign of degradation from primary forests to secondary forests, when secondary forest in the subregion is often a result of forest recovery from agricultural abandonment or from conservation of former agricultural patches.

Such classification of a uni-directional trend of deforestation and degradation would create a picture far different than the one demonstrated here not only of conservation, but communities actively conserving their forests. Gomez-Mendoza et al. (2006) largely sees 
communities as those who are deforesting and degrading forests and not those who are conserving them.

Furthermore, studies have indicated significant agriculture abandonment in the Sierra Norte which could likely be a driver leading to increased secondary forest (Hite, 2011; Robson, 2011). While Gomez-Mendoza et al., (2006) corroborate the success of pine-oak forest conservation, which are those worked by community forestry enterprises (Bray et al., 2008; Ellis et al., 2008), (Gomez-Mendoza et al., (2006) neglects observed conservation of tropical montane cloud forests (TMCF) in the region (Toledo-Aceves et al., 2011; Robson, 2011; Duran et al., 2012).

Other studies have previously found results contrary to those of Gomez-Mendoza et al. (2006). To the north of the subregion I have studied, Velasco-Murguia (2011) has found communities with extremely high forest cover maintenance $(>90 \%)$ and in some cases show an increase in forest cover in the last 20 years (1990-2010). Though much has been made of the analysis of common property governance in the area of the Sierra Norte (Robson, 2011; Bray et al., 2012); Velasco-Murguia (2011) found that while communities with collection action for conservation did maintain high forest cover, communities without collective action for conservation faced overall only slight losses over in forest cover from 1990-2010, while the difference were not nearly as striking as the author originally hypothesized. Such results that show conservation even in areas with less collective action provides further evidence for the important role of historical and current passive conservation in the region. The same drivers of passive conservation exist in her eleven communities as in my seven such as large territories, distant areas with difficult access, low population density, outmigration, lack of agricultural subsidies and steep slopes and poor soils exists through all communities. 
Figure 2.4. Forest Cover in Velasco-Murguia (2011) and this Study

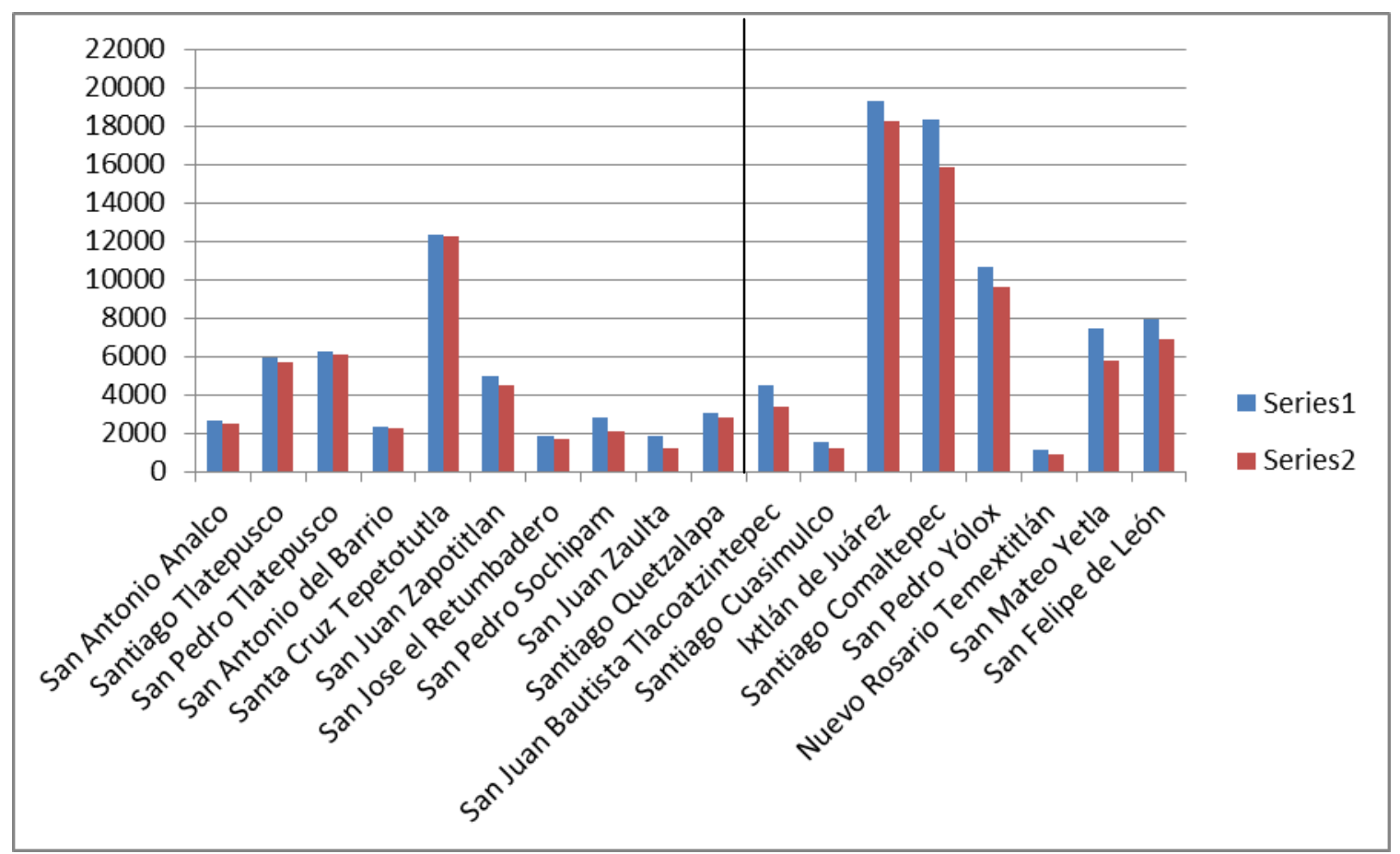

Source: Velasco-Murguia (2011) (my field notes).

Figure 2.4 shows the combination of 11 communities from Velasco-Murguia (20110 and the seven communities I studied blue there is the territorial size each community and in red is the amount forested for each community. While the two studies have differing methodologyrevision of documents and focus groups for my study and remote sensing for Velasco-Murguia (2011), the results both show high forest cover. The 11 communities from Velasco-Murguia begin to the left and my communities began with my communities at Santiago Cuasimulco. I have placed a line to divide the two study subregions. The subregion studied by Velasco-Murguia (2011) covers 48,659 hectares, $91 \%$ of which is forested and amounts to 44,884 hectares. My subregion has seven communities which cover 66,263 hectares, $88.34 \%$ of which is forested, which amounts to 58,596 hectares. Therefore in all, these communities are conserving 103,480 hectares of forest. While there are towns, milpas, coffee farms, cattle pasture and community forests in a complex patch-matrix that make up these 11 communities and so this is no way an 
unbroken block of forest, these neighboring contiguous communities, such conservation outcomes demonstrate a scenario far different that that argued by Gomez-Mendoza et al., (2006).

Here I have characterisized the Sierra Norte as a region of global imporatance for biodiversity according to CONABIO, the World Wildlife Fund, Conservation International and various systematic conservation plans (Arriaga, 2000; Brandon et al., 2005; Gordon, 2006; Illoldi-Rangel et al., 2008; CONABIO, 2010; Ponce-Reyes et al., 2012; Rojas-Soto et al., 2012). Nonetheless preliminary findings between the seven communities I have studied and the 11 by Velasco-Murguia (2011) show 114,923 hectares of territory and 103,080 forested hectares or $89.69 \%$ forested. While Velasco-Murguia (2011) used remote sensing to ascertain her forest cover numbers, I have largely used community documents such as forest management plans, OTC and PES-related documents. The forest cover found through these methods counteracts the findings of Gomez-Mendoza et al. (2006) which posit uni-directional degradation of primary to secondary forests in all forest types save pine/oak forests. Conversely, Ponce-Reyes et al. (2012) has found current high forest cover but predicts losses of $68 \%$ of TMCF due to anthropogenic climate change by 2080 . This study than imagines that all TMCF outside of protected forests will be cleared, which further strengths to case for the immediate action to create protected areas in the Sierra Norte of Oaxaca.

In Chapter 3, I will demonstrate that in fact the communities in this subregion are actively conserving TMCF as well as other forest types. I will show that while communities vary in land uses, histories and demographics that they have begun to conserve their forests through both informal conservation actions taken at the community level and formal efforts through their community forestry enterprises (CFES) as well as in the PES and VCA programs. 


\section{CHAPTER 3}

\section{Results}

In this chapter I will provide the results to my study. Currrently the subregion is $88.34 \%$ forested, which amounts to 58,596 hectares of a total of 66,264 hectares. While the subregion has maintained high forest cover both historically and currently, forest governance has changed. A central finding is that the documents examined show a trend from passive conservation to active conservation by communities. Prior to the 1980 s for CFE communiteis and prior to the 2000 s for non-CFE communities, they passively conserved their lands in unmanaged forest, generally in a high state of conservation. In three of the communities, forest management for timber under community control dates back to the 1980 s. In the 2000 s, as a part of the transition from passive to more active conservation, forest conservation received greater policy support in the form of PES and VCA. Throughout the subregion, forests provide a vast matrix with patchesof swidden agriculture (milpa), coffee, and pasture for cattle. The area in annual agriculture has remained relatively fixed, because of agriculture abandonment, a decrease in state support and since the 1990s and land use zoning. Coffee has also historically occupied relatively small areas. Since the early 1990s, it has faced large-scale abandonment because of a great instability and uncertainty in prices (periods of extremely depressed prices, with brief periods of higher prices). Outmigration from the region has been a contributing factor to increased forest cover as human populations show a general downward trend save for the village of Ixtlan. Also, these communities have large areas, most of which has steep slopes and is distant and difficult to access even in communities with multiple settlements. Community governance in general and forest governance has led to a more active form of conservatio in the subregion beginning in the 1980s and 1990s in the CFE communities and in the 2000s in the non-CFE communities. They have written OTCs, which have fixed urban, agricultural and areas for conservation. The three communities with CFEs also by law must create forest management plans, which in the case of Comaltepec holistically 
regulated not the only pine-oak forests that the communities logged, but also forest types such as TMCF that the community does not log. Furthemore all seven communities entered the PES program, while six currently receive PES. The only community not currently receiving PES is San Felipe de Leon, which has certified a VCA.

Conservation in these communities occurs both formally and informally at various levels. Formal conservation includes CFE acitivies and their pertaining forest management plans, PES and VCA. Informal conservation includes community conserved areas declared (in assembly acts), because they appear in the OTCs or more informally observed in unwritten practice. In total in the study communities, $59 \%$ of forest conservation comes from informal conservationl, $22 \%$ occurs in community forestry lands, $13 \%$ in PES areas and $6 \%$ in VCA. The amount of territory in the PES program varies widely from $1 \%$ in Ixtlan to $58 \%$ of forests in Nuevo Rosario. Ixtlán has the largest block of conserved TMCF and montane tropical forest at rougly 6,000 hectares which has essentially become to the community a "wilderness area" (Comision Asesor, 2010) Although rightsholders previously inhabited the lowland tropical area of Ixtlan in an earlier period, they abandoned the area despite its agricultural producivity in favor of jobs with the logging concession and later with Ixtlán's community forestry enterprise.

In this chapter I will present various figures that explore the subregion. First, I will give a general description of the subregion. Next, I will review factors which have lived to passive conservation including low and often decreasing population densities, steep slopes and distant agricultural lands. While demonstrating factors that lead to passive conservation, I will examine agricultural practice in the region that have allowed to communities to ensure household subsistence while also producing some coffee for market. Cattle ownership remains a potentially important land use for the future, but for now remains minimal in many communities.

Next, I will return to institutions and demonstrate how communities have entered a variety of government projects and worked at the community level to build collective action for 
conservation. While collective action for conservation started at least a decade earlier in forestry communities, it has spread throughout the subregion in the last decade. I will show communities have increasing begun to more consciously and actively conserve their forests. Finally, I will quantify ongoing conservation and categorize it according it its relation to intra-community decision-making as well as interactions with governmental policy.

\section{General Community Descriptions}

The following map shows the state of Oaxaca in yellow and the subregion in red in bottom left corner.

\section{Figure 3.1. Location of Mexico, Oaxaca and the Subregion}

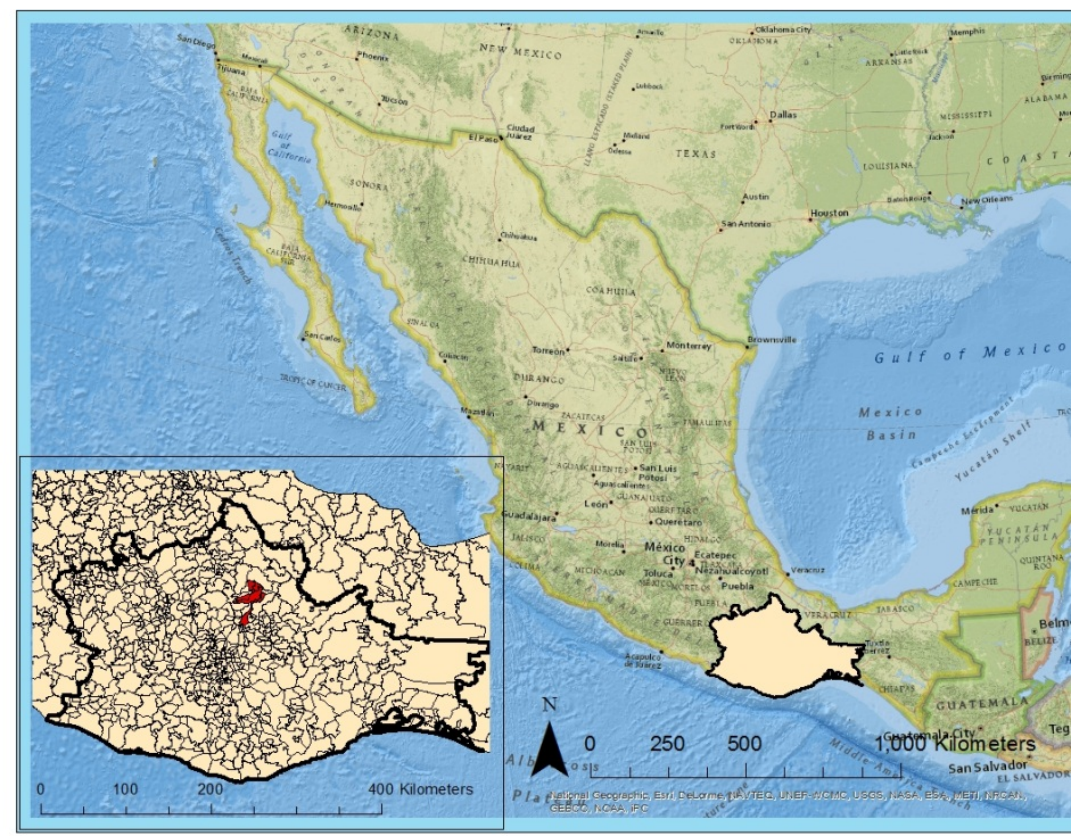

Source: http://www.conabio.gob.mx/informacion/gis/

It is not only my subregion which is mountainous. Figure 3.2 shows the elevation of the state of Oaxaca, its principal roads and important towns. The state capital is Oaxaca City, while Tuxtepec is a major regional center for commerce and less so for government administration. 
Unless government officials travel to these communities, in many cases community leaders will travel either Oaxaca or Tuxtepec for meetings related to conservation programs. The first road access to the communities came with the completion of the Oaxaca-Tuxtepec Highway in 1955. While it is only 220 kilometers between Oaxaca and Tuxtepec, the voyage in bus can take nearly five hours over a torturous and winding two lane road. Therefore, community leaders incur plenty of travel time in meeting with government officials in Oaxaca City or Tuxtepec.

Figure 3.2. The State of Oaxaca with Major Roads, Cities and Elevation

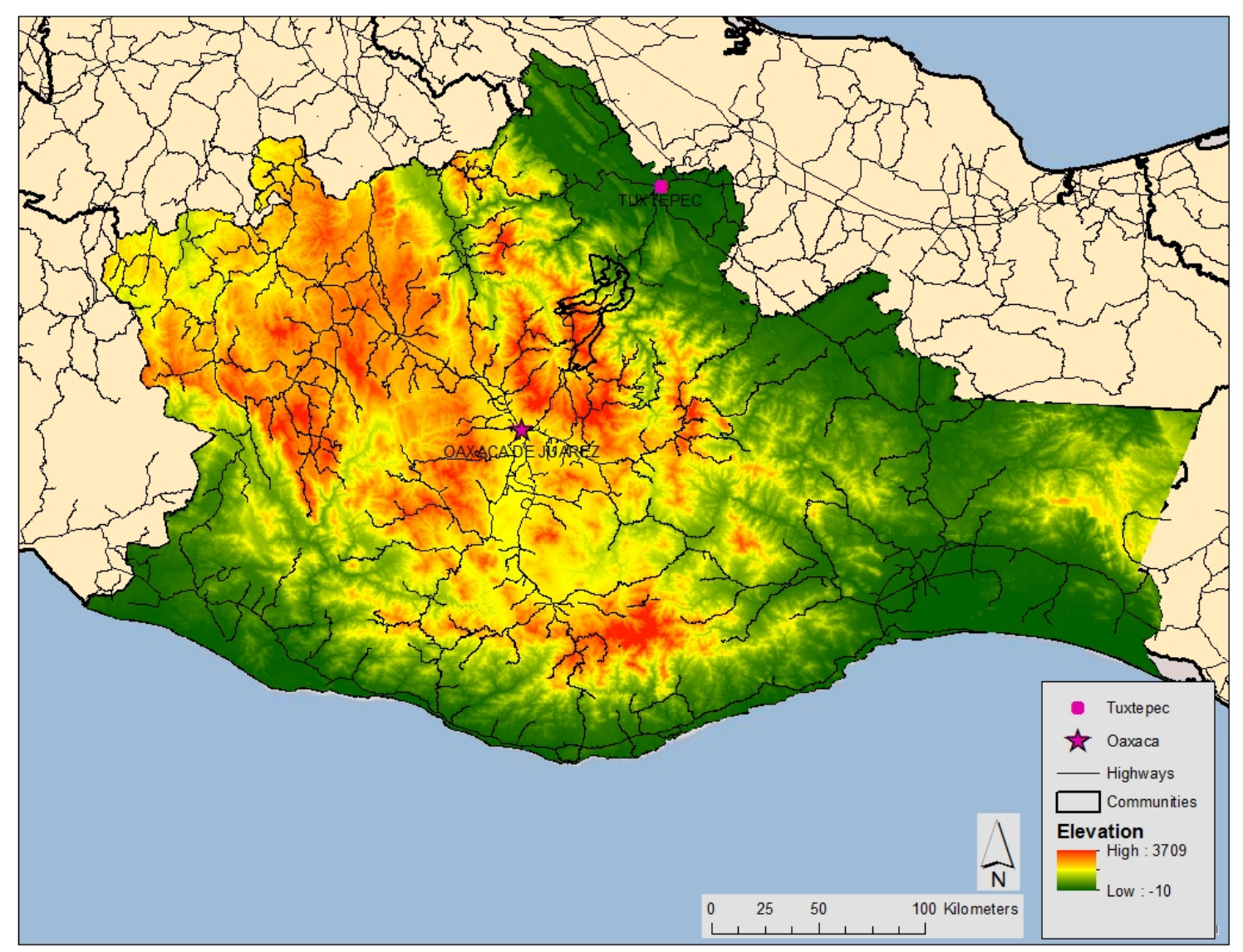

Source: http://www.conabio.gob.mx/informacion/gis/

Figure $3.3 \mathrm{a}$ shows communities the villages of subregion, while $3.3 \mathrm{~b}$ shows the communities. I have placed the communities on the municipalities also to illustrate the 
differences that exist in the amount of villages in each community. Again, census units are the municipalities, while communities are the units managed by Reforma Agraria Nacional (National Agrarian Reform). Part of the difficult of this study is that much of the information is available for municipalities; while I am interested in agrarian units I have called communities.

Communities make the land use decisions important for this thesis. Figure 3.3A makes clear that settlement density is far greater in the tropical regions of these territories, which is in the northern part of these communities. Nonetheless, the three largest towns in the region are Ixtlán de Juárez, Santiago Comaltepec and San Pedro Yolox all are located in the temperate highland areas. In many cases rightsholders in these three communities created additional settlements in the lowland tropical regions of their territory in order to grow a second corn harvest and tropical crops such as coffee. In the other cases, the other four communities lack temperate zones.

\section{Figure 3.3. Villages and Communities of the Subregion}

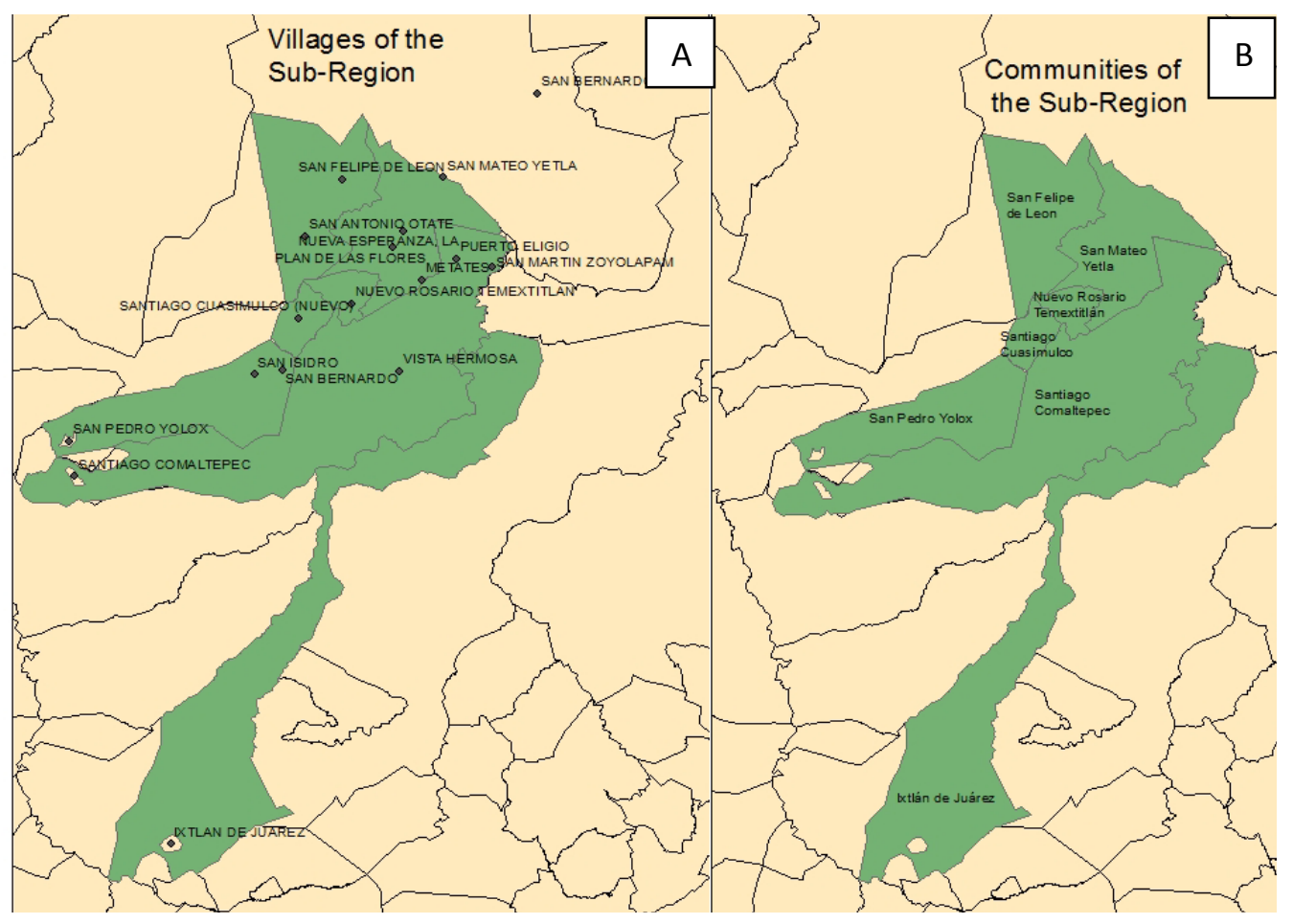

Source: http://www.conabio.gob.mx/informacion/gis/ 
Another important factor in differentiating these communities is their populations. I will show how many rightsholders each community has in a following graph, but Figure 3.4 below shows the share of overall populations each community has. What is notable is that Ixtlán has $49 \%$ of regional population, all in one large village and as the proceeding map shows, an elongated territory which lack road access to its northerly boundaries and has the least anthropogenic impact of any area. Other communities work their entire territories depending on what zoning they have implemented in their OTCs.

\section{Figure 3.4. Subregional Population by Communities}

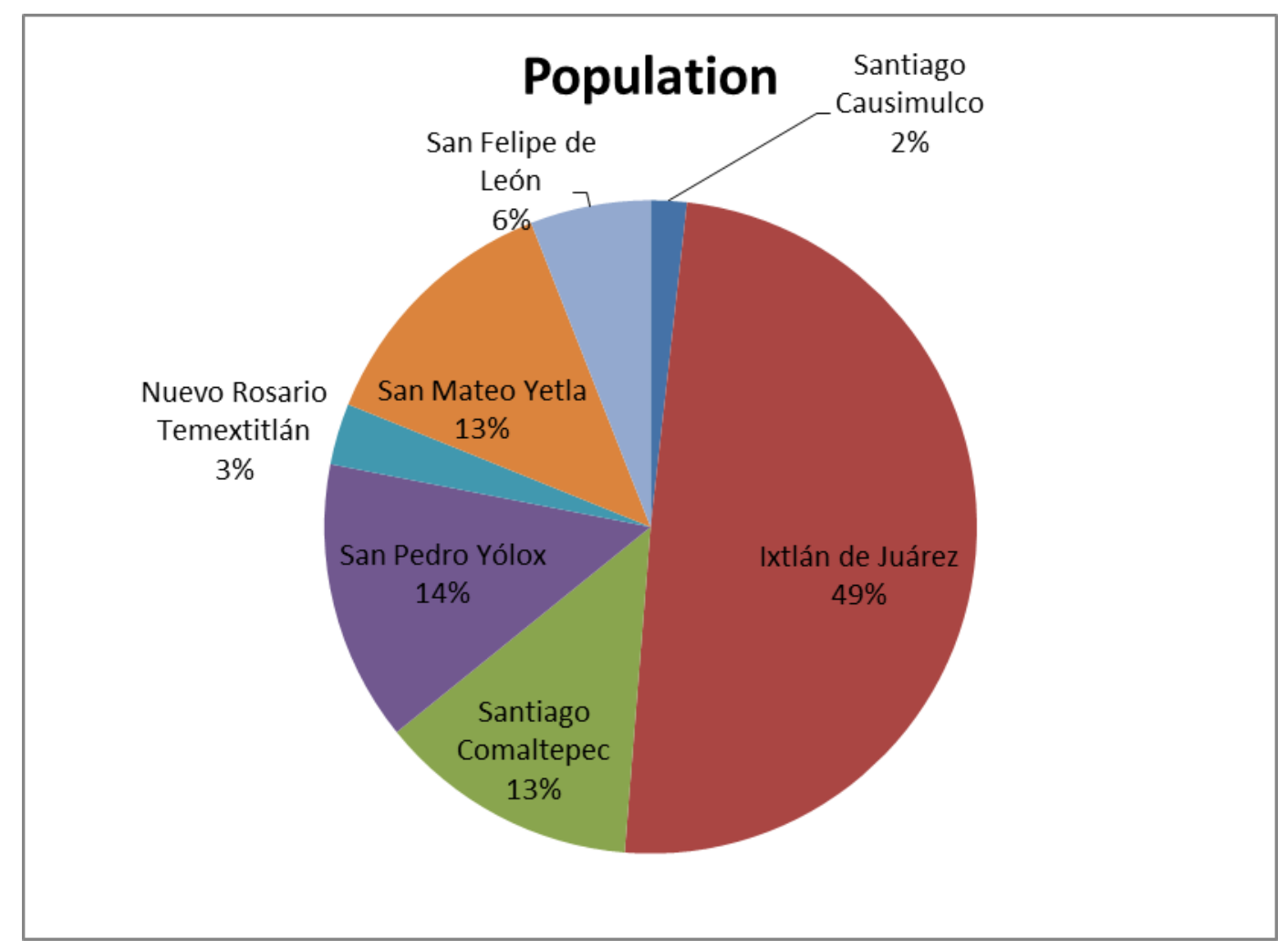

Source: $\underline{\text { http://www.inegi.org.mx/sistemas/consulta resultados/iter2010.aspx? } \mathrm{c}=27329 \& \mathrm{~s}=\mathrm{est}}$ 
Figure 3.5. Population by Village in 2010

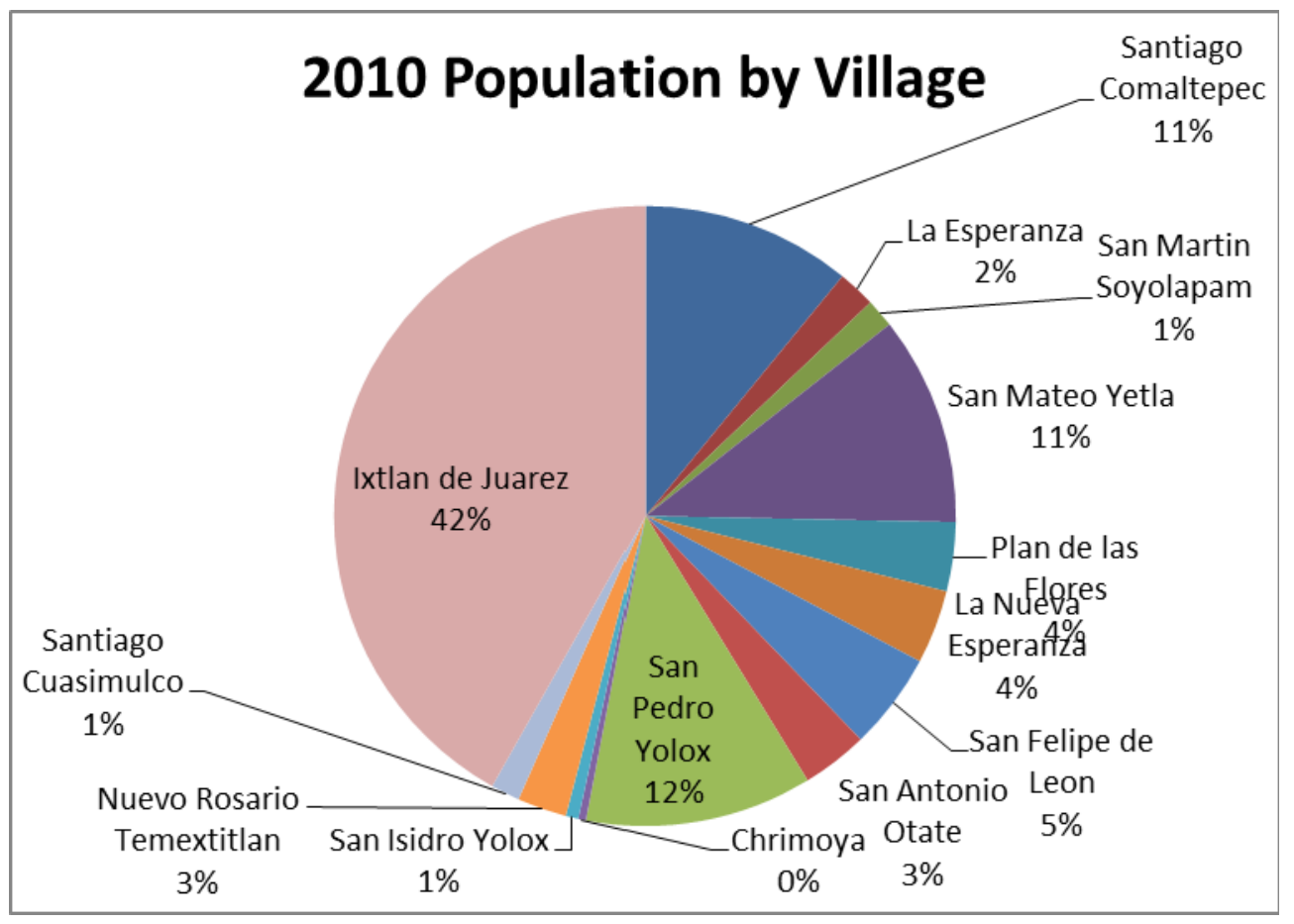

Source: http://www.inegi.org.mx/sistemas/consulta resultados/iter2010.aspx?c=27329\&s=est

Figure 3.5 shows populations by village. Forest recovery from agricultural abandonment has been encouraged by a historical process over the last several decades of people leaving the smaller settlements to emigrate to community centers and beyond. Yolox previously had small dispersed settlements called ranchos (ranches) including Chirimoya and San Isidro Yolox. These however are increasingly losing inhabitants from migration to the main village of San Pedro Yolox and outmigration to Mexican cities and the United States. Rightsholders than have ceased to work in areas which the community which is near the community's extensive tropical montane cloud forests (TMCF). San Felipe de Leon has two villages, the main village of San Felipe de Leon and the outlying village of San Antonio Otate. The community of Yetla has the main village of San Mateo Yetla, which is located on the Oaxaca-Tuxtepec Highway and two smaller villages Plan de las Flores and La Nueva Esperanza, which are both accessible on a three kilometer dirt 
road from the Oaxaca-Tuxtepec Highway. Also Yetla has a roadside settlement called Metates, which shares its border with Comaltepec. The community of Comaltepec has three main villages - the main village of Santiago Comaltepec in its temperate territory, La Esperanza in its cloud forest area and San Martin Soyolapam in its tropical area. It also has two almost entirely depopulated roadside settlements called Puerto Eligio and Vista Hermosa. The important point listing these separate villages is the founding of additional villages was an important means of increasing access to agricultural land and decreasing pressure around main village beginning in the 1960s until the 1970s (Wolf, 1959). However, beginning in the 1990s, this process of the dispersing of the population in the territory has been reversed, with most of these satellite villages losing population to the village center and emigration. This contraction has often led to the abandonment agricultural plots near these outlying villages.

Figure 3.6. Percentage of Subregion Occupied by Each Study Community

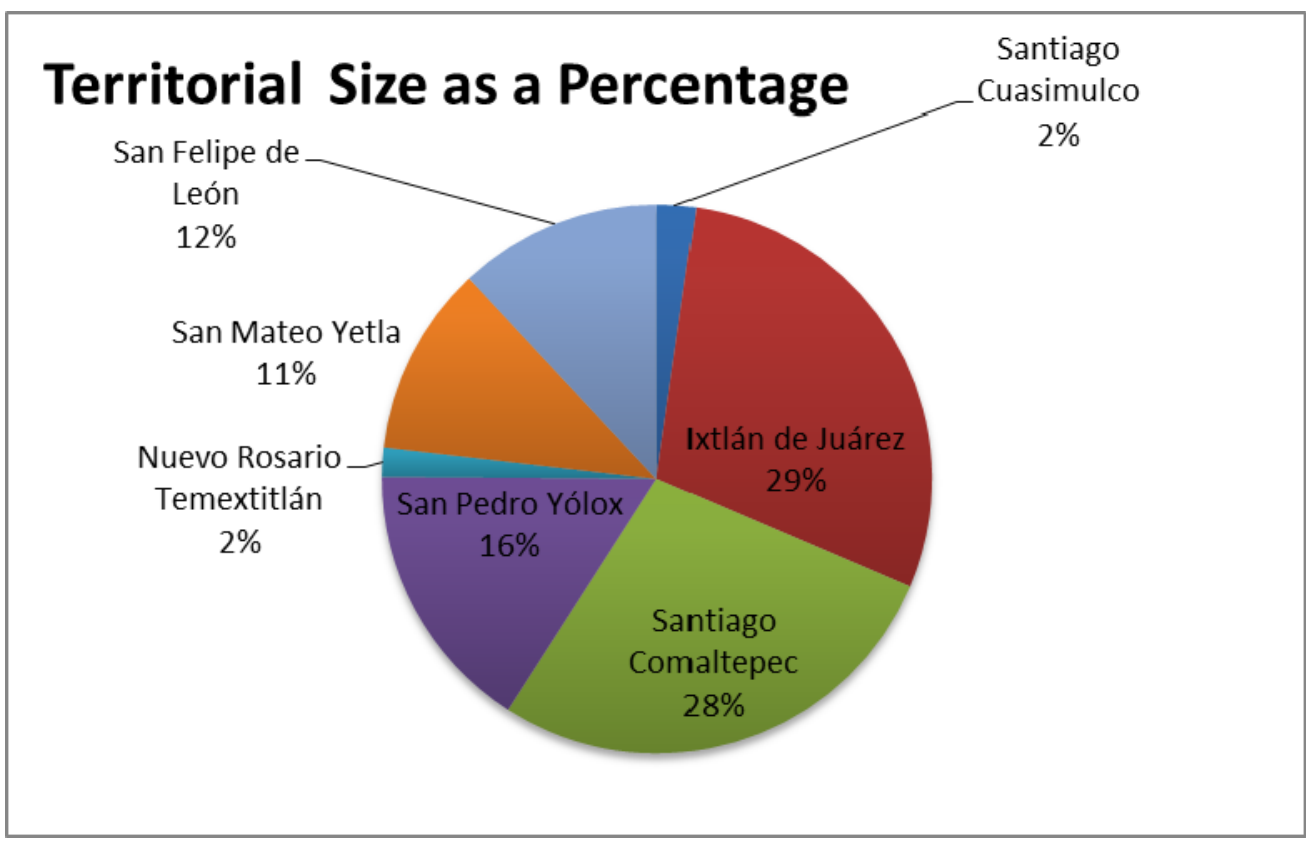

Source: Community OTCs, Statutes, PES documents, ACV documents and focus group interviews (field notes). 
Figure 3.6 shows overall territorial size and that the forestry communities of Ixtlán, Comaltepec and Yolox account for $73 \%$ of the subregion, with the other four communities of San Felipe, Yetla, Cuasimulco and Nuevo Rosario accounting for the other 27\%.

\section{Factors Leading to Passive Conservation}

Here I will explore factors that lead to passive conservation such as low and declining populations and population densities, steep slopes, distant lands as well as limited agricultural subsidies and low percentages of agriculturally suitable land in the subregion.

Figure 3.7 shows how population trends throughout much of the subregion exhibit declining populations. Comaltepec has seen rapid population declines in all its settlements as has Yolox to a lesser degree. While populations have remained more stable in the tropical communities, San Felipe de Leon has notable population declines. In contrast, the village of Ixtlán has gained 1000 people from 1990-2010 and so has offset trends in population losses throughout the region. Yet, jobs in community forestry jobs as well as other off farm employment town have largely offset high population growth rates in Ixtlán may have had on forest conservation. While Yolox had a more recent decline in population in the early 2000s, Comaltepec has a longer period of outmigration.

As important as total population for conservation is population density as shown in Figure 3.8. I have shown hectares per rightsholders in addition to pure population density below in Figure 3.7. In all communities, all lands outside of urban areas are common property. Therefore, rightsholders to common property lands can look for land zoned as agriculture which is not held in usufruct by any other rightsholder. Rightsholders are limited to the amount of agricultural land (almost exclusively corn and coffee plots) they can work by lack of capital, steepness of the terrain, difficulty of access to lands and poor soils. This population-territory ratio is one of the several factors identified, which contributes to the historical baseline of high forest 
cover. Low population densities like in the case Comaltepec are large enough to provide 50 hectares per rightsholders. Then, these low populations greatly contribute to passive conservation.

Figure 3.7. Yearly Population Trends 1990-2010

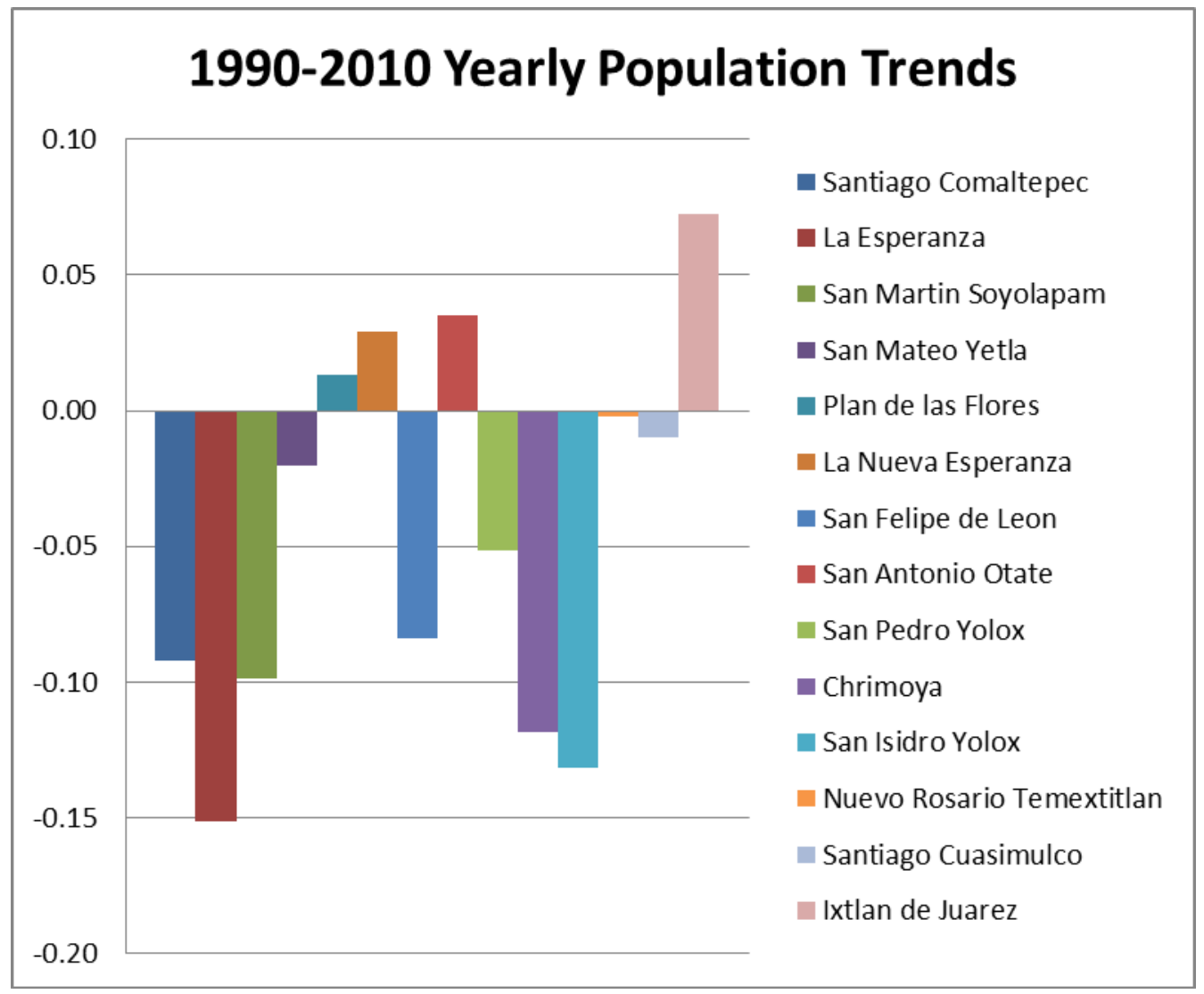

Source: http://www.inegi.org.mx/sistemas/consulta resultados/iter2010.aspx?c=27329\&s=est 
Figure 3.8. Hectares per Rightsholder and Population Densities

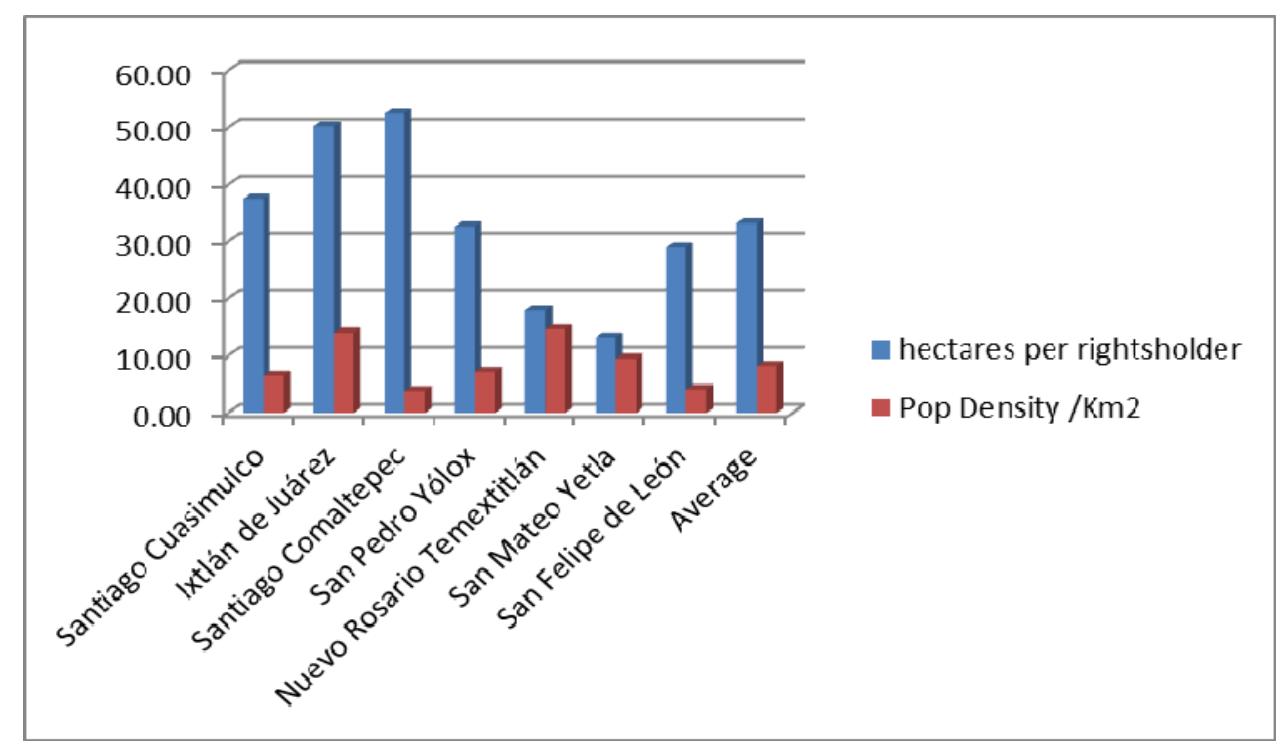

Source: http://www.inegi.org.mx/sistemas/consulta resultados/iter2010.aspx?c=27329\&s=est

Figure 3.9 shows that steep slopes in red and orange largely dominate the subregion, one of the factors that account for the historical baseline of high forest cover and passive conservation. In Figure 3.9 I have made graduated symbols to show the level marginalization of each village to show that villages vary considerably in their level of marginalization from Ixtlán to Cuasimulco. Also the road in purple shows that while the villages of Ixtlán and San Mateo Yetla both have access to the paved Oaxaca-Tuxtepec Highway, the other communities have gravel and dirt connecting roads to this highway, while Cuasimulco still lacks road access. This lack of highway access and general remoteness to markets also decreases drivers of deforestation while also likely increasing economic marginalization.

Longstanding villages like San Pedro Yolox, Santiago Comaltepec, Ixtlán de Juárez, Soyolapam and San Felipe de Leon are all in areas of more gradual slopes. Newer villages like Nuevo Rosario Temextitlán, La Esperanza in Comaltepec, San Antonio Otate and La Nueva Esperanza in Yetla, settled in the 1960s and 1970s, are all in areas of far steeper slopes. Though 
the plow was an invention of Spanish provenance (Wolf, 1959; Rodriguez, 2001), rightsholders first settled in these areas flatter areas they now work with plows because they were always more conducive to agriculture. A lack of agricultural land from increased population densities in the temperate zones of the subregion led rightsholders to found the villages of Nuevo Rosario Temextitlán, Santiago Cuasimulco and La Esperanza in the 1960s and 1970s.

Figure 3.9. Slope, Roads and Marginalization in the Subregion

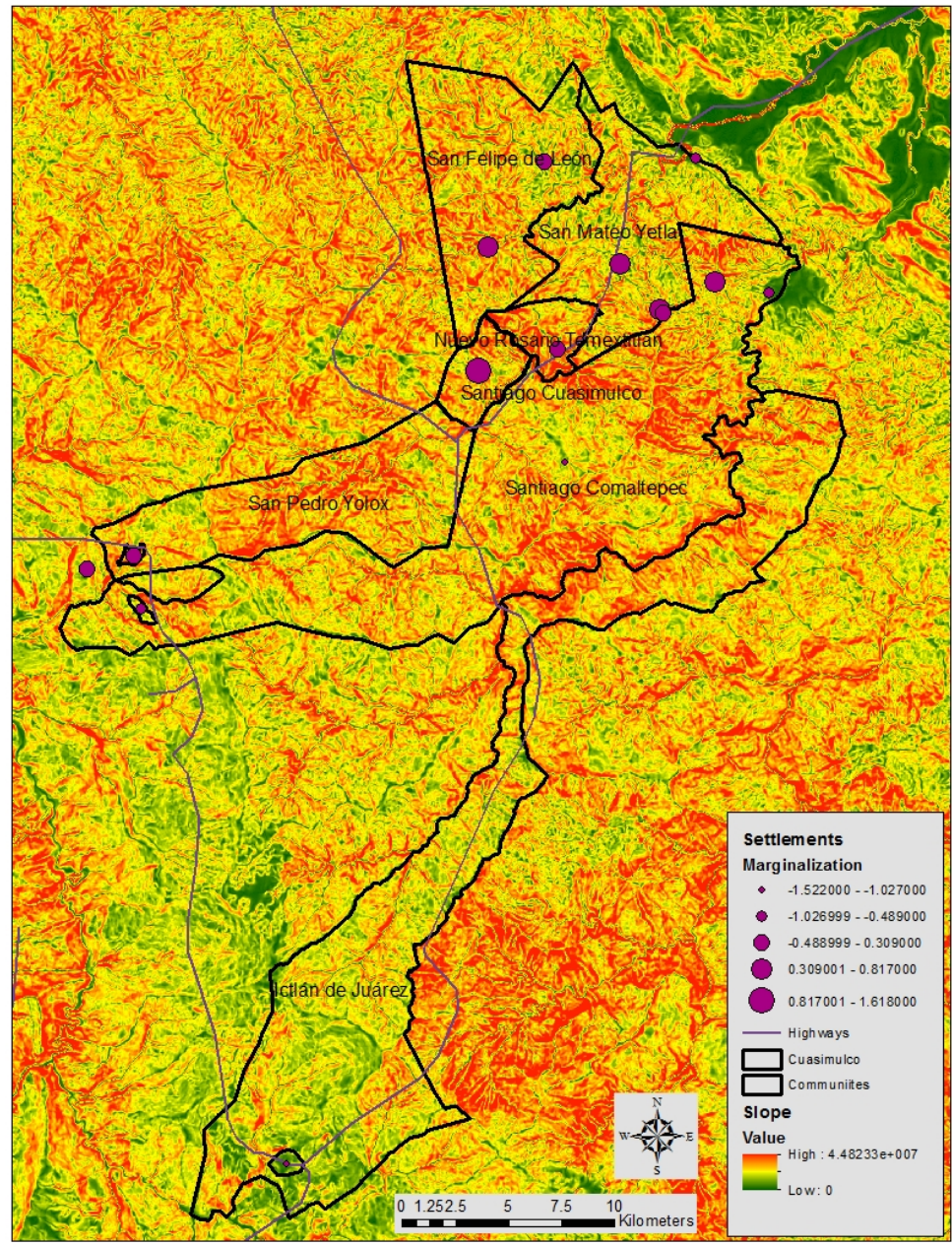

Source: $\underline{\text { http://www.conabio.gob.mx/informacion/gis/ }}$ 
Preference for the most gradual slopes nearest to villages means that passive conservation occurred in distant areas with steeper slopes. Rightsholders used their knowledge of ease of access, slopes, soils, precipitation to select their agricultural plots.

Figure 3.10. Non-Forested and Forested Areas with Roads and Village Populations

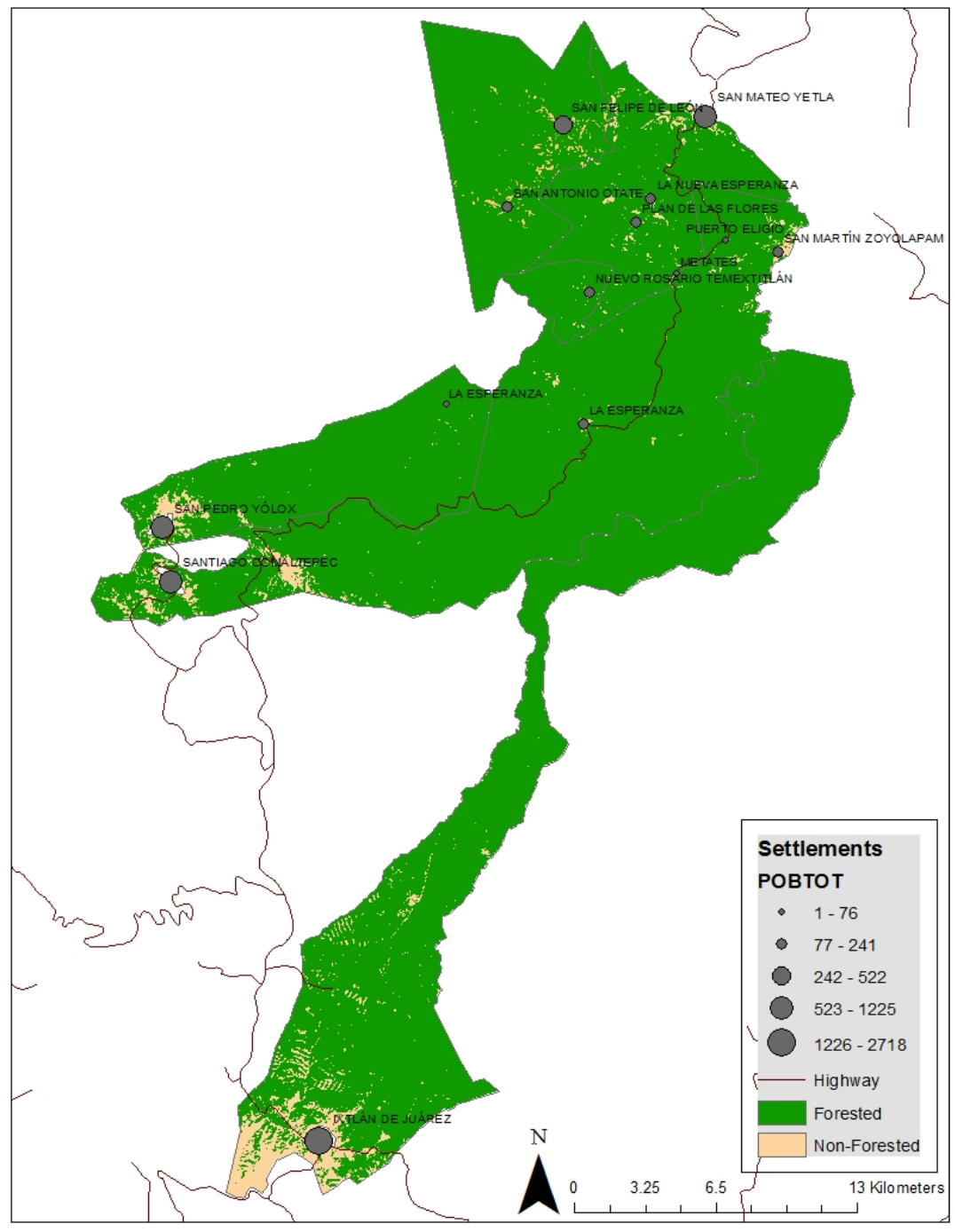

Source: Velasco-Murguia (2012)

Figure 3.10 shows the dominance of forest cover as a land use in the region. The classified area in the southern tip of Ixtlán is tropical dry forest and so likely is not agriculture as 
suggested classified by Velasco-Murguia (2012). What is clear is the sheer patchiness of agriculture in the region. While large cultivated areas exist near the villages of Santiago Comaltepec and San Pedro Yolox, forests become more fragmented as the number of settlements increases in the tropical region in the north. Here, communities like Comaltepec, Yolox, San Felipe and Yetla have all created multiple settlements in order to take advantage of the two corn harvests (temporada and tonamil) in the tropical regions and for coffee cultivation. The villages of the tropical region are comparatively smaller in population to Ixtlán, San Pedro Yolox and Santiago Comaltepec in the temperate zones. The nearly unbroken block of forest in the communities of Yolox, Comaltepec and Ixtlán (Duran et al., 2012) have been noted by scholars, but the much larger block of TMCF and trop montane forest in the larger part of my study area, has gone virtually unrecognized. Prior to this thesis, no studies exist on forest governance and conservation on Cuasimulco, Nuevo Rosario and San Felipe.

\section{Regional Land Uses}

In this section, I will examine how communities work their land, provide household subsistence and some market crops, log their forests, as well as how migration has been impacted and impacts these activities, and the consequences of these activities for forest cover.

I will briefly discuss each of these land uses shown in Table 3.1 and how they impact conservation in the proceeding section, communities have milpa (listed as annual agricultural in Table 3.1), because the corn, beans and squash produced by this swidden agricultural system is the basis of the regional diet and an important element in local food sovereignty. In all cases, milpa is the most important agricultural activity. Ixtlán, Yolox and to a lesser extent Comaltepec have shown historical sharp declines in milpa, while other communities have more or less maintained their area under milpa. Coffee was historically the most common cash crop and provides households with additional funds to buy needed goods. Coffee production is most important in Yetla and Cuasimulco. Coffee was previously more important in all communities, 
but since the price instability beginning in the 1990s it has become negligible in Yolox and Comaltepec and disappeared entirely in Ixtlán in the 1990s. Forestry creates the greatest economic disparity between these communities. Forests managed for timber provide a steady source of jobs and funds from timber sales have built many of the large community buildings in Ixtlán, Comaltepec and Yolox. Finally, cattle ownership varies greatly between these communities. In Nuevo Rosario cattle are nearly non-existent. The village of Soyolapam has recently increased its reliance on cattle, which has led to deforestation (Robson, 2011).

Table 3.1. Presence of Agricultural and Forestry Land Uses in Hectares (\%)

\begin{tabular}{|c|c|c|c|c|c|}
\hline Community & Territory (Ha) & $\begin{array}{c}\text { Annual } \\
\text { Agriculture }\end{array}$ & Coffee & Forestry & Cattle \\
\hline $\begin{array}{l}\text { Santiago } \\
\text { Cuasimulco }\end{array}$ & 1502 & $144(8 \%)$ & $100(7 \%)$ & $0(0 \%)$ & $54(3 \%)$ \\
\hline Ixtlán de Juárez & 19,310 & $393(2 \%)$ & $0(0 \%)$ & $\begin{array}{l}7,354 \\
(38 \%)\end{array}$ & $300(2 \%)$ \\
\hline $\begin{array}{l}\text { Santiago } \\
\text { Comaltepec }\end{array}$ & 18,366 & $989(5 \%)$ & $120(.6 \%)$ & $\begin{array}{l}3,000 \\
(16 \%)\end{array}$ & $340(2 \%)$ \\
\hline San Pedro Yolox & 10,626 & $288(3 \%)$ & $50(.4 \%)$ & $\begin{array}{l}2,300 \\
(22 \%)\end{array}$ & $150(1 \%)$ \\
\hline $\begin{array}{l}\text { Nuevo Rosario } \\
\text { Temextitlán }\end{array}$ & 1,140 & $215(19 \%)$ & $40(4 \%)$ & $0(0 \%)$ & $2(.1 \%)$ \\
\hline San Mateo Yetla & 7,434 & $1,298(17 \%)$ & $600(.8 \%)$ & $0(0 \%)$ & $297(4 \%)$ \\
\hline San Felipe de Leon & 7,916 & $1,488(19 \%)$ & $299(4 \%)$ & $0(0 \%)$ & $47(.5 \%)$ \\
\hline
\end{tabular}

Source: Source: Community OTCs, Statutes, PES documents, ACV documents and focus group interviews (field notes). 
Now that I have broadly characterized land uses in these communities, I will examine common land uses in the region. Again, forest conservation occurs largely as a result of communities dedicating relatively small percentages of their territories to milpa, coffee and cattle. Instead of reinforcing the argument of agriculture as the enemy of forest cover, here I am showing that local knowledge combined with biophysical/demographic/economic factors have helped lead to passive forest conservation. Through these agricultural practices, rightsholders provide households subsistence, income from market agriculture and retain a rich patch-matrix landscape which helps to maintain biodiversity (Robson, 2011).

Milpa

At the beginning of each different crop or land use, I will provide a chart showing this land use.

Figure 3.11. Area of Annual Agriculture/Milpa in the Subregion

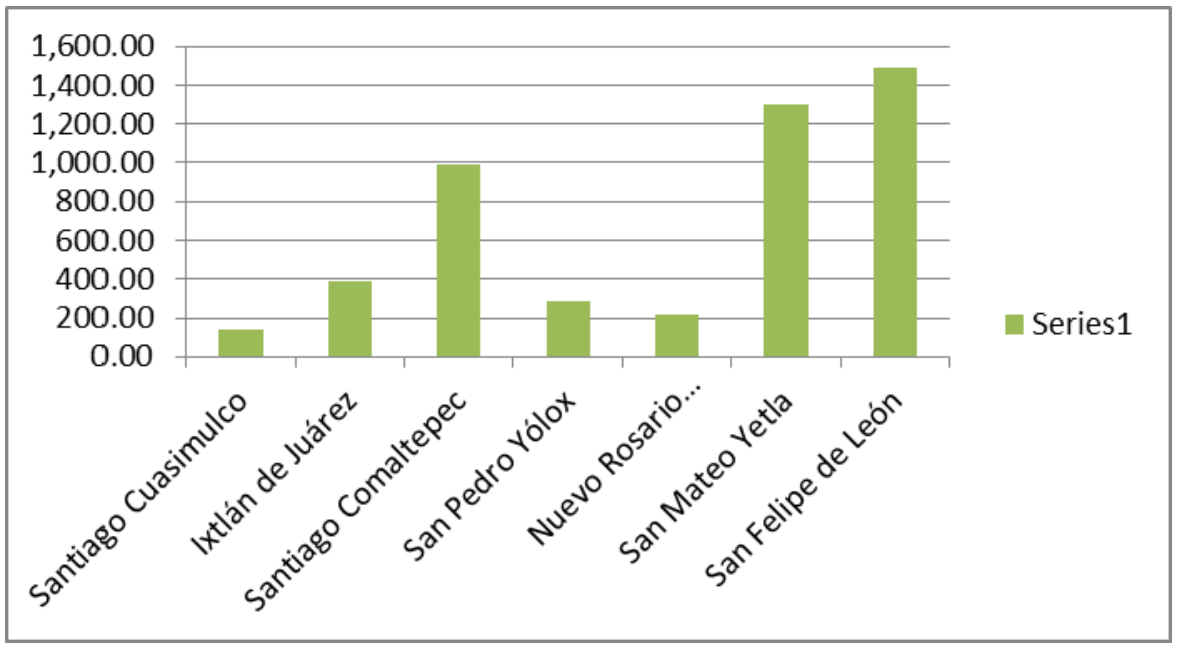

Source: Source: Community OTCs, Statutes, PES documents, ACV documents and focus group interviews (field notes).

The cultivation of corn (Zea mays) in Mexico has a history extending back at least 5,000 years. Geneticists have traced its origins to the teosinte plant, which is still likely exchanging 
genetic information with cultivated corn (Nadal, 2000). As of 1999, corn accounted for 53\% of cultivated land in Mexico (Nadal, 2002). As of the early 2000s, 2 million households still cultivated corn on six million hectares (Birol et al., 2006). Corn when grown on smaller scales like in this study area is cultivated with beans and squash through intercropping and planting seeds in the same holes for seed deposits know as a milpa system (Gonzalez, 2001). The milpa is characterized by the practice of roza-tumba-quema, which means that farmers first clear ground vegetation, felling some larger trees to be removed for timber or left for soil nutrient enrichment before burning the field. Such burning releases stored nitrogen and potassium in the burned material and the soil, which improves soil fertility (Ochoa-Gaona et al., 2000).

In this newly cleared plot, along with a variety of beans and squash, growers cultivate white, yellow, pinto and blue varieties of corn used determined by on soil conditions (Gonzalez, 2001). Cultivation will generally last only a single growing season. After a single year, farmers let the field return to forest. Growers will then save ears of corn from the most productive plants for the following harvest in a different plot. Notably the beans and squash chosen have generally evolved along with corn in the milpa system. Oaxaca currently leads the nation in diversity of local landraces and conserving these land races is important project in itself for food security (Birol et al., 2006) and should be recognized that milpas provide this valuable genetic information as global environmental service, since farmers in Mexico artificially selected what is now corn and have continued to plant native landraces (Jaffee, 2007). Communities utilize a wide variety of techniques depending on slope to work their milpas.

The predominance of steep terrain means that many rightsholders often work their milpa only with a machete to clear unwanted vegetation. In flatter areas in temperate zones, they work with oxen and plow. In the flattest areas of Soyolapam and Ixtlán, they work their milpas with a tractor. Since rightsholders work most of agricultural land in the subregion with machete, farming 
is extremely labor intensive. Nonetheless, in Comaltepec alone rightsholders have knowledge on how to work their milpas with machetes, oxen and plows and tractors.

The secure land tenure maintained by these communities is crucial in system of shifting agriculture and forest conservation. Secure land tenure will give a farmer the knowledge that when they return to their agricultural plot after seven fallow years, no one else will have come to clear and cultivate their land. This allows a farmer to plan for the future, instead of exhausting a plot of land as a consequence of unclear tenure and fear that someone will disrupt their fallow cycle by farming their plot (Albers et al., 2000).

Plots of land may be inherited to a family and so some families have cultivated milpa lands for successive generations while retaining fertility. Even if a migrant leaves for 15 years, they can return to their milpa plot well into its forest succession without fear that someone will farm it in their absence without their explicit permission. Therefore, the discount rates on milpa lands are sufficiently low that most common strategy taken is conservation of soil and its fertility. Farmers know that once they gain a plot, generations of their family will be farming it. While it is possible to buy usufruct rights to land between rightsholders, rightsholders are barred from selling milpa land to outsiders, though rightsholders do sell coffee plots to other rightsholders in their community. Nonetheless, rightsholders often retain milpas and work to conserve soil and soil fertility in this system which communities have practiced for centuries. The system works as fertility remains after hundreds of years of cultivation the same milpa land.

Robson (2011), who also studied the community of Santiago Comaltepec, found that remittances sent from migrants working abroad were sufficient that many households were abandoning their milpas. Clearly then, along with the fact that nearly half of rightsholders currently live outside the community, the importance of milpas have decreased largely because of outmigration and not directly related to productivity. 
It is commonly thought that outmigration has led to agricultural abandonment. However, in interviews community leaders stated that the area of milpa had been stable in recent years, while some rightsholders cited an increased importance for milpas because of rising food costs. Others expressed pride in the health benefits and cleanliness of the corn they grow compared to the corn they sometimes have to purchase at the market. Almost all said that their corn produces much better tortillas, which families consume with every meal. A tortilla factory owned by a family in Yolox largely has to sell its tortillas outside the village, because households still prefer to make homemade tortillas versus buy mass produced tortillas.

Public policy has also further disincentivized milpa expansion for market purposes. The importation of cheap corn form the US as a result of the North American Free Trade Agreement (NAFTA) as well as competition from highly capitalized Mexican corn farmers means that there is little opportunity for growers in the subregion to sell their corn outside their communities. While the implementation of NAFTA caused significant tumult in Mexico (Gollnick, 2008; Jung, 2008; Shapiro, 2010), few rightsholders mentioned it being a significant policy for the subregion since their milpas have always provided subsistence needs. Rightsholders only sell surpluses generally to other households in their communities. All of these factors combined means that the area of milpa will very likely remain more or less constant as these communities continue to practice the local knowledge they have developed and refined over centuries of working their milpas.

\section{Coffee}

Globally roughly 25 million people grow coffee and produce 12 billion pounds of coffee a year. Coffee generates for the global economy USD $\$ 70$ billion in retail sales. Production of coffee centers in tropical countries, while the United States, Europe and Japan import $75 \%$ of coffee. After oil, coffee is the second most valuable commodity in the world (West, 2012). Figure 3.12 shows coffee production in the subregion. 
Figure 3.12. Hectares of Coffee by Community

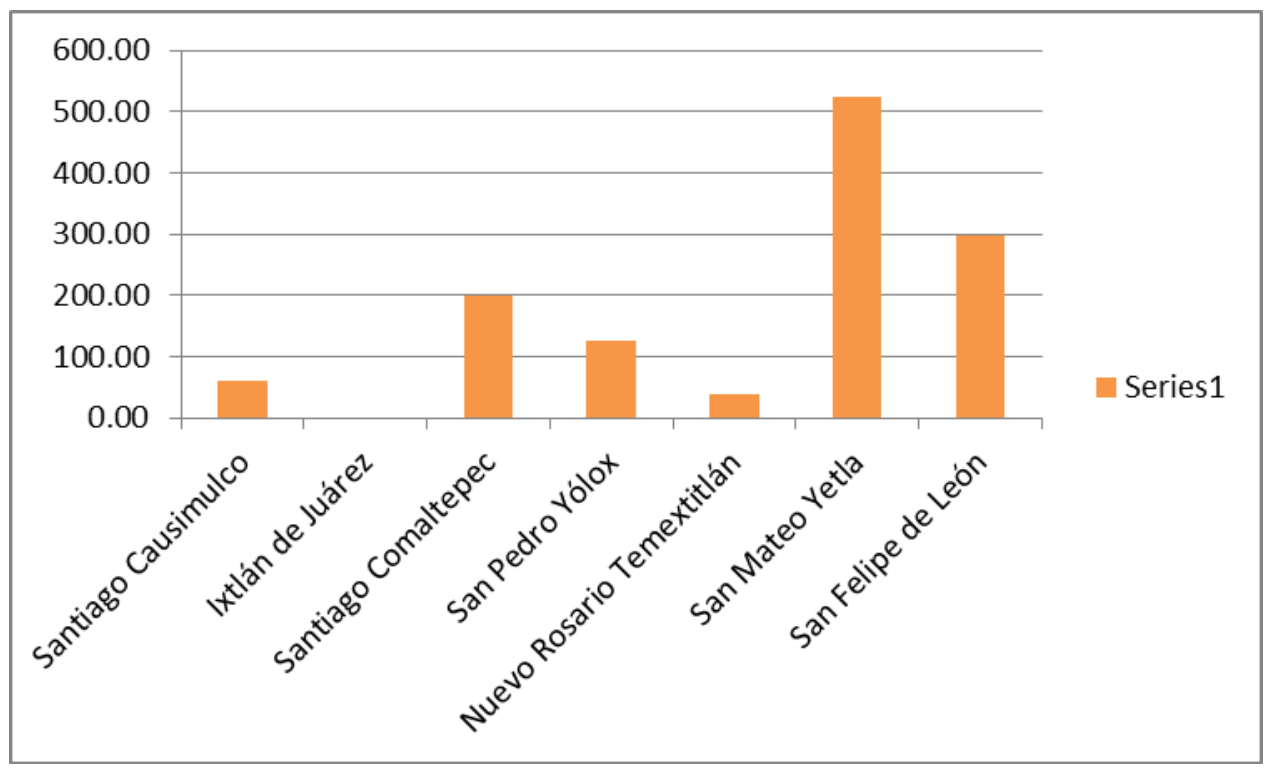

Source: Source: PES documents, focus group interviews and informal interviews (field notes).

Coffee cultivation in Mexico and in this subregion can be seen in two phases-before INMECAFE and after. While the government currently takes a markedly hands off approach to coffee, such was not always the case. A government official in the early 1970s predicted: "The day will arrive when the coffee industry is entirely in the state's hands in Mexico, the authentic representative of you the producers. This day should arrive and for this we're fighting," (Lombaro, 1991). The creation of INMECAFE was Mexico's response to the International Coffee Agreements created in 1962, which set country quotas with the intent of stabilizing global production and prices (Nestel, 1995).

Previously, INMECAFE attempted to highly regulate coffee and by the early 1980s was buying over $47 \%$ of the coffee in Mexico. It also provided funds for the organization of cooperative that increased from 1972 to 1975 from 115 million to 500 million pesos. Credit to farmers increased in the same period from 500 million to 1.75 billion pesos (Lombaro, 1991). 
From 1970 to 1982, land under coffee production in Oaxaca jumped from 59,657 hectares to 103,326 (Nestel, 1995).

Despite the price shocks that have visited growers since the end of the International Coffee Agreement in 1989, some have viewed the disappearance of INMECAFE as having some advantages (Nestel, 1995; Moguel et al., 1999). Some have criticized INMECAFE for furthering the PRI political party's heavy handing and paternalistic dealings in the Mexican countryside (Jaffee, 2007). INMECAFE had international production agreements to meet (Nestel, 1995). It attempted two routes to achieve agricultural efficiency - by expanding coffee into forests often at unsuitable elevations for quality coffee (Bray et al., 2002) and by promoting "sun coffee", which removed the usual shade tree canopy and necessitated high inputs of agricultural chemicals to limit pests thrived under such open conditions (Moguel et al., 1999).

Coffee growers in San Felipe de Leon are the only community who had a negative experience with INMECAFE. Officials from INMECAFE came to buy coffee, but growers said that their interactions with these officials were plagued by corruption and that they were being taking advantage of by these government employees. The relationship was short and not amicable, and INMECAFE soon disappeared from the community.

Generally though, there is still palpable disappointments among growers in the subregion with the fact that the government has largely taken a hands-off role, save for a small subsidy for each hectare under coffee production. Growers say they have been "abandoned" and forgotten by the government when INMECAFE ceased to support their coffee production. While some have stated that that the deregulation of the coffee commodity market was a necessary measure to limit global overproduction (Dietsch et al., 2004), growers experienced an all but immediate price collapse of around 85\% with the disappearance of INMECAFE in 1989. Coffee production in the region never quite recovered, despite occasional high prices. 
Current literature on coffee generally has two distinct focuses: the need of a variety of value added certifications to help smallholder growers survive the ongoing coffee crisis brought on by the dismantling of agencies like INMECAFE (Hull, 1999; Bray et al., 2002; Muradain et al., 2010; Jaffee, 2007; Fridell et al., 2008; West, 2012) and the environmental benefits of organic coffee grown under a canopy of shade trees in order to at least partially mimic a native forest for biodiversity (Moguel et al., 1999; Dietsch et al., 2004; Perfecto et al., 2005; Bandeira et al., 2005).

Some articles bridge this gap most frequently through the advocacy of some certification like "Bird Friendly coffee" which attempts to internalize the positive externality of the habit provided by shade tree coffee to migratory birds (Perfecto et al., 2005). A more recent focus pertinent to these six communities in regards to forest regeneration and conservation is the outmigration and abandonment of coffee farms in part because of the dissolution of INMECAFE in Mexico and the highly variable prices (Lewis, 2005). In some cases this has caused coffee farms to revert secondary succession forests as growers ceased to clear shade trees for coffee production. In other cases rightsholders have cleared shade trees for milpas or cattle pastures (Hite, 2011), which would create a reduction in forest cover.

Yet, shade tree coffee farms in some cases can help to preserve tropical forests and some of their ecological integrity. A study conducted in the village of Rancho Grande, a community near my study area which I also visited to better understand coffee growing in the region, found 34 different tree species occurred over the 240 hectares under coffee cultivation. Tree diversity is as such because there are certain trees that are valuable for timber or that amend soils which dominate coffee farms. Growers would continue to eliminate and maintain difference species, and often fell late secondary succession species (Bandeira, 2005). In other cases high arthropod and insect diversity attracts insectivore bird species, which not only increasing biodiversity, but the birds also provide biological control for agricultural pests (Perfecto et al., 2004). Levels of shade 
of around $75 \%$ on coffee farms can still maintain $23 \%$ of ant species and $80 \%$ of butterfly species in some cases (Perfecto et al., 2005). Yet, beyond a certain point shade begins to decrease yield (Dietsch et al., 2004). While some have advocated for shade tree certification as a means of conserving biodiversity related with shade tree coffee (Perfecto et al., 2005) sales have been minimal for such third-party certification such as Bird Friendly coffee (Dietsch et al., 2004; Perfecto et al., 2005), though Organic and Fair Trade coffee have found more success (Bray et al., 2002; Jaffee, 2007) though have failed to bring substantial improvements in the commodity chain, whereas most of the wealth generated by rural growers ends up in the global north through value added by roasting, marketing and sales of roasted coffee (West, 2012).

What distinguishes these six communities from much of the literature on coffee is that the shade provided by these coffee farms is arguably not as important as shade conserved on coffee farms in areas of high deforestation where coffee cover is the majority of forest cover remaining (Bandeira, 2005). In the case of El Salvador, the country lost $90 \%$ of its forest cover and shade tree coffee may account for $80 \%$ of current forest cover (Perfecto et al., 2005).

In my study region, coffee occupies roughly 1,200 hectares or $2 \%$ of all forest cover. Therefore, with such a small extent of about $2 \%$ in shade tree coffee, it is not playing the conservation values given to it in other studies that explore areas with higher rates of land cover changes (Bray, 2010; CONABIO, 2010). While its economic importance has drastically declined across the subregion, it is still an important source of income in the communities of San Mateo Yetla, San Felipe de Leon and Santiago Cuasimulco. Coffee is grown entirely in individual plots managed by rightsholders. Many communities previously had communal coffee farms, but now only Yetla maintain a small communal coffee farm. These communal coffee farms ended in the case of Yolox with the appearance of forestry jobs and in other cases with the decline in prices. The only rule pertaining to coffee farms is that they cannot be created in mature forests. Otherwise, of all the land uses in the community, the fewest rules pertain to coffee farms, and 
they are treated much like private property. Rightsholders work their farms individually and these farms are the most monetized agricultural practiced in the subregion. Lack of price supports have greatly decreases its once important place in income generation. Many rightsholders have noted that nothing has replaced the income once generated by coffee, save for migration.

When talking with coyotes in Valle Nacional, they confirm a decrease in coffee production in the subregion. The varying degrees of abandonment of coffee that have occurred have increased secondary succession but have produced a less varied economy and in some cases migration to the United States throughout Oaxaca (Lewis, 2005; Hite, 2011).

Largely given the fact that coffee exists in various stages of abandonment, quantifying it was difficult even through focus groups and other interviews. When not included in their OTC, rightsholders gave widely varying numbers to the hectares of coffee in their communities. As coffee is the most individualistic land use, rightsholders did not often know how much coffee other growers currently maintained and how much they had abandoned.

Figure 3.13. Hectares of Cattle by Community

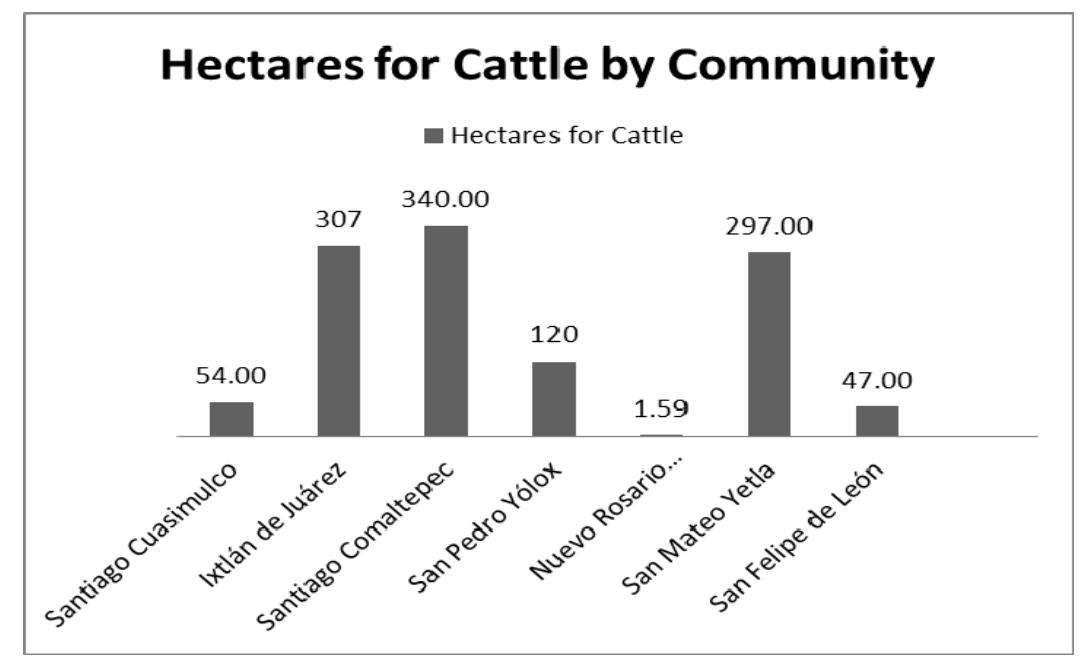

Source: Source: Community OTCs, forest management plans, statutes, PES documents, ACV documents and focus group interviews (field notes). 


\section{Cattle}

Cattle is an often cited driver of deforestation throughout tropical regions of the world (Toledo, 1989; Greenberg et al., 1997; Muniz-Castro et al., 2006; Nepstad et al., 2006, Walker et al., 2006; Busch et al., 2010). It has been a strong driver of deforestation in Brazil because peasants gained land tenure through cattle ownership and from forest clearance (Nepstad et al., 2006). Mexico's tropical forests have faced similar processes of government supported tropical forest colonization and in some cases have subsidized cattle operations (Toledo, 1998; Arizipe et al., 1996; Ellis et al., 2008; Busch et al., 2010; Doane, 2012). Diets have drastically changed in the subregion in recent decades from largely products derived from the milpa as well as some subsistence hunting to the increasing purchase of other foodstuffs including beef (Toledo, 1998; Ibarra et al., 2011) as younger people beg their parents to buy more beef.

While not yet a staple of their everyday diets, rightsholders do raise cattle (Busch et al., 2010; Figel et al., 2011). While in some areas communities in Mexico have received subsidization for cattle (Ellis et al., 2008; Busch et al., 2010); though in this sub-region no such massive subsidization ever arrived. Also, during the Spanish conquest, while colonists raised cattle in other regions of Oaxaca, they did not promote cattle in the mountainous regions of the Sierra Norte (Chance, 2001). Many difficulties emerge in raising cattle in the sub-region. In Nuevo Rosario Temextitlán, rightsholders have tried to start pastures at various times, though the ventures often have failed and currently there are only two hectares of pasture in the community. Both it and the neighboring community of Cuasimulco have had problems with vampire bats that have attacked and weakened cattle. Throughout the region cattle can degrade and destroy pasture if put on too steep of slopes. Growers rarely buy feed for cattle, though in some cases they will feed cattle limited amounts of corn. Therefore, the maintenance of pastures is difficult under local conditions. 
The only case of any programs to spur the improvement in cattle pastures was carried out by a Mexican and American university in the Comaltepec village of Soyolapam, which provided cattle owners with barbed wire and improved grass seed; though no direct subsidies for the purchase of cattle. This area does not have the steep slopes characteristic of the rest of Sierra Norte, and is the only area with ongoing deforestation (Robson, 2011) highlighting the role of topography in limiting cattle development elsewhere in the study area. In addition to the clearing forests to make way for pastures, cattle ownership has in some cases clashed with conservation objectives in the CORENCHI communities. Cattle owners see jaguars as a problem species, which can kill their cattle. By providing more forests, many then assume that jaguars and cattle losses will be more prevalent (Figel et al., 2011). Others have found that rightsholders have experienced more frequently attacks on their agricultural plots by pest species as conservation has increased (Berget, 2012).

Yet, cattle are also important part of the multiple use land management system that provides both subsistence and market access in communities. In these multiple use systems households engage in a variety of land uses in order to minimize risk (Toledo et al., 2003). In the absence of subsidies, the startup costs to clearing the land of forest, planting grasses and then buying the cattle is prohibitive. In some communities, far more people told me that they want to raise cattle than can afford it. It is largely middle-aged men or those with access to the necessary capital who own cattle (Busch et al., 2010). For example the village of Santiago Comaltepec now has a small butcher shop owned and operated by a rightsholders who worked in the United States and saved money to open it. As meat becomes an increasingly desired food especially among younger people, cattle can find a local market within the community, so future localized expansion of cattle pasture cannot be ruled out. 


\section{Community Rules Governing Cattle}

Communities have recognized the potentially negative environmental effects cattle can have on fields and forests and so have created rules to govern cattle. Yolox has some of the most complex rules in that cattle are able to roam free throughout the pastures and forests around the village after farms have finished with the temporada milpa harvest. When farmers plant their milpa again in the spring for the temporada harvest, cattle owners must keep their cattle in an enclosed pasture. They will also save corn stovers as cattle feed. In lowland ranches of Yolox, cattle owners will have largely pastures and cattle will rotate between various sections of pasture. Of all those I asked, no one said there were significant problems with these free-ranging cattle destroying harvests.

Comaltepec in its territorial rezoning and statues have specifically focused a series of rules on cattle. For example, no cattle can be raised on slopes of more than $40 \%$. Each rightsholder with cattle needs to report to the authorities how many head they have and must maintain their cattle outside of any areas of reforestation as well as out of agricultural areas and also respect the dates when cattle must be in an enclosure (Estatuto Comunal Santiago Comaltepec, 2004). In Ixtlán all rightsholders must restrain cattle from entering areas in the process of reforestation or face sanctions (Estatuto Comunal Ixtlán de Juárez, 2007). Also, both Soyolapam and Yetla maintain communal cattle pastures. The agencia authorities manage the communal pasture in Soyolapam, while in Yetla they have created a committee to manage the common pasture. Often neither village will frequently sell these cattle but can slaughter them for community festivals. In Yetla, they created the communal pasture from seized land from another community who was not respecting their designated boundary.

The amount of cattle in these communities is a trend to watch, especially since remittances and outmigration can promote cattle ownership. Again, it is difficult to earn the startup costs. Also, even though cattle might not be as lucrative as other land uses, it often will 
outperform other productive land uses in earnings per hour (Busch et al., 2010). All told there is as much as 1050 hectares of pasture throughout these seven communities.

Besides in Comaltepec and especially in Soyolapam, cattle ownership does not appear to be growing rapidly. Yet, in most conversations with cattle owners they said that they had invested in cattle within the last ten years. Nonetheless, the fact that communities have created rules pertaining to cattle ownership does show that institutions are reflecting their cognizance of cattle ownership and its potential effects on forests and agricultural areas. Both Comaltepec and to a far greater degree Yolox let cattle graze in areas not specifically designated as pastures.

\section{Forestry}

Figure 3.14. Percentage of Total CFE Land by Community

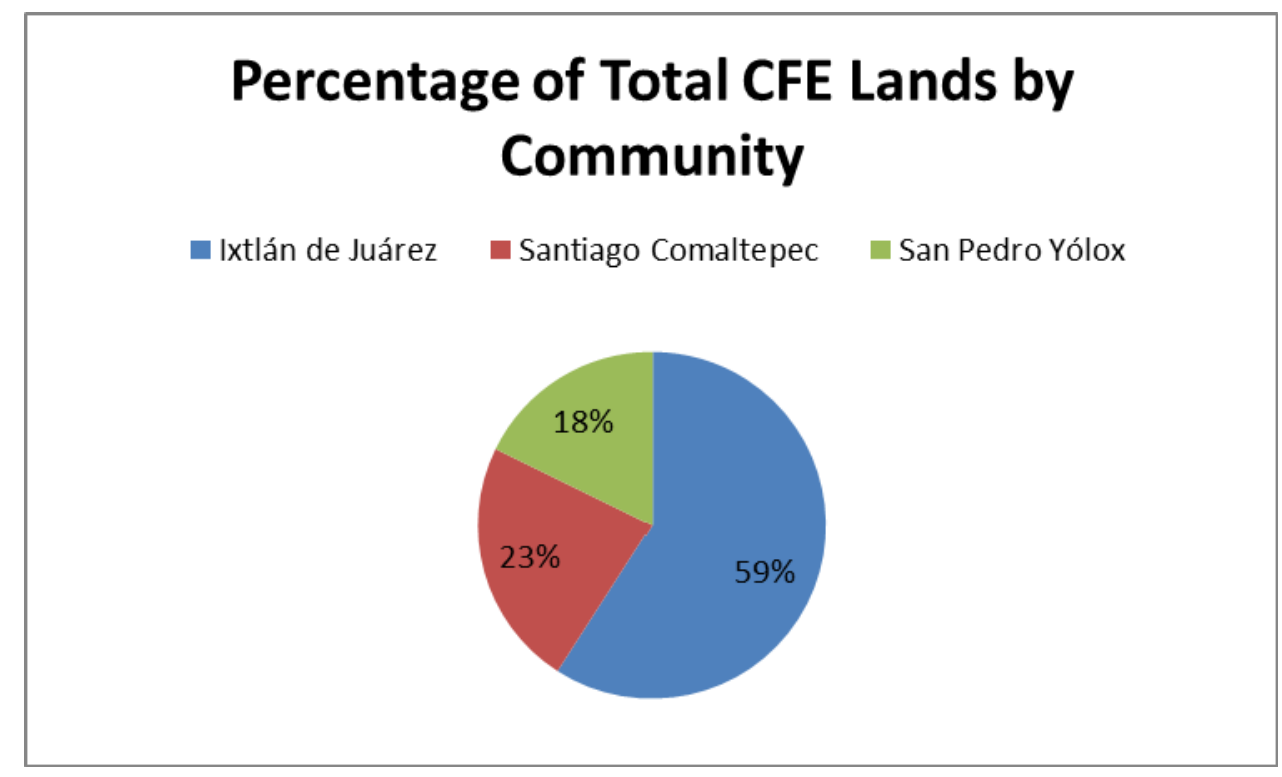

Source: Source: Community OTCs, forest management plans, statutes, PES documents, ACV documents and focus group interviews (field notes).

Here I will examine community forestry in the communities of Ixtlán, Comaltepec and Yolox. I have found that CFEs not only conserve forests cover in these pine/oak forests, but also have led to the management and conservation of other forest types in these communities. 
Contrary to a coffee sector all but abandoned first by the Mexican government and increasingly by growers, community forestry has received supportive public policies which have led to the growth of community forestry enterprises in Mexico, which are communities that are producing timber for commercial purposes (Bray et al., 2005). In fact, scholars have called community forest enterprises "global models for sustainable landscapes" (Bray et al., 2003). As previously discussed in the protected areas in Mexico section, in some cases community forests have shown to maintain forests cover as well as or better than protected areas (Duran et al., 2005, in Bray et al., 2005; Ellis et al., 2008; Bray et al., 2008). Currently community forests occupy 8 million hectares (Bray et al., 2005), while there are about 2000 communities with logging permits (Antinori and Rausser, 2007).

The pivotal moment in community control of their timber forests was the fight against the exploitation of their forests by parastatal logging concessionaires (Bray, 1991; Chapela, 2005, in Bray et al., 2005; Mathews, 2011). Merely having control of their forests and actively managing and logging them proved to be a difficult transition in itself (Bray, 1991).

They could choose to log these forests in part because of supportive policy relating to community forestry. The 1986 Forestry Law devolved further rights to communities and encouraged the formation of forestry unions in communities to manage their forests. No longer would communities need to be day laborers and watch wood leave their forests without their control (Merino and Segura, 2005, in Bray et al., 2005). In some cases infrastructure remained in communities follow the concessionaire period, which helped communities manage their logging operations (Mathews, 2011). By the end of the first decade of community control over their forests, $40 \%$ of wood and 15\% processed timber came from CFEs (Merino and Segura, 2005, in Bray et al., 2005).

The three communities in the sub-region that have CFEs-Ixtlán de Juárez, Santiago Comaltepec and San Pedro Yolox actually show a diverse set of responses to these new policies 
and the end of the concession era. San Pedro Yolox has a unique situation in that current logging occurs outside the communal territory boundaries, but within the municipal boundaries.

Rightsholders each contributed to acquire their forest in 1960 for 2300 hectares of land belonging to the municipality.

Currently, these 2300 hectares of pine and oak forest produces $3000 \mathrm{~m}^{3}$ of pine and 500 $\mathrm{m}^{3}$ of oak annually under ten year management plan. A rotation between stands allows for a regeneration period before logging again resumes there. Management plans are approved by SERMARNAT and are developed by professional foresters, either employed full time or contracted by the communities.

Yolox took control of its logging operating and began working its forests around 1992. While plans exist for the construction of a sawmill, the community currently looks for the best prices available for its logwood, usually selling in Oaxaca due to that being an easier access points and the generally higher prices provided. Despite their lack of ownership of a municipal sawmill, their pine-oak forest provides up to 20- 25 jobs from management to transporting the logs to market. While this is seasonal work, it is an important source of income and jobs within the community and in some cases for those outside the community.

Yolox's CFE generates yearly 1.5 million pesos (USD\$ 125,000 dollars at the common summer 2012 exchange rate of 12 pesos to a dollar). Benefits from logging include a new roof for the primary school in the village of San Pedro Yolox and also reconstructing the community church. While this area is relatively small compared to those in Ixtlán and elsewhere in Mexico in logging states like Durango and Chihuahua, it provides community benefits.

By 1982, Comaltepec began to organize its forest management and in 1984 Comaltepec had begun harvest under forestry union "Cerro Comal" (UZACHI, 1994). In 1989 it founded UZACHI (La Unión de Comunidades Productoras Forestales Zapoteco-Chinantecos-Union of Zapotec-Chinantec Forestry Producers) currently made up of four communities to aid in better 
management. With the goal of paper production, FAPATUX had sought to maximize logging of the forests under its concession; UZACHI (Unión Zapoteco Chinanteca) has changed the goals of forest management to reflect broader community benefits including: the provision of fuel wood, the protection of important habitat for wildlife, scenic areas as well as watersheds and the production of timber. A local NGO, Estudios Rurales y Asesoria (ERA), helped communities found UZACHI (UZACHI, 1994). Recently the community authorized the harvest of $2000 \mathrm{~m} 3 \mathrm{of}$ pine and $300 \mathrm{~m} 3$ of oak, all of which was certified by the Forestry Stewardship Council in the mid-1990s. Currently the community has 580 hectares under intensive silviculture as a consequence of the commercial quality of the forest and favorable logging conditions with "low intensity silviculture" for less favorable and commercial areas and 416 hectares for planting and natural regeneration (UZACHI, 1994).

The community has invested these earnings a meeting hall for assemblies, repairing the roof on their historic church, improving roads as well as the construction of the municipal palace. Long term plans may include the purchase of a wood dryer and/or stove which would allow them to increase quotas for oak. In both 1996 and 1997 Comaltepec won an award of "National Forest Merit" from SERMARNAT (Direcion Tecnica, 2003). While Comaltepec has managed its community forestry enterprise, a trend to watch is if the forests can enact the broad improvements in the community as some hope they might:

"We will use our natural resources with the end of creating a source of jobs and avoid the migration of our young people..." (Plan Municipal Santiago Comaltepec, 2010)

Furthermore, rightsholders see that the community has gained valuable knowledge about forest conservation from working its forests. As one rightsholder explained: "Logging our forests can be a way to conserve them. We are going to $\log$, but we're also going to reforest. Some of the forests will be for creating jobs but other areas can erode easily. Protected zones in the higher areas will be for watersheds and there are refuges for fauna." 
Recently they have built an upgraded sawmill near the Oaxaca-Tuxtepec Highway and process their own timber and well as timber the community produces from other communities. Forestry activities create roughly 30 jobs in the community and earn the community roughly 1 million pesos (USD $\$ 83,333$ ). They have roughly 3,000 hectares of pine and oak forests.

The third logging community in the study region, Ixtlán has 19,310 hectares, with over 18,000 hectares forested and 7,354 ha managed forest for timber. The yearly authorized volumes include $25,000 \mathrm{~m}^{3}$ for pine, $12,000 \mathrm{~m}^{3}$ for oak and $200 \mathrm{~m}^{3}$ for other broadleaf trees. Ixtlán actually $\operatorname{logs}$ yearly $25,000 \mathrm{~m}^{3}$ of pine, $1,000 \mathrm{~m}^{3}$ of oak and $200 \mathrm{~m}^{3}$ for other broadleaf trees (Comunidad de Ixtlán, 2002) with $P$. aycahuite, $P$. psuedostrobus y $P$. douglasiana being the most commonly pine species logged. In Ixtlán, over $90 \%$ of the managed forest is 50 years or older since its last harvest (Comunidad de Ixtlán, 2002). Ixtlán's community forestry enterprise sells manufactured wood products, including doors, furniture and broom handles from their community owned furniture factory (Comision Asesor, 2010), which has also become part of a joint venture with two other CFEs called TIP Muebles.

Recognized benefits for the community from logging include over 250 jobs for rightsholders. Daily salaries in the forestry sector range from 330 pesos daily for the coordinator of the (UCFAS) to a warehouse guard at 108 pesos daily with paid social security and vacations for all. Furthermore, forestry activities also pay for: 1) Social programs 2) Education 3) Neighborhood commissions 4) Sports and 5) other expenses. From 1998-2008 the forestry sector contributed 3.49 million pesos (USD\$290,833) for these programs ranging from 590,746 pesos in 2002 down to 63,090 in 2008 (Comision Asesor, 2010). Earnings also directly built the municipal auditorium, the municipal building as well as classrooms in the primary, secondary and high schools.

Four types/classifications of CFEs in Mexico include: 1) Stumpage 2) Sawnwood 3) Roundwood 4) Finished wood products (Antinori, 2005; in Bray et al., 2005). All three 
communities would have been obligated to sell only stumpage to parastatal concessionaires like FAPATUX. The rise of community forestry enterprises has created diversification. Given their over 7,000 hectares of prime pine/oak forest, location on the Oaxaca-Tuxtepec Highway, close involvement with concessionaires that built forestry capacity, long standing historical habitation and secure land tenure and likely many other factors, Ixtlán has emerged as a finished wood products community. Again, with stores in Oaxaca City as TIP Muebles, there community forestry enterprise is visible beyond the Sierra Norte. Comaltepec has recently upgraded its sawmill and begun to purchase more timber from surrounding communities. Therefore, they are a sawnwood community. Yolox currently is a roundwood community as they fell trees and sell them to various sawmills within the region.

What is also remarkable is the amount of community cohesion around these community forestry enterprises. During my research, I found little discord or bitterness about current management also confirmed for Ixtlán by Mathews (2011). Likely, as benefits continue to accrue to communities and individuals can look for jobs in community forests, this is one of the few cases in which the owning of large tracts of forests have direct financial benefits to rightsholders prior to PESs. Also, as work is seasonal, rightsholders could work the part of the year in agriculture.

It is safe to say that successful community forestry management will continue in these communities. Providing that public policy is supportive of community forestry in Mexico, these communities will continue to manage their forest for timber and do so in a way that has proven to be sustainable. The only doubts expressed relating to the community forestry enterprises in these communities is that if future generations will still be interested in working in these community forests or if they will increasingly seek work in Mexican and US cities. 


\section{Migration}

Migration has a variety of potential impacts for forest cover. In some cases households buy products with remittances they otherwise would have produced in their milpas (Robson, 2011). Also, as I have shown, unstable coffee prices, agricultural pests and rising local labor costs for day laborers have caused agriculture abandonment in milpas and coffee farms, a common result of emigration. With more people living outside the community and with the inflow of remittance dollars, cattle could be an adaptation for a livelihood strategy in light of a lack of day laborers on coffee farms (Busch et al., 2010).

The debate over the effects of migration on forest cover and biodiversity is a contentious issue among conservationists. Forest transition theory explores such a transition from deforestation and degradation to forest regrowth and conservation that can be driven by outmigration which leads to agricultural abandonment and forest regeneration (Rudel et al., 2005). Some conservationists have specifically advocated for agriculture abandonment and outmigration in areas important for biodiversity conservation such as the subregion. They then argue that for agricultural intensification in areas of suitable to mechanized farming as a means to conserve biodiversity and still provide food (Pimm et al., 2001; Gorenflo et al., 2005). While, communities would find the idea of them abandoning their land in order to strengthen global biodiversity conservation entirely repugnant, ecological gains from emigration are not always clear either. To state that agricultural abandonment is universally a net gain for biodiversity is an idea coming under increasing scrutiny. Scholars have argued that biodiverse landscapes often have had long historic habitation and maintained if not increased their biodiversity (GomezPompa and Kaus, 1999; Tsing, 2008; Robson, 2011).

Robson (2011) also has argued that the preponderance of mature and older secondary succession forest does not always equal the diversity that would exist in managed landscapes such as coffee farms, milpas, coffee farms and household gardens. In these areas, farmers will select 
species which may not be as abundant in natural forests (Bandeira et al., 2005; Bost, 2009).

Farmers then are promoting species that may be uncommon in non-human aided forest succession and so may increase biodiversity my managing forest succession.

Robson (2011) also argues that continued migration of rightsholders puts strains on community governance. If more rightsholders leave, each rightsholder will have to take on more frequent unpaid positions of community authority. These positions take rightsholders away from their fields and put strain on their production for their household. Rightsholders accept these unpaid positions for the benefit of the community, but need adequate time to financially recoup between positions. Rightsholders in some cases will migrate to escape any extremely rigorous and frequent communal obligations. Such migration exacerbates problems with community governance. As I argue that governance is a major contributing factor to the subregion's high forest cover, migration past a certain point could upset governance. Governance cannot happen without rightsholders filling positions of community authority that allow them monitor their forests and sanction and rule breakers.

The difference between this study and Robson (2011) is that I am examining only forest cover and he examined the biodiversity within this forest cover. From a commons perspective on emigration and forest conservation it is also important to note again that rightsholders retain usufruct rights over their land unless they explicitly cede them to another rightsholders. Therefore, if someone has five hectares of coffee and they migrate, those five hectares will likely revert to a more closed canopy forest. If no one works their milpa, then these patches will have increased fallow periods and revert to forest. While, many migrants stay away for only few years, I have met various rightsholders who have stayed away for 10-12 years. Their plots then remained increasingly forested while they were away. I asked if anyone thought this practice was unfair since it was good land that no one could work, rightsholders said that if these people were cooperating with communal responsibilities, and then they had the right to decide to do exactly 
what they wanted with their land. The fact that other rightsholders respect these wishes is a sign of community cohesion and respect for usufruct rights.

In many cases rightsholders do return to work their coffee farms and milpa fallows. In some cases migrant rightsholders gain skills in construction and carpentry and return to their communities and work for those who are building their houses largely from migration dollars. In the majority of cases, rightsholders do return to their fields after constructing their house, since there are few options other than agricultural or forestry in the subregion.

\section{Active Conservation}

In the proceeding section, I have reviewed casual factors leading to passive conservation such as large territories, many distant areas from roads with difficult access, low and often declining population densities, steep slopes, few areas of suitable agriculture as well as agricultural practices that have maintained soil and soil fertility. Now, I will turn my attention to active conservation in these communities. Again, while I have already demonstrated that CFEs and the fight for control of their forests has deepened conservation discourses since the 1980s in Ixtlán, Comaltepec and Yolox, the rest of the subregion has become increasingly focused on territory governance as well on forestry conservation within the last decade.

Table 3.2. Governance Data for the Subregion

\begin{tabular}{|c|c|c|c|c|c|c|c|}
\hline Community & Rightsholders & Year of Title & PROCEDE/FANAR & OTC & Statutes & PES & VCA \\
\hline Santiago Cuasimulco & 40 & 2009 & No & 2009 & No & 2009 & No \\
\hline Ixtlán de Juárez & 384 & 1986 & 2008 & Yes & 2004 & 2007 & 7 No \\
\hline Santiago Comaltepec & 350 & 1954 & 2004 & 2004 & 2007 & 2012 & 2 No \\
\hline San Pedro Yólox & 325 & 1961 & No & 2012 & 1996 & 2011 & No \\
\hline Nuevo Rosario Temextitlán & 63 & 2005 & 2006 & 2010 & No & 2007 & 7 No \\
\hline San Mateo Yetla & 560 & 1975 & 2007 & 2004 & 2004 & 2008 & 3 No \\
\hline \multirow[t]{2}{*}{ San Felipe de León } & 273 & 1987 & 2005 & 2009 & 2008 & 2006 & 2010 \\
\hline & 1,995 & 1976 & $2006^{\prime}$ & 2008 & $2004^{\prime}$ & 2009 & 2010 \\
\hline
\end{tabular}

Source: Community OTCs, Statutes, PES documents, ACV documents and focus group interviews (field notes). 
Table 3.2 is crucial in a discussion of in the subregion as governance is a central focus of this thesis. Table 3.2 shows some of the important dates that both consolidated territorial rights, a second major variable in the historical baseline of high forest cover, and the emergence of the new institutions that make conservation increasingly more conscious. I will conduct a column by column analysis of Table 3.2 in order to show the nuances in the subregion related to governance and conservation.

Currently here are 1,995 rightsholders in the subregion who have access to 66,264 hectares of communal lands. Again, this number is more complicated as the number of rightsholders not currently living in these communities varies from $30 \%-50 \%$ in each community. While they still technically hold rights to communal lands, they are not working the land. By supporting their community through repaying for replacements to complete their community obligations, rightsholders retain their rights to work community lands upon. Migrations can continue to maintain rights through financially supporting communities while abroad.

Also the naming of rightsholders is more complicated in some communities than in others. For example, many young men in Yetla gain status of rightsholders after they reach the age of 18. In Ixtlán, being a rightsholder grants a share in the community’s lucrative CFE. Current rightsholders have limited the granting of communal rights to many younger men (Mathews, 2011). In fact, in archival documents the number of rightsholders has remained more or less the same despite large increases in populations in Ixtlan.

Even though communities like Yolox, Ixtlán, Yolox and Yetla have inhabited their current lands before the Spanish conquest, legal title is more recent. The $20^{\text {th }}$ century Mexican national process of agrarian reform that began in earnest during the President Cardenas term in the 1930s, although these communities gained their land rights relatively late. Part of the reason for these later dates is that in the example of Ixtlán that they had to legally delimit their boundaries with over a dozen other communities. In the other two notable cases, Nuevo Rosario 
Temextitlán and Santiago Cuasimulco exist as a result of rightsholders from the highland communities of Santa Maria Totomoxtla and the village of Rosario Temextitlán in search of lands who arrived en masse in the 1960's to gain land tenure by felling tropical montane forests. They gained land because it was in a state that my system would classify passive conservation. Yet, previously agrarian reform granted lands for forest clearing to promote agriculture.

While land redistribution ended in 1992 with reforms to Article 27 of the Mexican Constitution, the government continued to adjudicated pending claims. In other cases communities were not so lucky in that they were unable to form verifiable claims and faced bureaucratic roadblocks which left them without land (Bartra, 1985; Klooster, 2002).

The communities in the subregion successfully navigated the tangle bureaucracy to gain their lands. Nuevo Rosario and Cuasimulco were able to settle disputes with each other in order in the 1970 s to eventually both receive their title in the 2000 s. Irregularities arose over 500 hectares of fertile agricultural between Comaltepec and Yolox led to intense conflict that included sabotage, murder and kidnapping such to the extent that attracted military attention in the 1950s. While the conflict continues, it is nonviolent and currently largely bureaucratic in nature. The disputed area remains in a state of passive conservation as rightsholders from neither community currently work there.

The territorial rights to land given in the presidential resolutions were strengthened by a 1992 constitutional reforms and the government programs established to implement it. PROCEDE/FANAR are two programs created by these reforms to Article 27 with the intent to register private parcels within ejido lands or to privatize the ejido entirely (Haenn, 2006). PROCEDE began the process of registering lands. FANAR has continued to finish pending matters from PROCEDE. In the study communities, PROCEDE and FANAR have helped communities to clarify boundaries and reaffirmed community land tenure. Both ejidos in this study, Nuevo Rosario and San Felipe de Leon entered the program, though neither created private 
parcels and thus formally designated all land as common property, reserving the right internally to assign agricultural lands.

All comunidades save Cuasimulco and Yolox entered the program, though they were not legally capable of creating private parcels. Similarly, they largely would have clarified boundaries. Whether or not it is related to Yolox not entering the program, when Comaltepec completed documents with FANAR, it did not settle the ongoing dispute between Yolox and Comaltepec. In all other cases PROCEDE/FANAR merely reaffirmed ongoing land tenure arrangements. One rightsholder in the village of San Felipe de Leon told me that an outsider had come with the intent of buying some property near the San Felipe River, but the community decided in an assembly not to sell the land. It is important to note that forested land cannot be sold (Antinori et al., 2005). Since communities have such high percentages of forests that could not be sold, they would gain little in attempt to sell their entire lands. Therefore, they could sell only individual parcels in land zoned as agricultural.

San Felipe de Leon is located 15 kilometers down a dirt road from the regional commercial center of Valle Nacional; Nuevo Rosario is 15 kilometers down a dirt road and also another half an hour in car to Valle Nacional. Given that both areas lack much suitable lands for mechanized agricultural and are not near large towns or touristic areas, it is unlikely that these ejidos receive many offers for the purchase of private parcels. Also, it is their refusal to create these parcels whether for sale or not that allows me to use the terminology communities to refer to both comunidades and ejidos as functionally they are operating identically.

Before PROCEDE/FANAR, San Mateo Yetla had to repeal incursion in its territory by non-rightsholders in the 1970s. While much of what I am describing in Table 3.2 deals with planning exercises and meetings, Yetla had in some cases had to re-occupy territory that nonrightsholders had attempted to take. Often after receiving no help from government officials in removing non-rightsholders, the community would organize en masse with rightsholders wielding 
machetes and other agricultural implements to drive off the invaders. Since they were willing to confront invaders, rightsholders in Yetla have been successful at territorial monitoring and consolidating boundaries, while likely never having to resort to actual violence. Therefore, just because agrarian reform granted communities their territory, did not mean that boundaries were automatically respected by outsiders. The example of Yetla as defending its territory is important because in many cases the government was slow to aid communities in matters of land tenure disputes (Bartra, 1985). In other cases these governmental interventions have been plagued by corruption (Doane, 2012). In the case of Yetla, they defend their land not through appeals to agrarian reform through with community cohesion the willingness to engage in what could have been potentially violent confrontations.

Next, the process of creating their ordenamiento territorial comunitario (land use zoning plan) (OTC)s was the first time non-CFE communities like San Felipe, Cuasimulco and Nuevo Rosario began to actively consider territorial management. Therefore with the planning of OTC, these non-CFE communities would likely be continuing to conserve their forests passively and not seeing these forests as one piece of territorial zoning and management.

While some authorities claimed that Ixtlán had completed an (OTC), no one could locate it. Despite their lack of an OTC, no community had a richer source of documents pertaining to its forests and territory than Ixtlán. While its forest management plan will examine standing trees stand by stand in its extensive pine/oak forests, other documents specifically looked at its PES area as well as other forested areas conserved through community institutions or because of distance and migration from these lowland areas to the village of Ixtlán. The profusion of documents pertaining to the forests in Ixtlán provides another indication that communities engage in these planning exercises and commission studies when financial incentives exist.

Otherwise, much of the data on forest cover and land use I have used in this study comes from careful review of these OTC documents. Local environmental NGOs, normally with 
government funding, have supported these exercises within the region (Chapela, 2005; in Bray et al., 2005). The 1988 LGEEPA promoted OTCs at various governance levels, though this planning was not meant for the community level. The intention was to indicate actual land uses as well as designate future land uses, to protect the environment and other public goods (LGEEPA, 1988). Later the government and NGOs have assisted communities with their OTCs (Doane, 2012).

While it is not required by agrarian law that communities complete an OTC, it is a testament to the interest these communities have in their forests that they completed them and hired NGOs to complete them at the expense of the community, though in some cases the government did provide funding. As the dates on the above chart show, these are a recent phenomenon in many communities. Comaltepec created its OTC when it revised its communal statues in 2004. Yetla was also an early pioneer in OTC, completing theirs in 2004 as well. It is also notable that a community with CFE like Yolox only recently completed their OTC in 2012, even though they have 20 years of experience with their CFE and have high forest cover. In fact, I was reading a large two volume draft of the OTC while conducting this research. Conversely, Cuasimulco officially received their land title as well as completed their OTC in 2009.

While community authorities admitted to rarely if ever consulting these documents, they are of value because of the participatory processes in crafting them and codifying existing land uses. Many of the OTCs conducted participatory mapping of community territories. Photos show how rightsholders would together sketch out the areas currently as agriculture and forest areas. Rightsholders would also walk transects through their territories to show characteristic species and forests. Furthermore, they would generally conduct sessions for oral histories of recent times, which have added additional data to what was available in state archives. In effect, OTCs include a combination of techniques virtually unknown to many rightsholders like GIS and remote sensing and combine them with local knowledge of their histories, land uses and forests. In part 
because of this collaborative approach I have felt confident in relying on these documents for an important source of data on land use and community history.

Community statutes are also an important part of territorial governance. While the OTCs often are the place where communities zone for different land uses, statutes can contain rules on how to govern their territory and also provide measures to sanction rule breakers.

Following Ostrom and her emphasis on rules in the robust governance systems for common property regimes (Ostrom, 1990), I argue that community statutes have played an important role in creating rules, though not nearly all rules for any communities find their way into these statutes. Communities will formulate their statutes during assemblies, which all rightsholders must attend or pay a fine. Therefore, these rules are not merely written down by one leader, but instead discussed at assemblies among rightsholders.

Communities range in the number of assemblies from Yetla who has four yearly regular assemblies, though leaders can call special assemblies, to Yolox which has twelve regular assemblies. As a result of not having neither roads nor telephone access, rightsholders in Cuasimulco have almost weekly short assembly as community leaders will receive communication from government officials roughly once a week when community authorities travel to the market in the town of Valle Nacional. While rightsholders will not always discuss conservation in assemblies, it is in their assemblies that communities decided whether or not to engage in community conservation or enter governmental conservation programs. It is in assemblies where they discuss rules or discuss when to rework their statutes.

Many informal rules exist beyond the formal ones included in these statutes. Nonetheless, they are a helpful starting point. What is notable is that in some cases there is coordination between the writing of community statutes and the crafting of an OTC. In fact, in San Felipe de Leon, the community, along with their partnering NGO specifically created their statutes, and then they completed their OTC all related to their entrance and the continuation of 
their PES contract. To solidify their application for continuing PES funds, they certified a VCA including and extending beyond their PES area. While I will discuss later their reactions to not having their PES contract renewed, this example shows how governance has been directed to conservation initiatives, though in this one example, it has not produced favorable results.

As Table 3.2 shows that both Nuevo Rosario and Cuasimulco lack community statutes. Nonetheless, during focus groups with community leaders and informal interviews with rightsholders, I learned that all communities in the region had the rule that they would not be felling mature forests. This rule in effect fixed any agricultural frontier which existed. While this rule was not written down in either of these communities, rightsholders throughout the subregion recognized this rule. Such a rule then means that while forest cover will remain dynamic in agricultural areas, the mature forests that are now standing will likely remain.

I will now review rules pertaining to forests and forest conservation in these statutes. While statutes widely vary in their comprehensive, they do provide rules and in some cases sanctions for activities related to forests. San Felipe de Leon has a rule that if rightsholder fells a tree not in their agricultural plots, then they must plant 10 trees to replace it. Yolox has an article of its statutes allowing the assembly to vote on community conservation. If rightsholders are caught clearing forests in Ixtlan not zoned for agriculture they must: 1) Cease all agricultural activity 2) Reforest the area based on recommendations from community forest technicians and may lose their rights to community lands for one year. They can also have their rights suspended for as much as six months if they are caught harvest non-timber forest products for sale without permission from community authorities. While these rules in Ixtlan sound harsh, they are a testament that in the particular case of Ixtlan robust forest governance has produced jobs and economic opportunities in a way that has stemmed the outflow of migrants. Ixtlán wants to maintain these benefits for all rightsholders and not have situations of excessive appropriation by 
a handful of outsiders. Such an outcome has not occurred in any other community in the subregion.

\section{Forest Types and Conservation}

Here I will shift from looking directly and planning exercises and community governance to focus on forest types and conservation. As discussed above, communities have limited productive uses to roughly 8,000 hectares total; they have maintained 59,319 as forest or $88.34 \%$ of their lands. Furthermore, what I have shown in the extended examination on productive land uses is that beyond the abandonment of coffee farms because of low prices and a modest increase in cattle largely within in the last ten years, that forest cover has likely remained stable. If anything with $30-50 \%$ of rightsholders living outside these communities, their agricultural plots have become forested and overall forest cover has increased. While the communities' current interest in conservation will become evident in the following section, it bears repeating from the proceeding sections that large territories with secure land tenure and well-delineate boundaries, low population densities, difficult access of remote areas, outmigration, community forestry, lack of agricultural subsidies and support, steep slopes which preclude mechanization and poor soils help to favor conservation on much of their lands. Now, I will bring back yet another procession of charts to explore forest cover in the subregion. 
Figure 3.15. Percentage of Total Subregional Forest Cover

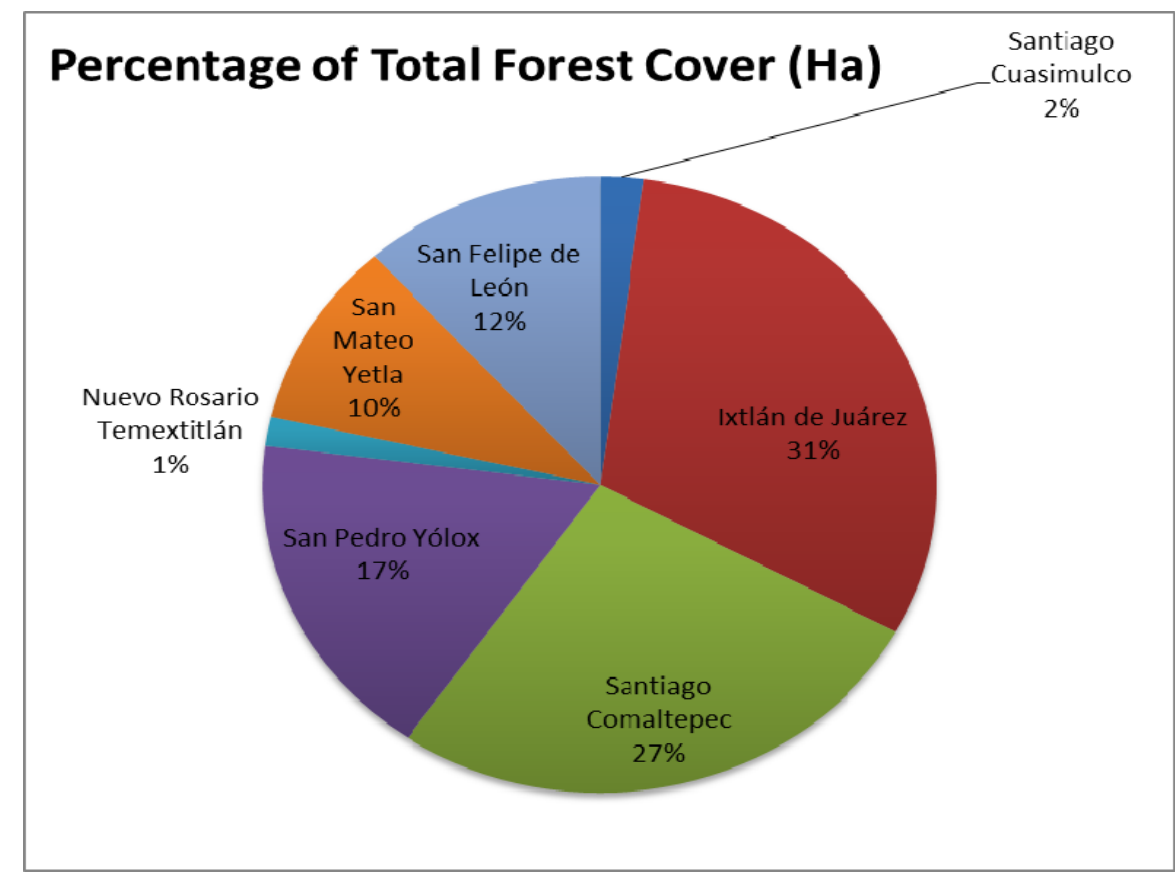

Source: Community OTCs, Statutes, PES documents, ACV documents and focus group interviews (field notes).

Figures 3.14 and 3.15 show the predominance of Ixtlán in the study region as it is the largest community, which has the most forest and 5\% more of its territory is forest than any other community. Predominantly agricultural communities with multiple settlements like Yetla still maintain $78 \%$ or higher of their territory as forest cover. Again, high forest cover is a regional trend at $88.34 \%$ of total area, though there is a sample standard deviation of $5.86 \%$ for forest cover in these seven communities. While pine-oak forests have provided CFE communities with minor benefits during the concession period and increasing benefits during the CFE period, the non-CFEs have only gained economic incentives for conservation within the past decade. Again, while passive conservation previously maintained forest cover, communities have begun to 
increase forest governance and formalize this conservation through interactions with governmental policy.

Figure 3.16. Percent of Territory as Forest Cover

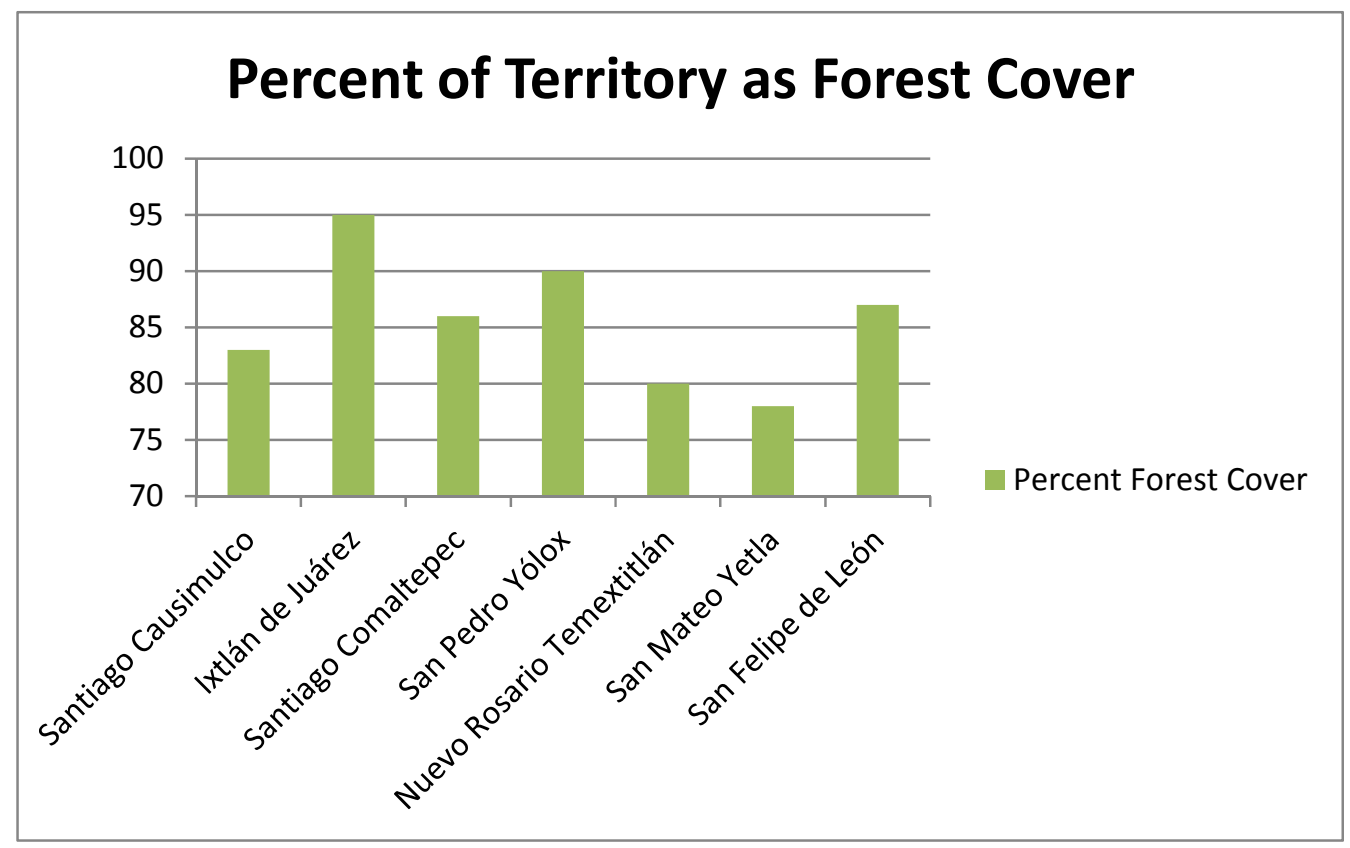

Source: Community OTCs, Statutes, PES documents, ACV documents and focus group interviews (field notes).

Figure 3.16 illustrates the differentiation of the forested block at the center of this thesis. While I have focused on TMCF in the region for the interest show in recent conservation publications (CONABIO, 2010; Golicher et al., 2011; Toledo-Aceves et al., 2011; Rojas-Soto et al., 2012; Ponce-Reyes et al., 2012), other forest types do exist. As I will discuss in the follow section, while TMCF may garner attention for biodiversity studies, the large tracts of pine/oak forests held by the three forestry communities in this study: Ixtlán, Comaltepec and Yolox, provide economic important opportunities as well as a highly developed conservation consciousness. 
Figure 3.17. Types of Forest by Community

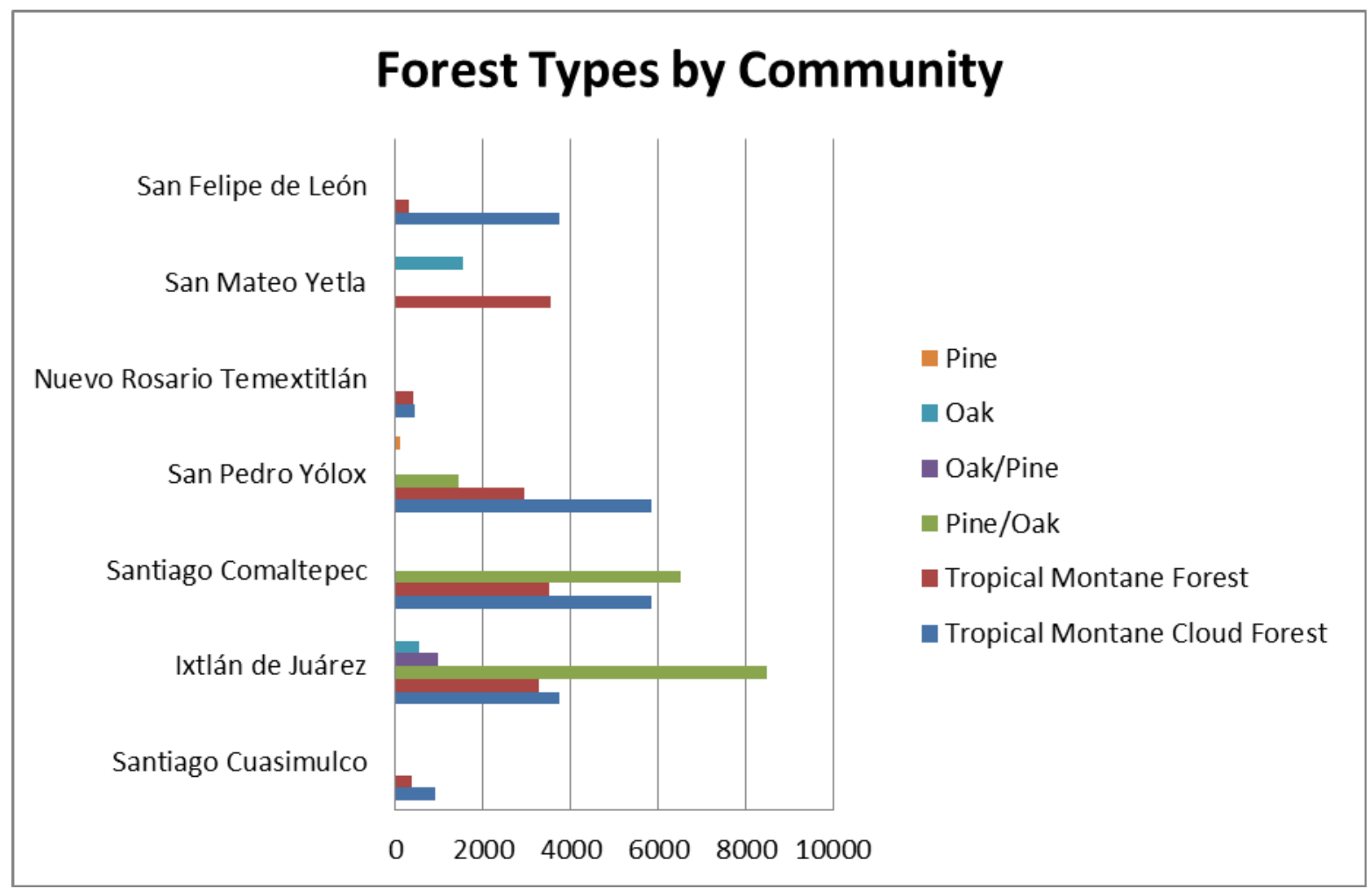

Source: Community OTCs, Statutes, PES documents, ACV documents and focus group interviews (field notes).

That being said, the neighboring communities of Ixtlán, Comaltepec and Yolox also have a very much intact tract of TMCF that equals nearly 16,000 hectares together. While Comaltepec does have agriculture in its TMCF zone largely surrounding the village of La Esperanza, Ixtlán has no agricultural or other activities occurring beyond conservation in its TMCF zone. Yolox has limited agriculture in this area, but is conserving 2060 hectares of TMCF through the PES program and additional conservation recognized in its OTC. The other important block of TMCF is that conserved by San Felipe de Leon in their VCA of 3500 hectares, with additional conservation outside of this area. PESs cover the TMCF also in Nuevo Rosario and Cuasimulco as well adding another 1883 hectares of TMCF conservation. As communities receive higher 
payments for $\mathrm{TMCF}$, they benefit more from conserving these forests than for other forest types (Alix-Garcia et al., 2005; Shapiro, 2010).

Tropical Montane forests are more commonly converted for agriculture in the region than TMCF. For example, Nuevo Rosario created its settlement in this forest type and has primarily converted tropical montane cloud forests to agriculture. Much is the same story in Yetla, where they have conserved tropical oak forests that the community feels are unsuitable for agriculture while they have created their milpas, coffee farms and pastures by clearing tropical montane forest. Soyolapam, the village most heavily clearing its surrounding forests is surrounded by tropical montane forests. Nonetheless, as the Figure 3.17 shows below, despite the fact that TMCF and pine/oak are the most prevalent forests in the region, there is still considerable tropical montane forest remaining.

Beyond pine/oak forests and their value as timber, the communities do not necessarily consider forest type as any unit of analysis, but instead consider slopes, soil types and distances in choosing which forests to select for agriculture. Again, TMCF have limited settlement in or near them, are only easily accessed in Comaltepec as a result of the road access via that OaxacaTuxtepec Highway and so is another example of the historical passive conservation of the region that has become increasingly conscious and reinforced by community institutions in the last two decades. Thus it is most remarkable that these TMCF forests remain in Comaltepec given the ease of access compared to many communities with difficult access. While rightsholders cleared forests in the 1960s to form a settlement at La Esperanza, rapid outmigration has decimated its population and caused massive abandonment of coffee farms in the wake of deregulation and the price collapse of 1989. Also though surrounded by TMCF, many rightsholders farm far down slope from the village in what would be tropical montane forest.

Of the pine/oak forests, the pine is the valuable species, and even Ixtlán has set comparatively low oak quotas for their timber harvests. In other communities oaks if used at all 
are mainly extracted for fuelwood. Therefore, again the forests of value are the pine/oak forest, while other forest types have only produced any real monetary value since PES began.

Figure 3.18. Forest Types by Percent

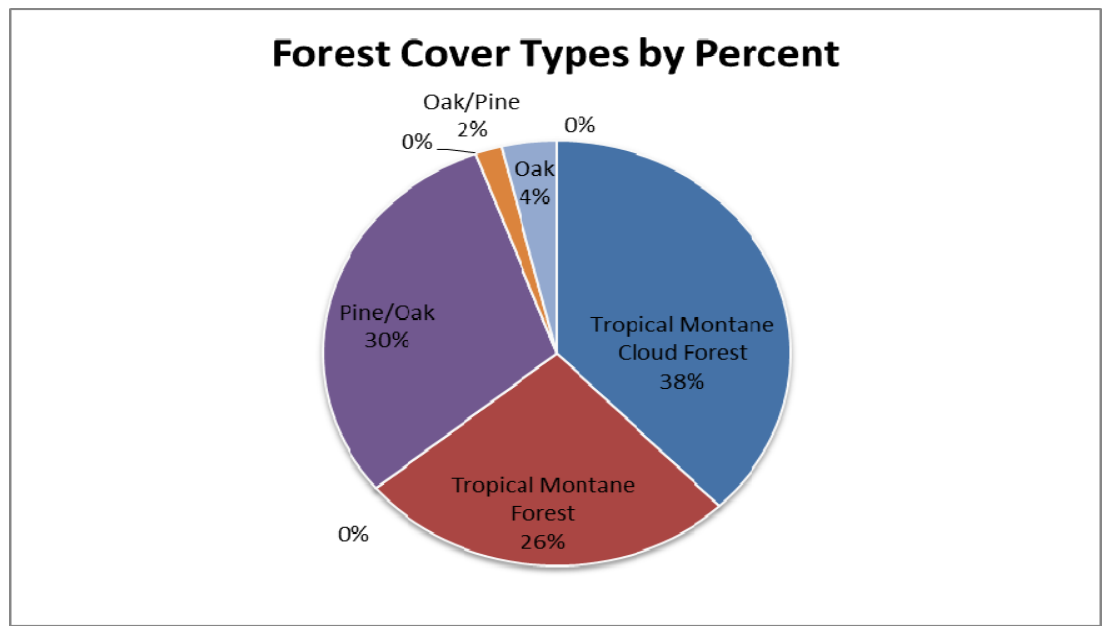

Source: Community OTCs, Statutes, PES documents, ACV documents and focus group interviews (field notes).

Figure 3.18 categorizes the conservation I discussed in Figure 3.16. Again, I have decided to classify community conservation forests which communities have conscious conserved at the community level, but which receives no formal recognition. In some cases communities create specific designations for these forests, though in other cases they do not. I have considered community conservation to be informal conservation, largely because it not recognized outside the community. As I will discuss in Chapter 4, this leads to confusion in that SCP articles such as Ponce-Reyes et al. (2012), which assume no conservation is occurring in the region of the Sierra Norte, when in fact these communities, along with the neighboring CORENCHI communities have engaged in community conservation (Bray et al., 2012; Duran et al., 2012). 
That being said, I have chosen to classify community forestry, PES conservation and Voluntary areas as formal conservation, because in the CFEs, they must submit logging management plans for government approval and so the government is aware of their logging and the extent of their logging. More recently all communities entered the PES program and have conserved forests in order to receive per hectare/per year payments for conservation. Though San Felipe no longer receives PES, they have entered the VCA program. Especially in the case of the VCA program that is published on CONANP's website (National Commission on Natural Protected Areas) (http://www.conanp.gob.mx/que hacemos/listado_areas.php), anyone with an internet connection can see which communities have certified a VCA. Again, while I am not arguing that formal areas are not necessarily better conserved than informal areas, the differentiation lies in that formal conservation receives government recognition and informal conservation does not.

\section{Forest 3.19. Conserved Forests by Management Type}

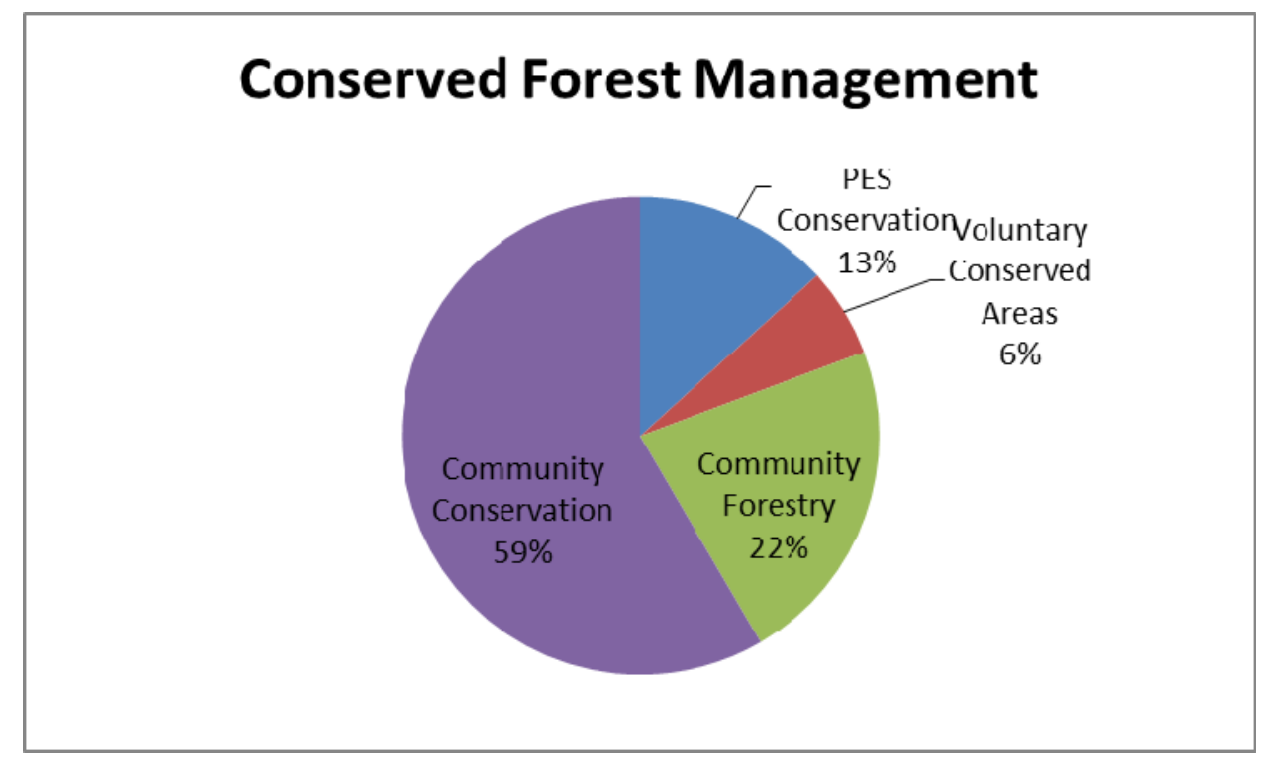

Source: Source: Community OTCs, forest management plans, statutes, PES documents, ACV documents and focus group interviews (field notes). 
Figure 3.19 shows a breakdown for conservation between "OTC" and "community conserved areas" only to demonstrate that communities like Ixtlán, Comaltepec and Yetla have all explicitly set aside lands for conservation prior to the writing of their OTC, while the other community conservation is a result of OTCs. Since few communities have explicitly set aside community conserved areas, it is likely that OTC become that much more important for at the very least the quantification of forest conservation. As for community conservation, Comaltepec has set aside 11,730 hectares as community conserved areas, only a small portion of which is now included in the PES area. Yet, all of this I have chosen to classify as informal conservation.

Figure 3.20. Forest Conservation by Community:

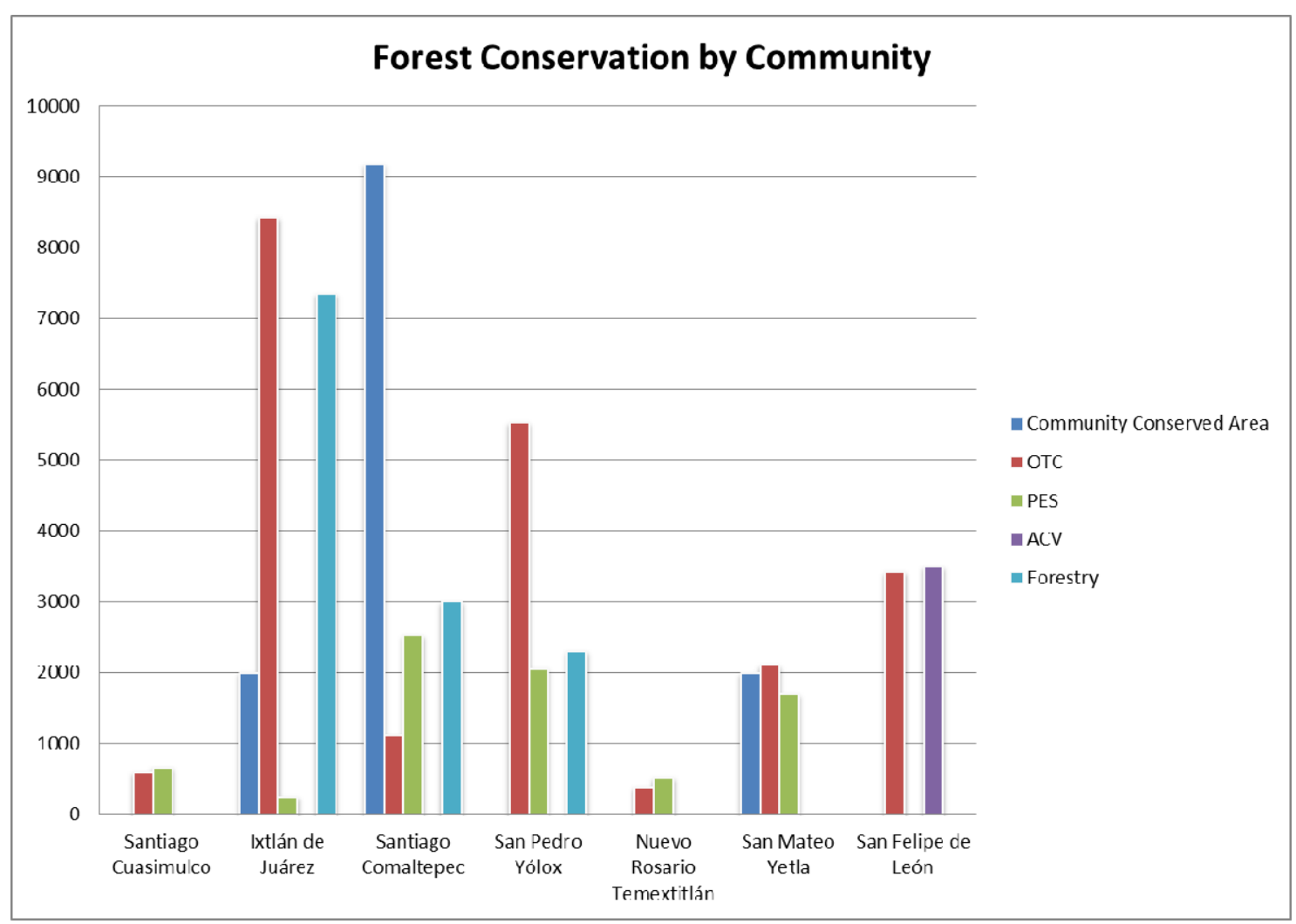

Source: Source: Community OTCs, forest management plans, statutes, PES documents, ACV documents and focus group interviews (field notes). 
Conservation does not remain wholly within the technocratic sphere of the land use zoning in these communities. The quote below comes for a document pertaining to Comaltepec's pine/oak forests and the construction of their new sawmill. It is highly uncharacteristic of all my interviews. Yet, when I read it to community authorities in Comaltepec they agreed with the sentiment that it expressed. If anything, like the community of Ixtlan, Comaltepec may be realizing a conservation discourse with an element of pathos may resonate with conservation organization and governments:

"The community of Santiago Comaltepec has had a cultural association with nature, due to the fact that their ancestors were there in their place of origin where they found refuge in the mountains, where today the community of Santiago Comaltepec is located. Here is where they learned to live in harmony with nature, because they depended on nature for finding their food and sustenance for their families. They care for water, the air, the sunlight, the plants, the animals and all that exists in their surroundings..."

(PROCYMAF, 2005; Direcion Tecnica, 2003).

On the basis of such ideas, rightsholders in Comaltepec have explored essential questions such as: "Why are we going to conserve?" and "For whom are we conserving", which produced much debate as well as decisions on how to manage lands to give a less than universally appreciated species like the jaguar the habitat and protection it needs. Rightsholders slowly realized the importance given globally to their TMCF from visiting scientists and government officials, which provided further rational for continued conservation. Having had considerable interaction with governments, NGOs and researchers, by the mid-1990s Comaltepec had already begun thinking about its TMCF. While one authority in La Esperanza argued that conservation is not new in Comaltepec, they have recently had a lot of attention focused on their conservation.

Of their forested areas, Figure 3.20 shows that Comaltepec has designated 503 hectares for watershed protection, 2754 hectares for wildlife protection and 8,446 as a protected forest 
reserve. Therefore, they have specifically protected 11,730 hectares of forest at the community level (UZACHI, 1994). This management plan then has not only considered how to manage pine/oak forests but all forests types within Comaltepec, and also focused on TMCF. Here as in Yolox and Ixtlán, logging management plans and CFE have produced positive spillover effects for forest conservation. As communities increasing began to manage their pine/oak forests for economic returns, they began to look elsewhere and begin to conserve other forest types also. Jobs provided by CFEs also provide off-farm employment, lowering deforestation pressures.

Figure 3.21. Conservation in Comaltepec

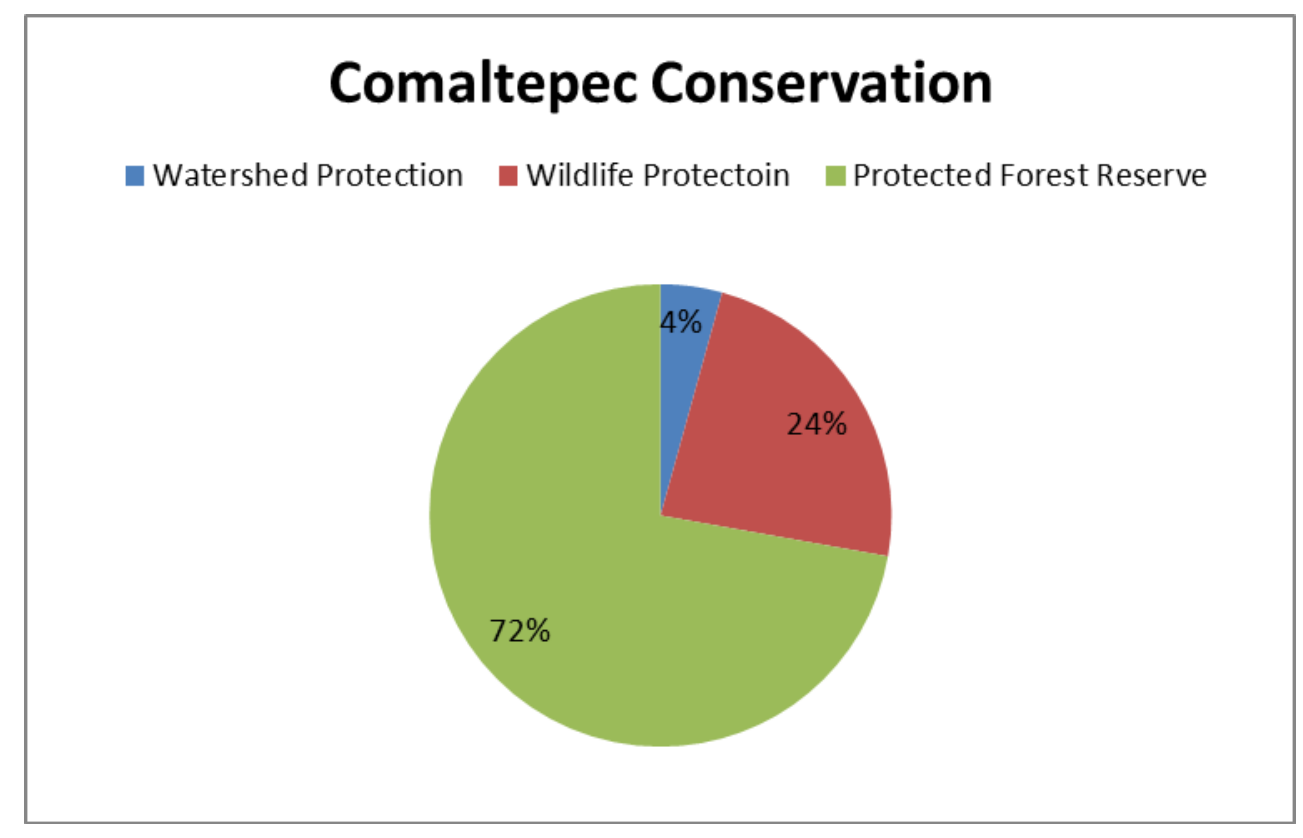

Source: UZACHI, 1994.

Ixtlán has also conserved areas in addition to those found its community forest managed for timber. Rightsholders in Ixtlán set aside 1192 hectares for watershed protection by an assembly vote in 1993 as the community wanted to insure its supply of both quality and quantity of water (Servicios Tecnicos, 2010). Yet, despite the area's community conserved status, it is not free of invasive species like muérdago verdadero (Psittancantus sp.) mistletoe, which is a can 
lead to further outbreaks of infestations from the descortezador (Dendroctonus adjuotus).

Psittancantus arrived as early as the 1960's in forests in Ixtlán and took over nearly 1000 hectares of this area. As birds deposit its seed, it is difficult to detain. It grows in treetops and since the area is specifically designed to protect and provide hydrological resources, plans do not include using herbicides in order to eradicate this invasive species.

Like many invasive species globally, the removal of Psittancantus from Ixtlán's forests is nearly impossible and could be considered that it is in the process of naturalization in temperate forests. Nonetheless the fight against this invader began in 2004 and community reports claim that Ixtlán is a national leader in the control of such semi-parasitic plants (Serivicios Tecnicos, 2010). Ixtlán also proudly notes that their TMCF has not faced major changes in the last 20 years (Servicios Tecnicos Alta Valor de Conservacion, 2010).

Again, Berget (2012) has shown that communities exercise local knowledge in the control of invasive species, but because in some cases of the availability of additional agricultural land, invasive species eradication is often too time consuming for rightsholders to undertake. Nonetheless, the existence and resulting management of invasive species in the subregion shows that community conservation does not exist under some ideal circumstances, but instead faces conditions similar to that of public protected areas such as the persistence of invasive species and the difficult choices managers need to make in attempting to control them.

Ixtlán also has the largest single block of conserved forests in the subregion. Conservation has occurred here largely as a result of jobs first with the logging concessionaire FAPATUX and secondly with the rise of Ixtlán's community forestry enterprise. This has left 6,000 hectares of forest at its elongated northern end. What is utterly unique about this section is that Ixtlán now speaks in wilderness terminology about an area that only 20 years ago was worked and lived in by rightsholders: 
"We're talking about lands little explored; fit for the development of wildlife in their natural state... at the margin of human perturbations, this area is in a condition that is completely wild... lacking the presence of the human factor." (Servicios Tecnicos, 2010)

Scholars have long argued that a wilderness discourse is not native to Mexico (GomezPompa, 1992; Simonian, 1995; Waklid, 2011). For better or for worse, as Ixtlán continues to produce what is the most intricate conservation discourse of any community in the subregion, they have learned to appropriate concepts not endogenous to local knowledge and ones that are attractive to many conservationists (Cronon, 1996). Such has been the case of denying that they practiced milpa in areas now considered important for conservation (Mathews, 2011). While this seems duplicitous, and other scholars have criticized indigenous groups for re-appropriating their history in order to place it in contemporary conservation discourses (Krech III, 2000), peasants in other parts of the world can gain land tenure for successfully appropriating a conservation discourse (Li, 2007). The modification of history to appear to be more conservationists by communities also is not more duplicitous than general environmental policy which promotes conservation on one hand, while also offering generally larger perverse incentives for activities which in some cases may be largely antithetical to conservation (Arizpe et al., 1996; Balmford et al., 2004; Ellis et al., 2008). Communities in the region do not need a conservationist discourse to protect their land, since they have clear land tenure. Instead, a conservationist discourse is a way of attracting funding and support from the government (Mathews, 2011). While communities do believe that forest conservation benefits them even within economic incentives, their discourse on conservation largely revolves around the potential to access additional support.

While in no way offering a "wilderness" discourse, San Mateo Yetla has moved in the last 20 years towards a much more active, institutionalized and conscious form of for the community's conservation of its forest. Forest conservation first came in form of the setting of community rules against the cutting of oak trees because of benefits perceived by the community 
of maintaining hydrological cycles, purity of springs, the provision of oxygen and habitat for wildlife. Currently the community has 1529 hectares of oak forests (ECOPRODES, 2005), whereby all land use and cover changes are denied and penalized by sanctions if altered.

The only access community members may have to these forests is for fuel wood collection for household use of dead and downed timber. Much of the community conserved oak forest is distant from road access, lacks any other species with great commercial timber value, rests on steep slopes with poor soil for agricultural production and heavy winds would fell enough trees to amply supply the community with fuel wood. Still, community members assert a more active approach than mere conservation passive conservation by default because of environmental, infrastructural and economic limitations. They stress that this has been a conscious choice with a long precedence, but only in the last two decades have banned through community assemblies the felling of living oak trees. In no interview did anyone believe that with the doubling of rightsholders since 1975 has there been increased pressure to lessen restriction of cutting oaks trees due to the fact that participants stated that each rightsholder had more than sufficient access to productive land and often more in unworked fallows in reserve if they were in need of more land at the present time. While dissent to conservation exists in Yetla, no rightsholders expressed disapproval of their community conservation largely because of its marginal value as agricultural land.

\section{Payments for Environmental Services and Voluntary Conserved Areas}

Since the inception of the program, CONAFORs PES program has greatly increased interest in conservation. Again, after decades of arguing that forests produced water and oxygen (Simonian, 1995; Mathews, 2011; Wakild, 2011), payments for such services appear nationwide in 2003. As a result of the PES program CONAFOR has created uniform criteria as described in the literature review section with the intent of conserving biodiversity as well as the provision of hydrological services, two distinct programs. Yetla is the only community to receive PES for 
biodiversity, though the requirements are the same for the other five communities receiving hydrological services. San Felipe de Leon currently does not receive PES. Their five-year contract ended and CONAFOR decided not to renew it.

Table 3.3 will reiterate the differences in forested areas in these communities as well as the role PES play in the conservation of forests. As previously discussed, Comaltepec, Ixtlán, and Yetla had previously set aside lands for forest conservation at the community level. In the next section, I will discuss San Felipe de Leon and their Voluntary Conserved Area. While a conservation discourse and practices arrived in Yolox prior to the PES program through their CFE, I suggest that it is the PES program that began a conservation discourse in Cuasimulco and Nuevo Rosario. Not only is the program responsible for this emerging conservation discourse, PESs cover $52 \%$ of forests in Cuasimulco and $59 \%$ of forests in Nuevo Rosario.

Table 3.3. PES as a Percentage of Forest Cover

\begin{tabular}{lcccc}
\hline & Forest Ha. & $\begin{array}{c}\text { \% Forested } \\
\text { of Territory }\end{array}$ & PES ha. & $\begin{array}{l}\text { PES as \% } \\
\text { of Forest }\end{array}$ \\
\hline Ixtlán & 18,280 & 95 & 250 & 1 \\
Comaltepec & 15,852 & 86 & 2525 & 16 \\
Yolox & 9577 & 90 & 2060 & 22 \\
Yetla & 6,925 & 78 & 1700 & 29 \\
Cuasimulco & 1,254 & 83 & 628 & 52 \\
NRT & 908 & 79 & 525 & 58 \\
Total/Average & 52,796 & 85 & 7688 & 15 \\
\hline
\end{tabular}

Source: Source: Community OTCs, forest management plans, statutes, PES documents, ACV documents and focus group interviews (field notes).

Again, a requirement of Mexico's PES is that those communities receiving payments exist in a watershed with at least five thousand inhabitants to ensure that forest conservation and the provision of hydrological services are beneficial to residents outside the community (AlixGarcia et al., 2005). Figure 3.21 shows the Valle Nacional River in the Papaloapan Basin that 
provides hydrological services to important cities in both the state of Oaxaca as well as the state of Veracruz as well as to industry.

Figure 3.22. Papaloapan Watershed

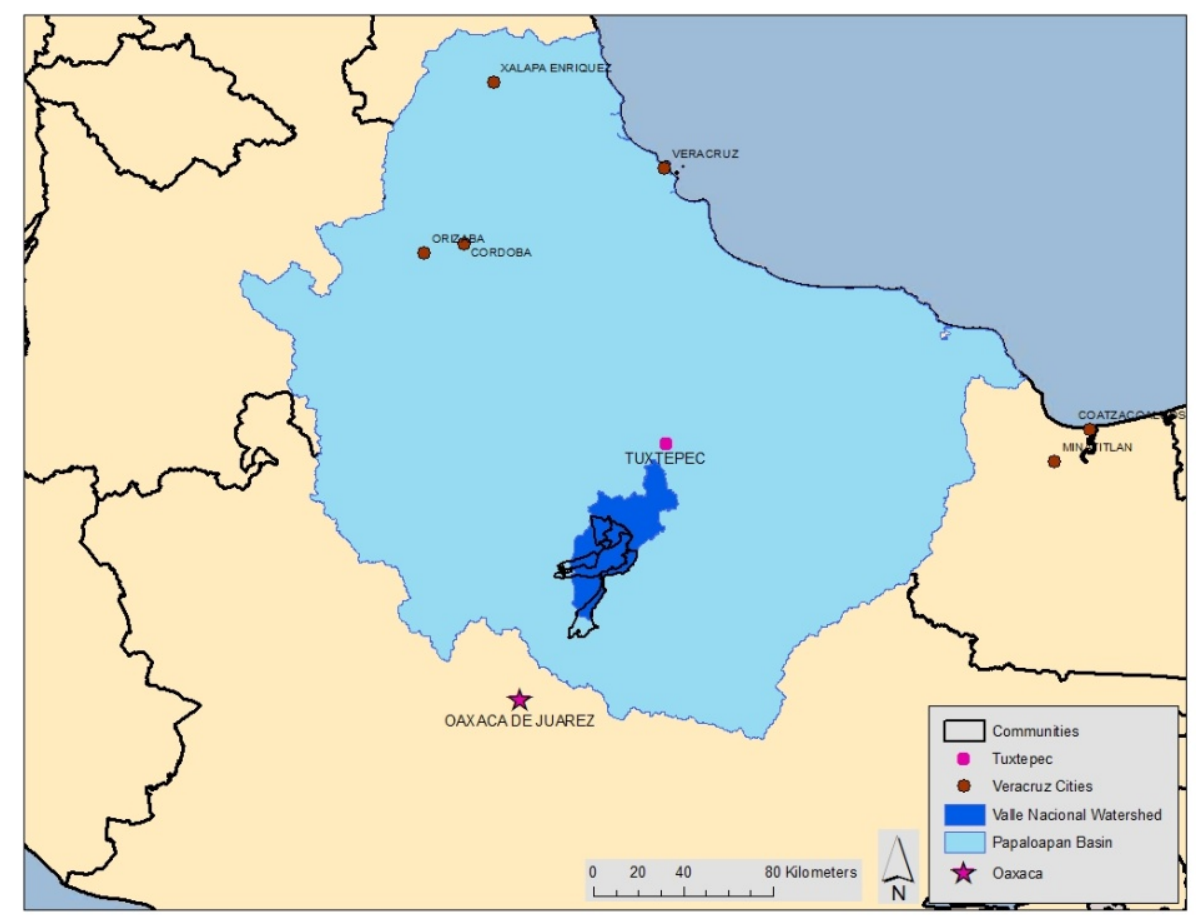

Source: http://www.conabio.gob.mx/informacion/gis/

While Nieratka (2011) has demonstrated the distribution of PES has helped to alleviate poverty in two of the CORENCHI communities, benefits have largely accrued in the subregion to communities and not to individuals through per rightsholder distribution of PES earnings. Yetla is the only community that after expenditures in order to meet program requirements divides the remaining money between rightsholders who have attended activities related to the PES program and distributes the remaining funds. In all communities paid work days throughout the year for projects related the PES area provide a sporadic source of cash for rightsholders. Therefore, PES payments at retained at the community level allow for additional investment in community 
infrastructure. Communities like Yetla that distribute payments to participating rightsholders focus more on individual benefits, while in all cases rightsholders receive daily wages for projects related to PES conservation.

Projects which provide paid employment for rightsholders have varied across communities. For example, rightsholders in Santiago Comaltepec patrol the long stretch of the Oaxaca Tuxtepec Highway running through their territory while collecting litter in order to receive payments. Rightsholders in Nuevo Rosario have cut extensive fire breaks to ensure that fires don't jump from milpa into conserved forests. Cuasimulco has undertaken land use planning at the community level and delimited areas for future agricultural expansion, ecotourism and forest conservation in their OTC. Yetla has used funds to place camera traps in the forest for jaguar monitoring and Yolox has used money for monitoring of forests above its seasonal ranches which have rapidly lost permanent inhabitants in the last few decades.

With the PES funds rightsholders in Cuasimulco decided to purchase a communally owned pickup truck to attend meetings in regional towns. Yolox has built a three story guesthouse with the PES money. Comaltepec is building a cabin near the agencia of La Esperanza with PES funds and has plans for a restaurant near the river in Soyolapam. Ixtlán uniquely spends its entire funds on monitoring and maintenance of its PES area.

The following Figure 3.22 will show that the PES program has focused largely on TMCF. These are in general distant areas from settlements, while communities also receive higher payments for these tropical montane cloud forests and so they are the clear choice for communities entering the PES program. 
Figure 3.23. PES Payments by Forest Type

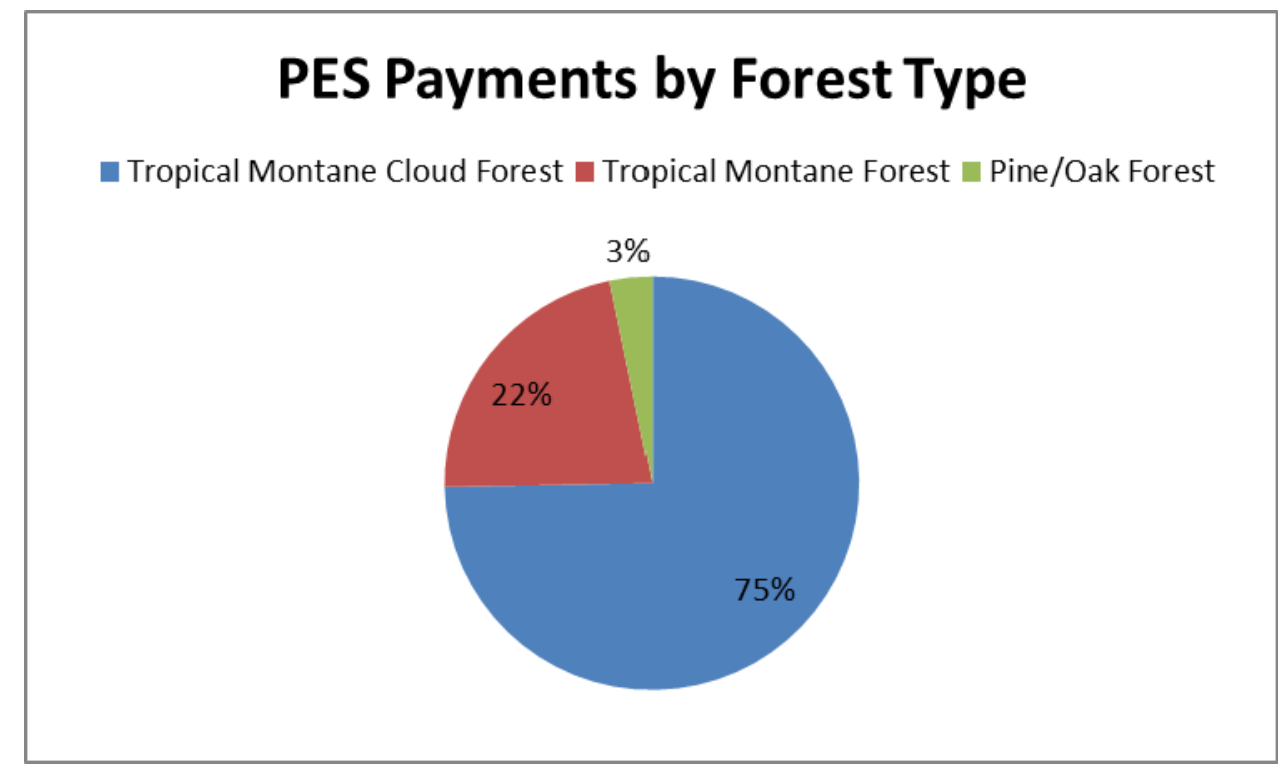

Source: Source: Community OTCs, forest management plans, statutes, PES documents, VCA documents and focus group interviews (field notes).

While the neighboring CORENCHI communities have the largest block of VCAs in Mexico (Bray et al., 2012; Duran et al., 2012), these seven communities in my subregion have not shown nearly the same interest. In the case of CORENCHI, NGOs have largely promoted the certifying of Voluntary Conserved Areas (Bray et al., 2012). While one of the same NGOs that works with CORENCHI works both in Yolox and Yetla, these communities have decided not to certify a Voluntary Conserved Area. In fact, only a few community authorities throughout the region were even aware of the existence of the program. Most confused it with the PES program.

In addition to the 7,688 hectares conserved by PES through the subregion by all seven communities, San Felipe de Leon has conserved another 3,500 hectares as a Voluntary Conserved Area. Though not direct yearly payments like the PES program, San Felipe de Leon did receive support for their certification for the 3500 hectares. CONANP discussed with community authorities what assistance they needed. Rightsholders decided they would like a processing plant 
for achiote (annatto) (Bixa orellana) and tepejilote (Chamaedorea tepejilote), which are products grown in the community. Though they say it produces limited income, rightsholders were overall content with this small processing plant.

The VCA previously was passively conserved as it is a half day walk from the village of San Felipe de Leon. Rightsholders said that because of its distance, no one in memory has ever worked this area. It is in effect what could be considered an old-growth example of TMCF.

Rightsholders did not proceed directly to certifying their voluntary conserved area with CONANP. Instead, the certification of their VCA was one step in a process of territorial management launched in partnership between the community's assembly and their partnering NGO. First they wrote a new communal statute. Instead of having this document remain in the office of the comisariado, they printed and distributed a copy to all rightsholders. First, they applied for and access PES funds for a five year contract starting in 2006. Next, they created their statutes and OTC. Then finally, they certified their VCA for 3500 hectares and 15 years in 2010 with a management plan created by community authorities along with the partner NGO. Their VCA included lands already covered by the PES program. CONANP accepted the management plan as it was presented.

However, when their contract for the PES program ended in 2011, CONAFOR decided not to renew it despite the fact that San Felipe de Leon completed all requirements. There is no stipulation that CONAFOR needs to do so even if a community has met the requirements. Contracts last for five years without any expectations or assumptions that they will continue. In other cases, CONAFOR did renew contracts both with Yolox and Comaltepec and in both cases enlarged PES areas once during these contractual periods.

\section{Conservation Conflicts}

Within this subregion of high forests cover and overall acceptance PES, there are a vocal minority of dissenters to conservation practices in three main cases of the community of San 
Felipe de Leon, in the agencia La Nueva Esperanza in the community of Yetla and the agencia of Soyolapam in community of Comaltepec. What is notable is that many of those who contest both informal conservation and formal conservation. Many of the dissenters reside in the agencias, or outlying villages within a single community. Overall, they feel that the monetary benefits arriving in the community largely remain in the main village, even if the conservation areas are located closer to outlying villages. Furthermore, often funds from conservation are a fraction of what rightsholders would earn working the land. Communities often created these agencias to increase agricultural production and expand production through their territory. Some rightsholders in agencias maintain that they live their still to increase agricultural production.

The most marked example of a growing weariness to conservation initiatives with the Mexican government is occurring in the agencia of San Antonio Otate and throughout the community of San Felipe de Leon. Again, though San Felipe de Leon crafted both their community statutes and OTC and later certified their VCA primarily to receive renewal of their contract in the PES program, CONAFOR did not renew their contract. Therefore, the community had engaged in substantial collective action and contracted their partnering NGO to try to gain five additional years of payments. CONAFOR did not fail to renew their contract for any reason of non-compliance. The loss of the PES contract led to a lack of payments for 1500 hectares of tropical montane cloud forest and 938 hectares of tropical montane forests. With the end of payments the community lost MXN\$1,097,204 (USD\$ 158,933 annually) or MXN\$ 6986 (USD\$ 582) per rightsholder.

For a community with no community forestry and therefore no forest revenue earned for rightsholders, this is substantial loss of revenue, as investments were 1) in community infrastructure and 2)in paid employment on PES projects, and so in the absence of PES and these paid workdays, households lost this income also. The only benefit of conservation in San Felipe 
currently is the continued use of the processing plant for non-timber forest products that they received in exchanged for certifying 3500 hectares as a VCA.

While they still work with the original NGO, a second group of NGOs has been communicating with rightsholders in San Felipe de Leon and especially in San Antonio Otate. This second group of NGOs has distributed a pamphlet called La Trampa de Pagos de Servicios Ambientales y Áreas Naturales Protegidas (The Trickery of Payments for Environmental Services and Natural Protected Areas). This pamphlet argues that both PES and protected areas are means of weakening community control over their lands before outright dispossessing them of their lands. It further argues that while proposed as means of mitigation climate change, PES and protected areas are actually false solutions to climate change and benefit the global north, while hurting indigenous people in the global south. Lastly, the pamphlet, with the seal of a regional peasant organization and a US-based NGO, argues that communities themselves are repositories of vast ecological knowledge and themselves are mitigating climate change with endogenous land management and conservation efforts. They need no help for the government and should remain autonomous from exogenous conservation efforts.

While communal authorities approved and supported this study in the community of San Felipe de Leon, authorities and rightsholders in the agencia San Antonio Otate denied access for this study and after my presentation asked me to leave, which I did. The pamphlet appears to have been powerful in Otate in creating a distrust of those arriving in the community to discuss conservation even though I made it clear I did not offer or come to profess my support for any governmental conservation programs.

In the village of San Felipe de Leon, various rightsholders stated that if the government would not pay them for their conservation through the PES program, they would work the forests current certified as a VCA. All who expressed this opinion also stated that there is no memory of anyone working this area and that there are massive trees that remain there. My guide in the 
community joked that while there were valuable timber trees there, they would need a helicopter to extract them, since this area was remote and not located near any roads. Therefore difficult access had largely conserved the area passively before the community actively and formally certified their VCA, but some rightsholders spoke of a retaliatory clearing of this forest if the government would not renew their contract.

Such activities would void their VCA agreement. In only one other case did a community ask for the revocation of the certification of a VCA in the Oaxacan community of Santiago Lachiguiri. CONANP revoked the certificate without arguments with the community. Rightsholders in Lachiguiri felt the certification had taken important milpa areas out of production. After revoking the certificate they once again cultivated these lands (Schmidt, 2010; Ibarra et al., 2011).

Such an outcome as in Lachiguiri is not inconceivable in San Felipe, especially if the second group of NGOs begins to influence rightsholders into believing that government-backed conservation is a trick to steal ejidal land.

In a second case of community dissent from conservation, the agencia of La Nueva Esperanza in the community of Yetla has disputed that the 1,700 hectares of PES for biodiversity provide benefits equal to what working this land would bring. La Nueva Esperanza is surrounded by steep hillsides the community has cultivated in coffee. Therefore, they need to climb higher up to reach milpa areas. Rightsholders in the village of San Mateo Yetla agree that rightsholders in La Nueva Esperanza do indeed not have the ease of access to agricultural lands near their village to the degree that rightsholders in Yetla do. Therefore, all acknowledge that the opportunity costs of conservation are far greater in La Nueva Esperanza than they are near San Mateo Yetla. Nonetheless, the majority of rightsholders in the community of Yetla voted to accept PES. Furthermore, they are the only community which directly distributed part of these payments to all 
rightsholders who have attended assemblies and participated in tequios. Rightsholders can receive MXN\$ 1200 (USD\$ 100).

Therefore, for those who live in San Mateo Yetla feel they have adequate lands in close proximity to their village, these 1200 pesos help meet household expenses without incurring high opportunity costs. In La Nueva Esperanza, they note that it would only take the sale of 48 kilos of coffee to earn them 1200 pesos. They argue that by not accepting payments all together, or reducing the area under conservation, they could farm this land and make more money farming it than conserving it. What further compounds this issue of access to land is that some rightsholders had coffee farms in the PES that were grandfathered in and not banned in the PES, but which these rightsholders decided to abandon. Many of these farms are currently abandoned, but again since they are held by rightsholders in usufruct, they can retain these plots without working them under the rational that someday they might choose to work these plots. Rightsholders who have abandoned their coffee farms can sell land to other rightsholders within the same community, but this has not happened with any regularity, likely as a consequence of the persistently low coffee prices.

Rightsholders in La Nueva Esperanza have a far different vision of biodiversity or more likely an appropriation of the term that does not as the conservation of flora and fauna for its own sake, but instead one that generates monetary benefits through working their lands by planting valuable tree species. One community leader stated that he wanted to remove trees that did not have economic value and replace them with species that did. While his description was more of a tree plantation than a biodiverse forest, yet when describing this tree plantation he argued for the economic value of biodiversity for rightsholders. As discussed in Chapter 2, the global biodiversity discourse describes one version of biodiversity, while communities may have different visions of biodiversity. Likely they heard biodiversity described as a positive attribute of forests, though they see forests more positively when they are generating wealth. 
In the third case of dissent from conservation, rightsholders in the agencia of San Martin Soyolapam in the community of Comaltepec expressed that they are conserving forests largely because of poverty; if they had sufficient access to capital and technology, then they would strip the hillsides bare of trees in order to increase cattle pastures. Such clearing would provide them the economic benefits the village needed. Their neighbor across the Soyolapam River, Santiago Progreso, has largely completed this narrative and cleared the substantial tracts of flat land in its territory for cattle pastures.

As other studies have noted, Soyolapam is the only area in Comaltepec experiencing ongoing deforestation (Robson, 2011). Part of the reason for the continued forest cover is that the community assembly of Comaltepec has created conservation areas above the village of Soyolapam, which prevents rightsholders with lands near Soyolapam from clearing land on hillsides that would otherwise be at suitable altitudes for coffee. This conservation received no payments or certification, nor is it even recognized by the government. Therefore, the community as a whole, in a democratic decision in their community assembly decided to create a conservation area that some rightsholders feel is impinging on the management of the lands surrounding their village. This informal conservation receives no payments or recognition from the government.

Again, all forests in the subregion are held as common property, while individual rightsholders hold usufruct over their plots. Therefore, the land around Soyolapam, though more easily accessed by rightsholders who live in Soyolapam still is communal land accessible to all rightsholders. The community then votes in their assembly regarding the zoning of this land. A majority of rightsholders support this conservation, including some rightsholders in Soyolapam and so despite the contestation such measures receive from some rightsholders in Soyolapam, the community designated these forests for conservation. While not all pleased with this zoning, rightsholders in Soyolapam have respected the conservation designation and not worked this area. 
While generally supportive of conservation throughout the subregion, in specific cases rightsholders have expressed dissent against VCA, PES and community conservation. Thus far, rightsholders have only discussed the benefits of overturning conservation practices in order to cultivate this land. Also, while I have highlighted these three cases of dissention regarding conservation, no community is united to conservation. Likewise, even in San Felipe, rightsholders have not yet actually gone to the VCA and felled trees. Many rightsholders expressed support for conservation, but hold reservations that the government ceased payments. A trend worth noting will be if the other communities in these studies will continue to receive PES or what their reaction will be if CONAFOR does not renew their contract and takes away the economic incentive for conservation. Communities may be far more supportive of conservation practice as they are receiving remuneration for ongoing conservation, but may change their opinions in the absence of payments.

In sum, community governance along with a patch-matrix landscape had conserved $88.34 \%$ of forests in the subregion, with forest cover ranging within individual communities from $78 \%$ to $95 \%$. Community forestry enterprises, PES and VCA account for $41 \%$ of conservation and resulting forest cover, while community level conservation accounts for $59 \%$ of conservation and forest cover. Ixtlán, Comaltepec and Yetla have all set aside community conserved areas, San Felipe de Leon certified an ACV, while Yolox, Nuevo Rosario and Cuasimulco all receive payments PES, which accounts for their conservation outside of OTCs. Despite noteworthy forest conservation, not all rightsholders, villages and communities hold universal support for conservation. Rightsholders in San Felipe have questioned their VCA; rightsholders in the village of La Nueva Esperanza in the community of Yetla have questioned their receiving PES funds, while rightsholders in the village of Soyolapam in the community Comaltepec have questioned community conservation. While conservation continues and general support remains in the subregion for conservation, these examples demonstrate an incipient backlash to conservation. 
In chapter 4, I will I examine the implications of the increasingly active conservation I have described in Chapter 3, with the studies from Chapter 2, which repeatedly argued that this region is important for global biodiversity conservation. I will also re-examine my classification of passive conservation to show some of the underlying factors which have led to passive conservation. My contention is that academic, NGO and government interest in forest conservation has far eclipsed support to communities for their past and ongoing conservation. As I have shown that conservation has become increasingly active, communities have taken time from their fields to gain land titles, enter PROCEDE, craft OTCs, attend assemblies and create community statutes, all of these activity have not received remuneration that has done much to alleviation poverty and provide additional opportunities in the subregion. 


\section{CHAPTER 4}

\section{Discussion: A Critical Analysis of the Implications of Passive and Active}

\section{Conservation}

In this chapter I will examine potential ways of thinking about compensation for communities who are conserving forests that systematic conservation plans and biodiversity assessments have repeatedly singled out as having global importance (Arriaga et al., 2000; Cantu et al., 2004; Brandon et al. 2005; Illoldi-Rangel et al., 2008; CONABIO, 2010; Ponce-Reyes et al., 2012; Rojas-Soto et al., 2012).

I will explore the analytic framework I have proposed of a transition from passive conservation to more active and conscious conservation. There are underlying elements of public policy and political economy that have helped to lead to passive conservation, which have not necessarily benefited livelihoods in the subregion. After examining underlying causes of passive conservation, I will move to analyze active forms of conservation in the subregion, with greater focus on the PES program and later on how the seal of sustainability including in the VCA's policy could make use of its seal of sustainability to make the program more attractive for communities.

Much of the focus of the chapter will center on an analysis of PES and their ability to provide benefits for the subregion. By not merely assuming that current compensation for conservation is sufficient or unchangeable, I will suggest that payments levels are not based on any clear rationale. Instead, political will to support the program and the past role of social movements as well as their potential future role could help increase payments so that they could become something that makes a greater positive impact in these marginalized communities. Therefore, the Mexican government as well as international governments can decide if a greater economic valuation will back up studies that argue the subregion has forests of global importance for biodiversity conservation and carbon storage. Another means of supporting communities in 
addition to PESs would be to provide support for the shade tree and often uncertified organic coffee grown in the region. The seal of sustainability provision of the VCA policy could provide the framework for further compensation to communities would benefit communities and likely greatly increase attention in certifying VCA if certification provided more financial benefits.

After examining PESs and what could be a new round of environmental coffee supports, I will review underlying assumptions of recent forest cover studies (Gomez-Mendoza et al. (2006) and SCP exercises (Ponce-Reyes et al. (2012), which argue that communities are either currently deforesting or likely in the future to deforest. Such assumptions deny well-documented cases of conservation in the region (Bray, 1991; Gordon, 2006; Figel, 2008; Bray, 2009;

CONABIO, 2010; Nieratka, 2011; Hite, 2011; Robson, 2011, Toledo-Aceves et al., 2011; Berget, 2012; Bray et al., 2012; Duran et al., 2012).

I will analyze how such SCP exercises are at best of debatable efficacy in a region of common property regimes and robust community forest governance. At worst these SCP exercises are playing into the arguments of the anti-outside conservation NGO working in San Felipe de Leon that is claiming that conservation is merely a trick to vastly limit territorial sovereignty or outright steal indigenous lands.

If SCP exercises do not take into account of land tenure or any ongoing conservation strategies, they appear to negate the fact that communities can conserve their forests and there is no need for the creation of public protected area. By portraying either ongoing or impending forest degradation on community lands they uncritically repeat arguments of the "tragedy of the commons" (Hardin, 1968) that lack validity in the region. While protected area policy has backed democratic decisions taken by communities regarding their desire to have a protected area on their lands (LGEEPA, 1988), governments do not consult communities in many cases in other parts of the world (Dowie, 2009). Instead of trying to implement a protected area in the subregion, conservationists have a chance to change an often fractious relationship with 
communities (Chapin, 2004) and move towards increasingly valuing local knowledge and governance (Escobar, 2008).

While a vocal minority of rightsholders in the subregion expresses dissent to forest conservation, the majority of rightsholders support conservation practices. Yet, migration in all communities save Ixtlán has proven for the last 20 years to be a more reliable source of income than either funds from conservation or the production of agriculture commodities and timber. In a region where communities have clear land tenure and have become environmental subjects (Agrawal, 2005), governments and NGOs have the chance to work to better compensate communities for their conservation and give them additional opportunities other than migration. PES and other financial support tied to conservation practices in these communities could help to mitigate entrenched economic marginalization and potentially provide alternatives to migration for rightsholders. The challenge for those working in conservation in the subregion is not to increase conservation as communities already conserve $88.34 \%$ of the total territory as forests, but rather how to continue high forest cover and active conservation while increasing economic benefits for communities.

To better make this argument, I will utilize political ecology to examine the simultaneous preponderance of high levels of forest cover and economic marginalization that exists in the subregion. Political ecology has focused on a wide variety of issues including: the limiting of access and displacement from protected areas and forest reserves (Neumann, 1998; Haenn, 2005; Odgen, 2010), environmentalism and racism (Kosek, 2007), the politics behind the social construction of nature (Braun, 2002), the role of local social movements in challenging global conservation discourses (Escobar, 2008), the production of State knowledge (Mathews, 2011), identity formation related to conservation practices (Agrawal, 2005) and differing versions of local knowledge and Western scientific thought (Tsing, 2008). Despite this diversity of analysis, all cases save Mathews (2011), who studied Ixtlán, focus only on areas where local people are 
either being displaced, having their access to resources severely curbed or are subject to the massive degradation of their lands by outsiders.

As I have shown in this thesis, rightsholders in the subregion maintain clear land tenure; have excluded destructive logging concessions from their forests and in the case of Yetla repeatedly expelled outsiders from invading their lands. Furthermore, communities maintain high forest cover. Therefore, this subregion is a novel subject for such analysis. Despite the apparent lack of conflicts over access to forests, many younger rightsholders see their future outside the communities because of a lack of economic opportunities. I will share political ecology's emphasis on the political nature of environmental problems and policies. Yet, departing from much political ecology, I make policy suggestions. I argue that conservation programs should increase payments and support to better acknowledge and compensate communities for their past and ongoing conservation.

Martinez-Alier (2002) argues for "the environmentalism of the poor as an environmentalism of livelihood" in connecting the global struggle of poor people in cities and distant forests to retain access to resources and to not disproportionately face the negative consequences of environmental degradation. Wakild (2011) in her masterful examination of protected area and conservation policy in Mexico since the 1930s has questioned the supposed division between white, urban and middle class environmentalists who advocate for protected areas in lands distant from where they live and non-white, urban poor people who practice environmental justice to protect the neighborhoods or cities where they live. Her contention is that such a division is not helpful. Environmentalism should not have a free pass on concerns of social justice, while environmental justice should keep environmental protection as a central aim as well as human health and livelihoods. Many of those who practice environmental justice have steered away from the label of environmentalists because of its connotations with white and upper class people largely concerned with wilderness protection and endangered species and less so on 
human livelihoods (Di Chiro, 1995). Many wilderness supporters began to push back from a more inclusive environmental vision of nature conservation that they felt placed too much emphasis on human livelihoods and poverty alleviation and not enough on strict conservation (Wilshusen et al., 2002). Much of the same division exists in ecological economics between those who argue primarily for economic efficiency in conservation the most land for the lowest cost and those who emphasize the social implication of PES programs (Wunder, 2005; Kosoy and Corbera, 2010; Muradain et al., 2010; Vatn, 2010).

My argument is that a kind of environmental justice directed by political ecology is applicable to the subregion. While it is rural place without massive resource degradation, communities remain poor even after decades of conservation of globally important forests. As forests continue to receive economic valuation, mechanisms exist through Mexico's PES program to compensate communities. While they do receive compensation, I argue that it is not commiserate with importance of their forests. Also, thus far the PESs in the subregion have produced little in the way of poverty alleviation. They continue to produce ESs, but they have yet to produce considerable material benefits for rightsholders. If conservationists cannot direct more funds to these poor communities who are conserving their forests, then conservationists really need to reconsider their role in working with communities.

Conservation programs too should begin to better improve livelihoods in the subregion. Rightsholders have increasingly become environmental subjects in the managing of their forests specifically for conservation. Rightsholders already firmly believe that forest conservation provides them with clean air and clear water. Now they need assistance in increasing sustainable development at the community level, which could augment existing agricultural practices with payments for their past and ongoing conservation. Rightsholders repeatedly asked for any assistance if I could provide in helping them to achieve economic development for their community. In many other cases they sighed and said, "Here we are poor.” Many older 
rightsholders said communities need help with creating jobs and opportunities so young people do not have to leave their communities in search of work. They want their land to provide for their livelihoods either through an existing cash crop or from the introduction of a new cash crop. Public policy should attempt to provide economic opportunities while maintaining high forest cover. While PES likely cannot solve these issues alone, communities, increased payments would provide more funds for community projects.

\section{Underlying Factors Leading to Passive Conservation}

Throughout this section I will show how factors that have led to passive conservation are not only often factors which also lead to economic marginalization, but also that they are often inter-connected. Figure 4.1 will demonstrate some of the connections between the various drivers passive conservation.

\section{Figure 4.1. Factors Driving Passive Conservation}

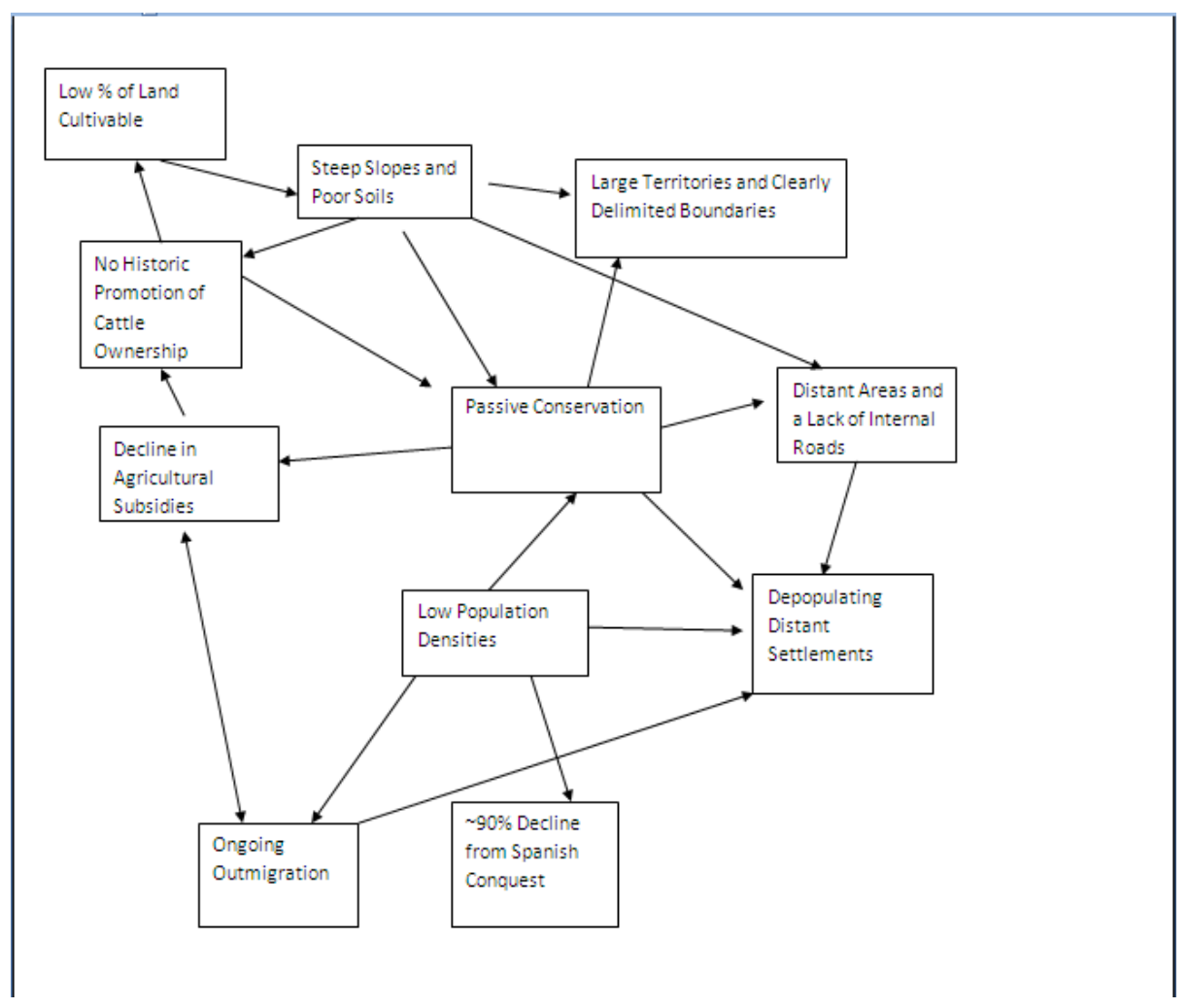


Source: Chance, 1989; Barabas and Bartolome, 1999; Clarke, 2000; OTCs, focus groups and field notes.

While when applied specifically to forest conservation itself, the word passive accurately describes processes that have conserved forests largely because of remoteness, difficulty of access and low opportunity costs as has also occurred in national protected areas around the world (Deinenger and Minton, 1999; Joppa et al., 2008). Yet, the underlying processes that created the conditions which can lead to passive conservation are not exactly passive and definitely not apolitical or predetermined. Furthermore, factors that are drivers of deforestation may very well also lead to poverty for communities dependent on agricultural production. Factors that drive deforestation such as decreased slopes, rising prices of agricultural commodities, greater access to roads and markets (Angelsen and Kaimowitz, 1999), governmental subsidies, increased agricultural infrastructure (Deinenger and Minton, 2002)and high corn prices compared to low fertilizer prices (Barbier and Burgess, 1996) are absent in the subregion and are normally associated with rich and productive agricultural lands. Instead, a driver of deforestation common to the subregion is the lack of off-farm employment (Deinenger and Minton, 2002). Communities lack the drivers of deforestation which would likely lead to a stronger agricultural economy, but have the driver which leads to a lack of economic options.

To begin with, the Mexican agrarian reform was a negotiated process whereby certain presidential administrations were more dedicated to its ideals far greater than others (Beezley, 2009). Particularly the Cardenas regime in the 1930s granted more productive land to ejidos for commercial agriculture in some cases. In many other cases, agrarian reform intended to pacify rural radical social movements and provide subsistence agriculture during the season when rightsholders would not be busy working as agricultural day laborers on commercial farms (Bartra, 1985). The Mexican writer Carlos Fuentes in his novel The Death of Artemio Cruz describes the rationale which led to the redistribution of land largely to stave off a more 
comprehensive seizure and redistribution of more commercially valuable land from wealthy landowners (Fuentes, 1962; 1991):

"It's impossible to escape the course of events. Let's turn over those plots to the peasants; after all, they're only good for dry farming, so no one's going to get much out of them. Let's give out those plots so they can only be used for smallscale farming. You'll see that, to thank us they'll leave their women to work that dust and come back to take care of our good land. Think about it: you could turn out to be a hero of the agrarian reform program, and it won't cost you a thing."

Therefore in some cases agrarian reform would do little to upset the status quo of large commercial landowners, while quelling continued rebellion from historically marginalized sections of society. The Sierra Norte experienced agrarian reform differently than described by Fuentes and other regions in Mexico in that in the subregion the government largely recognized land claims that stretched at least back to the colonial era in some cases. Communities such as Ixtlán, Comaltepec, Yolox and Yetla all appear on maps from the colonial era and possessed documentation from the period of Spanish colonization reinforcing their territorial claims. Nuevo Rosario and Cuasimulco officially gained land in the more recent period in the two thousands as a result of tropical forest colonization in the 1960s. San Felipe colonized their land prior to agrarian reform but after the colonial period. The founding documents for many of the communities in the subregion state that only $10-30 \%$ of the lands are suitable for agriculture.

In fact, much of the territory of these communities, though in name agrarian communities, is marginally suitable for any agriculture other than subsistence with smaller areas suitable for coffee and less so for cattle pastures. They have extensive territories that have led to conservation because they had few other viable uses, and only a small percentage of this land can bring economic benefits through agriculture. Policy 
could have hypothetically helped to offset these low percentages of suitable agricultural land with infrastructure that led to the intensification of suitable lands for subsistence and market agriculture. Yet, except in the case of coffee subsidies, broad support for agriculture did not occur.

Historically the Sierra Norte held a reputation for its remoteness and difficulty of access, which spared it from prolonged occupation from both Aztec and Spanish colonizers, though diseases did decimate the regional population (Chance, 1989; Barabas and Bartolome, 1999). While communities did pay tribute to the Aztecs and also to the Spanish, the subregion lacked the large haciendas in the flatter and more commercially productive agricultural lands (Clarke, 2000). The Spanish did not promote cattle ranching in the subregion either (Chance, 1989) nor has the Mexican government since. This comparative lack of attention did not exclude the subregion from the production of commodities for global trade through the colonial and post-colonial period (Mathews, 2011). Yet, despite their argument for a great inclusion in national economic development (McNamara, 2007), Oaxaca and the Sierra Norte in particular earned the reputation as a backward or anachronistic region not worth government attention for economic development (Clarke, 2000; McNamara, 2007). Early on even generally progressive presidents like Cardenas argued that certain regions would be developed and others would not, with the Sierra Norte explicitly falling into the latter category (Mathews, 2011).

Therefore, to some degree for better or for worse the Sierra Norte remained largely outside the most oppressive conditions of continued Spanish occupation and labor on haciendas, but also received little financial assistance or infrastructural development. Many rightsholders argue to this day that the government has abandoned them. While the comparative lack of attention paid to the region has granted communities in the Sierra Norte increased autonomy, rightsholders repeatedly argued during fieldwork that they wanted additional financial assistance for existing crops like coffee or a new crop altogether that would bring increased economic 
benefits to their communities. Yet, difficulties of access to many parts of their territory as well as general distance from markets has limited the production of agricultural commodities in the region despite having secure land tenure over large territories.

The first major effort to bring economic development to Sierra Norte was a road started by the 1950 s began to give access to the commercially viable pine-oak forests. However, that fact that this development was not directed at the communities is exemplified by the fact that the first road that entered the Sierra Norte bypassed villages like San Pedro Yolox and Santiago Comaltepec, which had been in their present location for hundreds of years. The government instead built the Oaxaca-Tuxtepec Highway in the 1950s largely to provide access to the commercially valuable pine and oak forests in the communities of Comaltepec, Ixtlán and Yolox. Paternalistically, the government argued that communities were not capable of logging these forests and so granted them to parastatal concessions (Mathews, 2011). The communities either had to build connecting roads to their communities with rigorous and demanding communitywide unpaid labor days (tequios) or needed to pay with the communities own timber to the parastatal concession so that the concession would build roads to their villages. Also, community members worked as day laborers in their own forests. The concessions deposited payments for harvested timber in an account which was ensnared in bureaucratic process which made the withdrawal of payments difficult (Chapela, 2005; in Bray et al., 2005).

As a result of this singular focus on logging of pine/oak forests, the highway cut through these forests led to subsequent logging roads so that these concessions could high grade timber, and they built additional roads to fell the largest trees. This high grading of timber altered species compositions and massively devalued pine-oak forests in Comaltepec (Chapela, 2005; in Bray et al., 2005). These logging roads constructed by concessions would later be used by communities when they began form their CFEs. In other cases infrastructure left by the concessions helped to launch CFEs (Mathews, 2011). 
Compared to the construction of logging roads, the political will at the governmental level has not existed prior or currently to open up roads into agricultural areas. An important regional coffee growing village like Rancho Grande has recently built their own roads to their coffee farms and milpas, but the communities in this subregion have neither received outside support nor have voted internally to build additional roads near their agricultural areas.

This lack of roads outside of pine-oak forests in non-CFE communities then leaves many distant areas difficult to access even though rightsholders in many communities say that there are productive agricultural lands that remain too distant from roads to work. Furthermore, a high corn or coffee harvest of 2000 kilos would lead to a rightsholder needing to carry their harvest out on their backs 30 kilos at a time. Also as a result of the steep slopes through the subregion, pack animals are not common as rightsholders say they are unable to handle the terrain. Also, rightsholders say that many farmers are less and less willing to work distant areas and live for stints in a shack without electricity or running water. Additional infrastructure has followed roads in these communities. As all of the villages save Santiago Cuasimulco have at least one road and electricity, such conditions as farming distant plots are a significant change from having these amenities in a village. In effect, rightsholders in many communities argue that there are fertile areas that would produce well, but the lack of infrastructure prevents them from working there. In the case of Nuevo Rosario seasonal streams make crossings dangerous just so that rightsholders can arrive at their existing milpas which provide household subsistence.

As previously described, coffee subsidies from INMECAFE are the only policy intervention in the region aimed at increasing commercial agriculture production. In Yetla, rightsholders saw that during the 1970-1990 period of stable prices, price subsidies, marketing and other supports from INMECAFE all the hillsides around the village of Yetla were producing coffee farms. Farmers knew the prices they would receive and could make investments accordingly. Prices allowed paying day laborers and in some cases expand their farms. Unlike 
other areas of Mexico, these subsidies never led to the reduction or elimination of shade or the introduction of high inputs of agrochemicals (Moguel and Toledo, 1999). Barring crop failure, households had a consistent source of income.

Though some have argued a pure supply and demand rationale dictated that price supports needed to end (Dietsch et al., 2004), others have contextualized the event within a time period when Mexico have many structural adjustments from international lenders who used their leverage to drive Mexico to adapt neoliberal policies (Jaffee, 2007; Shapiro, 2010) related to agricultural even though countries like the United States did not deregulate its agricultural sector to the extent it demanded that Mexico and other countries to do (Jung, 2008). Scholars have long acknowledged that deregulation is not some nature state of markets, but something that requires forceful state intervention to create and maintain it (Polyani, 1944). No invisible hand deregulated markets for the benefit of growers and coffee drinkers alike.

When the subsidies ended in 1989, prices dropped from MXN\$ 25 a kilo to MXN\$ 3 per kilo (USD \$2.08 to .12). At these prices, some did not harvest their coffee, which left the coffee crop increasingly susceptible to the invasion of the coffee berry borer (la broca). The infestation combined with steep price declines led many to fully abandon their coffee farms as in the case of Nuevo Rosario. Globally, increased coffee production promoted by the International Monetary Fund in countries like Vietnam further depressed prices, which had effects on global prices and those received by Mexican growers (Eakin et al., 2008). In effect in the subregion growers only receive what they consider to be fair prices at around MXN\$ 60 per kilo (USD\$ 5 per kilo) when there is massive crop failure in Brazil. Unstable coffee prices led to outmigration through the state and region (Lewis, 2005; Hite, 2011; Robson, 2011), which led to a scarcity of day laborers and a tripling of labor prices in the last 20 years. In part because of rising labor costs many have abandoned or semi-abandoned their coffee farms. This had led to declining incomes and has been a contributing factor in outmigration. 
The vast majority of rightsholders cite lack of economic opportunity for the reason that they have migrated. Therefore, unstable coffee prices have led to a lack of household income as coffee income provides all necessary food and other expenses including education, transportation and household items not provided by subsistence agricultural and firewood collection in subsistence plots. A lack of off-farm employment in all communities save Ixtlán exacerbates migration drivers.

Anecdotally, the deregulation of the coffee market led to substantial migration in the subregion beginning in the 1990s. Coffee-related and non-coffee-related emigration hit its peak in the region in the late 1990s in many villages while others had their peaks in the early 2000s. As of the early 2000s and increasing through the decade, many rightsholders have cited that the clampdown on the US border by US migration policy as well as the ongoing narcotics-related violence in northern Mexico has increased the cost and danger for crossing. Some quoted a figure to pay for crossing at 84,000 pesos (USD\$ 7,000), which would be equivalent to 3360 kilos of coffee, which would be two to three harvests for even many of the most dedicated growers. Often family members will pay for their crossing and rightsholders will not have to earn this money working the land, but family members in the US are feeling increasingly less able to pay for family members to migrate.

Therefore, while a lack of economic opportunities in the subregion was migration driver in the early 1990s as a result of coffee commodity deregulation, the cost and danger of crossing in more recent years including at present is currently mitigating what would likely be a more sizable migrant population. Also, because of this depressed economy rightsholders currently living outside the community are having a difficult time sending the remittances their households have come to depend on. Some rightsholders have argued that these declining remittances have led some households to return to their plots or open new areas for agriculture in an attempt to make up for money lost from remittances. For this reasons rightsholders want additional assistance to 
improve the economies of their communities which for twenty years have heavily relied on remittances in the absence of a more supportive agricultural policy.

The point I have briefly argued here is that the factors that have lead to passive conservation are not necessarily themselves passive. Factors like large territories predominantly having steep slopes, poor soils and distant access is not entirely predetermined or apolitical. Factors like a lack of agricultural subsidies, the deregulation of the coffee market and the lack of cattle promotion are far less apolitical. Migration has recently on both sides of the border has become a hotly debate political issue. While I have classified passive conservation as such because communities were not consciously conserving their forests prior to the arrival of the conservation discourse largely based on new opportunities from changes in governmental environmental policy, the underlying drivers of conservation are not nor were not entirely passive.

I will now shift to examine if more active and formal conservation with linkages to governmental programs. I will examine specifically the compensation from the PES program. As I have argued in this thesis, while passive conservation occurred largely until the 1980s for CFE communities and the early 2000s in non-CFE communities. Since the 2000s researchers, NGOs and the Mexican government has become increasingly interested in the forests communities own in the subregion for conservation.

Yet, this recognition has not always improved material conditions in these communities. In many cases rightsholders would ask me what direct monetary benefits my study would provide. Unfortunately, besides the immediate benefits of my paying for all trips with community guides, food and my accommodations while staying the communities, I felt incapable of guaranteeing much else. Communities have welcomed researchers previously, only to receive nothing more than a copy of the study, and often not even that. All this governmental and academic interest and attention has made communities more aware and in many cases 
appreciative of their forests, but it also has been another factor leading them to wonder when these studies often demonstrating the biodiverse nature of their forests and the robust forest governance of communities will finally lead to monetary benefits and not merely academic publications. Again, conservation is increasingly thought of as way to attract funding. Communities now wonder when it will begin to attract enough funding to significantly help them economically. So far, studies have far outnumbered beneficial projects.

\section{Increased Compensation for Active Conservation}

Following Ostrom (1990) I have argued that collective action for conservation is promoted by economic incentives. Yet, while CFEs produce timber as a commodity through the sustainable logging of forests, PESs are not nearly as clear as why the current compensation is given in the amount as it is for ongoing no-go, protected area-style conservation. In effect, the PES program in Mexico has been and likely will continue to be a profoundly political and negotiated affair. More importantly, I would argue that Mexico's PES program as it stands has not fully answered fundamental quandaries: If the forests in the subregion are of global importance, who should fund PESs and what level of PESs are appropriate for the conservation of such forests? If these forests are important for global biodiversity conservation, then why are the payments to the communities conserving them so modest?

The answer so far has been that the Mexican government is the only buyer and that they are offering modest payments generally for the single ES of hydrological services despite the importance of the subregion in global biodiversity conservation. While Yetla receives payments for biodiversity, their requirements for receiving payments are identical to that of all the five communities who are receiving PESs for hydrological services. They payment amounts for hydrological services and biodiversity do not widely differ either. Therefore, while these two programs propose to provide to different ES, but the differences in practice are negligible. After briefly reviewing CFEs, I will move to PESs in order to discuss active conservation, because in 
non-CFE communities, rightsholders most commonly link the concept of conservation to PESs. Again, communities like Cuasimulco and Nuevo Rosario have 52\% and 58\% respectively of forests under PES, while Ixtlán has only 1\% of their forests receiving PESs. As these communities received their land title in the 2000 s and had no community conserved areas prior to PESs, rightsholders equate conservation directly with PESs.

Therefore in communities without CFEs, PESs have introduced the idea that forests are economically valuable. Communities believe in this valuation and have worked in order to better govern their forests and enter the program. Therefore, the government has implanted at least part of the logic of the value of ecosystem services and communities have accepted it. Yet, before PESs convinced rightsholders to the value of their forest for conservation, CFEs showed the value of forests through working in them.

First, the emergence of CFEs in the Sierra Norte is a classic win/win conservation story and has played an important role in conservation discourses (Mathews, 2011). Communities along with NGOs fought against conniving parastatal logging concessionaires to wrest control of their forests and bring benefits to their communities. CFEs combine knowledge of gained during the concession era with community-level democratic decision-making to provide jobs as well as sustainable outcomes (Bray et al., 2005). The experiences in Ixtlán, Yolox and Comaltepec fighting for and winning control of their forests has created a far more nuanced conservation discourse than in communities without CFEs, who are relatively newcomers to discourses about forest conservation. Above all, CFEs have shown that well-managed, logged forests provide communities with jobs and millions of pesos a year for community projects. These pine-oak forests are commercially valuable and so communities have enacted community collective action for conservation to manage them.

By 1995, Comaltepec had created a comprehensive management plan for the entire community which, in addition creating inventories for pine-oak forests, also set aside 11,730 ha 
in community conserved areas. The community began an ongoing process of dialogue and education between rightsholders to understand why they were conserving forests. Through years of dialogue about conservation a majority of rightsholders began to believe that it should conserve species like the jaguar that can directly affect the livelihoods of cattle owners through cattle predation. Ixtlán would by the end of the 1980s created its management plan. Jobs first with the logging concessions and later with the CFE acted as magnets which attracted citizens from tropical lowland lands. By the 1990s the lowlands of Ixtlán were depopulated. In more upland areas rightsholders in Ixtlán would create additional community conserved areas for hydrological services in the 1990s prior to the PES program. Yolox learned how to prevent and fight fires from the careless practices as well as use all that they cut, compared to the decaying trunks scattered about from the concession era. Also, many of the large municipal buildings in Yolox were constructed with CFE funds, further demonstrating the benefits of a well-managed forest for rightsholders and linking the conservation of forest cover with increased livelihoods and community benefits.

Rightsholders in managing their CFEs have fought for and succeeded in the two of the essential actions of the governance of common pool resources: 1) Exclusion and 2) Subtractibility. In effect, they succeeded in excluding the concessionaires with their unsustainable high-grading logging techniques from community lands. Since gaining control of their forests these communities have avoided internal the corruption and elite capture which has plagued other CFEs (Klooster, 2000). Ixtlán has forest guards to monitor and exclude nonrightsholders from appropriating forest resources.

Rightsholders and forestry employees in all communities continue to argue that they learned much from the logging concessions and they are thinking about inter-generational benefits of their forests. In fact, in all three communities at various points, the assembly voted to harvest lower amounts than foresters had recommended. Rightsholders say that they cut trees and 
also replant them, while doing so in a way that will provide them with valuable pine species for many generations to come. Having learned from the concession period, they do not want to make the same mistakes in not conserving the forest and the timber the forest provides.

CFEs have helped to produce high forest cover in the region. Ixtlán, Yolox and Comaltepec have $94 \%, 90 \%$ and $86 \%$ of forest cover respectively. They recognize they are both conserving and logging their forests. At various points rightsholders made it clear they while they were interested in conserving forests in the sense of a protected area where no one would work there, they made it clear that by working their pine-oak forest they were also conserving these forest types. They are proud of their success in gaining and maintaining control of these pine-oak forests.

In one case, a CFE employee questioned whether or not I believed all forests should be strictly conserved similarly to protected areas. He said that yes while tropical montane cloud forests were suitable for conservation, pine/oak forests needed skilled and continuous logging to maintain species composition. In a separate interview, an employee of the CFE asked me if I had come on behalf of the CIA in order to learn more about communities and their pine-oak forests.

These questions clearly show that while not against conservation in itself, they wanted to clearly reiterate that conservation could also occur in a worked forest and did not always need protected area-like strategies to maintain forest cover. Clearly, the communities see the value in these forests in that they are commercially valuable as well as having high conservation value. The concession period showed them the commercial interest relating to their pine/oak forests. The arrival of logging was likely the first time that the communities saw the economic benefits of forests, though they had previously needed to conserve forests for building materials and fuelwood. As it is by the 2000s, both Conservation International and the World Wildlife Fund (Gordon, 2006; Robson, 2011) have highlighted these pine/oak forests for global biodiversity conservation either despite the fact or potentially because these forests have faced considerable 
logging. These designations show that a logged forest is still can be a biodiverse forest.

Therefore, the discourse which emerged in the 1990s was that communities can better manage their forests than the concessionaires or top-down governmental policy can manage their forests (Mathews, 2011). This discourse of a worked and conserved forest has largely driven the desire for communities to be viewed as conservationists. While communities view CFEs as combining conservation with labor, these same CFE communities began to consider conservation in unlogged forests as conservation too in response to programs like PESs.

Except for in the case of forestry, government policy has largely shifted in the forests of Mexico towards conservation and away from commodity production (Simonian, 1995; Wakild, 2011). The seventies in Mexico saw the rise of a national and international push for biodiversity conservation and a corresponding increase in national protected area creation of Biosphere Reserves (Wakild, 2011). Since, programs like PESs and VCAs in Mexico have followed a general global trend of the neoliberalization and decentralization of activities previously relegated to the State such as conservation (Shapiro, 2010; Doane, 2012). While in some cases it has caused increased community autonomy, it has in other cases provided additional access to NGOs and other organizations that in some cases maintain a close relationship to the State and in other cases have brought a far more critical discourse to conservation in Oaxaca (Doane, 2010).

Policies like PESs and VCAs have begun to recognize previously passive conservation at the community level by creating rules for management where in some cases in the subregion no rules existed pertaining to distant forests which communities had not recently worked. A further proliferation of programs and planning exercises has directly and indirectly affected forest governance. As I demonstrated in Chapter 3, non-CFE communities have responded to policies like PESs and VCAs by writing communal statutes, creating OTCs and discussing conservation in community assemblies. These actions show they are becoming increasingly formal and 
conscious in the governing their common property forests. Communities began writing their OTCs in the mid-2000s all in close proximity to entering the PES program.

Communities do not see conservation entirely as something they will do only for money as in the case of informal community conserved areas in Comaltepec, Ixtlán and Yetla. For nonCFE communities, PESs funds are the common connection with conservation that most rightsholders have in San Felipe, Cuasimulco and Nuevo Rosario. While the full discourse of ecosystem valuation is far from having penetrated these communities, rightsholders have already begun to equate conservation as something that can earn payments and something that deserves payments in some cases.

Therefore, in the following pages I will focus largely on an economic analysis of PESs in the subregion, though I do not argue that all active conservation is tied to PESs. Rather, by beginning payments, CONAFOR has established them as a prominent outcome of conservation practices. In introducing payments for behavior that previously received no remuneration, interviews suggest that they have altered motivations in how communities think about conservation. Increasingly for rightsholders, conservation is a monetized process when previously they did not believe they would receive financial compensation for their conservation. Having rather successfully convinced rightsholders that conservation deserves remuneration, communities will now come to expect that conservation will provide them with financial compensation. Such logic potentially has far reaching implications as I will address below. First, I will examine the reasons CONAFOR pays what it does to communities for PESs.

Over a half century prior to the PES and VCA programs, the government had disseminated information to communities that forests are vital to the local provision of water and oxygen. Even though the Mexican government has long sustained the argument that forests directly lead to the provision of hydrological services (Simonian, 1995; Wakild, 2011), considerable evidence shows the link is not based on a far more complex set of factors than 
merely maintaining forest cover (Forsyth, 2003; Mathews, 2011). Nonetheless, this sustained campaign of linking forests with water and oxygen has been a driving force in the creation of environmental subjects in the subregion. Without motivation for conserving forests based on the direct, local and inevitable provision of water and oxygen, I would argue that conservation in the protected area sense for many rightsholders in the subregion would lack a fundamental rationale.

This educational campaign linking forests to water and oxygen has been a resounding success as the vast majority of rightsholders argue that conserving forests will provide direct human well-being. Some rightsholders also add the biodiversity benefits forests provide, though this discourse is not widely shared. Largely in Yetla, who receive PES for biodiversity and in the CFE communities did various rightsholders talk about how communities had explicitly discussed biodiversity and how to conserve it. Far fewer rightsholders, generally only community leaders mentioned how their forests are aiding in the storage and sequestration of carbon and how this is a benefit to the world.

When payments for hydrological services became government policy in 2003 , it was a material manifestation of the governmental discourse on the importance of forest cover for providing hydrological services. Yet, as I will discuss later in this chapter, limiting this education of ESs related to forests to producing largely local benefits like hydrological services limits their knowledge of forests producing global ES like biodiversity and carbon sequestration and forests. In effect, by focusing on local benefits, the government does not explain the value that the big environmental NGOs like Conservation International and the World Wildlife Fund find in these forests (see Chapter 2).

While the initial intention was to focus on areas of deforestation and recharge exploited aquifers (Alix-Garcia et al., 2005), the PES program became far recently more focused on marginalized communities regardless of their proximity to an exploited aquifer (Shapiro, 2010; Munoz-Piña, 2011). Based largely these social criteria, the subregion has received payments for a 
total of 7,718 hectares of PESs or 13\% of total forest cover. In the case of Comaltepec and Yolox, each applied for roughly double the land than what they have actually received payments for. The PES program has consistently received far more applications than what allotted funds could cover (Muñoz-Piña et al., 2008) even though the Calderon administration had drastically increased the budget of the program on various occasions (Shapiro, 2010, also see Figure, 1.3).

Yet, in an interview with a CONAGUA (National Water Commission) official in Oaxaca City, they argued that PESs were not largely contingent on a water tax as has been previously argued (Alix-Garcia et al., 2005). Instead, as President Felipe Calderon proved, the government is capable of supporting the PES program as it sees fit and can raise funds in part according to their political will (Shapiro, 2010). Therefore, as I will scrutinize payments further, it would be incorrect to say that the funds of the program are bounded by anything other the opinion of the electorate and likely more important, the political will of politicians to argue not only for increased area in hectares under the program, but also for the increase of per hectare/per year payments. While conservation programs worldwide face budgetary issues (Pimm et al., 2001; Balmford et al., 2004), social movements in Mexico have had some success in arguing that the PESs have both social as well as environmental benefits (Shapiro, 2010). Therefore the PES program is not wholly an environmental program, nor is it merely a rural subsidy given out without compliance to the rules of the PES program. Since the majority of points communities can gain to enter the program are based on social factors, I argue that CONAFOR needs to examine if PESs are providing poverty alleviation in the majority of communities receiving PESs.

Comprehensive ecological data for setting prices for PES in Mexico are largely deficient (Alix-Garcia et al., 2005). In the mainstream PES literature, there is the idea of additionality. Additionality means that PES is only economically efficient when they are producing additional conservation which might have occurred in the absence of PES. A PES program is supposed to 
pay amounts that tip the scales from land use change to conservation. In tipping these scales away from production and towards conservation, PESs produce additionality (Wunder, 2005).

Yet, Mexico did not conduct sufficient studies to actually have a baseline measurement by which project implementers could test any additionality. Funding as well as political issues caused a quick roll out of the program which made collecting such baselines unfeasible (AlixGarcia et al., 2005). Therefore it is difficult to ascribe clear causation for whatever hydrological services are produced or not produced from PES. If some quantified additionality were available, then CONAFOR could set PES rates to the additionality from a participating community, but since baselines do not exist, rates cannot be set by actual ES provision.

Much of the economic logic for low payments in a PES program would be that payments need to adequately capture opportunity costs. While early project planners sought to implement varied payments based on opportunity costs (Alix-Garcia et al., 2005), project implementers in Mexico's PES program chose across the board rates depending on forest types regardless of opportunity costs, conservation value of the land and deforestation pressure (Alix-Garcia et al., 2005; Muñoz-Piña et al., 2011).

Yet opportunity costs are not an apolitical manner of thinking about conservation. I have argued in the passive conservation section of this chapter that the subregion has received little attention for economic development. Had these investments been greater and roads built to suitable areas for agriculture, then opportunity costs would be higher because rightsholders would be more capable of working these areas and bringing products to markets. Had coffee deregulation not occurred and if price supports continued, growers would have far greater incentives to maintain if not increase production of coffee, which would also increase opportunity costs. For example, the supportive policy given to CFEs (Bray et al., 2005) makes rightsholders suspicious that outsiders want to place these commercially valuable forests in protected area-style 
conservation. Opportunity costs are very high in pine-oak forests, while comparatively lower in TMCF.

Yet, opportunity costs vary in the subregion and can vary in a single community as well. Again, the conflict over PES in Yetla and the agencia of La Nueva Esperanza exist because rightsholders feel they can earn more farming coffee than conserving forests. Yetla again has 13.27 hectares per rightsholder, which would seem to predict low opportunity costs, but again land is more abundant for those who live in the village of San Mateo Yetla than those who live in La Nuevo Esperanza who perceive high opportunity costs for conservation and express dissent to the PES program.

As a part of their disapproval of their community entering the PES program, one leader appropriated the discourse of biodiversity to mean making forests more economically valuable. As Yetla receives payments for biodiversity, CONAFOR has attempted to teach how the conservation of biodiversity brings benefits to the community. Taking this idea of the economic value of biodiversity, this leader argued that the community should plant to a monoculture tree plantation of valuable timber species to provide future income for rightsholders. While this project would be in fact be a markedly not biodiverse forest and far different than the aims of the PES program to conserve native, species rich non-plantation forests, such a discourse shows how communities may attempt to appropriate discourses such as biodiversity to promote local economic development.

Doane (2012) found similarly in the Chimalapas region of eastern Oaxaca that conversations which began about community conservation often drifted towards economic development and agriculture. Gordon (2006) argues similarly that conservation NGOs commonly address economic issues because of the prominence rightsholders give to them and because Oaxaca is an economically marginalized but also biodiverse state. 
Related to opportunity costs, Landell-Mills and Porras (2002) argued in many PES programs in the global south that the poor sell it cheap. The poor may have had access to marginal agricultural lands, but which are capable of provision significant ES. As a result of these marginal lands the poor may have that land that will allow them to enter programs with low payments, while wealthier land owners with better access to capital will continue not conserving and earning more from productive uses and not through conservation. Given that marginalized landowners cannot compete with the production of wealthier land owners, there opportunity costs are likely lower. As payments often cover a fraction of agricultural production, richer land owners will continue to earn great economic than those who are conserving their lands.

Rightsholders in Soyolapam argued they were conserving and had lower opportunity costs based largely on poverty and a lack of technology that had created initial passive conservation that the community reinforced as an informal community conserved area. They said they conserved because they were poor. They explicitly argued that they needed economic development which would increase cattle pastures and reduce forest cover, which they said would bring greater benefits to their community. Then it is possible that low PESs will further lead to an economic disparity against those who are conserving and those who are working their more suitable lands.

Richer land owners will continue to produce agricultural commodities and poorer land owners will continue to conserve and receive a portion of the payments they could have earned from agricultural production. Low PES levels then maintain economic disparity. While rightsholders in the community of Comaltepec largely are pleased with the PES as they have conserved a distant area under the program, one rightsholder in the village of Santiago Comaltepec argued that the PES was a means of purposely dividing rightsholders from their agricultural plots and making Comaltepec a fundamentally less agrarian community in order to sever their attachment to the land. In Comaltepec as in Yetla, rightsholders opinions in different 
villages even in the same community differ in their opinions of the PES program largely because rightsholders face different opportunity costs. Still instead of setting up a scenario where the poor sell these ESs for low rates, governments can increase their payments.

Payments from CONAFOR for PES are MXN \$860 for TMCF and MXN\$ 658 for other forest types (USD\$ 72 and USD\$ 58) (Shapiro, 2010). For the entire subregion PES earn communities MXN\$ 6,243,580 (USD\$ 520,298). If evenly divided between the 1995 rightsholders in the subregion, each rightsholders would receive MXN\$ 3130 (USD\$268), which is the equivalent to 125 kilos of coffee production sold for the 2013 low prices of 25 pesos a kilo (USD \$ 2.08/kilo).

I will tie the following prices I have quoted to coffee because coffee is the most common cash crop through the region. No community would or has placed in the PES an area of milpa agriculture or cattle pastures, but they have conserved suitable land for coffee farms. Therefore, the opportunity costs rightsholders bear in entering the PES program are largely related to coffee. Also, many households gain their primary cash inflows from coffee if they do not receive remittance money. An alternate calculation would be the average wage for a day laborer of MXN\$ 150 (USD\$ 12.50), though some growers are only utilizing household labor in their coffee farms as a result of the recent dip in prices and so wage laborer is not assured in the subregion. Also, because the price of coffee is currently low, it provides a conservative estimate for opportunity costs. For this reasons, I will often compare PESs and coffee.

Such PESs rates assume incredibly low opportunity costs. Again a hectare of coffee in high producing areas of the subregion can produce 1000 kilos. At 25 pesos a kilo rightsholders intensively farming one hectare for coffee could gain 25,000 pesos (USD \$2083). These higher yields for the subregion would need substantial labor, which would reduce profits to roughly 20,000 pesos (USD\$1666). Therefore coffee earnings could equate roughly to a ratio of 29:1 for coffee earnings to TMCF conservation. Such top rates comparing coffee to conservation are why 
rightsholders in the agencia of La Nueva Esperanza argue that they should grow coffee in the PES as the community previously had done in the area before entering the program.

Conversely, Martinez et al. (2009) has argued that TMCF have a per hectare value of USD \$ 728 when PES are only (USD\$ 72). Therefore CONAFOR is paying at 1:10 to the amount TMCF produces in ESs, which is a veritable bargain for buyers of ESs. Also, even though the PESs ostensibly cover hydrological services in five of the six cases in the subregion, the regulations may lead to the provision of other ESs. Therefore, both the value of the forests for ESs and the opportunity costs for coffee demonstrate that payments are low by economic and ecological measurements.

Entering the PES program does not only impose opportunity costs on agricultural uses, but hunting as well. The signs communities must post in order to receive funds near their PES area state that that there is no hunting in the PES area, even for PES areas for hydrological services. There is some debate whether the regulations of the program actually ban hunting (Elvira Duran, personal communication), but rightsholders believe the program bans hunting as signs they must post to receive yearly payments says the areas prohibit hunting. Some communities had already banned hunting outside of agricultural areas for pest animals before the PES program, while other would have adopted such rules with the arrival of the PES. Ibarra et al. (2011) have argued that this ban on hunting has limited the food sovereignty and access to protein for communities in the Sierra Norte. Furthermore, rightsholders have said that the bans of hunting have increased the incidence of pest animals attacking and damaging crops (Ibarra et al., 2011; Berget, 2012). While these are pest animals which can jeopardize food sovereignty at the household level by damaging harvests, the presence if not proliferation of these animals is biodiversity conservation according to global discourses.

The PES program at least in its public presentations is advocating against hunting for programs for hydrological services. In no way have ecological studies of particular sites been 
done to find any important contribution of seed bearing animals in forest ecology and that hunting would be ecologically damaging for forest health. Therefore, this ban is in effect gaining both hydrological and well as biodiversity services for a single price. In addition, since there was agricultural production recently before they became conserved under the PES program in Yetla and Nuevo Rosario, the abandoned milpas and coffee farms are now adding biomass and capturing carbon. These additional services of biodiversity and carbon begin to come closer to the higher estimate by Martinez et al. (2009) yet remain outside and not captured by the prices paid to these communities.

Rightsholders in the village of Yetla have begun to look for ways of increasing PES, arguing that if communities are providing hydrological services and face the resulting opportunity costs as a result of the program, then they should be compensated for these opportunity costs. Their target for additional payments is a large downstream brewery, which produces internationally sold brands. Rightsholders have entered talks with other communities in the Papaloapan Watershed in order to pressure the brewery to support community conservation efforts through PES. This watershed provides water for the brewery as well as for millions of people in the state of Oaxaca and Veracruz. Rightsholders argue that if the brewery can earn millions of dollars from the hydrological services they are helping to provide, then rightsholders deserve at least some small share in the profits the brewery makes while using this water.

While such actions do fall in line with CONAFORs interest in having NGOs and private businesses share in the costs of funding the PES program, which would lessen their funding burdens through these co-payments (fondos concurrentes) (Nieratka, 2011), such an unprecedented social movement in these non-CFE communities if it goes forward may or may not fit within CONAFORs objectives. In many communities, environmental subjects have merely passively waited for payments and programs to arrive either by the government itself or from NGOs. In the case of Yetla considering a movement to obtain PES from this brewery, such 
actions would indicate a more active phase for environmentality in the subregion, one not entirely under the auspices of government direction and far more activist in its orientation than waiting for programs to arrive.

Communities are being modestly paid often a modest amount for a single ES, when it is likely that these forests are producing additional services. Yet, the conflict over payments is not merely between communities and the federal agency CONAFOR as well as potentially with large Mexican corporations. Van Hecken et al. (2010) have argued that nationally funded programs are providing environmental services not just within national boundaries, but like carbon and biodiversity, which have global benefits. Northern countries do nothing to ensure the provision of these ES in national programs, but continue to benefit from them and so are freeriders of these ESs. Therefore in programs in Nicaragua, Ecuador and Mexico, as well as other countries in the global South, these nations are staving off species extinction and endangerment with their conservation while all sequestering and storing massive amounts of carbon without receiving major funding from the global north. While REDD+ (Reducing Emissions from Deforestation and Degradation) intends to provide such a carbon market between global North and South (Parker, 2009), conservation has occurred for decades in the subregion without PES without any financial compensation. Communities have historically been providing ES, while only since the mid-2000s have they begun to receive modest national payments for a single ES.

Bray (2009) has argued that the high forest cover such as in the subregion studied here are what once forested landscapes could look like after REDD + , providing that the program is a success and leads to reforestation and conservation. Yet, the question remains if payments will largely focus on communities have current high deforestation pressures or historically deforested and degraded their landscapes or if REDD+ will also provide payments for communities which have historically conserved their forests such as the communities of the subregion. 
Such a payment scheme would allow these communities who have high deforestation pressure or who have deforested in the past to gain the double advantage of having received the income from the initial deforestation as well as payments for reforestation. Meanwhile, this subregion which has conserved and likely will continue to conserve may not be a focus of payments despite maintaining $88.34 \%$ forest cover and having taken collective action for conservation largely at the community level. Therefore, through the period of passive conservation, these communities in the subregion were providing ES. Currently, they continue to conserve, though they receive recognition and compensation for only a fraction of their conservation. Only $13 \%$ of forest conservation is linked to the PES program, which $6 \%$ in the PES program. Therefore, issues related to compensation exist because only $13 \%$ of ongoing forest conservation receives PES. Communities applied in some cases for double the PES are that they received.

For coffee, growers receive low payments, while the vast majority of wealth coffee produces is added and captured in global north countries through the process of roasting and marketing to bourgeois coffee culture (West, 2012). Conservation in Mexico's PES program follows this trend of modest payments by global south countries with benefits also accruing in the global north.

In fact, paying for some ES and not for others, CONAFOR is extracting surplus value from the strict conservation of creating no-go zones in the region that potentially provide far more than either the biodiversity of hydrological services that PES cover. This surplus value comes in that forests are producing hydrological, biodiversity and carbon ES, while CONAFOR pays for a single service. Communities undertake strict protection and face the resulting opportunity costs, yet receive compensation for a fraction of the ES value proposed by Martinez et al. (2009).

Communities do continue to receive PESs and so remain in the program and continue to produce surplus value, but often have argued that payments should better compensate them 
because of the lack of economic opportunities in their community. Given that there are no conservation auctions or negotiations in Mexico's program (Alix-Garcia et al., 2005; Shapiro, 2010), communities can either accept the payment levels or not enter the program. The program has always had more applications than it has had funds (Muñoz-Piña et al., 2008), and so even communities with forests that are important for global biodiversity conservation have little if any negotiating power. In this all or nothing scenario, communities choose to continue to receive PESs, even if they believe PESs should be higher. If they choose not to accept payment regimes, another community will likely accept these payments and so this community will receive nothing for its conservation.

PES outcomes have proven more favorable in other communities than in the subregion. In two of the CORENCHI communities, which have comparatively larger PES areas and fewer rightsholders than many communities in the subregion, PES have made modest yet observed reductions in poverty at the household level as each rightsholder (Nieratka, 2011). The scenario in these CORENCHI communities of a large PES area with a small number of rightsholders mimics what higher payments per hectare would accomplish and potentially expand poverty alleviation benefits. Yet, in other communities in CORENCHI, others have argued that the conserved area from both PES and VCA is too large, which has led to less agriculture and decreased food sovereignty (Ibarra et al., 2011). Therefore, PESs need to balance their ability for poverty alleviation without comprising food security and taking important agricultural lands out of production.

Increased payments per hectare may be able to further reduce poverty without compromising food sovereignty. Increased payments may bring the benefits of poverty alleviation found by (Nieratka, 2011) to other communities with smaller PES areas or more rightsholders. Payments could reflect that really there are global benefits to the conservation occurring in this 
subregion and that the program in the majority of cases is paying only for the most localized ES forest cover may provide-hydrological services.

Communities are largely unaware of the discourses related to biodiversity as well as anthropogenic climate change and the seemingly looming global cataclysms relating to species diversity and greenhouse gas concentrations in the atmosphere, communities have yet to demand increased payments for the additional services their conservation is providing. Clearly it would benefit communities in increasing payments if they could forcefully argue that forests do not only provide largely localized benefits in the form of water and oxygen and are providing biodiversity and carbon sequestration benefits of global importance. Though it would benefit them, their partnering NGOs and the government has either not tried or not been successful in teaching communities about biodiversity and carbon storage.

Yet, this approach of continuing if not ramping up PES logic has its detractors. Those who are highly critical of PESs argue that they are engaged in selling nature to save it (McAffee, 1999) and that PES are another form of commodity fetishism (Kosoy and Corbera, 2010). Kosoy and Corbera (2010) focus on the fact that commodity fetishism obscures a commodity from the socially necessary labor time to produce it. For one, this thesis intends to have demonstrated that the active form of conservation has motivated additional assemblies and planning exercises. Community leaders in carrying out these plans also often have less available time for agricultural labor and so need to save money for at least a year before starting services in order to continue to provide necessities for their households. Rightsholders have also agreed to conserve and refrain from working in certain areas.

A quick calculation is demonstrative. If a community of 300 rightsholders discusses the PES program for two entire days at the rate of the sanction for missing an assembly of MXN\$ 150 in assembly, the labor of rightsholders would be equivalent to MXN\$45,000 (USD\$3750). The amount generated here would be equivalent to the payments for 59 hectares of PES in 
administration costs alone bore by the community. Additional costs would come in trips to Oaxaca to meet with CONAFOR officials as well as the preparation for inspections and the filling out pertinent documents.

Therefore labor in complying with the program as well as opportunity costs in certain areas is embedded in conservation practices in the subregion. While rightsholders are paid daily wages for completing programs related to the PES areas, meetings and discussions related to PES remain unremunerated. Community and forest governance takes time, which rightsholders complete in unpaid positions of authority for the community. Assembly meetings can go for days as rightsholders painstakingly discuss issues in their communities.

What is also important and less examined by Kosoy and Corbera (2010) is that the fetish in itself carries mystical powers to the believer, which are not apparent to the non-believer. The fetish takes on additional characteristics which are not easily observable. A commodified good takes on additional relations and meanings and may change existing relations and means. As such, the commoditization of ES purports that a conserved forest meant to provide hydrological services downstream of Comaltepec is also storing carbon that benefits dwellers of low-lying coastal cities around the world in averted increases in greenhouse gases and rising seas. Until recently, conservation did not take on such significance and to many rightsholders in the subregion conservation does not link them to global forces like climate change or biodiversity conservation. Furthermore, until recently few envisioned that something like carbon sequestration could be commodified. Now, a growing movement argues that conservation and carbon forestry is an important activity not locally but globally. Mexico has entered the carbon market in the form of carbon forestry, though the sale of carbon credits largely on a voluntary basis (Osborne, 2011).

Yet, carbon sequestration is a commodity that is produced by planting trees which more quickly sequester carbon than standing mature forests (Osborne, 2011). Yet, in the case of tree 
planting, the region has $88.34 \%$ forest cover. There are limited areas and additional plantings could further exacerbate the conflicts between agriculture and conservation already occurring in the Sierra Norte (Ibarra et al., 2011). Therefore, while carbon forestry is increasingly recognized as a benefit of forest management and especially tree planting, existing forest high forest cover limits the potential for such programs in the subregion.

Therefore, it is more likely that communities are more capable of gaining benefits from programs for forest conservation, much like the existing PES program managed by CONAFOR. Thus, I have argued that while a generally positive for subregion, payments would need to increase to reflect the high conservation value attributed to the forests in this economically marginalized subregion. Funding could increase either through increased government spending or through partnerships with NGOs, private firms, international organizations or foreign governments. Instead of merely decreasing budgetary burdens through fondos concurrentes, such a system of multi-payers could increase compensation to each community in the program.

Like rightsholders in the subregion, Shapiro (2010) has found that rightsholders elsewhere are worried about the withdrawal of payments. The withdrawal of payments can occur either because of a lack community compliance with program rules or by CONAFOR merely deciding to cut funding. CONAFOR has already done the later and it has proved damaging for the approval for conservation in the case of San Felipe de Leon. It is likely that other communities would also act adversely to the nonrenewal of their contracts. Social movements in Mexico argued and won selection for PES based increasingly on social characteristics (Shapiro, 2010). If conservation is important for the Mexican government and for the world, then these communities should receive compensation if they comply with rules. Yet, Shapiro (2010) argues that an argument based purely on economic efficiency would see no problem with eliminating payments if forests will be conserved long into the future as a result of a single five-year PES contract. Such an argument would seem to be only appealing to economic efficiency when it is convenient. If 
social criteria are largely what determine entrance into the program for a community and not perceived risk of deforestation or other more ecological criteria (Shapiro, 2010; Munoz-Piña, 2011), the program should continue such social aims in reviewing applications for contract renewal. If a community continues to conserve its forests and continues to have a high rate of marginalization, then CONAFOR has no justification for removing them from the program, since the community has fully honored the contract and maintains the relevant conditions to that contract.

Not renewing contracts could also produce crowding out, which is when economic incentives eliminate or limit socially beneficial behavior which previously existed without economic incentives (Kosoy and Corbera, 2010; Vat, 2010). Such a scenario is particularly relevant to this thesis as I have shown how passive and informal conservation practiced by communities without government recognition has become active conservation with formal government recognition largely as a result in the subregion of the PES program and less so the VCA program.

While communities were conserving forests largely because of remoteness, low population densities, difficulties in accessing distant areas, etc., especially in communities without CFEs, they have since the 2000s begun a more formal phase of conservation through OTCs and the PES program. The PES program has now given clear valuation to the forests and so it may be difficult to return to a time when forests were informally and passively conserved without payments or government recognition.

Yet, crowding out could occur if payments disappear and CONAFOR eliminates payments for areas once passively conserved. Interviews with rightsholders in San Felipe indicate that crowding out may soon occur as CONAFOR did not renew their PES contract. While they were conserving this distant forest as long as any rightsholder can remember, rightsholders now say that in the absence of PES, they want to go and work the area which is still certified as a 
VCA. If the government will not financially support their conservation with direct payments, then they will gain benefits through felling these forests and farming there. While it is unclear if rightsholders will act on these ideas, it should act as a warning of the potential crowding out of previously passive conservation if CONAFOR does not renew PES contracts. Rightsholders in San Felipe passively conserved this area for generations. Now the failure to continue payments could lead to five years of incentives to crowd out generations of conservation. Such crowding out would lead to a net loss in forest cover as the area was likely to be conserved until economic incentives raised expectations in San Felipe.

Other communities may react similarly to the non-renewal of their PES contracts. In communities like Cuasimulco and Nuevo Rosario it would cut an important source of funding for communities which equate conservation with the PES program. CONAFOR has been successful in promoting the PES program and having communities adapt to formal conservation in the PES. I would argue that CONAFOR needs to continue payments as not to spur a backlash to formal conservation as is occurring in San Felipe de Leon. Having opened Pandora's Box in given economic valuation to forest that rightsholders previously believed had no direct monetary, it is unlikely they can close it without alienating communities who created engaged in community collective action for conservation.

That being said, crowding out may be sensitive to the levels of economic marginalization in a community. In one case in the subregion, CONAFOR cut payments by $75 \%$ in Ixtlán. Among the few rightsholders I interview in Ixtlán, no one was upset largely because the PES provided such a miniscule amount compared to their CFE. In fact, unlike other communities like Cuasimulco, Comaltepec and Yolox which have invested PES in community projects, Ixtlán spent their entire PES funds in forest monitoring and other projects. While the payments were welcome, they are not nearly as pivotal in Ixtlán for community finances as in non-CFE communities like San Felipe de Leon. 
Not all communities can follow the development trajectory of Ixtlán, but as deforestation studies suggest (Deininger and Minton, 1999), policy that supported increased off-farm employment in the region would provide benefits to rightsholders while further decreasing deforestation drivers. I have argued that the PES program would be a potential means of better compensating communities for their conservation of globally important forests. As detailed in Chapter 3, communities have in some cases distributed these payments to rightsholders, while in other cases they have invested PES funds in community projects like ecotourism, which could provide additional off-farm employment. In these cases PES funds are an investment into the community. Higher payments would increase the percentage of these earnings that could go to community projects and not to administration costs.

Rightsholders throughout the subregion on many occasions said that while they supported conservation, they wanted to make sure that I did not lose sight of the fact that agricultural production is still important. In many cases communities want increased support for agricultural as much or more as they want payments for conservation. Yet, if PES will not increase to better approximate the value of the forests being conserved in the subregion, then there are still additional options for compensating communities for their conservation.

While PES could play a more important role in the economies of these communities, these communities are still fundamentally agricultural communities save for the case of Ixtlán. Instead of assuming that communities will increasingly dedicate themselves solely to conservation, a well-designed policy could attempt to better link conservation with biodiversity friendly agricultural production. Existing agricultural practices in these communities have managed to retain soil as well as soil fertility. Usufruct recognition of plots and inheritance of these plots has led to low discount rates as farmers can assume no one will disrupt their management of individual plots as well as pass down productive plots. As I argued in Chapter 3, these sustainable farming practices in milpas and coffee farms have led to passive conservation of 
forests. Then, by the 2000s OTCs began to set boundaries around agricultural areas. Many rightsholders argue that while conservation is important, communities need to increase the profitability of agriculture. Largely they discuss coffee as it is the agricultural commodity with the longest longevity in the subregion. Growers have amassed local knowledge around the cultivation of coffee and a clear market already exists for it.

\section{VCAs and the Seal of Sustainability for Coffee}

Instead of treating agricultural as the enemy of forests, agriculture could lead to more stable incomes in the subregion. Agricultural public policy could be beneficial for communities and forests if it focused on maintaining forest cover and agricultural in lands zoned in OTC for agriculture. Ixtlán has the highest forest cover of any study community not because of difficulty of access or high rates of migration and low population densities or purely from passive conservation. Instead they have experienced a forest transition from a landscape of agricultural to one of conservation (Rudel et al., 2005) largely through the pathway of increasing the value of their pine-oak forests as they increased their vertical integration of their CFE and having control over the entire commodity chain for timber products. While no community in the subregion has come close to the community-based development that Ixtlán has achieved, a new and more environmentally-focused coffee policy could improve livelihoods in the subregion by reinvigorating coffee production to more formally sustainable ends.

Shade tree coffee has been shown to be ecological beneficial in many tropical regions (Perfecto et al., 2005; Bray, 2010) as well as in the Sierra Norte (Bandeira et al., 2005). All coffee in the subregion is shade tree coffee and much of it again is organic, though it receives no price premiums. I have used coffee throughout to compare opportunity costs because rightsholders in the region have or currently grow coffee and have substantial knowledge for growing coffee. Also, it is the main source of cash for households. Therefore it functions will as a measure of opportunity costs as well as value of forest cover for instrumental uses in communities without 
CFEs. Furthermore, it is a crop that is actually suited to the steep slopes and high forest cover of these communities.

Therefore the roughly 1200 hectares dedicated to coffee in these seven communities receive no additional payments other than the market prices, despite the additional benefits for households a coffee farm provides in addition to its ES. When a farm is completely abandoned or converted to another land use, growers then lose both the sale price of the coffee but also these other products extracted from their coffee farms such as fuelwood and edible wild greens (quelites).

If the government paid a premium equal to organic coffee at 8 pesos per kilo (USD\$ .67) --which most produce but without certification-- for the coffee grown in the community at average production rates of 750 kilos a hectare they would be paying $\$ 7,200,000$ pesos (USD $\$ 600,000)$, more than is currently paid for the PES program. The government previously paid much more during the INMECAFE era and all growers say production was higher because of guaranteed prices. Such premium would incentivize production and provide increased household incomes on the existing coffee land. Coffee also creates additional employment in communities for day laborers and allows families to send their children to school to continue their education (Jaffee, 2007).

If clearly explained that it was a production subsidy allied to ongoing conservation, community members would be paid for knowledge they have acquired in decades of coffee production while also further recognizing the benefits of shade tree coffee and forest cover in general. Subsidies could apply only to current areas or recent areas of coffee production as not to induce expansion into mature forest as was the case of a result of prior INMECAFE subsidies which promoted only production without environmental concerns (Moguel and Toledo, 1999; Bray et al., 2002). While agricultural subsidies have in some cases produced negative effects on ecosystems (Balmford et al., 2004), these subsidies from INMECAFE were meant only to 
increase protection without any environmental measures. The subsidy or economic support I am proposing is necessarily tied to conservation.

Programs in the last decade in the region have focused almost exclusively focused on conservation. The majority of community members support conservation. Still, they were worried that I and likely other researchers exploring conservation were missing they were still agricultural communities and their livelihoods and household management depends vastly more upon their agricultural production than from conservation. Unpaid conservation of globally important forests for biodiversity may gain accolades as in the case of the WWF certificate declaring forest conservation in Comaltepec as a Gift to the World, yet protected area-like conservation in the PES program has thus far provided economic benefits per rightsholder of what roughly a $1 / 5$ of a hectare of coffee can provide.

Such a policy promoting shade tree coffee is not entirely far-fetched in the subregion. In areas coffee playing a more fundamental role in maintaining forest cover it may be even more fitting. The VCA policy has proposed, though not implemented, a seal of sustainability for certain products extracted in the VCA area (LGEEPA, 2008). Such a seal with pertaining price premiums could be directed to communities which demonstrate ongoing forest conservation and who certify a VCA on their lands. Efforts at creating a market-oriented Bird Friendly certification without state intervention and assistance have produced little impact (Bray et al., 2002; Jaffee, 2007), even though coffee provides important habitat for neotropical migratory birds that winter in countries such as Mexico and summer in important coffee-consuming countries like the United States (Perfecto et al., 2005). Potentially state support and promotion could aid such a shade tree coffee certification that has failed to gain traction in the market (Bray et al., 2002). If the certification of a VCA granted communities they ability to gain price premiums for shade tree coffee grown in areas of traditional coffee cultivation and not cut from mature forest, then it is likely that the interest these communities have in certifying a VCA would greatly increase. 
Through the promotion of the seal of sustainability, VCAs could also give yearly income to communities while favoring conservation. The government could increase land under VCA which is currently nationwide only 370,805 hectares, or the size of a single medium-sized Biosphere Reserve. In fact the 18 communities studied here and by Velasco-Murguia (2011) conserve onefourth as much forests as all that is certified VCA land nationwide. Likely the VCA program includes a miniscule fraction of the forests communities are conserving. Again, according to rightsholders in the subregion, communities would find the VCA far more attractive if it provided greater economic benefits.

Unfortunately, the Mexican government has neglected to implement the seal of sustainability which limits the economic benefits of VCA to the one time project provided upon the community signing their contract. As a consequence of the lack of economic incentives, many communities in the subregion expressed a disinterested in certifying a VCA. They realize that they can conserve forests without receiving payments and do not enter a program which has in at least one case complicated management and taken an important agricultural area out of production (Schmidt, 2010; Ibarra et al., 2011). In fact, VCA certification has in some cases come after substantial interaction between communities and trusted environmental NGOs which promoted VCA certification (Bray et al., 2012). No such push from NGOs exists in many communities, nor are communities themselves driving VCA certification. PESs are far more attractive to rightsholders because of their yearly direct payments.

Environmentality posits that communities begin to care about their forests and become environmental subjects because users had control over their forests and could capture the benefits they received from conserving them (Agrawal, 2005). While the CFE communities learned of the timber value of their forests nearly two decades before, active conservation in non-CFE communities centers on the PES program, which is less than a decade old and has thus far provided modest benefits. 
Yet, if payments remain of minimal impact or worse yet if they cease, environmentality takes on a less positive veneer. If these communities conserve forests without economic benefits or with limited benefits, one has to question if communities should not better refocus on agricultural production to improve their livelihoods. Global freeriding occurs in Mexico's nationally funded program. These marginalized communities in effect very much are playing a beneficial role to more wealthy people without receiving much in return.

Conservation has long assumed to be arguing its case with the best interest of society in mind (Forsyth, 2003). Yet, in this case, communities in the Sierra Norte have potentially sacrificed their very food sovereignty for conservation (Ibarra et al., 2011). While rightsholders in the subregion studied in this thesis argued that conservation has not caused the weakening of food sovereignty in these communities, it is a trend to watch in a subregion that has $19 \%$ of forests either conserved as PES or VCA. Looking at the distribution of costs and benefits from an environmental justice angle and communities are bearing opportunity costs and receiving all modest benefits that have thus far done little to alleviate poverty. While PESs are far better than nothing, communities in the subregion deserve better compensation for their conservation of forests important for globally biodiversity.

\section{Flaws of Systematic Conservation Planning in the Sierra Norte}

Yet, if the PES program and its compensation levels are problematic, recent systematic conservation plans are far more potentially limiting for community management through top down measures that would limit resource access without direct compensation. Communities can leave the PES program and cease to receive funds at any time if they so choose. Protected areas have not proven so flexible for communities (Haenn, 2005; Garcia-Frapolli et al., 2009).

Again, Gomez-Mendoza et al. (2006) found a linear trend of deforestation for most forest types in the Sierra Norte and did not argue that forest conservation was an important indicator of forest cover. Other studies have since questioned this narrative of linear deforestation (Toledo- 
Aceves et al., 2011; Velasco-Murguia, 2011; Bray et al., 2012; Duran et al., 2012). More recently Ponce-Reyes et al. (2012) and Rojas-Soto et al. (2012) have predicted massive losses of TMCF in the Sierra Norte as a consequence of anthropogenic climate change.

What Ponce-Reyes et al. (2012) supposes is that all TMCF outsides of protected areas could be cleared in the Sierra Norte, leading to a loss of as many of $70 \%$ of species. Based on the assumption that forests would be cleared, they advocated for the creation of protected areas on community lands. Ponce-Reyes et al. (2012) do not mention community land tenure or ongoing conservation. The situation, though based on little regional evidence carries out of the tropes of the Tragedy of the Commons (Hardin, 1968) by in effect proposing the creation of national protected areas to be created on top of communal lands. They neglect to mention that communities have twice rejected proposals for Biosphere Reserves (Bray, 1991; Bray et al., 2012) by arguing that they wished to retain control at the community level. Yet, Ponce-Reyes et al. (2012) do not consider such factors; merely their methodology finds a biodiverse area and assumes that local communities are bent on the destruction of their forests.

What is troubling is that this study I have undertaken is by no means the first demonstrating forest management and territorial management in the Sierra Norte. In fact such studies have over 20 years of history (Bray, 1991; Chapela, 2005, in Bray et al., 2005; CONABIO, 2010; Mathews, 2011; Figel et al., 2011; Hite, 2011; Nieratka, 2011; Robson, 2011; Mathews, 2011; Toledo-Aceves et al., 2011; Bray et al., 2012; Duran et al., 2012). Evidently, the power of the narrative of communities being bent deforestation and degradation remains strong, even in a region where such a narrative has debatable validity. Despite the plethora of studies cited above, Gomez-Mendoza et al. (2006) and Ponce-Reyes et al. (2012) take into consideration the vast body of literature cited above and not advocate for protected areas based on ongoing or potential deforestation. 
Under such rationale, if communities are not conserving now, then the region needs a protected area. If communities may even potentially not conserve in the future, then the region needs a protected area. In effect, this strips communities of agency in conservation, since it seems the high biodiversity attracts plans for conservation largely at a level of analysis that ignores the communities themselves much less that they may themselves be effectively conserving forests. Globally important biodiversity exists in places where communities have lived and worked for hundreds of years. Yet, it is common conservationist thinking that some force is bound to arrive to despoil interactions which have led to passive conservation (Terborgh, 1999; Wilshusen et al., 2002). Unfortunately, this lack of analysis of land tenure and the potential of existing forest governance seems systemic of SCP exercise in general (Smith et al., 2006). SCP exercises are often so interested in finding gaps in species coverage that they often let people fall into such gaps. In some cases these SCP exercises are used as expert knowledge created with such complex methodologies that local people have difficulties debating such SCP exercises (Kosek, 2007; Doane, 2012).

Such a view of communities gives some degree of credence to the pamphlet circulating in San Felipe that conservationists have designs on community lands. These SCP exercises do not discuss dispossession or undercutting food sovereignty by conserving these areas for the most part because they do not have any in-depth discussion of people or land tenure (Ponce-Reyes et al., 2012; Rojas-Soto et al., 2012). One would gather from this plans that only biodiversity exists beyond that humans are uniformly threatening to forests if they are mentioned at all. In other cases, global level plans merely search for gap species and underrepresented ecosystems and assume parks can be created (Brooks et al., 2004).

As explored by Scott (1998) such a view of viewpoint of forests as places only of biodiversity conservation to be protected in a public protected areas massively simplifies the reality that communities live, work and conserve these forests. Protected areas have long since 
attempt to displace humans entirely or from core areas of the protected area (Wilshusen et al., 2002; Dowie, 2009) as an area would be a wilderness of a degraded landscape. In reality, biodiversity exists with people and is increased by some farming practices in the subregion (Robson, 2011). Furthermore, communities have already systematically planned land uses through the creation of OTCs. They have considered urban areas, agricultural areas and forested areas. They have discussed and debated the suitable amount for each. Instead of recognizing that communities must earn their living for their lands, these SCP exercises create through GIS and remote sensing a vision of communities largely as avid destroyers of forest from whom forests must be protected. Communities see themselves as those who have protected their forests.

Systematic conservation planning needs to re-examine the case of Sierra Norte with secure common property and ongoing conservation by communities and wonder what they hope to gain in creating plans for areas with secure land tenure and going conservation throughout the 18 community block between those communities studied by Velasco-Murguia (2011) and this thesis, which has found $90 \%$ forest conservation. While others have argued that systematic conservation planning often is nothing more than an intellectual exercise that rarely comes to fruition (Knight et al., 2007), in some cases the failure of these plans to become implemented is likely a positive outcome for community land tenure which will not face the kind of limitations on land uses or displacement that communities have faced in protected areas around the world (Neumann, 1998; Dowie, 2009).

As Hayes (2006) argued, it is not the designation of a protected area itself that leads to conservation. Rather it is governance at the local level by park managers that leads to forest conservation. Again, in other cases, paper parks exist that exist only on paper but are in effect open access resources without monitoring and sanctions of those breaking the rules of the protected area (Brandon et al., 1998). Again the IUCN in its definite makes no distinction that protected areas must be run by states (Borrini-Feyerbrand et al., 2002). Nonetheless, all 
systematic conservation plans for Mexico and the Sierra Norte assume forest conservation is the role of governments (Arriaga et al., 2000; Brandon et al., 2005; Illoldi-Rangel et al., 2008; PonceReyes et al., 2012; Rojas-Soto et al., 2012). While Ostrom et al. (2007) have recognized that common property is no panacea for resource management, many conservationists remain locked in the thinking that protected areas area a panacea (Wilshusen et al., 2002; Hayes, 2006).

Such a rationale based on the "myth of the noble state" questions the underlying assumption in systematic conservation planning that governments can automatically manage forests better than local users (Alcorn, 1993). Such rational of the need of government control also echoes Hardin (1968) Tragedy of the Commons argument that the commons must be broken up and made either private or public property so that they can be properly managed. Hardin (1968) cites the breakup of the English commons as one of his fundamental examples of a tragedy of the commons. Yet other scholars have shown that it was rich elites who broke up common property and disposed the peasants of their land in order to further enrich themselves (Marx, 1867; 2011; Fukuyama, 2011). While public policy prevents such dispossession in Mexico, in other cases elites have displaced local users on the basis that local users would destroy forests if left to their own resources (Nuemann, 1998; Kosek, 2007; Dowie, 2009).

Such articles as Ponce-Reyes et al. (2012) that advocate for protected area in the absence of analyzing how community management can also maintain forest cover make PES seem far more attractive in that they allow communities to retain forest governance and receive modest payments while doing so. Communities enter agreements in the PES and VCA program which they can voluntary exit if they are not pleased with the results of these programs. Conversely, Biosphere Reserves receive a presidential decree (Bray et al., 2012) and so may be far more difficult to modify or annul if communities did not agree with the management of the reserve.

Likely for this reason, the communities that make up CORENCHI have certified VCA and entered the PES program but democratically voted against a Biosphere Reserve (Bray et al., 
2012). In my study area, Comaltepec has successfully managed their forests for timber and conserved 11,730 hectares at the community level but did not want a Biosphere Reserve (Bray, 1991). Communities recognize that maintain as much control as possible of their territory is of the utmost importance.

SCP exercises need to focus more on communities and see them as potential allies instead of enemies. In effect these plans, like much official State knowledge attempt produce an all knowing gaze (Mathews, 2011) over a series of complex interactions such as biodiversity conservation. They produce the veneer of an understanding of a place (Kosek, 2007), yet they ignore land tenure, local beliefs and knowledge pertaining to conservation and institutions. They intend to create an apolitical method of biodiversity conservation, yet the creation and ongoing management reserves if profoundly political and often distributes costs and benefits unequally (Neumann, 1998; Haenn, 2007; Li, 2007; Dowie, 2009; Odgen, 2010). SCP exercises need to better work to incorporate local factors into its analysis. In the case of the subregion such analysis would show not what types of public protected areas are needed, but that no top-down public protected areas are needed at all. Such a result should be possible for SCP exercises.

In this chapter, I have argued that the forces that have driven passive conservation in the region are not entirely apolitical. Communities have territories where they had millennial presence which they formally applied for through the agrarian reform processes and received that have small percentages of suitable agricultural land. Lack of infrastructure such as roads has further made reaching more suitable areas for agricultural difficult. Declining subsidies has led to coffee abandonment in the subregion. No commodity has since replaced it in for income generation.

These factors in effect have led to low opportunity costs in the subregion, which may explain the enthusiasm over PES compensation which equates roughly to earnings from $1 / 5$ an acre of coffee production. Though communities have enacted collective action for conservation 
they are receiving a fraction of what studies have estimated TMCFs are worth in their ES provision.

The idea of global freeriding is highly explanatory in that communities receive national payments for a single ES like hydrological services, while there is global appropriation of all the additional ES their forest conservation produces. In effect, economically marginalized communities limiting agricultural production and are producing ES in the service the world, while only receiving modest national payments.

Yet if PES compensation is problematic, recent SCP exercises have advocated for the creation of public protected areas without considering community land tenure and ongoing conservation practices. These articles assume that such biodiversity is not sustainable in community management regimes and so the government needs to take control in form of public protected areas. Such SCP exercises ignore over two decades of studies in the Sierra Norte alone that demonstrate community management of their forests. 


\section{CHAPTER 5}

\section{Conclusion}

In this thesis, I have examined that this subregion of the Sierra Norte made up of seven communities which has conserved $88.34 \%$ of the total area as forest cover, which 58,956 hectares of a total 66,264 . This high forest cover is not the result of national protected areas, but instead community forest governance. While various SCP exercises have focus on the Sierra Norte as important for biodiversity conservation (Arriaga, 2000; Cantu et al., 2004; Brandon et al., 2005;

Illoldi-Rangel et al., 2008; CONAFOR, 2010; Ponce-Reyes et al., 2012; Rojas-Soto et al., 2012), communities have democratically voted against reserve creation on two occasions (Bray, 1991; Bray et al., 2012).

Instead of being managed as public protected areas, $82.3 \%$ of forests in the state of Oaxaca (Madrid et al., 2009). and 100\% of forests in the subregion and are managed as common property by communities. While commons studies have generally focused on the appropriation and provision of resources for productive uses (Ostrom, 1990; Agrawal, 2001), others have examined how communities can organize collective action around conservation (VelascoMurguia, 2011; Bray et al., 2012).

Mexican environmental policy has recently sought to form linkages to communities through its PES and VCA programs. Communities apply for five year contracts for the PES program, which gives yearly payments based on compliance. Six of seven of the communities in the subregion receive PES, while the other community, San Felipe, formerly received PES. The certification of a VCA generally awards communities a one-time project for community development, but offers no yearly payments. Contracts range from 15 years to perpetuity. Communities in the CORENCHI communities to are the national leaders in VCA certification (Bray et al., 2012; Duran et al., 2012). The only community to not currently receive PES 
payments, San Felipe de Leon, is the only community in the subregion to have certified a VCA. The other communities were either unaware or seemingly disinterested in the VCA program because of its lack of continued direct payments for conservation.

The methods I selected for this study included: archival research and the revision of documents in communities, focus groups with community leaders and land use transects. I visited three archives in the state capital of Oaxaca City to gather data on the founding of these communities, historical narratives, boundary disputes and any other pertinent information. In the communities I solicited and reviewed OTCs, logging management plans, community statutes, PES documents and any other documents related to forests and community governance. I obtained the majority of my quantitative data from OTCs, which provided the amount of land zoned for agriculture and often classified forests types. In some cases the OTC also specified specific zones for conservation.

Next, I invited past and present community leaders to attend a focus group interview. I conducted focus group interviews in each in all the main villages of the communities (cabeceras) as well as outlying villages (agencias). These focus groups lasted between 1 and 2 hours and ranged in participants from 2 to 7 people. The focus of these focus groups was obtaining quantitative data related to different agriculture areas and practices for milpas, coffee farms, cattle pastures and any other major crops in the community. I explored the historical agricultural areas and how these may have changed. I also asked specifically about informal conservation at the community level as well as their entrance into governmental programs. These focus group interviews led to snowball sampling which generating roughly 50 informal interviews with rightsholders.

Last, I conducted land use transects with a community guide. Generally these were halfday hikes around agricultural areas, as the conserved areas were distant from villages. Here I would make frequent stops to ask the guide what the current land use was, what it had been and 
what it might be in the future. During these walks I collected important data related to agricultural practices and observed that there was significant agricultural abandonment even in areas zoned as agriculture. These land use transects have led me to believe that the estimates I have given for forest cover are if anything are conservative. Agricultural abandonment as a result of migration has likely increased forest cover beyond the already high forest cover numbers which I have provided in this thesis, because land zoned for agriculture is now forested.

I chose this region along with my advisor because of the dominance of common property and high forest cover shown in classified remote sensing images. Previous students had extensively studied the CORENCHI communities to the north of the subregion (Figel, 2008; Hite, 2011; Nieratka, 2011; Velasco-Murguia, 2011; Berget, 2012) and this thesis intended to explore if similar processes had conserved forests in the subregion made up of seven communities.

Furthermore, studies have selected it as an important area for TMCF conservation, which is a forest type that has faced high rates of clearing nationwide (CONABIO, 2010; Ponce-Reyes et al., 2012; Rojas-Soto et al., 2012).

All communities have milpa agricultural with the extent dedicated to milpas ranging from 1,488 hectares in San Felipe to 144 hectares in Cuasimulco. Hectares for coffee production range from 0 hectares in Ixtlán to roughly 600 hectares in San Mateo Yetla. Cattle ownership is a more recent land use in the region and ranges from 2 hectares in Nuevo Rosario to 340 in Comaltepec. The communities of Ixtlán, Comaltepec and Yolox all commercially log their pine-oak forests. Ixtlán has 7,354 hectares; Comaltepec has 3,000 and Yolox, 2,300 hectares. Yet, despite these differing land uses, the commonality among all communities is high forest cover, which ranges from $78 \%$ in Yetla to $94 \%$ in Ixtlán.

Upon the suggestion of my advisor, I have classified this data into two epochs of conservation in the subregion. The first was composed of largely passive conservation. Drivers of passive conservation for the subregion include: large, well-delimited territories, distant areas with 
difficult access, low population densities, continued outmigration, historical and current lack of cattle promotion, diminishing agricultural subsidies for corn and coffee as well as steep slopes and poor soils. Farming practices for milpa agriculture and for coffee production have managed to work under these constraints while maintaining soil fertility and the soil itself. The considerable knowledge rightsholders have to work common lands in the subregion has allowed agricultural areas to remain relatively fixed, because rightsholders have not had to expand into forests because of a loss of agricultural productivity.

Conservation in the subregion previously was passive because communities did not necessarily discuss or plan this conservation, but occurred largely because of the aforementioned factors. I have categorized this passive conservation as informal because it has historically not been recognized by the government. While they have been and continue to be agricultural communities, communities have increased attention paid to nonproductive forests in some cases where they have not farmed for decades if not longer.

I have classified this movement away from passive and informal conservation to formal and active conservation. It is active because communities have undertaken considerable work and collective action to examine their entire territories. It happened largely in two phases throughout the subregion: 1) CFEs (1980s) 2) PES (2000s).

Ixtlán, Comaltepec and Yolox have community forestry enterprises (CFEs) CFEs log their forests for commercial purposes (Bray et al., 2005). For the CFE pathway to active conservation, communities forged inter-community collective action in order to end the era of logging concessions which had unsustainably logged forests and provided few benefits to rightsholders who had to work in their own forests as day laborers (Chapela, 2005; in Bray et al., 2005). The communities in the Sierra Norte who won the control of their forests speak proudly of their victory in early 1980 s. Gaining control of their forests led to them to create management 
plans for their pine-oak forests and in the case of Comaltepec for all forests in their territory in the late 1980 s and early 1990s.

Community forestry now produces roughly 300 jobs in a region where off-farm employment is minimal. Furthermore, these CFE communities have had the time to produce far more potent conservation discourses (Mathews, 2011), while rightsholders see working their forests as a way that has and will conserve them for future generations.

The most important move to active conservation among the non-CFE communities has been the creation of OTCs which communities undertook in the 2000s. To categorize current land uses, NGOs use a combination of geospatial techniques such as remote sensing and GIS combined with participatory methods. In completing these OTCs, partnering NGOs had rightsholders fill in maps with current land uses and as well as supply a community history. NGO employees and rightsholders also went for walks through their territories. Therefore, communities began to envision their entire territory as a planning unit and have planned accordingly with predominance towards forest conservation. All communities have created an OTC, though rightsholders in Ixtlán were not able to locate their OTC for my revision.

Five of the seven communities have created community statutes, with Nuevo Rosario and Cuasimulco lacking statutes. These statutes create rules pertaining to the naming of rightsholders and in some cases also contained rules and sanctions pertaining to forests. Ixtlán, whose forests directly and indirectly have created 250 jobs has far and away the most comprehensive statutes explicitly detailing rules and sanctions related to forests. They have the easily the most commercially valuable forests as they have 7,354 hectares of pine-oak forest and have the most incentive to increase rules and sanctions to govern these forests. Like Ixtlán, the community of San Felipe created its community statutes and distributed a copy to rightsholders in a move of community-level democracy. 
All communities save Yolox and Cuasimulco, who received their official land title in 2009, entered the PROCEDE program or its successor FANAR. While PROCEDE intended to create private parcels from formally communal ejido lands, (Haenn, 2006; Barismantov, 2009; Shapiro, 2010), like in much of Mexico, San Felipe and Nuevo Rosario, which are the two ejidos in the subregion, decided not to create private parcels or privatize their ejidal lands. Instead, communities maintained common property and clarified boundaries through a program meant to privatize ejidal land (Shapiro, 2010). While an unresolved boundary dispute lead to murders and kidnappings between Comaltepec and Yolox in the 1950s, the conflict currently remains in a bureaucrat stage with neither community working the area in conflict.

In descending order, OTCs, community statutes and PROCEDE prepared non-CFE communities to enter the stage of more active and formal conservation. The PES program, which began in 2003 provided benefits for forest conservation and the hydrological and in some cases the biodiversity services they provide. The government had long promoted the importance of forest cover for the local provision of hydrological services (Simonian, 1995; Mathews, 2011; Wakild, 2011). Evidence has shown the relation to contingent on a far more complex set of factors than merely maintaining forest cover (Forsyth, 2003; Mathews, 2011). Nonetheless, the almost universal response from rightsholders as to why they are conserving is because forests provide local benefits such as water and oxygen.

Currently, communities receive payments for 7,718 hectares of forest, which is only $13 \%$ of total forest cover in the subregion. Payments are MXN \$860 for TMCF and MXN\$ 658 (USD\$ 72 and USD\$ 58) for other forest types (Shapiro, 2010). For the entire subregion PES earn communities MXN\$6,243,580 (USD\$ 520,298). Evenly divided between the 1,995 rightsholders in the subregion, each rightsholder would receive MXN\$ 3130 (USD\$268). The total would be greater except that CONAFOR did not renew its PES contract with San Felipe de Leon for 2438 hectares. 
Though the VCA program provides a one-time investment in community infrastructure, communities in the subregion have not expressed interest in certifying VCAs. Only San Felipe de Leon has a VCA of 3500 hectares of $6 \%$ of forests in the subregion, which they certified after promotion from their partnering NGO. Promotion from NGOs has been crucial in the certifying of the largest block of VCAs in the country in the CORENCHI communities (Bray et al., 2012).

Despite the willingness by communities to actively conserve their forests, a vocal minority in the subregion expresses dissent to conservation. Dissent exists most prominently in the communities of San Felipe, Yetla and Comaltepec and primarily in their outlying villages (agencias). In San Felipe dissent largely revolves around the fact that rightsholders create OTCS, their community statues to enter the PES program. They certified their VCA to strengthen their case for contract renewal, but CONAFOR ceased PES after a single five-year contract. In Yetla rightsholders in the agencia of La Nueva Esperanza argued that they could earn more by growing coffee in the PES area than through PES and conservation. In fact, current PES rates pay one-fifth of what average production would be for a coffee farm in the subregion. Lastly, rightsholders in the agencia of Soyolapam in Comaltepec argue that it is their poverty and lack of technology which maintains forest cover. They express dissent that the community assembly of Comaltepec has informally conserved at the community level a hillsides rightsholders in Soyolapam would like to work. Despite this dissent, there is no case yet of any rightsholders going against community decisions and working in these conserved areas.

Taking a cue from this dissent to conservation, I argued in Chapter 4 that material benefits have been modest for forests which researchers and the government have argued are important for global biodiversity conservation (Arriaga, 2000; Cantu et al., 2004; Brandon et al., 2005; Illoldi-Rangel et al., 2008; CONAFOR, 2010; Ponce-Reyes et al., 2012; Rojas-Soto et al., 2012). Factors which have led to passive conservation often have led to poverty in the region such as lack of access to suitable agricultural areas, lack of infrastructural development and 
dwindling support and subsidies for agricultural. Migration, along with its positives and negatives for families and communities has been the answer to the lack of off-farm employment in much of the region beginning in 1990s. Recent border crackdowns and drug-related violence as well as a depressed economy in the United States have made crossing the border prohibitive. Rightsholders argue that they will now need to support their families from agriculture more than they have had for decades now that remittances are dwindling.

PES that better compensate the subregion for the globally important forests they are conserving could aid communities who have passively conserved these forests for decades without payments and are now actively managing their entire territories. In these communities conservation has the chance to demonstrate that it can compensate communities who in the absence of protected areas that have maintained high forest cover. Instead of offering modest payments, PES should adequately compensation economically marginal communities for their ongoing conservation of globally important forests. Yolox and Comaltepec have also begun to invest PESs in ecotourism projects meant to diversify local economies. Greater funds could aid these job creation efforts.

Other scholars argued that protected areas are necessary in the Sierra Norte (Ponce-Reyes et al., 2012; Rojas-Soto et al., 2012), despite the fact that communities have twice voted against the creation of Biosphere Reserves on their land (Bray, 1991; Bray et al., 2012). Furthermore, this thesis is by no means the first document to demonstrate forest management in the Sierra Norte (Bray, 1991; Chapela, 2005, in Bray et al., 2005; CONABIO, 2010; Mathews, 2011; Figel et al., 2011; Hite, 2011; Nieratka, 2011; Robson, 2011; Mathews, 2011; Toledo-Aceves et al., 2011; Velasco-Murguia, 2011; Bray et al., 2012; Duran et al., 2012). Others have argued for a linear deforestation trend in the Sierra Norte from 1980-2000 for all forest types save pine-oak forests (Gomez-Mendoza et al., 2006). Conversely, Ponce-Reyes et al. (2012) has argued that even if communities are currently conserving TMCF, unspecified factors may lead to the clearing of all 
TMCF not in protected areas. Authors then suggest for the rapid creation of protected areas in the TMCF areas of the Sierra Norte. They make this recommendation without examining land tenure or ongoing community conservation.

Save for Brandon et al. (2005), these SCP exercises neglect land tenure and the possibility that the high incidence of biodiversity may be connected to the historical and ongoing community ownership of the lands. While protected areas have caused human displacement since the inception of government protected areas in Yosemite (Dowie, 2009), the communities in the subregion do not face such threats as they hold secure land tenure and the ability to democratically decide whether they accept a protected area or not (Bray et al., 2012).

As communities have the final say over a protected area, conservation scholars should use their time more wisely and not create SCP exercises in regions where communities hold strong land tenure and where they are conserving their forests. Though many conservationists have their doubts about communities as conservationists (Terborgh, 1999; Wilshusen et al., 2002; Chapin, 2004), this thesis shows how communities have conserved, are conserving and likely will continue to conserve their forests informally at the community level and formally through government programs. A far more important task than yet another SCP for the Sierra Norte would be to work with communities, NGOs and the government to enact policies that continue to support communities in their conservation and compensate these communities, while giving rightsholders another option other than to migrate and work abroad in order to provide for their families. While I would not argue that conservation has necessarily been a cause of poverty in the subregion, forest conservation outside of commercially valuable pine-oak forests has done little to alleviate poverty in the subregion.

What remains now to watch for is how Mexico and the world will choose to recognize and reward such conservation with the importance so many studies grant these forests, or if modest payments and global freeriding will largely continue. Conservation has thus far garnered 
far more academic and governmental attention that it has improved the material condition of these communities. It is time for governments, NGOs and citizens to decide if they wish to continue to freeride and take advantage of the host of environmental services provided by these communities, of if there is a more just way of compensating these economically marginalized yet proactive and cohesive communities for their conservation.

As of now communities receive far more praise and attention than they receive funds for their conservation. With continued species endangerment and extinction as well as more pronounced affects from anthropogenic climate change continue wreaking havoc globally; it would seem that conservation is more needed than ever. Yet, large and unresolved questions pertaining to conservation remain about how to provide more support and payments for communities that are conserving biodiversity and storing carbon, and who are not threatening them with deforestation. REDD+ may be able to provide additional funds for these communities, though many questions remain regarding REDD+ (Parker, 2009). Thus far, conservation has been more talk than action in relation to providing incentives that adequately compensate these communities for their conservation. 


\section{Bibliography}

1. Agraria, L. (1993). Ley Agraria de 1992. México, Sista,

2. Agrawal, A. (2001). Common property institutions and sustainable governance of resources. World Development, 29(10), 1649-1672.

3. Agrawal, A. (2007). Forests, governance, and sustainability: Common property theory and its contributions. International Journal of the Commons, 1(1), 111-136.

4. Agrawal, A., Gupta, A., Hathaway, M., Narotzky, S., Raffles, H., Skaria, A., . . Agrawal, A. (2005). Environmentality. Current Anthropology, 46(2), 161-190.

5. Albers, H. J., \& Goldbach, M. (2000). Irreversible ecosystem change, species competition, and shifting cultivation. Resource and Energy Economics, 22(3), 261-280.

6. Alcorn, J. B. (1993). Indigenous peoples and conservation. Conservation Biology, 7(2), 424426.

7. Aldrich, M., Billington, C., Edwards, M., \& Laidlaw, R. (1997). Tropical montane cloud forests: An urgent priority for conservation World Conservation Monitoring Centre.

8. Alier, J. M., \& Martinez-Alier, J. (2002). The environmentalism of the poor: A study of ecological conflicts and valuation Edward Elgar Pub.

9. Alix-Garcia, J., de Janvry, A., Sadoulet, E., Torres, J. M., Varela, J. B., \& Ramos, M. Z. (2005). An assessment of Mexico's payment for environmental services program.

Unpublished Paper Prepared for FAO by UC Berkeley and the Centre for Research and Teaching of Economics, Mexico,

10. Alix-Garcia, J., Shapiro, E., \& Sims, K. (2010). Forest conservation and slippage: Evidence from Mexico's national payments for ecosystem services program. University of WisconsinMadison, Department of Agricultural and Applied Economics, Staff Paper Series, 548, 1-53.

11. Angelsen, A., \& Kaimowitz, D. (1999). Rethinking the causes of deforestation: Lessons from economic models. The World Bank Research Observer, 14(1), 73-98.

12. Antinori, C., \& Bray, D. B. (2005). Community forest enterprises as entrepreneurial firms: Economic and institutional perspectives from Mexico. World Development, 33(9), 15291543.

13. Antinori, C., \& Rausser, G. (2007). Collective choice and community forestry management in Mexico: An empirical analysis. The Journal of Development Studies, 43(3), 512-536.

14. Arizpe, L., Paz, F., \& Velázquez, M. (1996). Culture and global change: Social perceptions of deforestation in the lacandona rain forest in mexico University of Michigan Press.

15. Arriaga, L. (2000). Regiones terrestres prioritarias de méxico Comisión Nacional para el Conocimiento y Uso de la Biodiversidad. 
16. Arriaga, L., Aguilar, V., \& Alcocer, J. (2001). Regiones hidrológicas prioritarias.

17. Balmford, A., Bruner, A., Cooper, P., Costanza, R., Farber, S., Green, R. E., . . Madden, J. (2002). Economic reasons for conserving wild nature. Science, 297(5583), 950-953.

18. Bandeira, F. P., Martorell, C., Meave, J. A., \& Caballero, J. (2005). The role of rustic coffee plantations in the conservation of wild tree diversity in the chinantec region of mexico. Biodiversity and Conservation, 14(5), 1225-1240.

19. Barabas, A., \& Bartolomé, M. A. (1999). Historia chinanteca Centro INAH Oaxaqua y CONACULTA.

20. Barbier, E. B., \& Burgess, J. C. (1996). Economic analysis of deforestation in mexico 31. Environment and Development Economics, 1, 203-239.

21. Barsimantov, J. A., Racelis, A. E., Barnes, G., \& DiGiano, M. (2009). Tenure, tourism and timber in quintana roo, mexico: Land tenure changes in forest ejidos after agrarian reforms. International Journal of the Commons, 4(1), 293-318.

22. Bartra, A. (1985). Los herederos de zapata: Movimientos campesinos posrevolucionarios en méxico, 1920-1980 Ediciones Era.

23. Beezley, W. H., \& MacLachlan, C. M. (2009). Mexicans in revolution, 1910-1946: An introduction University of Nebraska Press.

24. Berget, C. (2012). Invasion of bracken fern in southern mexico: Local knowledge and perceptions in two indigenous communities in the chinantla region, oaxaca, mexico.

25. Berkes, F. (2007). Community-based conservation in a globalized world. Proceedings of the National Academy of Sciences, 104(39), 15188-15193.

26. Berkes, F., Colding, J., \& Folke, C. (2000). Rediscovery of traditional ecological knowledge as adaptive management. Ecological Applications, 10(5), 1251-1262.

27. Birol, E., \& Villalba, E. R. (2006). Estimating mexican farmers' valuation of milpa diversity and genetically modified maize: A choice experiment approach. Environmental Economy and Policy Research Working Papers, 21

28. Birol, E., Villalba, E. R., \& Smale, M. (2009). Farmer preferences for milpa diversity and genetically modified maize in mexico: A latent class approach. Environment and Development Economics, 14(4), 521.

29. Bonilla-Moheno, M., Aide, T., Alvarez-Berrios, N., Andrade-Nunez, M., Arache-Martinez, A., Roman, G., \& Sanchez-Cuervo, A. (2012). Environmental social science: Humanenvironment interactions and sustainability. Conservation and Society, 10(4), 386.

30. Bonilla-Moheno, M., Redo, D. J., Aide, T. M., Clark, M. L., \& Grau, H. R. (2013). Vegetation change and land tenure in mexico: A country-wide analysis. Land use Policy, $30(1), 355-364$. 
31. Borrini-Feyerabend, G., Banuri, T., Farvar, T., Miller, K., \& Phillips, A. (2002). Indigenous and local communities and protected areas: Rethinking the relationship. Parks, 12(2), 5-15.

32. Bost, J. B. (2009). Edible Plants of the Chinantla, Oaxaca, Mexico with an Emphasis on the Participatory Domestication Prospects of Persea Schiedeana,

33. Bowles, S., \& Gintis, H. (2000). The evolution of strong reciprocity. Economics Department Working Paper Series, , 85.

34. Brandon, K., Gorenflo, L. J., Rodrigues, A. S., \& Waller, R. W. (2005). Reconciling biodiversity conservation, people, protected areas, and agricultural suitability in mexico. World Development, 33(9), 1403-1418.

35. Brandon, K., Redford, K., \& Sanderson, S. (1998). Parks in peril: People, politics, and protected areas Island Press.

36. Braun, B. (2002). Intemperate rainforest: Nature, culture, and power on canada's west coast University of Minnesota Press.

37. Bray, D., Duran, E., Molina,O. (2012). Beyond harvests in the commons: Multi-scale governance and turbulence in indigenous/community conserved areas in oaxaca, mexico. International Journal of the Commons, 6(2)

38. Bray, D. B., Sanchez, J. L. P., \& Murphy, E. C. (2008). Social dimensions of organic coffee production in mexico: Lessons for eco-labeling initiatives. Confronting the Coffee Crisis: Fair Trade, Sustainable Livelihoods and Ecosystems in Mexico and Central America, , 237260.

39. Bray, D. B. (1991). The struggle. Grassroots Development, 15, 3.

40. Bray, D. B. (2010). Forest cover dynamics and forest transitions in mexico and central america: Towards a "Great restoration"? Reforesting Landscapes, , 85-120.

41. Bray, D. B., Duran, E., Ramos, V. H., Mas, J., Velazquez, A., McNab, R. B., . . . Radachowsky, J. (2008). Tropical deforestation, community forests, and protected areas in the maya forest. Ecology and Society, 13(2), 56.

42. Bray, D. B., Duran, E., Ramos, V. H., Mas, J., Velazquez, A., McNab, R. B., . . . Radachowsky, J. (2008). Tropical deforestation, community forests, and protected areas in the maya forest. Ecology and Society, 13(2), 56.

43. Bray, D. B., Merino-Pérez, L., \& Barry, D. (2005). The community forests of mexico: Managing for sustainable landscapes University of Texas Press. 
44. Bray, D. B., Merino-Pérez, L., Negreros-Castillo, P., Segura-Warnholtz, G., Torres-Rojo, J.

M., \& Vester, H. F. (2003). Mexico's Community-Managed forests as a global model for

sustainable landscapes. Conservation Biology, 17(3), 672-677.

45. Bray, D. B., Sanchez, J. L. P., \& Murphy, E. C. (2002). Social dimensions of organic coffee production in mexico: Lessons for eco-labeling initiatives. Society \&Natural Resources, 15(5), 429-446.

46. Brockington, D., Duffy, R., \& Igoe, J. (2008). Nature unbound: Conservation, capitalism and the future of protected areas Earthscan/James \& James.

47. Brooks, T. M., Mittermeier, R. A., da Fonseca, G. A., Gerlach, J., Hoffmann, M., Lamoreux, J. F., . . Rodrigues, A. S. (2006). Global biodiversity conservation priorities. Science, 313(5783), 58-61.

48. Brown, K. (1998). The political ecology of biodiversity, conservation and development in nepal's terai: Confused meanings, means and ends. Ecological Economics, 24(1), 73-87.

49. Bruner, A. G., Gullison, R. E., Rice, R. E., \& Da Fonseca, G. A. (2001). Effectiveness of parks in protecting tropical biodiversity. Science, 291(5501), 125-128.

50. Busch, C., \& Geoghegan, J. (2010). Labor scarcity as an underlying cause of the increasing prevalence of deforestation due to cattle pasture development in the southern yucatán region. Regional Environmental Change, 10(3), 191-203.

51. Butchart, S. H., Scharlemann, J. P., Evans, M. I., Quader, S., Aricò, S., Arinaitwe, J., . . Besançon, C. (2012). Protecting important sites for biodiversity contributes to meeting global conservation targets. PloS One, 7(3), e32529.

52. Cantu, C., Gerald Wright, R., Michael Scott, J., \& Strand, E. (2004). Assessment of current and proposed nature reserves of mexico based on their capacity to protect geophysical features and biodiversity. Biological Conservation, 115(3), 411-417.

53. Cantú, C., Scott, J. M., \& Wright, R. G. (2001). The gap analysis program on the assessment of nature reserves of mexico. Gap Analysis Bulletin, 10, 8-11.

54. Caro, T., Jones, T., \& Davenport, T. R. (2009). Realities of documenting wildlife corridors in tropical countries. Biological Conservation, 142(11), 2807-2811.

55. Cayuela, L., Benayas, J. M. R., \& Echeverría, C. (2006). Clearance and fragmentation of tropical montane forests in the highlands of chiapas, mexico (1975-2000). Forest Ecology and Management, 226(1), 208-218. 
56. Ceballos, G. (2007). Conservation priorities for mammals in megadiverse mexico: The efficiency of reserve networks. Ecological Applications, 17(2), 569-578.

57. Ceballos, G., Rodríguez, P., \& Medellín, R. A. (1998). Assessing conservation priorities in megadiverse mexico: Mammalian diversity, endemicity, and endangerment. Ecological Applications, 8(1), 8-17.

58. Chance, J. K. (2001). Conquest of the sierra: Spaniards and indians in colonial oaxaca University of Oklahoma Press.

59. Chapin III, F. S., Zavaleta, E. S., Eviner, V. T., Naylor, R. L., Vitousek, P. M., Reynolds, H. L., . . Hobbie, S. E. (2000). Consequences of changing biodiversity. Nature, 405(6783), 234-242.

60. Chapin, M. (2004). World• watch world• watch.

61. Chazdon, R. L., Harvey, C. A., Komar, O., Griffith, D. M., Ferguson, B. G., Martínez-Ramos, M., . . Van Breugel, M. (2008). Beyond reserves: A research agenda for conserving biodiversity in human-modified tropical landscapes. Biotropica, 41(2), 142-153.

62. Clarke, C. G. (2000). Class, ethnicity, and community in southern mexico Oxford University Press.

63. CONABIO. (2010). El bosque mesófilo de montaña en méxico: Amenazas y oportunidades para su conservación y manejo sostenible.

64. Cronon, W. (1996). The trouble with wilderness: Or, getting back to the wrong nature. Environmental History, 1(1), 7-28.

65. Dalle, S. P., de Blois, S., Caballero, J., \& Johns, T. (2006). Integrating analyses of local landuse regulations, cultural perceptions and land-use/land cover data for assessing the success of community-based conservation. Forest Ecology and Management, 222(1), 370-383.

66. de Población, XI Censo General.Vivienda y conteo 1995.

67. DeFries, R., Hansen, A., Newton, A. C., \& Hansen, M. C. (2005). Increasing isolation of protected areas in tropical forests over the past twenty years. Ecological Applications, 15(1), 19-26.

68. Deininger, K., \& Minten, B. (2002). Determinants of deforestation and the economics of protection: An application to mexico. American Journal of Agricultural Economics, 84(4), 943-960. 
69. Del Castillo, R., \& Rios, M. P. (2008). Changes in seed rain during secondary succession in a tropical montane cloud forest region in oaxaca, mexico. Journal of Tropical Ecology, 24(4), 433.

70. Dietsch, T. V., Philpott, S. M., Rice, R. A., Greenberg, R., \& Bichier, P. (2004). Conservation policy in coffee landscapes. Science, 303(5658), 625-626.

71. Dietz, T., Ostrom, E., \& Stern, P. C. (2003). The struggle to govern the commons. Science, 302(5652), 1907-1912.

72. Doane, Molly. Stealing Shining Rivers: Agrarian Conflict, Market Logic, and Conservation in a Mexican Forest. University of Arizona Press, 2012.

73. Dowie, M. (2009). Conservation refugees: The hundred-year conflict between global conservation and native peoples MIT Press.

74. Duran, E., Robson, J., Briones-Salas, M., \& Barton, D.Mexico: Wildlife conservation on community conserved lands in oaxaca. Protected Landscapes and Wild Biodiversity, , 71.

75. Durand, L., \& Lazos, E. (2008). The local perception of tropical deforestation and its relation to conservation policies in los tuxtlas biosphere reserve, mexico. Human Ecology, 36(3), 383394.

76. Durán-Medina, A., Mas, J., \& Velázquez, A. (2005). Land use/cover change in communitybased forest management regions and protected areas in mexico. The Community Forests of Mexico: Managing for Sustainable Landscapes. University of Texas Press, United States of America, , 215-238.

77. Durán-Medina, A., Mas, J., \& Velázquez, A. (2005). Land use/cover change in communitybased forest management regions and protected areas in mexico. The Community Forests of Mexico: Managing for Sustainable Landscapes. University of Texas Press, United States of America, , 215-238.

78. Elizondo, C., \& López, D. (2009). Las áreas voluntarias de conservación en quintana roo. México: Corredor Biológico Mesoamericano México.México: Conabio,

79. Ellis, E. A., \& Porter-Bolland, L. (2008). Is community-based forest management more effective than protected areas?: A comparison of land use/land cover change in two neighboring study areas of the central yucatan peninsula, mexico. Forest Ecology and Management, 256(11), 1971-1983.

80. Ellis, E. A., \& Porter-Bolland, L. (2008). Is community-based forest management more effective than protected areas?: A comparison of land use/land cover change in two neighboring study areas of the central yucatan peninsula, mexico. Forest Ecology and Management, 256(11), 1971-1983.

81. Engel, S., Pagiola, S., \& Wunder, S. (2008). Designing payments for environmental services in theory and practice: An overview of the issues. Ecological Economics, 65(4), 663-674. 
82. Escobar, A. (1998). Whose knowledge, whose nature? biodiversity, conservation, and the political ecology of social movements. Journal of Political Ecology, 5(1), 53-82.

83. Escobar, A. (2008). Territories of difference: Place, movements, life, redes Duke University Press Books.

84. Feyerabend, G., \& Kothari, A. (2004). Indigenous and local communities and protected areas: Towards equity and enhanced conservation World Conservation Union.

85. Figel, J. J., Durán, E., \& Bray, D. B. (2011). Conservation of the jaguar panthera onca in a community-dominated landscape in montane forests in oaxaca, mexico. Oryx, 1(1), 1-7.

86. Figueroa, F., \& Sánchez-Cordero, V. (2008). Effectiveness of natural protected areas to prevent land use and land cover change in mexico. Biodiversity and Conservation, 17(13), 3223-3240.

87. FIGUEROA, F., SÁNCHEZ-CORDERO, V., MEAVE, J. A., \& TREJO, I. (2009). Socioeconomic context of land use and land cover change in mexican biosphere reserves. Environmental Conservation, 36(3), 180.

88. Figueroa-Navarro, C., Etchevers-Barra, J., VELAZQUEZMARTÍNEZ, A., \& AcostaMireles, M. (2005). Concentración de carbono en diferentes tipos de vegetación de la sierra norte de oaxaca. Terra Latinoamericana, 23, 57-64.

89. Flamenco-Sandoval, A., Martínez Ramos, M., \& Masera, O. R. (2007). Assessing implications of land-use and land-cover change dynamics for conservation of a highly diverse tropical rain forest. Biological Conservation, 138(1), 131-145.

90. Flamenco-Sandoval, A., Martínez Ramos, M., \& Masera, O. R. (2007). Assessing implications of land-use and land-cover change dynamics for conservation of a highly diverse tropical rain forest. Biological Conservation, 138(1), 131-145.

91. Fridell, M., Hudson, I., \& Hudson, M. (2008). With friends like these: The corporate response to fair trade coffee. Review of Radical Political Economics, 40(1), 8-34.

92. Fukuyama, F. (2011). The origins of political order: From prehuman times to the french revolution Profile Books.

93. Fuller, T., Sánchez-Cordero, V., Illoldi-Rangel, P., Linaje, M., \& Sarkar, S. (2007). The cost of postponing biodiversity conservation in mexico. Biological Conservation, 134(4), 593600 .

94. García-Frapolli, E., Ramos-Fernández, G., Galicia, E., \& Serrano, A. (2009). The complex reality of biodiversity conservation through natural protected area policy: Three cases from the yucatan peninsula, mexico. Land use Policy, 26(3), 715-722.

95. George, A. L., \& Bennett, A. (2005). Case studies and theory development in the social sciences Mit Press. 
96. Ghilarov, A. (1996). What does 'biodiversity'mean—scientific problem or convenient myth? Trends in Ecology \& Evolution, 11(7), 304-306.

97. Gibson, C. C., Williams, J. T., \& Ostrom, E. (2005). Local enforcement and better forests. World Development, 33(2), 273-284.

98. Golicher, D. J., Cayuela, L., \& Newton, A. C. (2011). Effects of climate change on the potential species richness of mesoamerican forests. Biotropica, 44(3), 284-293.

99. Gollnick, B. (2008). Reinventing the lacandón: Subaltern representations in the rain forest of chiapas University of Arizona Press.

100. Gómez-Mendoza, L., Vega-Peña, E., Isabel Ramírez, M., Palacio-Prieto, J. L., \& Galicia, L. (2006). Projecting land-use change processes in the sierra norte of oaxaca, mexico. Applied Geography, 26(3), 276-290.

101. Gomez-Pompa, A. (1987). On maya silviculture. Mexican Studies/Estudios Mexicanos, , $1-17$.

102. Gomez-Pompa, A., \& Kaus, A. (1992). Taming the wilderness myth. Bioscience, , 271279.

103. Gómez-Pompa, A., \& Kaus, A. (1999). From pre-hispanic to future conservation alternatives: Lessons from mexico. Proceedings of the National Academy of Sciences, 96(11), $5982-5986$.

104. Gomez-Pompa, A., Vazquez-Yanes, C., \& Guevara, S. (1972). The tropical rain forest: A nonrenewable resource. Science, 177(4051), 762-765.

105. Gonzalez, R. J. (2001). Zapotec science: Farming and food in the northern sierra of oaxaca University of Texas Press.

106. Gordon, J. E. (2006). The role of science in NGO mediated conservation: Insights from a biodiversity hotspot in mexico. Environmental Science \& Policy, 9(6), 547-554.

107. Gorenflo, L. J., \& Brandon, K. (2005). Agricultural capacity and conservation in high biodiversity forest ecosystems. AMBIO: A Journal of the Human Environment, 34(3), 199204.

108. Greenberg, R., Bichier, P., \& Sterling, J. (1997). Acacia, cattle and migratory birds in southeastern mexico. Biological Conservation, 80(3), 235-247.

109. H. Bernard. (2011). Research methods in anthropology: Qualitative and quantitative approaches Altamira press.

110. Haenn, N. (2005). Fields of power, forests of discontent: Culture, conservation, and the state in mexico University of Arizona Press.

111. Haenn, N. (2006). The changing and enduring ejido: A state and regional examination of mexico's land tenure counter-reforms. Land use Policy, 23(2), 136-146. 
112. Hayes, T. M. (2006). Parks, people, and forest protection: An institutional assessment of the effectiveness of protected areas. World Development, 34(12), 2064-2075.

113. Hayes, T., \& Ostrom, E. (2005). Conserving the world's forests: Are protected areas the only way. Ind.L.Rev., 38, 595.

114. Hite, E. B. (2011). Transformations of a coffee landscape in southern mexico: A case study of emigration and conservation in the sierra norte, oaxaca.

115. Holwerda, F., Bruijnzeel, L., Muñoz-Villers, L., Equihua, M., \& Asbjornsen, H. (2010). Rainfall and cloud water interception in mature and secondary lower montane cloud forests of central veracruz, mexico. Journal of Hydrology, 384(1), 84-96.

116. Hull, J. B. (1999). Can coffee drinkers save the rain forest. The Atlantic Monthly, 284(2), $19-21$.

117. Illoldi-Rangel, P., Fuller, T., Linaje, M., Pappas, C., Sánchez-Cordero, V., \& Sarkar, S.

(2008). Solving the maximum representation problem to prioritize areas for the conservation of terrestrial mammals at risk in oaxaca. Diversity and Distributions, 14(3), 493-508.

118. INEGI, I. Censo Nacional De Población y Vivienda (2010) Del INEGI.Censos y Conteos. Consultado El 21 De Octubre De 2011,

119. INEGI, I. (2005). Conteo de población y vivienda 2005. Indicadores Del Censo General De Población y Vivienda, Ed.INEGI, México,

120. INEGI, X. (1992). XI censo general de población y vivienda, 1990, resumen general.

121. Informática (México). (2001). Tabulados básicos: Estados unidos mexicanos: XII censo general de población y vivienda, 2000 INEGI.

122. Jaffee, D. (2007). Brewing justice: Fair trade coffee, sustainability, and survival University of California Press.

123. Janssen, M. A., \& Ostrom, E. (2006). Governing social-ecological systems. Handbook of Computational Economics, 2, 1465-1509.

124. Joppa, L. N., Loarie, S. R., \& Pimm, S. L. (2008). On the protection of "protected areas". Proceedings of the National Academy of Sciences, 105(18), 6673-6678.

125. Joppa, L. N., Loarie, S. R., \& Pimm, S. L. (2009). On population growth near protected areas. PLoS One, 4(1), e4279. 
126. Jung, C. (2008). The moral force of indigenous politics: Critical liberalism and the zapatistas. Public Archaeology, 7(4), 265-269.

127. Klooster, D. (2002). Community forestry and tree theft in mexico: Resistance or complicity in conservation? Development and Change, 31(1), 281-305.

128. Klooster, D. (2003). Campesinos and mexican forest policy during the twentieth century. Latin American Research Review, 38(2), 94-126.

129. Kosek, J. (2006). Understories: The political life of forests in northern new mexico Duke University Press Books.

130. Kosoy, N., \& Corbera, E. (2010). Payments for ecosystem services as commodity fetishism. Ecological Economics, 69(6), 1228-1236.

131. Krech, S. (1999). The ecological indian: Myth and history. New York,

132. Lambin, E. F., Turner, B. L., Geist, H. J., Agbola, S. B., Angelsen, A., Bruce, J. W., .. . Folke, C. (2001). The causes of land-use and land-cover change: Moving beyond the myths. Global Environmental Change, 11(4), 261-269.

133. Landell-Mills, N., \& Porras, I. T. (2002). Silver bullet or fools' gold?: A global review of markets for forest environmental services and their impact on the poor IIED London.

134. Lawton, R. O., Nair, U. S., Pielke Sr, R., \& Welch, R. M. (2001). Climatic impact of tropical lowland deforestation on nearby montane cloud forests. Science, 294(5542), 584-587.

135. Leroux, S. J., Krawchuk, M. A., Schmiegelow, F., Cumming, S. G., Lisgo, K., Anderson, L. G., \& Petkova, M. (2010). Global protected areas and IUCN designations: Do the categories match the conditions? Biological Conservation, 143(3), 609-616.

136. Lewis, J. M. (2005). Strategies for survival: Migration and fair trade-organic coffee production in oaxaca, méxico Center for Comparative Immigration Studies, University of California, San Diego.

137. Madrid, L., Núñez, J. M., Quiroz, G., \& Rodríguez, Y. (2009). La propiedad social forestal en méxico. Investigación Ambiental.Ciencia y Política Pública, 1(2), 179-196.

138. Martínez, M. L., Pérez-Maqueo, O., Vázquez, G., Castillo-Campos, G., García-Franco, J., Mehltreter, K., . . . Landgrave, R. (2009). Effects of land use change on biodiversity and ecosystem services in tropical montane cloud forests of mexico. Forest Ecology and Management, 258(9), 1856-1863.

139. Martínez, M. L., Pérez-Maqueo, O., Vázquez, G., Castillo-Campos, G., García-Franco, J., Mehltreter, K., .. . Landgrave, R. (2009). Effects of land use change on biodiversity and ecosystem services in tropical montane cloud forests of mexico. Forest Ecology and Management, 258(9), 1856-1863.

140. Marx, K. (1867). Capital, volume I. 
141. Mas, J. (2005). Assessing protected area effectiveness using surrounding (buffer) areas environmentally similar to the target area. Environmental Monitoring and Assessment, $105(1), 69-80$.

142. Mas, J. (2005). Assessing protected area effectiveness using surrounding (buffer) areas environmentally similar to the target area. Environmental Monitoring and Assessment, 105(1), 69-80.

143. Mathews, A. S. (2011). Instituting nature: Authority, expertise, and power in mexican forests MIT Press.

144. McAfee, K. (1999). Selling nature to save it? biodiversity and green deveiopmentaiism. Environment and Planning, 17, 133-154.

145. McNamara, P. J. (2007). Sons of the sierra: Juárez, diaz, and the people of ixtlán, oaxaca, 1855-1920 University of North Carolina Press.

146. Mendoza, E., \& Dirzo, R. (1999). Deforestation in lacandonia (southeast mexico): Evidence for the declaration of the northernmost tropical hot-spot. Biodiversity and Conservation, 8(12), 1621-1641.

147. México, Ley General del Equilibrio Ecológico. (2000). La protección al ambiente (LGEEPA), 1988. Ciudad De México (Con Reformas),

148. Moguel, P., \& Toledo, V. M. (1999). Biodiversity conservation in traditional coffee systems of mexico. Conservation Biology, 13(1), 11-21.

149. Molnar, A., Scherr, S. J., \& Khare, A. (2004). Who conserves the world's forests. Community-Driven Strategies to Protect Forests and Respect Rights.Forest Trends, Washington DC Available at: Www.Forest-Trends.Org,

150. Muñiz-Castro, M. A., Williams-Linera, G., \& Martínez-Ramos, M. (2012). Dispersal mode, shade tolerance, and phytogeographical affinity of tree species during secondary succession in tropical montane cloud forest. Plant Ecology, , 1-15.

151. Muñoz Piña, C., Rivera, M., Cisneros, A., \& García, H. (2011). Payment for environmental services in mexico: Targeting challenges. Revista Española De Estudios Agrosociales y Pesqueros,

152. Muñoz-Piña, C., Guevara, A., Torres, J. M., \& Braña, J. (2008). Paying for the hydrological services of mexico's forests: Analysis, negotiations and results. Ecological Economics, 65(4), 725-736.

153. Muñoz-Piña, C., Guevara, A., Torres, J. M., \& Braña, J. (2008). Paying for the hydrological services of mexico's forests: Analysis, negotiations and results. Ecological Economics, 65(4), 725-736. 
154. Muradian, R., Corbera, E., Pascual, U., Kosoy, N., \& May, P. H. (2010). Reconciling theory and practice: An alternative conceptual framework for understanding payments for environmental services. Ecological Economics, 69(6), 1202-1208.

155. Muradian, R., \& Pelupessy, W. (2005). Governing the coffee chain: The role of voluntary regulatory systems. World Development, 33(12), 2029-2044.

156. Nadal, A. (2000). Corn and NAFTA: An unhappy alliance. Seedling, 17(2), 10-17.

157. Nadal, A. (2002). Corn in NAFTA: Eight years after. Mexico.Informe Preparado Para La Comisión Norteamericana Para La Cooperación Del Medio Ambiente,

158. Nagendra, H. (2008). Do parks work? impact of protected areas on land cover clearing. AMBIO: A Journal of the Human Environment, 37(5), 330-337.

159. Naughton-Treves, L., Holland, M. B., \& Brandon, K. (2005). The role of protected areas in conserving biodiversity and sustaining local livelihoods. Annu.Rev.Environ.Resour., 30, 219-252.

160. Nepstad, D. C., Stickler, C. M., \& Almeida, O. T. (2006). Globalization of the amazon soy and beef industries: Opportunities for conservation. Conservation Biology, 20(6), 15951603.

161. Nestel, D. (1995). Coffee in mexico: International market, agricultural landscape and ecology. Ecological Economics, 15(2), 165-178.

162. Neumann, R. P. (2002). Imposing wilderness: Struggles over livelihood and nature preservation in africa University of California Press.

163. Nieratka, L. R. (2011). Do payments for hydrological services reduce poverty and strengthen social capital? an examination of household welfare and collective action in the sierra norte of oaxaca, mexico.

164. Ochoa-Gaona, S., \& González-Espinosa, M. (2000). Land use and deforestation in the highlands of chiapas, mexico. Applied Geography, 20(1), 17-42.

165. Ostrom, E. (1990). Governing the commons: The evolution of institutions for collective action Cambridge University Press.

166. Ostrom, E. (2008). Tragedy of the commons. The New Palgrave Dictionary of Economics,

167. Ostrom, E., Janssen, M. A., \& Anderies, J. M. (2007). Going beyond panaceas. Proceedings of the National Academy of Sciences, 104(39), 15176-15178.

168. Paavola, J. (2007). Institutions and environmental governance: A reconceptualization. Ecological Economics, 63(1), 93-103.

169. Perfecto, I., Vandermeer, J., Mas, A., \& Pinto, L. S. (2005). Biodiversity, yield, and shade coffee certification. Ecological Economics, 54(4), 435-446. 
170. Pimm, S. L., Ayres, M., Balmford, A., Branch, G., Brandon, K., Brooks, T., . . Curran, L. M. (2001). Can we defy nature's end? Science, 293(5538), 2207-2208.

171. Pineda, E., \& Halffter, G. (2004). Species diversity and habitat fragmentation: Frogs in a tropical montane landscape in mexico. Biological Conservation, 117(5), 499-508.

172. Polyani, K. (1944). The great transformation. New York: Rinehart,

173. Ponce-Reyes, R., Reynoso-Rosales, V., Watson, J. E., VanDerWal, J., Fuller, R. A., Pressey, R. L., \& Possingham, H. P. (2012). Vulnerability of cloud forest reserves in mexico to climate change. Nature Climate Change, 2(6), 448-452.

174. Porter-Bolland, L., Ellis, E. A., Guariguata, M. R., Ruiz-Mallén, I., Negrete-Yankelevich, S., \& Reyes-García, V. (2012). Community managed forests and forest protected areas: An assessment of their conservation effectiveness across the tropics. Forest Ecology and Management, 268, 6-17.

175. Ragin, C. C., \& Amoroso, L. M. (2010). Constructing social research: The unity and diversity of method Sage Publications, Incorporated.

176. Ramírez-Marcial, N., González-Espinosa, M., \& Williams-Linera, G. (2001). Anthropogenic disturbance and tree diversity in montane rain forests in chiapas, mexico. Forest Ecology and Management, 154(1), 311-326.

177. Robson, J. P. (2011). The impact of rural to urban migration on forest commons in oaxaca, mexico.

178. Rodrigues, A. S., Andelman, S. J., Bakarr, M. I., Boitani, L., Brooks, T. M., Cowling, R. M., ... Hoffmann, M. (2004). Effectiveness of the global protected area network in representing species diversity. Nature, 428(6983), 640-643.

179. Rodrigues, A. S., Andelman, S. J., Bakarr, M. I., Boitani, L., Brooks, T. M., Cowling, R. M., ... Hoffmann, M. (2004). Effectiveness of the global protected area network in representing species diversity. Nature, 428(6983), 640-643.

180. Rojas-Soto, O. R., Sosa, V., \& Ornelas, J. F. (2012). Forecasting cloud forest in eastern and southern mexico: Conservation insights under future climate change scenarios.

Biodiversity and Conservation, , 1-20.

181. ROMÁN-CUESTA, R., \& MARTÍNEZ-VILALTA, J. (2006). Effectiveness of protected

areas in mitigating fire within their boundaries: Case study of chiapas, mexico. Conservation Biology, 20(4), 1074-1086.

182. Romero, H. G. (2012). Payments for environmental services: Can they work?. the case of mexico. Field Actions Science Reports.the Journal of Field Actions, (Special Issue 6) 
183. Rudel, T. K., Coomes, O. T., Moran, E., Achard, F., Angelsen, A., Xu, J., \& Lambin, E. (2005). Forest transitions: Towards a global understanding of land use change. Global Environmental Change, 15(1), 23-31.

184. Rudel, T. K., Defries, R., Asner, G. P., \& Laurance, W. F. (2009). Changing drivers of deforestation and new opportunities for conservation. Conservation Biology, 23(6), 13961405 .

185. Sánchez-Cordero, V., Illoldi-Rangel, P., Linaje, M., Sarkar, S., \& Peterson, A. T. (2005). Deforestation and extant distributions of mexican endemic mammals. Biological Conservation, 126(4), 465-473.

186. Sanderson, S. E., \& Redford, K. H. (2003). Contested relationships between biodiversity conservation and poverty alleviation. Oryx, 37(04), 389-390.

187. Schlager, E., \& Ostrom, E. (1992). Property-rights regimes and natural resources: A conceptual analysis. Land Economics, , 249-262.

188. Scott, J. C. (1999). Seeing like a state: How certain schemes to improve the human condition have failed Yale University Press.

189. Shapiro, E. N. (2011). To revalue the rural? transformation of the mexican federal payments for ecosystem services programs from neoliberal notion to development dogma University of California, Berkeley.

190. Simonian, L. (1995). Defending the land of the jaguar: A history of conservation in mexico University of Texas Press.

191. Stadmuller, T. (1987). Cloud forests in the humid tropics. The United Nations University,

192. Still, C. J., Foster, P. N., \& Schneider, S. H. (1999). Simulating the effects of climate change on tropical montane cloud forests. Nature, 398(6728), 608-610.

193. Svancara, L. K., BRANNON J, R., SCOTT, M., Groves, C. R., Noss, R. F., \& Pressey, R. L. (2005). Policy-driven versus evidence-based conservation: A review of political targets and biological needs. Bioscience, 55(11), 989-995.

194. Terborgh, J. (2004). Requiem for nature Island Press.

195. Toledo, V. M., Ortiz-Espejel, B., Cortés, L., Moguel, P., \& Ordonez, M. d. J. (2003). The multiple use of tropical forests by indigenous peoples in mexico: A case of adaptive management. Conservation Ecology, 7(3), 9.

196. Toledo, V. M. (1989). Naturaleza, producción, cultura: Ensayos de ecología política Universidad Veracruzana.

197. Toledo-Aceves, T., Meave, J. A., González-Espinosa, M., \& Ramírez-Marcial, N. (2011). Tropical montane cloud forests: Current threats and opportunities for their conservation and sustainable management in mexico. Journal of Environmental Management, 92(3), 974-981. 
198. Tsing, A. L. (2011). Friction: An ethnography of global connection Princeton University Press.

199. Tucker, C. M. (2010). Learning on governance in forest ecosystems: Lessons from recent research. International Journal of the Commons, 4(2), 687-706.

200. Van Hecken, G., \& Bastiaensen, J. (2010). Payments for ecosystem services: Justified or not? A political view. Environmental Science \& Policy, 13(8), 785-792.

201. Vatn, A. (2010). An institutional analysis of payments for environmental services. Ecological Economics, 69(6), 1245-1252.

202. Velázquez, A., Durán, E., Ramírez, I., Mas, J., Bocco, G., Ramírez, G., \& Palacio, J. (2003). Land use-cover change processes in highly biodiverse areas: The case of oaxaca, mexico. Global Environmental Change, 13(3), 175-184.

203. Vitousek, P. M., Mooney, H. A., Lubchenco, J., \& Melillo, J. M. (1997). Human domination of earth's ecosystems. Science, 277(5325), 494-499.

204. Wakild, E. (2011). Revolutionary parks: Conservation, social justice, and mexico's national parks, 1910-1940.

205. Walker, R., Moran, E., \& Anselin, L. (2000). Deforestation and cattle ranching in the brazilian amazon: External capital and household processes. World Development, 28(4), 683699.

206. West, P. (2012). From modern production to imagined primitive: The social world of coffee from papua new guinea Duke University Press Books.

207. White, A., \& Martin, A. (2002). Who owns the world's forests? forest tenure and public forests in transition Washington, DC, USA.

208. Wilder, M., \& Romero Lankao, P. (2006). Paradoxes of decentralization: Water reform and social implications in mexico. World Development, 34(11), 1977-1995.

209. Williams-Linera, G. (2002). Tree species richness complementarity, disturbance and fragmentation in a mexican tropical montane cloud forest. Biodiversity and Conservation, 11(10), 1825-1843.

210. Wilshusen, P. R., Brechin, S. R., Fortwangler, C. L., \& West, P. C. (2002). Reinventing a square wheel: Critique of a resurgent" protection paradigm" in international biodiversity conservation. Society \&Natural Resources, 15(1), 17-40.

211. Wunder, S. (2005). Payments for environmental services: Some nuts and bolts CIFOR Bogor. 


\section{Appendix 1}

\section{Focus Group Interview}

\section{I.Land Use History}

Ia. In the principal cultivated area closest o the community, was there anything historically cultivated more than corns, squash and beans.

Ib. Has the area under corn cultivation decrease, what size was it in the 1950s?

1c. If coffee is cultivated now, when was it introduced and in what areas on the map are the cultivated areas of coffee? What is the total current size of the cultivated coffee area?

Id. Is there forest management for timber? When did this start and in what area on the map is it located?

Ie. Are there any important crops other than corn and coffee? If yes, which and were are these cultivated areas located?

If. Are there cattle? Where are they found on the map? In how many areas are there cattle? What is the total area of cattle?

\section{Community Rules}

IIa. Historically, were there laws about the use of land? For example, were there laws about where community members could cultivate corn?

IIb. Where there laws about the cultivated areas of coffee?

IIc. Where there laws against the collection of firewood? Medicinal plants? Other forest products?

IId. Does the community have written statues? If yes, when were they adapted? (If there are I will ask for a copy.)

\section{Community Conservation}

IIIa. Of the forests on the map, which have a management plan? Who utilizes this areas and why? Are there and how are they?

IIIb. Beyond the plan for forest management, are there other areas that the community doesn't permit that the land is cultivated or other land uses?

IIIc. Has the community formally decided that they will conserve this area? When did the community begin conservation?

IIId. Was there a community assembly to discuss matters of conservation? Was there a vote? 
IIIe. Where there any arguments against conservation? What arguements did they make?

\section{Conservation and Management}

IVa. What does conservation mean? What benefits does conservation have? What are the negative aspects of conservation?

IVb. Is it possible that community members extract non-timber forest projects from the conserved forests? Could they extract timber? Could community members live in the conserved forest? Could the community have an ecotourism project there? Does conservation last forever?

IVc. Does the community inspect the conserved forest? How often? How many people make these inspections? Are they paid?

IVd. Are there sanctions for those community members who utilize the conserved forest? What are the sanctions like for community members who use the conserve forest? Has anyone seen anyone breaking the rules? What would the sanctions be like for these people?

\section{Basis for Conservation}

Va. Did the population of the community change before conserving the forest? How?

$\mathrm{Vb}$. Has the economic situation of the community change before conserving the forest? How?

Vc. Was there an evironmental disaster or crisis before conserving the forest? How and where did it occur?

Vd. Has anyone from the goverment visited the community to talk about conservation? When? What did they say?

Ve. Has the community been interested in certifying the forest as an voluntary conserved area?

Vf. Has the community applied for payments for environmental services? When? For much much of the forest?

Vg. Is anyone familiar with the REDD+ program? Are you interested in participating? Why or why not? 